\title{
Essays on the role of knowledge, R\&D, and Technology-based firms in the evolution of socio- techno-economic system
}

Citation for published version (APA):

Shafique, M. (2016). Essays on the role of knowledge, R\&D, and Technology-based firms in the evolution of socio-techno-economic system. [Doctoral Thesis, Maastricht University]. Universitaire Pers Maastricht. https://doi.org/10.26481/dis.20160419ms

Document status and date:

Published: 01/01/2016

DOI:

10.26481/dis.20160419ms

Document Version:

Publisher's PDF, also known as Version of record

Please check the document version of this publication:

- A submitted manuscript is the version of the article upon submission and before peer-review. There can be important differences between the submitted version and the official published version of record.

People interested in the research are advised to contact the author for the final version of the publication, or visit the DOI to the publisher's website.

- The final author version and the galley proof are versions of the publication after peer review.

- The final published version features the final layout of the paper including the volume, issue and page numbers.

Link to publication

\footnotetext{
General rights rights.

- You may freely distribute the URL identifying the publication in the public portal. please follow below link for the End User Agreement:

www.umlib.nl/taverne-license

Take down policy

If you believe that this document breaches copyright please contact us at:

repository@maastrichtuniversity.nl

providing details and we will investigate your claim.
}

Copyright and moral rights for the publications made accessible in the public portal are retained by the authors and/or other copyright owners and it is a condition of accessing publications that users recognise and abide by the legal requirements associated with these

- Users may download and print one copy of any publication from the public portal for the purpose of private study or research.

- You may not further distribute the material or use it for any profit-making activity or commercial gain

If the publication is distributed under the terms of Article $25 \mathrm{fa}$ of the Dutch Copyright Act, indicated by the "Taverne" license above, 


\section{ESSAYS}

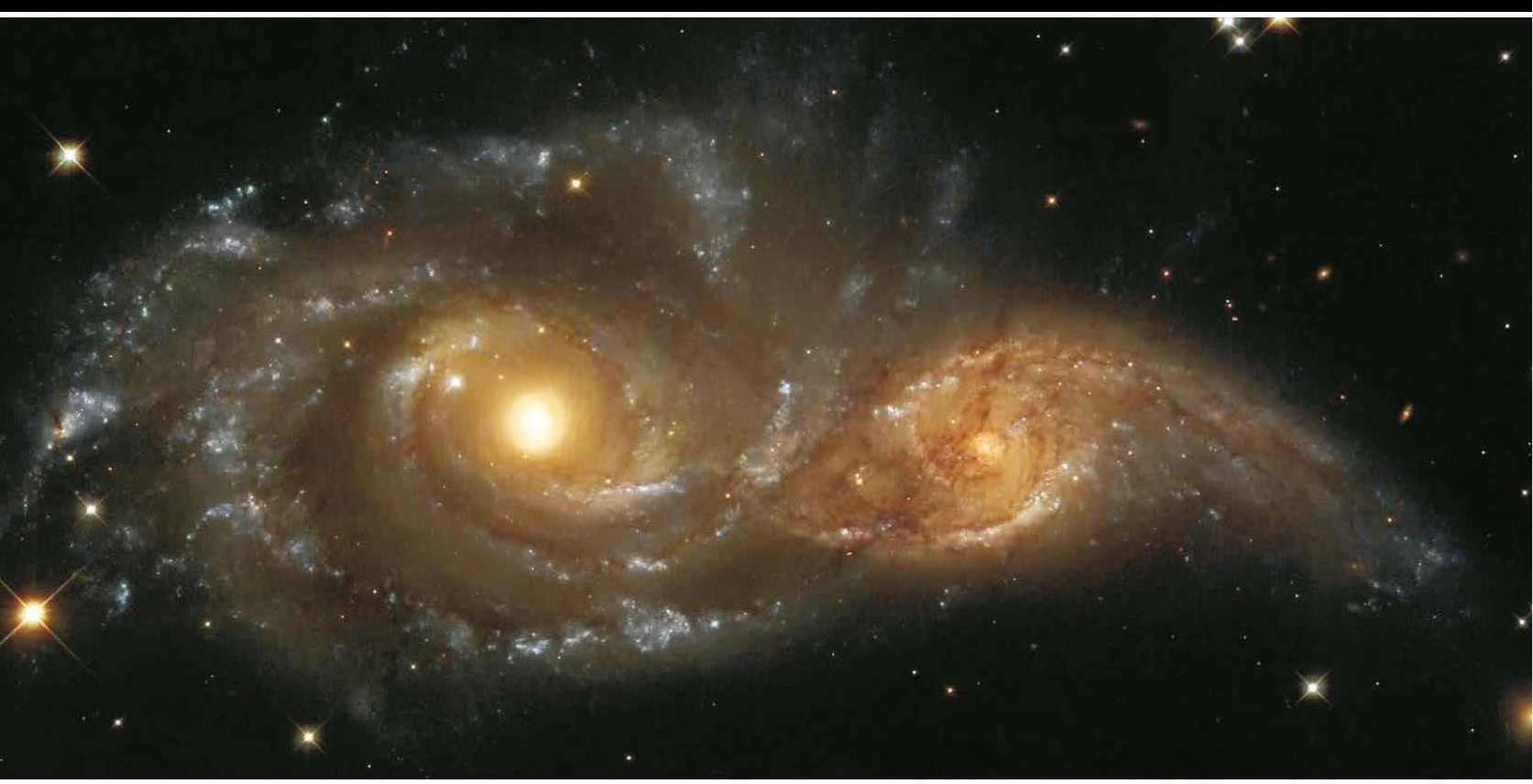

On the Role of

Knowledge, R\&D, and Technology-Based Firms in the Evolution of

Socio-Techno-Economic System 
Essays on the Role of Knowledge, R\&D, and Technology-Based Firms in the Evolution of Socio-Techno-Economic System

(C) 2016 Muhammad Shafique

ISBN 978-94-6159-538-6

All rights reserved.

The cover image, called "Eyes in The Sky", is the property of the National Aeronautics and Space Administration (NASA), USA.

Printed by: Datawyse/Universitaire Pers Maastricht 


\section{ESSAYS \\ ON THE ROLE OF \\ KNOWLEDGE, R\&D, AND TECHNOLOGY-BASED FIRMS IN THE EVOLUTION OF SOCIO-TECHNO-ECONOMIC SYSTEM}

\section{DISSERTATION}

to obtain the degree of Doctor at Maastricht University, on the authority of the Rector Magnificus, Prof. Dr. L. L. G. Soete, in accordance with the decision of the Board of Deans,

to be defended in public

on Tuesday $19^{\text {th }}$ of April 2016, at 14.00 hours

by

Muhammad Shafique

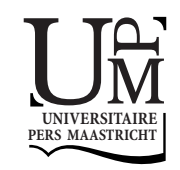




\section{Supervisor:}

Prof. Dr. John Hagedoorn

\section{Assessment Committee:}

Prof. Dr. Friso den Hertog (Chair)

Prof. Dr. René Belderbos

Prof. Dr. Geert Duysters (Tilburg University)

Prof. Dr. Wilko Letterie 
Nay it is a point fit and necessary in the front and beginning of this work without hesitation or reservation to be professed, that it is no less true in this human kingdom of knowledge than in God's kingdom of heaven, that no man shall enter into it except he become first as a little child.

Sir Francis Bacon (1561-1626): Valerius Terminus 



\section{ACKNOWLEDGEMENTS}

$\mathrm{PhD}$ is typically considered a once-in-a-lifetime opportunity for an aspirant researcher to outline a personalized field of knowledge for a productive career in research. Accordingly, I wished to exploit this opportunity to explore the phenomena of invention, innovation, and technological change and identify fruitful avenues for long-term engagement with research, ideally from an innovative perspective. Luckily, I was able to identify and connect to a few intellectuals whose contributions inspired me and formed my intellectual compass that guided me during this venture and set the direction for my intellectual endeavours in future.

On the ideological and philosophical front, the insights of Sir Francis Bacon provided the inspiration as well as the intellectual anchors for this venture. On theoretical side, my understanding of invention, innovation, technological change, and the management of these phenomena has been shaped in large part by the contributions of William F. Ogburn, Nathan Rosenberg, Peter F. Drucker, and Alfred D. Chandler Jr. On the professional front, I owe the coherence and focus of my thesis to my supervisor, Prof. Dr. John Hagedoorn. He has been genuinely considerate to my ideas, sympathetic to my aspirations, and very helpful in realizing my intent and purpose of the $\mathrm{PhD}$. He proved to be a remarkably thoughtful leader and insightful professional who has an amazing ability of giving the freedom to stretch thinking in any direction and to any extent, and then lending it coherence and focus with a few masterful strokes like a master artist. Hardly anyone else could have channeled the chaos of ideas I had come to grapple with in connection with my thesis. Working with him has been one of the most delightful and fruitful academic experiences of my life. I am highly indebted to him for his guidance and help. I am also thankful to Prof. Friso den Hertog, Prof. Geert Duysters, Prof. Rene Belderbos, and Prof. Wilko Letterie for their contributions as learned members of the assessment committee.

I am especially thankful to my friend and colleague Faqir Taj for sparing countless hours for discussions on my crude ideas and providing invaluable comments and suggestions that enriched my understanding and helped refine my thesis. Thanks are also due to Nico Rasters for his help in MySQL and the PATSTAT, and to Dr. Bulat Sanditov for his help in visualization of networks. I also owe my gratitude to Dr. James P. Bagrow for generously sharing his network computing codes and allowing me to use those in my research.

Apart from the professional academics, the vital part of energy for this venture came from an exceptionally understanding and supportive family, particularly from my wife. She braved enormous difficulties due to this venture. Owing to some unexpected and unfortunate circumstances I could not bring her along to the Netherlands and had to leave her in Pakistan with our few-months old baby. She always encouraged me to continue despite the challenges both of us were 
facing here and there. I cannot thank her enough for her extraordinary courage and support nor can I make up for leaving her alone with the baby when both of them needed me the most. I am also grateful to my parents-in-law for their understanding and support during this extremely difficult period. I also owe my deepest gratitude to our neighbors, Mr. and Mrs. Sohail Umar, for their parents-like support to my family, especially during my absence from Pakistan. Without their help, it would have been impossible for me to continue with this venture. Lastly, I thank Eveline in de Braek for her consideration and help that relieved me of many worries from the first to the last day of this venture.

I regret that despite having a deep appreciation of the contributions of everyone I interacted with in connection with this venture, I could not acknowledge all of them as they merit. Despite this omission here, their consideration and contributions will remain a part of my indelible memories. Finally, thinking about this venture from the beginning to the end reminds me of the famous saying of Sir Winston Churchill, "This is not the end, it is not even the beginning of the end, but it is, perhaps, the end of the beginning."

Muhammad Shafique

1st February 2016

Islamabad 


\section{ABSTRACT}

Technological change is a central topic in the field of economics and management of innovation. The aggregate technological change that manifests in transformative changes in the structure of socio-techno-economic system (STES) is particularly important due to the scope and magnitude of its impact. Identifying the locus of transformative technological change (TTC) and determining its direction is an important problem from the perspective of public policy as well as business strategy. Following Peter Drucker's insights, this $\mathrm{PhD}$ thesis proposes that this problem can be solved by shifting the focus of scientific inquiry from the product space to the knowledge space. It posits that knowledge as the DNA and ideas as the genes determine the evolution of STES and that structural change in this system follows the structural change in the universe of knowledge that is broadly organized in two domains, science and technology. It argues that the proposed change in the focus of inquiry will help depict the TTC more clearly and increase the prospects of predicting it. Employing the trans-disciplinary approach, the four empirical essays comprising this thesis explore the dynamics of knowledge production by analyzing the structure of knowledge domains on the one hand and motivations and conduct of the knowledge producers on the other, with a focus on technology-based firms (TBFs). It indicates that while inter-disciplinarity, multi-disciplinarity, and trans-disciplinarity are often advocated for the advancement of knowledge, these may actually be much more constrained in practice than usually expected. It proposes that knowledge-based perspective of technology may be more helpful to understand TTC than the artifact-based view of technology. Moreover, it proposes a technological ecosystem approach that can provide an integrated view of the product space and the knowledge space. Using this approach, it identifies three episodes of TTC during the 2oth century. Furthermore, based on the analysis of changes in the technological profiles of TBFs and the impact of their technological mergers and acquisitions (M\&As) on their inventive output, it challenges the prevailing assumption that exploitation and exploration are two mutually exhaustive facets of organizational search. It suggests that excursion is another important but neglected facet of organizational search that is distinct from exploration. Finally, it indicates the need for an integrated global intelligence system in order to monitor changes in the universe of knowledge, help detect and depict TTC, and possibly predict it. 



\section{CONTENTS}

1

1.1

1.2

1.3

1.4

2

2.1

2.2

2.2.

2.2 .2

2.2 .3

2.2 .4

2.3

2.3.1

2.3.1

2.4

2.4.

2.4 .2

2.4 .3

2.4 .4

INTRODUCTION

EVOLUTION OF SOCIO-TECHNO-ECONOMIC SYSTEM AND

STRUCTURAL CHANGE 1

KNOWLEDGE AND STRUCTURAL CHANGE $\cdot 3$

TECHNOLOGY-BASED FIRMS (TBFs), CREATIVE ACCUMULATION, AND TECHNOLOGICAL CONVERGENCE 6

PUTTING IT ALL IN A 'CRYSTAL BALL' $\cdot 7$

THINKING INSIDE THE BOX? INTELLECTUAL STRUCTURE OF THE KNOWLEDGE BASE OF INNOVATION RESEARCH (1988-2008) .15

INTRODUCTION 16

METHODOLOGY .18

SAMPLE .18

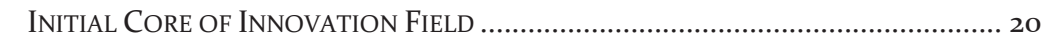

CitATION AND Co-CitATION MATRICES ............................................................... 21

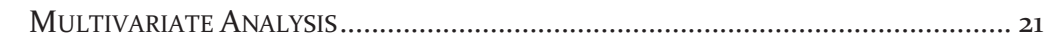

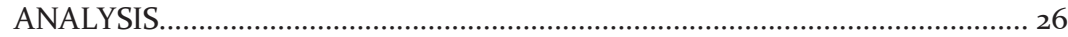

COMPOSITION OF THE KNOWLEDGE BASE .............................................................. 26

RESEARCH TRADITIONS AND THEIR INTERRELATIONSHIP ...................................... 29

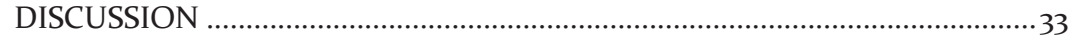

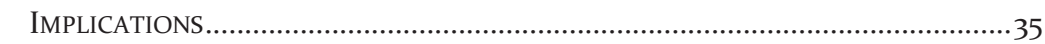

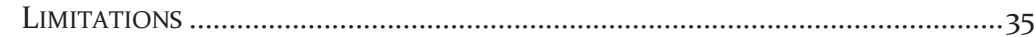

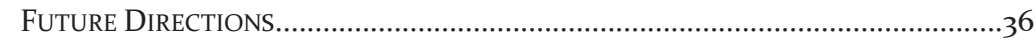

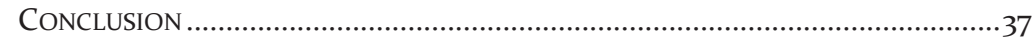

3

CO-EVOLUTION OF TECHNOLOGIES: A HISTORICAL PERSPECTIVE ON THE EMERGENCE AND CONVERGENCE OF INFORMATION AND COMMUNICATION TECHNOLOGIES

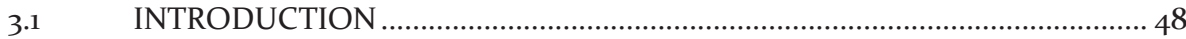

3.2 BEGINNING OF REVOLUTIONARY TECHNOLOGIES .................................. 49

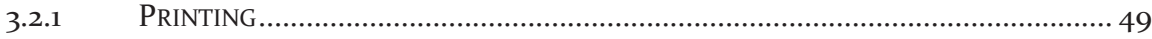

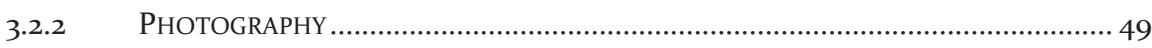


3.2.3 MECHANICAL TELEGRAPHY ............................................................................52

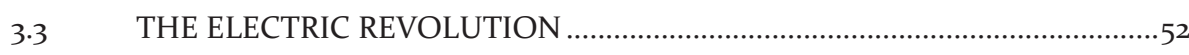

3.3.1 ELECTRICITY AND COMMUNICATION ………....................................................5

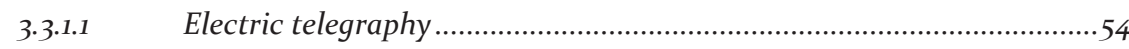

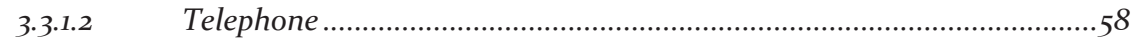

3.3.2 ELECTRICITY, LIGHT AND POWER …................................................................ 60

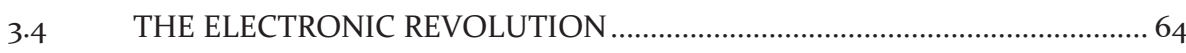

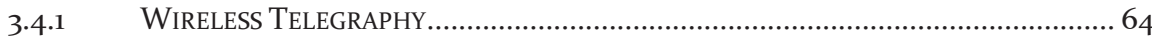

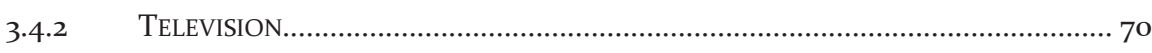

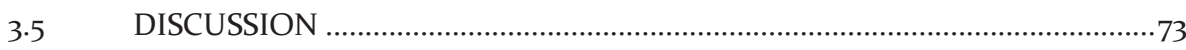

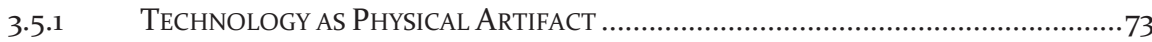

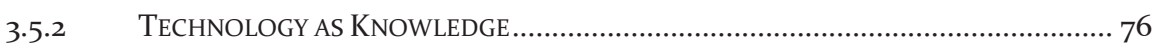

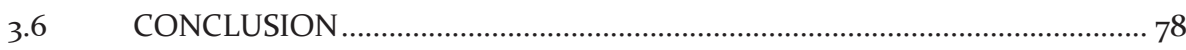

4 STRUCTURE OF TRANSFORMATIVE TECHNOLOGICAL CHANGE....... 79

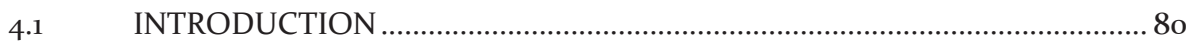

4.2 TRANSFORMATIVE TECHNOLOGICAL CHANGE..........................................83

4.3 TECHNOLOGY DOMAINS AND TECHNOLOGICAL ECOSYSTEMS ............ 84

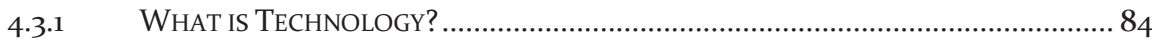

4.3.2 ReCOMBINANT InVENTION, KNOWLEDGE Fusion, AND FORMATION OF

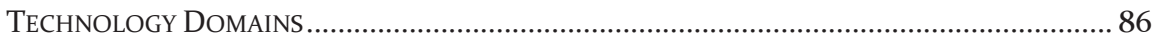

4.3.3 Diversification, Technological Convergence, and Formation of

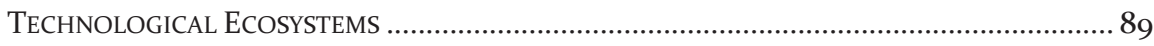

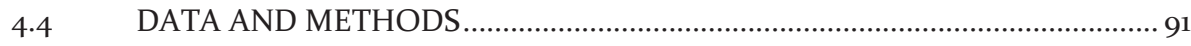

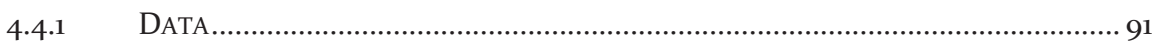

4.4.2 IDENTIFYING TECHNOLOGY DOMAINS............................................................ 92

4.4.2.1 Overlap among technology domains.......................................................95

4.4.1 IDENTIFYING TECHNOLOGICAL ECOSYSTEMS ........................................................ 95

4.4.1.1 Technological ecosystems and diversity of actors................................ 99

4.4.1.2 Technological ecosystems and technological diversification of actors 101

4.4.1.3 Technological ecosystems and product domains ...................................101

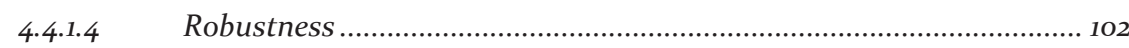

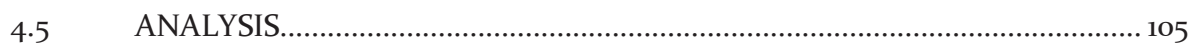

4.5.1 Growth of Technological Knowledge and Structural Change.............. 105

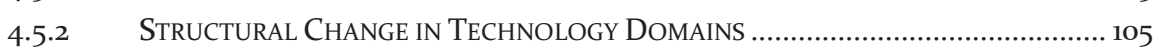

4.5.3 Structural Change in TEChNOLOGical Ecosystems......................................... 107 
4.5.4 Structural Change in Product Domains........................................................ 109

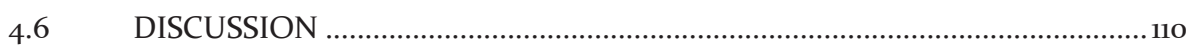

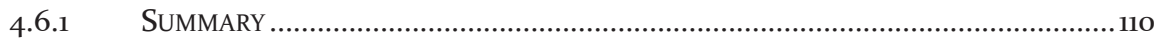

4.6.2 IMPLICATIONS.......................................................................................111

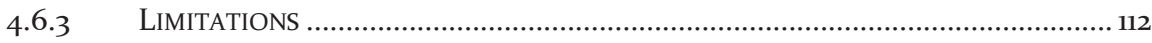

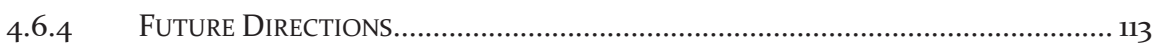

5 EXPLOITATION, EXPLORATION, OR EXCURSION? WHEN AND HOW TECHNOLOGICALLY DIVERSIFIED FIRMS BENEFIT FROM TECHNOLOGICAL MERGERS AND ACQUISITIONS ..............................123

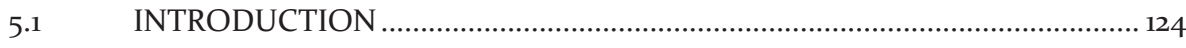

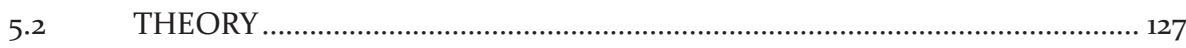

5.2.1 DifFERENTIATING AMONG TECHNOLOGICAL OpPORTUNITIES: EXPLOITATION,

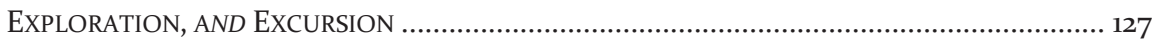

5.2.2 SEARCH FOR NEW TECHNOLOGICAL OpPORTUNITIES THROUGH M\&As ............... 129

5.2.3 Technological History of the AcQuirer and Post-AcQuisition Search for

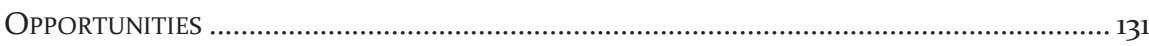

5.2.4 TeChnOlogical Diversity of the AcQuirer and Post-AcQuisition SEARCH

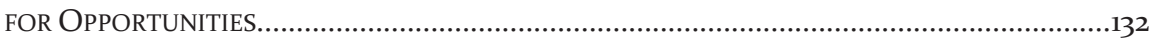

5.2.5 Technological Similarity and Post-AcQuisition SEARCh FOR OPPORTUNities 133

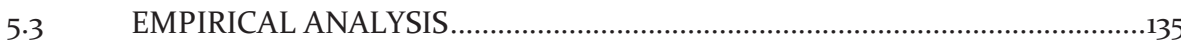

5.3.1 EMPIRICAL DESIGN, DATA, AND SAMPLE ……...................................................135

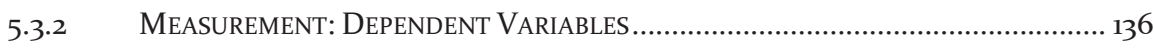

5.3.2.1 Post-Acquisition Total Inventive Output............................................. 136

5.3.2.2 Exploitative and Explorative Output .....................................................137

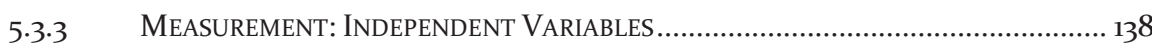

5.3.3.1 Acquirer's Technological History ........................................................... 138

5.3.3.2 Acquirer's Technological Diversity .................................................... 138

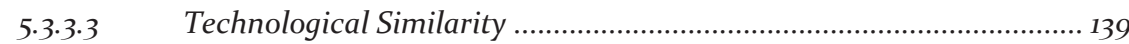

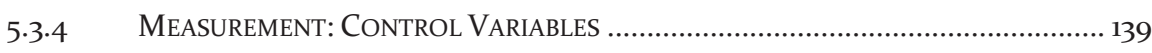

5.3.4.1 Target's Technological History .............................................................. 139

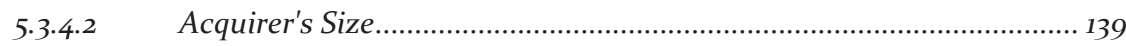

5.3.4.3 Acquirer's RED Intensity .................................................................... 140

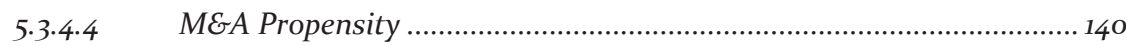

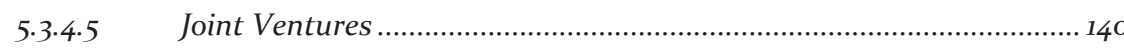

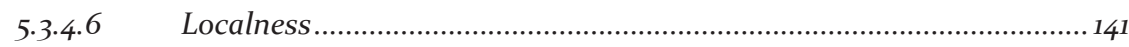

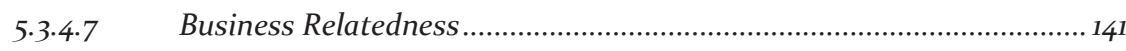

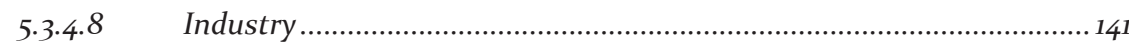




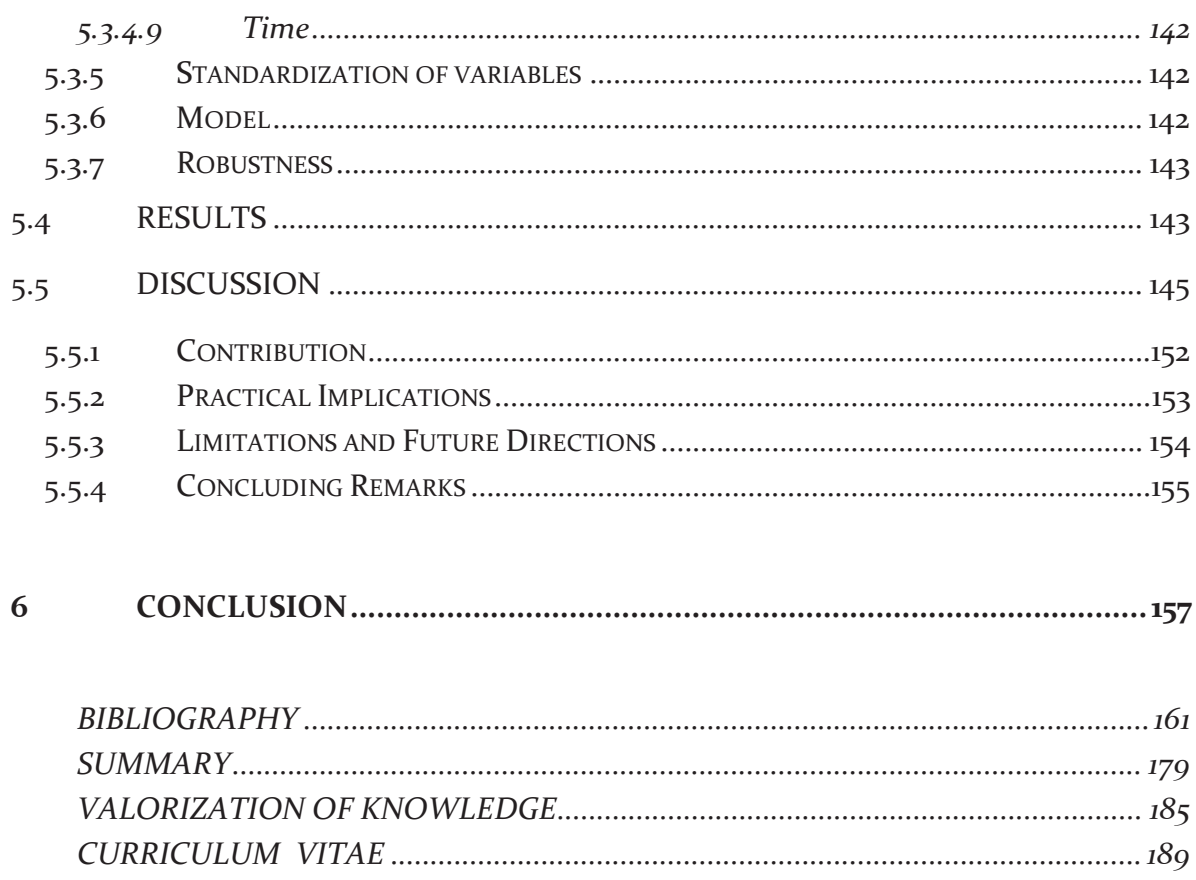




\section{INTRODUCTION}

\subsection{EVOLUTION OF SOCIO-TECHNO-ECONOMIC SYSTEM AND STRUCTURAL CHANGE}

Change has been one of the central themes of intellectual inquiry in almost all social science disciplines during the 2oth century (cf. Porter \& Ross, 2008), particularly in sociology, economics, and management (e.g., Ogburn, 1922; Schumpeter, 1934; Drucker, 1969; Chandler, 1977). This is, perhaps, due to the fact that social systems evolve due to complex interactions among human needs, problems, resources, and the individual and collective capacity to solve those problems. These interactions manifest in substantive changes in social, economic, and governance systems over time. Accordingly, changes in culture and social and institutional structures have been a matter of interest for sociology, changes in structure of economy in terms of sectoral and industrial composition have been a matter of interest for economics, and changes in the modes of configuration and effective deployment of resources for meeting the needs and problems of society have been a matter of interest for business and management. These three disciplines deal with the same fabled 'Elephant', the society, and hence co-evolve with the society and the knowledge related to it. Therefore, substantive changes in social systems and subsystems comprising it can be better understood by combining the perspectives and insights from these disciplines.

The evolution of society, and hence the evolutionary perspective, in sociology became a highly contested terrain in early $20^{\text {th }}$ century. The idea of knowledge, developed and learned through socialization rather than heredity, and the role of invention and technology in the advancement of human civilization emerged as a potent contender in the face of Darwinian view of evolution and changes in society (Kroeber, 1917). In a similar vein, Ogburn (1922) identified creation and diffusion of knowledge and inventions as important determinants of social change, particularly in the material culture. Hence, the co-evolution of society and technology has been one of the most prominent themes in sociology proper as well as in the sociological history of technology, particularly in connection with socio-technical change (Bijker, 1995; Basalla, 1988).

In parallel with the sociological thought, the evolution of economy and hence the evolutionary perspective of economic change was explicated by Veblen (1898) that identified history, knowledge, and cumulative adaptation as the major elements of cultural change (Hodgson, 1998). In this evolutionary tradition of economics, Schumpeter (1934) identified innovation and creation of new enterprises by the innovative entrepreneurs as the key to endogenous, spontaneous,

\footnotetext{
${ }^{1}$ Reference to the poem "The Blind Men and The Elephant", John Godfrey Saxe (1816-1887).
} 
and discontinuous change in economy. However, in his later work, Schumpeter (1942) highlighted the increasing influence of large "bureaucratized" firms and replacement of entrepreneurs by bureaucratic managers in defining the nature and direction of economic change. Similarly, in the management tradition, Chandler (1977) also shared the views of Schumpeter and Ogburn and highlighted the role of large firms in invention, innovation, and diffusion and their contribution to the change in economy and society. Later, Nelson \& Winter (1982) elaborated the evolutionary processes of development and change within firms, which, in turn, drive economic growth and change. This evolutionary perspective, that combines economic and organizational perspectives, has served as the basis for understanding the interaction between technological change and economic change as technoeconomic change (Perez, 1985). In short, evolutionary perspective has been widely used in 2oth century in order to explain substantive change in society and economy at various levels of analysis, ranging from the firm to the global political economy (e.g., Grant, 1996; Kogut \& Zander, 1993; Malerba, 2002; Mowery \& Rosenberg, 1993; Moore, 1966).

The socio-technical and techno-economic perspectives of change involve significant overlap, partly because of the centrality of technology and technological change in both and partly because both represent different facets of a "gestalt" (Wertheimer \& Riezler, 1944), the society. Therefore, from the evolutionary perspective noted above, it may be fruitful to combine both perspectives to represent the gestalt, a socio-techno-economic system (STES), which is essentially a social system as opposed to a natural system. A substantive change in this system may sprout from social, technological, or economic forces or some combination of these. This demands the integration of knowledge about these three facets in order to develop a "holistic" understanding of substantive changes in the STES that encompasses the socio-technical and techno-economic subsystems (cf. Bijker, 1995; Perez, 1983; Esfeld, 2001).

Substantive change in the STES manifests in the structural change, that is, gradual change in the nature and composition of activities within the system, change in the loci of catalytic activities, as well as changes in relative contribution and status of different activity subsystems. This phenomenon has been studied in sociology from the perspective of increased differentiation in society through institutionalization (Eisenstadt, 1964), in economics from the perspective of evolution of new industries (e.g., Malerba, 2007), in organization studies from the perspective of evolution of new populations of organizations (e.g., Astley, 1985) and adaptation within existing populations (Tushman \& Anderson, 1986), and in strategic management from the perspective of "value migration" among firms, industries, and sectors (Slywotzky, 1996). These structural changes emanate from within the system due to the adaptive and creative responses of the actors in the form of invention and innovation (Ogburn, 1922; Schumpeter, 1947; cf. Godin, 2010). 
Invention involves the creation of a new idea or technology and innovation involves implementation of the idea or technology to solve some substantive problem of the society. Invention and technological innovation are the response to the inducements in the environment and focusing mechanisms on the one hand (Rosenberg, 1969), and the knowledge- and capability-base of the society, on the other (Nelson \& Winter, 1982). These reasons sufficiently indicate the enormous complexity of the STES that cannot be captured by any single theoretical or analytical system. Consequently, an all-encompassing "theory of everything" is not possible to describe the structural changes in this system. However, it seems that this system has a collective 'mind' that forms and acts on the collective wisdom as well as the collective mood of the society at any given time. It is difficult to specify as yet what constitutes this 'mind' but it is possible to discern its wisdom and mood from the inputs it takes and the outputs it generates. These inputs and outputs are the knowledge that the society utilizes and produces in a given era (Machlup, 1962; Drucker, 1969).

\subsection{KNOWLEDGE AND STRUCTURAL CHANGE}

It has already been said a century ago that now an average student of secondary school knows much more than what Aristotle could possibly know, not because of greater intellect than Aristotle but because of the knowledge that prevails in the society (Kroeber, 1917; cf. DeWitt, 2010). This knowledge has been accumulated over a very long period of time that spans the whole history of humankind (McClellan \& Dorn, 2006). This accumulation and diffusion has been made possible by the invention of various methods and means for systematic preservation and transmission of knowledge in time and space. These inventions relate to the technologies and technological artifacts-such as paper, ink, printing press, typewriter, computer, internet etc.-as well as formal and informal institutions that create and disseminated technological and scientific knowledge. Accordingly, the essential 'matter' of the STES is knowledge that determines the nature, structure, and conduct of the system and evolutionary changes thereof. In other words, knowledge is to social evolution what DNA is to biological evolution, and hence, ideas are to the former what genes are to the latter.

Co-evolution of technologies and institutionalization of knowledge production and dissemination have played an important role in bringing about significant changes in STES. For example, knowledge has been considered as a catalyst in economic and industrial growth and change (e.g., Kuznets, 1965; Mokyr, 2002, 2005). It has also been found to be an important source of change in occupational and industrial structure during the zoth century (Machlup, 1962). It has also been considered as the principal element in the evolution of firm which, in turn, is a key actor in the evolutionary changes in economy (e.g., Nonaka \& Takeuchi, 1995; Grant, 1996; Nelson \& Winter, 1982). Particularly, the emergence of technology- 
based firms and science-based industries (Granstrand, 1998; Pavitt, 1984) has been instrumental in bringing about the structural change in the industrial system during the 2oth century. Due to such reasons, knowledge has been recognized as an essential and integral part of $20^{\text {th }}$ century society and economy, hence the terms "knowledge society" and "knowledge economy" (Drucker, 1969). Therefore, structural changes in STES are closely linked with knowledge (Quatraro, 2012; Antonelli, 2014).

The ever-expanding universe of useful knowledge has a structure of its own. Historically, this universe has been divided into two broad domains of knowledge: technology and science. A knowledge domain is a constellation of interrelated pieces of knowledge in the universe of knowledge at any given time. Technological knowledge deals with the techniques for producing particular technical effects while scientific knowledge deals with the explanation of the natural or social phenomena by applying the scientific methods. Technological knowledge has existed since the time humankind started life on earth and began to devise various techniques to harness the resources and forces of nature (McClellan \& Dorn, 2006). For instance, humans devised various techniques to kindle fire by experimenting with various materials found in nature without knowing the properties of those materials. These technologies tended to be strictly local because these would emerge due to the demands of the physical and social environment of the people living in a particular part of the world. Moreover, their diffusion would be extremely restricted due to the constraints of mobility and demonstration as the primary method of teaching and learning. Consequently, many technologies devised by different civilizations went extinct with the extinction of respective civilization.

The process of knowledge accumulation and wider diffusion began with the invention of writing. The journey from the invention of engraving symbols on stones to the storage of information on semiconductor chips is an exceptional record of the quest for technological knowledge and ingenuity of humankind (McClellan \& Dorn, 2006). However, two innovations in $15^{\text {th }}$ century played an instrumental role in stimulating the creation, preservation, and dissemination of knowledge in the world. First, introduction of the patent system was a revolutionary institutional innovation that stimulated the creation of technological knowledge and facilitated its accumulation and diffusion. The first patent statute was enacted in 1474 by the Venetian Republic (Nard, 2008, pp. 7-8). It was based on the idea of using economic incentive to extract technical knowledge from the inventor and make it public by eliminating the need for demonstration and apprenticeship as the means for transmission and diffusion of the knowledge (Machlup, 1958). Second, printing press was a revolutionary technological innovation that allowed storing and transmitting ideas and information across time and space and served as the primary vehicle for the Scientific Revolution (Eisenstein, 1980). 
The emergence of technologies is stimulated by substantive problems facing the society at any given time (Rosenberg, 1969) and technology domains emerge because people pursuing technological solutions use the extant technological knowledge as the primary input to the process of experimentation (Fleming, 2001; Arthur, 2007). Since the extant technological knowledge is likely to be the same for all the aspirant experimenters of the time, they tend to use same knowledge for similar problems, and hence, arrive at closely related solutions (Simonton, 1979). The solutions that are interrelated in terms of inputs (knowledge) or output (applications), or both, tend to form clusters or domains due to their technological proximity (Perez, 2010). The location and size of these clusters in extant technological knowledge as well as their interrelationships determine the network structure of technologies.

The structure of technology domains tends to change over time due to several reasons but two of them are particularly noteworthy. First, the need for particular kind of knowledge in interrelated problems and solutions leads to the creation of demand for relevant resources from the system, including the knowledge itself being the principal resource and the human capital carrying this knowledge (Drucker, 1969). Those technology domains that offer greater and more valuable technological and economic opportunities tend to attract more resources and hence grow. A technological opportunity is defined as a possibility of technological advance, given the current state of technology (Klevorick et al., 1995, pp. 188). Since valuable resources, particularly human capital, are limited, resources migrate from less attractive to more attractive technology domains. Second, new applications of existing technologies and technological knowledge as well new combinations of existing knowledge with emergent knowledge may also change the relevance and significance of different domains and their interrelationships. Thus, the structure of the universe of technological knowledge co-evolves with the social, economic, and technological needs and problems of the society. Substantial changes in the structure of techno-economic system has been termed as "technological revolutions", the latest being the "information and telecommunications" revolution in 1970s (Perez, 2010).

Scientific knowledge, however, is a relatively recent phenomenon unlike technology, that has existed ever since the earliest ancestors of humankind (McClellan \& Dorn, 2006). Science emerged as the rare art of understanding natural phenomena by erudite intellectuals and quickly gained superior status than technology that was the practice of mundane craftsmanship as the former was associated with "knowing" and the latter was considered as "doing" (Bernal, 1969; McClellan \& Dorn, 2006). This dichotomy has fueled the popular debate whether the industrial revolution of 18th century was a sequel of the scientific revolution of the 17th century (cf. Bernal, 1969; Mokyr, 2005). Nevertheless, technology and science as distinct domains of knowledge have largely evolved independently till the 19th century when chemical and electrical industries emerged and the two 
domains became interdependent (Bernal, 1969; Chandler, 2005; McClellan \& Dorn, 2006). Thus the substantive changes in the STES during the 19th and 2oth century were driven by the interaction of the two domains of knowledge.

The interdependence between science and technology started due to the combination of the "knowing" (science/research) and the "doing" (technology/development) on two fronts. First, the need of industry for human capital and scientific solutions for technical problems prompted the polytechnics and universities to start new training and research programs. For instance, the need for electrical engineers by the electrical industry prompted the educational institutions to start new programs that combined the knowledge of physics and engineering (Hunt, 2010). Second, the institution of organized research-and-development (R\&D) emerged whereby academically trained scientists and engineers were employed to create commercially valuable technological solutions (Nelson \& Rosenberg, 1998; Chandler, 2005). Thomas Edison's "invention factory" emerged as the model of industrial R\&D during the late 19th century (Hunt, 2010). This model widely diffused in the science-based industries and the inventive activity began to concentrate in large firms (Chandler \& Hikino, 1997, 2004; Chandler, 2005). These large firms, driven largely by $\mathrm{R} \& \mathrm{D}$, have come to be known as "technology-based firms" (TBFs) and "multi-technology corporations" (MTCs) (Granstrand, Patel \& Pavitt, 1997; Granstrand, 1998).

\subsection{TECHNOLOGY-BASED FIRMS (TBFs), CREATIVE ACCU- MULATION, AND TECHNOLOGICAL CONVERGENCE}

Large firms have played a key role in technological, economic, and social changes in the world during the 2oth century (Schumpeter, 1942; Chandler, 1977; Chandler \& Hikino, 1997, 2004). Of particular note among these are the TBFs that ushered in a new era of technological change by linking science and technology through $R \& D$. These firms tend to use $R \& D$ as the springboard to enter multiple product and technology domains and hence become multi-product multi-technology corporations (Patel \& Pavitt, 1997; Granstrand, Patel \& Pavitt, 1997). Due to their engagement with multiple domains, they become part of multiple organizational communities and hence multiple ecological environments (Astley, 1985). Consequently, TBFs remain abreast of the incremental changes in their environments and hence adapt their knowledge base according to the developments in their respective domains. Therefore, technological capabilities of TBFs tend to coevolve with science and technology.

Technological capabilities of TBFs, however, tend to be path-dependent and cumulative, that is, which kind of knowledge and capabilities they can acquire and which product and technology domains they can enter is largely determined by their existing knowledge and capabilities (Nelson \& Winter, 1982; Patel \& Pavitt, 1997). Consequently, firms tend to diversify in related product and tech- 
nology domains (Breschi, Lissoni \& Malerba, 2003; Miller, 2006) due to the constraints of absorptive capacity as well as the need for corporate coherence (Cohen \& Levinthal, 1990; Teece et al., 1994). Therefore, despite enjoying the economies of scale and scope in R\&D (Chandler, 2004), they tend to engage in local search, and hence, produce incremental inventions and innovations (Stuart \& Podolny, 1996). In other words, they tend to pursue exploitative search more than explorative search (March, 1991).

On the other hand, it has been argued that due to their engagement with multiple domains, TBFs tend to lack distinctive core competencies (Granstrand, Patel \& Pavitt, 1997) but somehow maintain a fairly stable portfolio of businesses (Gambardella \& Torrisi, 1998). However, engagement in multiple technology and product domains has two important implications. First, they serve as carriers of knowledge across all their concerned domains and hence facilitate diffusion of knowledge. This implies greater technological convergence among those domains (Rosenberg, 1963), greater isomorphism in those populations of organizations (Astley, 1985), and rapid erosion of technological advantages of individual firms (Derfus et al., 2008). Second, access to greater variety of knowledge implies greater possibility of increase in quantity as well as quality of inventive output (Schoenmakers \& Duysters, 2010; Datta \& Jessup, 2013). In other words, TBFs tend to enjoy greater technological opportunities for explorative and radical inventions. Consequently, TBFs face several paradoxes related to invention and innovation.

Nevertheless, TBFs enjoy a decisive advantage over individual inventors in terms of resources and capabilities. They exploit their resources and capabilities to stay at the frontiers of technology and often internalize the technologies and technology-based ventures of individual inventors as well as other TBFs through mergers and acquisitions. Hence, inventive activity has become increasingly concentrated within the TBFs since the time R\&D became an institutionalized function. Consequently, TBFs account for a large portion of total inventive output of the world. Therefore, the nature and purpose of inventive activity of TBFs during any given period not only reflects their collective wisdom about valuable technological opportunities and technologies but also indicates the technological "zeitgeist" of the time (cf. Simonton, 1979).

\subsection{PUTTING IT ALL IN A 'CRYSTAL BALL'}

Given that substantive social, technological, and economic changes co-evolve, the big question is: does there exist an 'epicenter' of the change in STES, and if so, is it possible to locate that epicenter in order to understand the change, and ideally, predict one? The extant knowledge in the disciplines of sociology, economics, and management suggests the existence of such a possibility as technological change is one of the possible loci of such a change. However, Peter Drucker (1969) has suggested: 
'Prediction' of technological change - in the strict meaning of the term would require ability to know both what changes could be expected and when they would occur. I doubt that the timing of major technological changes can ever be known in advance. But what technological changes are likely; which of those are likely to have major economic impact, that is, to bring about new industries; and whether such changes are indeed approaching or imminent, this we can know with high probability. The dynamics of technology are not particularly mysterious... The first dynamic element in technology, and the one most easily identified, is economic needs and opportunities... The next place to look to anticipate technology, is to [look at the] knowledge of all kinds. One asks: 'What is going on in knowledge areas and what technological opportunities might this create?'... Finally, new major technological opportunities are pre-figured in new intellectual attitudes, and even in intellectual slogans... Not only do such slogans indicate new needs; they indicate new insight. And a great deal of new technology is not new knowledge; it is new perception. It is putting together things that no one had thought of putting together before, things that, by themselves had been around a long time. [pp. 40-44]

Following these insights, this $\mathrm{PhD}$ research project is based on a simple thesis: nature and direction of substantive changes in social, technological, and economic systems and subsystems-as well as the STES as a whole-can be depicted as well as predicted by the substantive changes in the nature and purpose of useful knowledge produced in the society during a given period. Indeed, the production of knowledge is not centrally planned but determined by the co-evolutionary dynamics of society which are determined by the interaction among the history, present needs and problems, and intended future outlook of the actors and society. The need for articulating, understanding, and creating solutions for the real or perceived needs and problems of present and future engenders the need for production of relevant and useful knowledge. This need is catered by the knowledge producing arm of the society. However, during the deliberate pursuit of knowledge, not only new insights and learning opportunities emerge but also new needs and problems surface, continuously reinforcing, realigning and redirecting the production of knowledge.

Given the fact "theory of everything" is hard to achieve, at least in social sciences, evolutionary changes in the structure of STES can be examined via changes in the structure of knowledge. Knowledge production can be examined from the perspective of nature of inputs and outputs on the one hand, and the motivations and conduct of the producers, on the other. From the input/output perspective, useful knowledge belongs to two domains, science and technology, and each domain has its own internal structure in the form of sub-domains. The structure of the universe of knowledge is quasi-stable because it changes due to the emergence of new sub-domains and reconfiguration of existing sub-domains, 
which takes a fairly long time. The attribute of quasi-stability makes its examination feasible and the structural changes discernible.

On the other hand, useful knowledge is mainly produced by two groups of producers, universities and TBFs. Interestingly, they are also the major users of knowledge as part of their inputs. These actors significantly differ in terms of their motives and mechanisms to choose the kind of knowledge that they produce. The knowledge produced by universities largely flows into the domain of science whereas the knowledge produced by TBFs mainly flows into the domain of technology, though both sets of actors draw on extant knowledge from both domains. In general, TBFs tend to be more effective and efficient than universities in sensing the need for useful knowledge and responding to it in a timely fashion because they are driven by the need to earn profit on their investments in the production of knowledge.

In order to capture the most important aspects of change in the structure of the universe of knowledge, we set out to examine changes in the nature of knowledge production from input/output perspective on the one hand and changes in motivations and conduct of the producers of knowledge, on the other. We asked four substantive questions to guide our research. These are:

1. How scientific domains emerge and co-evolve?

2. How technology domains emerge and co-evolve?

3. How emergence and co-evolution of scientific and technology domains lead to structural changes in the techno-economic system?

4. Why do firms enter multiple domains and how do they benefit from a multi-technology multi-product capability base?

These questions have served as the focusing devices amidst an astounding body of extant knowledge in the disciplines of sociology, economics, management, and history. We do not claim that these questions, even fully addressed, can substantially depict the complex phenomenon that we wished to grasp. However, we do believe that the understanding stimulated by these questions can make the endeavor of finding the locus of technological change more meaningful and fruitful. These questions have guided thinking about the four parts of our research project presented in this $\mathrm{PhD}$ thesis, though these parts vary in terms of theoretical and methodological approaches. Each part is intended to correspond to a question and presented in the form of an empirical essay. Accordingly, this $\mathrm{PhD}$ thesis is structured according to the sequence of these questions and each essay belongs to the respective question in the sequence. The rationale and role of each essay in our project are briefly described in the following.

Essay 1: Thinking inside the box? Intellectual structure of the knowledge base of innovation research (1988-2008). Science is purportedly becoming increasingly inter-disciplinary and inter-disciplinarity is generally considered as the source of 
growth in scientific knowledge, particularly among social sciences. This conjecture provides a two-fold opportunity in the context of our research project. First, the conjecture is plausible but it is important to learn whether it is true. Second, the conjecture is directly relevant to the subject matter of this project, that is, growth and diffusion of scientific knowledge and emergence of new scientific domains. Therefore, we selected the "innovation studies" as a case for testing this conjecture for three reasons. First, it is naturally a multidisciplinary field of inquiry where knowledge of almost all social sciences is relevant. Second, it can be expected that the analysis would provide valuable understanding of the knowledge being used and generated in the field. Third, an examination of the field may provide useful insights about the evolutionary dynamics of the structure of scientific fields in general. Accordingly, this essay presents the results of our empirical examination of the field.

We collected the publication data of innovation-related papers that were published in top twenty journals in four major social science disciplineseconomics, sociology, psychology, and management-during the 21-year period between 1988 and 2008. We used scientometric approach and bibliometric method to perform longitudinal and structural analysis of the data. The co-citation analysis helped us identify major research traditions in the field, determine the content and disciplinary composition of each tradition, and map the changes in the intellectual structure of the field over time. To our surprise, we found that innovation research is becoming increasingly compartmentalized between economics and management disciplines and each segment is becoming increasingly self-contained. This finding, coincidentally, provides yet another reason to integrate relevant knowledge from multiple disciplines to develop a more holistic understanding of the co-evolutionary dynamics of social, technological, and economic changes.

This essay has been published as a research article in Strategic Management Journal.

Essay 2: Co-evolution of technologies: A historical perspective on the emergence and convergence of information and communication technologies. Technology is the outcome of experimentation with different ideas and pieces of knowledge that tend to be scattered in time and place. The proximity of location and prior relationship of ideas and relevant knowledge greatly affect the rate of creation and speed of diffusion of new technologies. This signifies the relevance and importance of those technologies that facilitate the preservation and transmission of information. Therefore, in order to understand the locational and combinatorial dynamics of inventive activity, we used historical approach and explored the origins and timing of the discoveries and inventions related to information and communication technologies during the 18th and 19th centuries. This essay pre- 
sents the historical account of major information and communication technologies and describes how these technologies co-evolved. We found that inventive activity tends to be contextualized by the societal and technological problems prevailing at a given time that are pursued by scientists and engineers working in the domains of science and technology. The insights from the study are put in the context of Hebert Simon's idea of nearly decomposable hierarchical systems and neo-Schumpeterian perspective of clusters of technologies. We find that the former is more practical from an artifact-based perspective of technology while the latter is more useful from the knowledge-based perspective of technology. We conclude that the latter perspective can help solve the problem of measuring the rate and direction of technological change.

Essay 3: Structure of transformative technological change. Structural change in the STES is a matter of interest from the perspective of public policy as well as business strategy because it essentially involves "creative destruction" (Schumpeter, 1942). Conventionally, structural changes have been studied ex post using the context of industries, that is, the product space as a frame of reference. These changes are always underway in the realm of industrial system due to the processes of innovation. However, STES periodically undergoes structural changes of great magnitude that alter not only the structure of industrial system but also the institutional and social structure of society. Accordingly, we refer to this kind of change as "transformative technological change" (TTC).

In this essay, we attempt to capture the dynamics of such transformative changes in a conceptual framework. This framework is based on the NeoSchumpeterian approach that emphasizes the role of invention due to the fact that invention precedes innovation and hence transformative changes in the STES occur due to the emergence of new clusters of technologies. We extend this perspective by proposing that technology space is a better 'place' to locate TTC than the product space, more so because it can help identify transformative changes ex ante. Thus, TTC is a manifestation of structural changes in the technology space. We illustrate this framework with the help of all available US patent data. We found that there occurred three successive episodes of TTC during the 2oth century; the first took place around 1950, the second occurred around 1980, and the third took off around 2000 and it is currently underway.

Essay 4: Exploitation, Exploration, or Excursion? When and how technologically diversified firms benefit from technological mergers and acquisitions? As noted above, large TBFs perform a key role in creating new technologies and products through $R \& D$ and inventive activity has become increasingly concentrated among these firms during the 2oth century. TBFs tend to be multi-technology multiproduct firms and hence simultaneously operate in multiple domains of knowledge and technological ecosystems. Due to their institutionalized R\&D, they 
also play an important role in the assimilation, creation and diffusion of new technological knowledge in the STES. Accordingly, the structure of their technological capabilities co-evolves with multiple domains of knowledge and technological ecosystems. Therefore, understanding the determinants of structural change in their technological capabilities and portfolios is important to understand the determinants of structural change in knowledge domains which drive structural change in the STES. This essay contributes towards understanding mergers and acquisitions as a popular strategic tool and an important mechanism through with TBFs enter multiple domains and technological ecosystems.

In this essay we build on prior research that has established that technological M\&As positively contribute to the technological output of the acquirers and seek to extend the research that aims to identify the drivers of postacquisition performance. The extant research based on resource-based and organizational learning theories assumes that organizational search is deliberate and driven by the strategic intent to use existing capabilities of the firm or develop new capabilities through M\&As. Accordingly, it is also assumed that organizational search through M\&As and the performance outcomes thereof either constitute exploitation or exploration.

We argue that these assumptions need to be revisited for two important reasons. First, TBFs ultimately seek technological opportunities rather than technological capabilities per se. Second, TBFs also come across unintended and serendipitous opportunities that constitute the emergent aspect of organizational search and performance thereof. In case of M\&As, unintended or unexpected technological opportunities are likely to emerge due to technological complementarities and substitutabilities between the technological bases of the acquirer and target and many of these emergent opportunities are likely to fall outside the core domains of the acquirer and the target. We argue that such emergent opportunities constitute "excursion" which are distinct from exploration which involves the pursuit of intended opportunities. Therefore, we argue that exploitation and exploration can be understood better by (i) changing the frame of reference from capabilities to opportunities and (ii) isolating excursion from exploration.

This essay explicates and illustrates these ideas using 160 TM\&A deals of large TBFs from global information and communication technology sector during a 21-year period and measuring the post-acquisition inventive output of acquirers. Empirical evidence suggests that excursion is a significant contributor to the postacquisition inventive output of TBFs, alongside exploration and exploitation. Results of negative binomial regression also suggests that technological diversity of acquirer negatively affects the post-acquisition exploitative and explorative output, exploitative output is negatively affected by technological history of acquirer, and technological similarity between acquirer and target negatively affects the explorative output. 
To conclude this introductory discussion about the idea of STES as the gestalt, knowledge as its DNA, and ideas as the 'genes' of this system, we wish to remind the reader that this idea is not the "theory of everything" about society or its constituent systems. Instead, the research presented in this $\mathrm{PhD}$ thesis is a humble attempt to explore and develop the idea and highlight its salient aspects in keeping with the calls for inter-disciplinary, multi-disciplinary, and transdisciplinary research to produce useful knowledge (Nissani, 1997; Lawrence \& Després, 2004; Balsiger, 2004). 



\title{
2 THINKING INSIDE THE BOX? INTELLEC- TUAL STRUCTURE OF THE KNOWLEDGE BASE OF INNOVATION RESEARCH (1988- 2008)
}

\begin{abstract}
Innovation is becoming increasingly popular as a concept as well as a field of research and attracting the interest of scholars from several disciplines. As a field of research, it has accumulated a large body of knowledge. Due to its increasing importance and popularity, there is a need to learn about the content and structure of the field. Based on the past 21-years bibliometric data from 80 most influential journals of economics, sociology, psychology, and management, this study takes a 'global view' of the field by combining longitudinal and structural perspectives. Using standard multivariate techniques, it identifies major research traditions in the field, determines the content and disciplinary composition of each tradition, and maps the changes in the intellectual structure of the field over time. The analysis suggests that: (i) innovation research is being mainly contributed and influenced by economics and management disciplines, (ii) it is gradually losing its multidisciplinary character within the mainstream of each discipline, and (iii) while being increasingly compartmentalized between economics and management disciplines, the loci of contribution and influence have migrated to the latter. The paper also provides a framework and suggests a strategy for identifying the opportunities for contribution to the field.
\end{abstract}

Keywords: Innovation, sociology of scientific knowledge, multidisciplinarity, knowledge convergence, absorptive capacity, creative capacity 


\subsection{INTRODUCTION}

The term "innovation" has become increasingly popular as part of common vocabulary as well as a key component of policy and strategy ${ }^{2,3}$. Correspondingly, researchers from different disciplines have been participating in and contributing to the research related to innovation as an economic, social, and technological phenomenon. Owing to the growth and diversity in innovation-related literature, some have even suggested that it is an emerging scientific field that is attracting scholarly interest from several disciplines (Fagerberg \& Verspagen, 2009). Due to the growing importance and popularity of the field, there is a need to learn about the subject matter and the intellectual structure of the field as well as the disciplinary roots of its knowledge base. This knowledge may help pave the way for the development of the field as it can help identify the opportunities for future intellectual investments in the field.

While there exists some literature that sheds light on the content of innovation as a field of research and identify a few prominent research traditions ${ }^{4}$ in the field (Freeman, 1994; Wolfe, 1994; Gopalakrishnan \& Damanpour, 1997; Anderson, De Dreu \& Nijstad, 2004; Hauser, Tellis \& Griffin, 2006), there is hardly any literature that could provide a 'global view' of the field from a longitudinal and/or structural perspective. Traditionally, such objectives are attained through literature reviews by experts of a given field. However, innovation field spans several disciplines and hence the breadth of its scope is prohibitive of a comprehensive review due to the limits to individual expertise. This problem can be solved by employing a quantitative approach. Hence, this paper is intended to fill this void as a descriptive study of the field by combining longitudinal and structural perspectives.

The emergence and growth of scientific fields is a dynamic process which involves several facets (Frickel \& Gross, 2005; Hambrick \& Chen, 2008). Since the

\footnotetext{
${ }^{2}$ It is hard to find any formal and widely accepted definition of the term "innovation". However, the term broadly refers to any act or artifact that is a significantly novel outcome of deliberate human activity in any sphere of human behavior which is spurred by an incentive to create value in a given environment and realized by acquiring and utilizing appropriate capabilities and resources. The concepts, "incentive" and "value", are used here in fairly broad sense and include all economic and non-economic drivers of behavior.

${ }^{3}$ It is increasingly found in the discussions and speeches of corporate and political leaders. For instance, the US President, in his State of the Union address of January 2011, highlighted that innovation is the key to economic growth and prosperity.

${ }^{4}$ The term "research tradition" here refers to a fairly broad but distinguishable part of scientific literature in a field of research. It is a coherent collection of various subgroups of research themes/fronts which are identifiable through shared topic and common theoretical perspectives.
} 
most important output of these processes is the scientific knowledge actually produced, studying the kind and content of the knowledge produced by a scientific field can inform about the justification and contribution of the field as well as its evolution and future prospects. Scientific knowledge is cumulative, meaning that new knowledge is created based on existing knowledge (Jefferson, 1972; Cowan \& Foray, 1997). Therefore, the term "knowledge base" hereby refers to the ideas, perspectives, approaches, theories, and methods used in the creation of new knowledge in a scientific domain. It can be empirically measured via the existing knowledge used in the creation of new knowledge. In the scientific literature, references to the previous literature are conventionally used as a proxy for the knowledge used, and hence, for the knowledge base. ${ }^{5}$ Correspondingly, the term "intellectual structure" refers to a set of salient attributes of the knowledge base which can provide an organized and holistic understanding of the chosen scientific domain. Therefore, the intellectual structure of a scientific domain includes its constituent research traditions, their disciplinary composition, topics addressed by these, and the pattern of their interrelationships.

Any endeavor of measuring such conceptual entities of a field that spans several disciplines demands the adoption of objective methods and measures which have been tested, established, and accepted across disciplines. Therefore, this study employs bibliometrics which is a well-known science of measuring and mapping scientific communication within and across scientific domains and disciplines (White \& McCain, 1989; Tabah, 2001; Borgman \& Furner, 2002; Börner, Chen \& Boyack, 2003; Boyack, Klavans \& Börner, 2005). Bibliometrics uses citations and co-citations as indicators of scientific communication and flows of knowledge among domains and disciplines (Small, 1973, 1978; Garfield, 1979; Lievrouw, 1989). It has established scientific methods and approaches which are widely accepted in tracking and measuring scientific communication and development of scientific fields (Price, 1965; Garfield, 1979; White \& Griffith, 1981; Cottrill, Rogers \& Mills, 1989; McCain, 1990). Due to its scientific authenticity and rigor, several studies have used bibliometrics to map the intellectual structure of

\footnotetext{
${ }^{5}$ Citations to previous literature may be motivated by numerous reasons. These include, for instance, need for evidence, comparison, contrast, refutation, rebuttal, and indication of further literature. Unfortunately, these may also include ritualistic citations meant to create a façade of standing on the shoulders of giants and seeking legitimacy without a careful reading and deliberation on the cited publication (Latour, 1987; DiMaggio, 1995). However, based on the presumption of academic integrity of researchers and conventions of practicing science, it seems reasonable to assume that a large part of the citations is attributable to the texts which the writers deliberated on and found relevant to some aspect of their argument presented in the publication. These assumptions are mandated by the need to study the history and sociology of scientific knowledge.
} 
various fields of research including the diffusion of innovations (Cottrill et al., 1989), macroeconomics (McCain, 1983), organizational-behavior (Culnan, Oreilly \& Chatman, 1990), consumer research (Hoffman \& Holbrook, 1993), operations management (Pilkington \& Liston-Heyes, 1999; Pilkington \& Meredith, 2009), and strategic management (Ramos-Rodriguez \& Ruiz-Navarro, 2004; Nerur, Rasheed \& Natarajan, 2008), to mention a few.

This study uses publications as the unit of analysis rather than persons who authored these because publications are permanent and lasting imprints in science that serve as long-term, impersonal, verifiable, and debatable sources of ideas, theories, and methods that can be used as an input for creation for further knowledge (Small, 1973, 1978, 1980; Griffith et al., 1974; Small \& Griffith, 1974; Cowan \& Foray, 1997; Ramos-Rodriguez \& Ruiz-Navarro, 2004). Furthermore, it employs a combination of standard multivariate techniques and network tools for an objective analysis of the bibliometric data.

The paper provides a global view of the field from longitudinal and structural perspectives by identifying and mapping various research traditions, characterizing their respective knowledge bases, and tracking the pattern of their development and diffusion over time. In addition to that, it provides a longitudinal view of the changes in the influence of key publications, journals, and major social science disciplines in innovation research. In this way, the study also makes an empirical contribution to the sociology of scientific knowledge as studied by Merton $(1968,1972,1973)$, Kuhn (1970), and Latour (1987).

The methodology of the study is described in the next section followed by the section presenting the analysis. Then the implications of the study, its limitations, and directions for further research are discussed followed by some conclusions.

\subsection{METHODOLOGY}

\subsubsection{Sample}

Based on the understanding that innovation as a research field belongs to the broad domain of social sciences (Freeman, 1994), four closely related social science disciplines-economics, sociology, psychology, and management-were selected for the study. These academic disciplines can be represented by relevant academic journals (Agarwal \& Hoetker, 2007) which were selected using Eigenfactor $^{T M}$ classification and ranking of ISI-listed journals for the year 2006 ( $c f$. Palacios-Huerta \& Volij, 2004). Further upon the understanding that scientific communications are characterized by scale-free network topology (Price, 1965; Merton, 1968; Barabási, 2003), top 20 journals were selected from each discipline. The publication and citation data for these journals was collected from Thomson 
Reuters' "Web of Science" covering a period of 21 years (January 1988-December 2008).

During the sample period, a total of 18,361 papers were published in selected economics journals, 14,423 in management journals, 9,592 in sociology journals, and 19,908 in psychology journals. From among these papers, innovation-related papers were identified using the string "innovat" in the search field of topic (which includes title, abstract, and author-supplied keywords). ${ }^{6}$

The electronic database search resulted in the identification of 3,517 innovation-related papers, of which 79 percent came from management, 15 percent from economics, five percent from sociology and one percent from psychology journals. After cleaning and normalizing the bibliographic references contained in these papers, the final sample included 21,008 cited publications that comprise the knowledge base of the innovation field during the period, and hence the base data for this study.

Again, based on the understanding of scale-free topology of scientific communication networks, 50 most cited publications in each discipline were selected for further analysis. This cut-off resulted in the selection of publications which had citation frequency as low as 79 in management, 15 in economics, 7 in sociology and 30 in Research Policy ${ }^{7}$. The citations in psychology papers were excluded because the highest citation frequency of any publication in sample psychology papers was only three.

\footnotetext{
${ }^{6}$ It is acknowledged that the use of this string selects only those papers which have explicitly mentioned the term "innovation" or any variant of it in the lead part. It can be expected that there would be numerous papers whose topics relate to innovation without having to mention it explicitly. However, including the latter would have caused a sampling bias. Therefore, by using this string, the study was deliberately limited to those papers where authors unambiguously noted that some aspect of their paper was related to innovation. Moreover, in order to detect the amount of noise by possible presence of such terms as "methodological innovation", "innovative tool/technique/method/approach" etc., the text analysis of all the titles, abstracts, and keywords was conducted using a text analysis software. The presence of such usage of the term was negligible and hence no arbitrary change was made in the sample with the assumption that subsequent procedures would naturally eliminate such papers.

${ }^{7}$ Research Policy (RP) was significantly correlated with economics as well as management disciplines in terms of the knowledge base. However, it was more closely linked to the management group (as its sample papers shared 5,297 citations with the sample from the management group) than to the economics group (1,335 shared citations) and sociology group (865 shared citations). For this reason, although RP was treated as a management journal in the final analysis, its top 50 cited papers were included in the base matrix separately.
} 
This data was organized in a binary $(0,1)$ matrix, henceforth referred to as the Base Matrix. A discipline was attributed to each journal paper based on Eigenfactor $^{\mathrm{TM}}$ classification of journals whereas Library of Congress (LoC) online catalogue was used for attribution of disciplines to the books. The count data of cited publications and related disciplines is presented in Table 2.1. ${ }^{8}$

TABLE 2.1

\section{Distribution of All Citations Among Disciplines}

\begin{tabular}{|c|c|c|c|c|c|c|c|c|c|c|c|c|c|c|c|}
\hline & \multicolumn{15}{|c|}{ Citing papers } \\
\hline & \multicolumn{5}{|c|}{$1988-94$} & \multicolumn{5}{|c|}{ 1995-2001 } & \multicolumn{5}{|c|}{$2002-08$} \\
\hline & Man & Eco & Soc & Psy & \begin{tabular}{|l|} 
Total \\
\end{tabular} & Man & Eco & Soc & Psy & Total & Man & Eco & Soc & Psy & Total \\
\hline No. of citing papers & 207 & 47 & 6 & 1 & 261 & 728 & 107 & 27 & 2 & 864 & 1277 & 135 & 39 & 0 & 1451 \\
\hline \multicolumn{16}{|l|}{ No. of cited publications: } \\
\hline Books & 801 & 153 & 31 & 1 & 986 & 2548 & 231 & 140 & 1 & 2920 & 3867 & 224 & 129 & 0 & 4220 \\
\hline Papers & 794 & 213 & 19 & 0 & 1026 & 5540 & 555 & 165 & 13 & 6273 & 15073 & 753 & 257 & 0 & 16083 \\
\hline Total cited & 1595 & 366 & 50 & 1 & 2012 & 8088 & 786 & 305 & 14 & 9193 & 18940 & 977 & 386 & 0 & 20303 \\
\hline \multicolumn{16}{|c|}{ Disciplinary distribution of total cited: } \\
\hline Management & $53 \%$ & $18 \%$ & $14 \%$ & $0 \%$ & $46 \%$ & $66 \%$ & $12 \%$ & $28 \%$ & $86 \%$ & $60 \%$ & $73 \%$ & $15 \%$ & $29 \%$ & $0 \%$ & $70 \%$ \\
\hline Economics & $23 \%$ & $71 \%$ & $30 \%$ & $0 \%$ & $32 \%$ & $16 \%$ & $78 \%$ & $13 \%$ & $0 \%$ & $21 \%$ & $15 \%$ & $80 \%$ & $10 \%$ & $0 \%$ & $18 \%$ \\
\hline Sociology & $12 \%$ & $1 \%$ & $36 \%$ & $0 \%$ & $10 \%$ & $8 \%$ & $1 \%$ & $47 \%$ & $14 \%$ & $9 \%$ & $6 \%$ & $0 \%$ & $52 \%$ & $0 \%$ & $5 \%$ \\
\hline Psychology & $0 \%$ & $0 \%$ & $0 \%$ & $0 \%$ & $0 \%$ & $1 \%$ & $0 \%$ & $0 \%$ & $0 \%$ & $1 \%$ & $0 \%$ & $0 \%$ & $0 \%$ & $0 \%$ & $0 \%$ \\
\hline Industry & $4 \%$ & $7 \%$ & $6 \%$ & $0 \%$ & $5 \%$ & $3 \%$ & $6 \%$ & $5 \%$ & $0 \%$ & $3 \%$ & $1 \%$ & $3 \%$ & $2 \%$ & $0 \%$ & $1 \%$ \\
\hline Technology & $2 \%$ & $2 \%$ & $0 \%$ & $0 \%$ & $2 \%$ & $2 \%$ & $2 \%$ & $1 \%$ & $0 \%$ & $2 \%$ & $1 \%$ & $2 \%$ & $0 \%$ & $0 \%$ & $1 \%$ \\
\hline Other & $6 \%$ & $0 \%$ & $14 \%$ & $100 \%$ & $5 \%$ & $5 \%$ & $0 \%$ & $6 \%$ & $0 \%$ & $4 \%$ & $3 \%$ & $0 \%$ & $6 \%$ & $0 \%$ & $4 \%$ \\
\hline Total & $100 \%$ & $100 \%$ & $100 \%$ & $100 \%$ & $100 \%$ & $100 \%$ & $100 \%$ & $100 \%$ & $100 \%$ & $100 \%$ & \multicolumn{5}{|c|}{$100 \% 100 \% 100 \% \quad 0 \% \quad 100 \%$} \\
\hline
\end{tabular}

\subsubsection{Initial Core of Innovation Field}

A typical challenge in this kind of study is the identification of the "core" publications. Since there is no consensus about core publications of innovation field across all disciplines, two seminal publications of Schumpeter (1911 and 1942) were used as the "starter publications" to determine the initial core through "snowball sampling" (Cottrill et al., 1989; Tushman \& Nelson, 1990; Freeman, 1994). Then, 100 publications most frequently co-cited with each of Schumpeter I (1911) and Schumpeter II (1942) were selected from the Base Matrix. This resulted in the selection of 134 publications, all of which were co-cited with Schumpeter I and/or II at least thrice. These publications were used as the initial core and the subsequent analysis was focused only on those publications which cited or were co-cited with at least two publications from the initial core or subsequent cores derived from the preceding cores using the same criteria.

\footnotetext{
${ }^{8}$ It is worth mentioning here that there were only 7 publications representing psychology in the Base Matrix. These included Nunnally (1978), Mumford (1988), Altman (1995), Frable (1997), Weick (1999), Bargh (2004), and Latham (2005). Moreover, the LoC categorized some publications into "industry" and "technology" categories rather than in any specific discipline. These were treated as such.
} 


\subsubsection{Citation and Co-Citation Matrices}

In order to ascertain the development of the field over time, the total period (1988-2008) was divided into three equal 7-year periods; 1988-94, 1995-2001, and 2002-08 ( $c f$. Ramos-Rodriguez \& Ruiz-Navarro, 2004). Then, by snowballing the initial core, citation matrices were constructed for each sub-period and the cumulative period. From these matrices, co-citation matrices were derived for each period (Small, 1973) and then transformed into respective correlation matrices because the co-citation correlation coefficient is conventionally used as a standard measure of similarity/dissimilarity between any two publications. It is due to the reason that it measures the correlation between complete co-citation profiles of each publication w.r.t. every other publication in the matrix (McCain, 1990). These matrices served as the basis for further analysis.

\subsubsection{Multivariate Analysis}

Since the citation data represents a high-dimensional space, it necessitated the use of multivariate techniques, specifically multidimensional scaling (MDS) and principal component analysis (PCA). ${ }^{9}$ Several similar studies have used these two techniques complementarily (e.g., White and Griffith, 1981; McCain, 1990; RamosRodriguez and Ruiz-Navarro, 2004; Nerur et al., 2008).

In order to perform the multivariate analysis, all the publications in the cumulative period matrix of citations (1988-2008) were ranked based on the frequency of received citations and then top 100 among these were selected. The resulting 106 publications account for 46 percent of all citations during the whole period and serve as the input for multivariate analysis. ${ }^{10}$

\footnotetext{
${ }^{9}$ The citation and co-citation matrices represent unweighted/binary and weighted networks, respectively. There are two possible approaches to analyze this data; standard multivariate analysis and network analysis. The data for this study, in both forms, involved a significant amount of overlap across disciplines. In network analysis, this problem pertains to the detection of overlapping communities which is only beginning to be explored (Fortunato, 2010). The use of network approach in this case would require a combination of several network analytical algorithms to complement each other. The complexities and limitations of this approach necessitated the use of more compact methods which are well-known, widely used and approved by the concerned scientific community.

${ }^{10}$ The list of top 100 publications is given in Table 2.B1 in Appendix 2.B. Incidentally, these publications included 50 most cited publications in each period. It is worth noting that this set includes 18 of the "top twenty contributions" and 44 of the "core innovation literature" identified in a similar bibliometric study of six handbooks and textbooks of innovation by Fagerberg and Sapprasert (Innovation: exploring the knowledge base. Working paper No. 20100616, Centre for Technology, Innovation and Culture, University of Oslo, 2010).
} 
The MDS map for a period represents certain knowledge space in two dimensions whereby the elements of the knowledge base (i.e., cited publications) are represented as data points. The distances among the data points represent their proximity based on the relative frequency of their co-participation (cocitation) in the knowledge base. Using the top 100 publications, MDS maps were prepared for each sub-period and the whole period (Figures 2.A1-2.A4 in Appen$\operatorname{dix} 2 . A){ }^{11}$

In co-citation correlation data, distinct research traditions are supposedly represented by major principal components (McCain, 1990; Acedo, Barroso \& Galan, 2006; Nerur et al., 2008). Therefore, using the co-citation correlation matrices and corresponding scree graphs, seven principal components were selected for the first period, seven for the second period, nine for the third period, and eight for the cumulative period. The total variance (proportion of knowledge base) explained by these components was 65.9 percent, 65.5 percent, 76.7 percent, and 63.7 percent for each period, respectively (Tables 2.B2-2.B5 in Appendix 2.B).

In order to make MDS and PCA comparable, every publication was assigned to the component where it had the highest loading. ${ }^{12}$ Then the MDS data points corresponding to each component were manually demarcated as a group and labeled on the MDS map.

For each principal component, the publications with factor loadings $\geq+$ o.4 were identified and the percentage of total loadings attributable to each discipline was determined. This percentage was used to ascribe a descriptive title to each component (research tradition). For instance, management and sociology publications accounted for 61 percent and 39 percent, respectively, of the loadings total for the first component of the first period. Therefore, its disciplinary composition is represented in its title as "management and sociology". Finally, research themes/fronts were identified within each research tradition by complementing the information from multivariate analysis with the relevant content analysis (publication titles, abstracts, editorial policy of concerned publication outlets, and contents pages and published reviews of the concerned books) (Table 2.2). ${ }^{13}$

\footnotetext{
${ }^{11}$ The correspondence between these data points on each MDS plot and publications is indicated in the Table $\mathrm{B} 1$ under respective period.

${ }^{12}$ Certain publications loaded on several components, often with slight difference in their loadings on different components. The grouping was only meant to represent distinct domains of knowledge to which they most closely belonged.

${ }^{13}$ It is acknowledged that this process involved a significant amount of reading and qualitative judgment which was necessitated by the unavailability of appropriate objective measures for the purpose.
} 


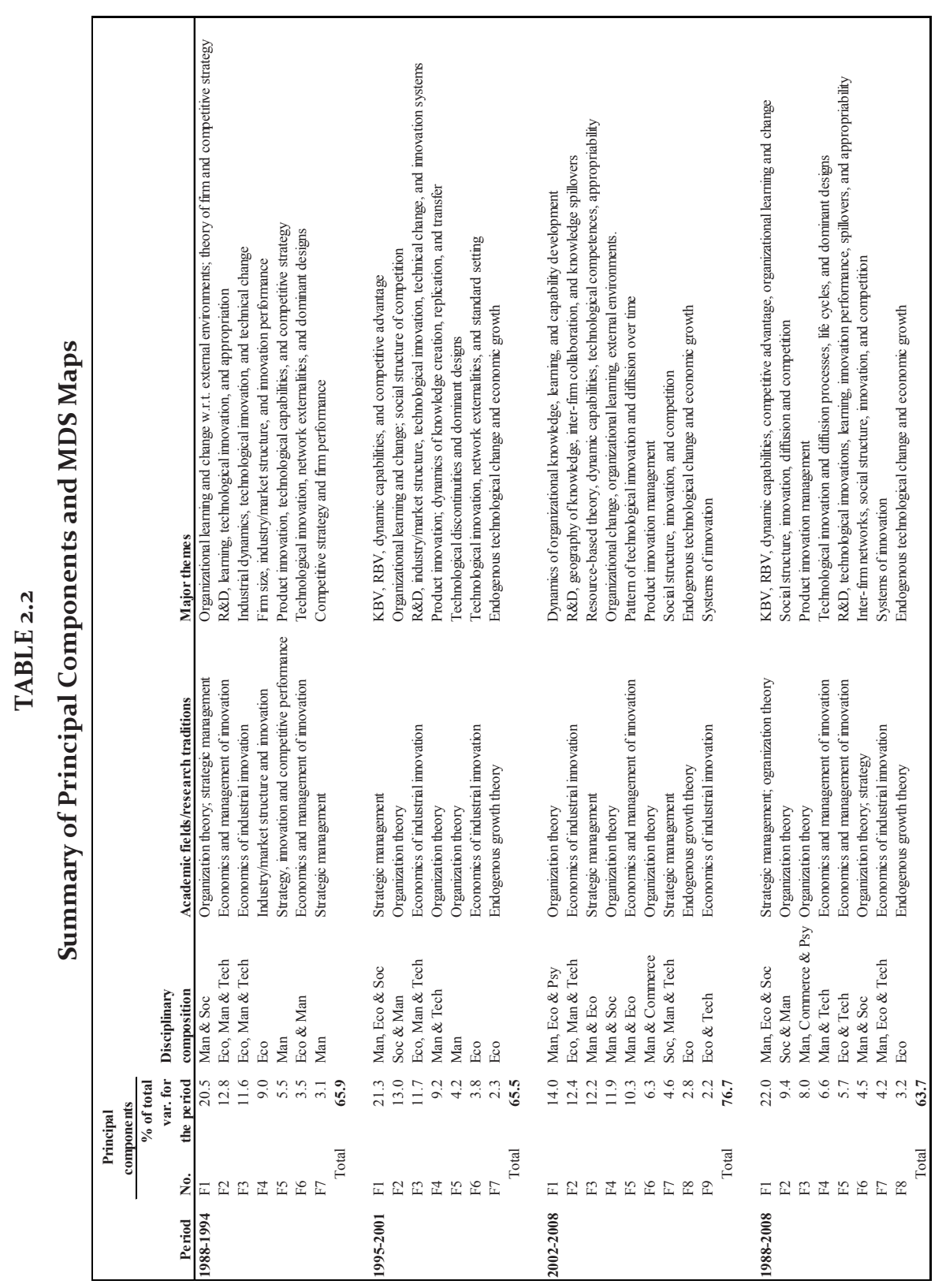




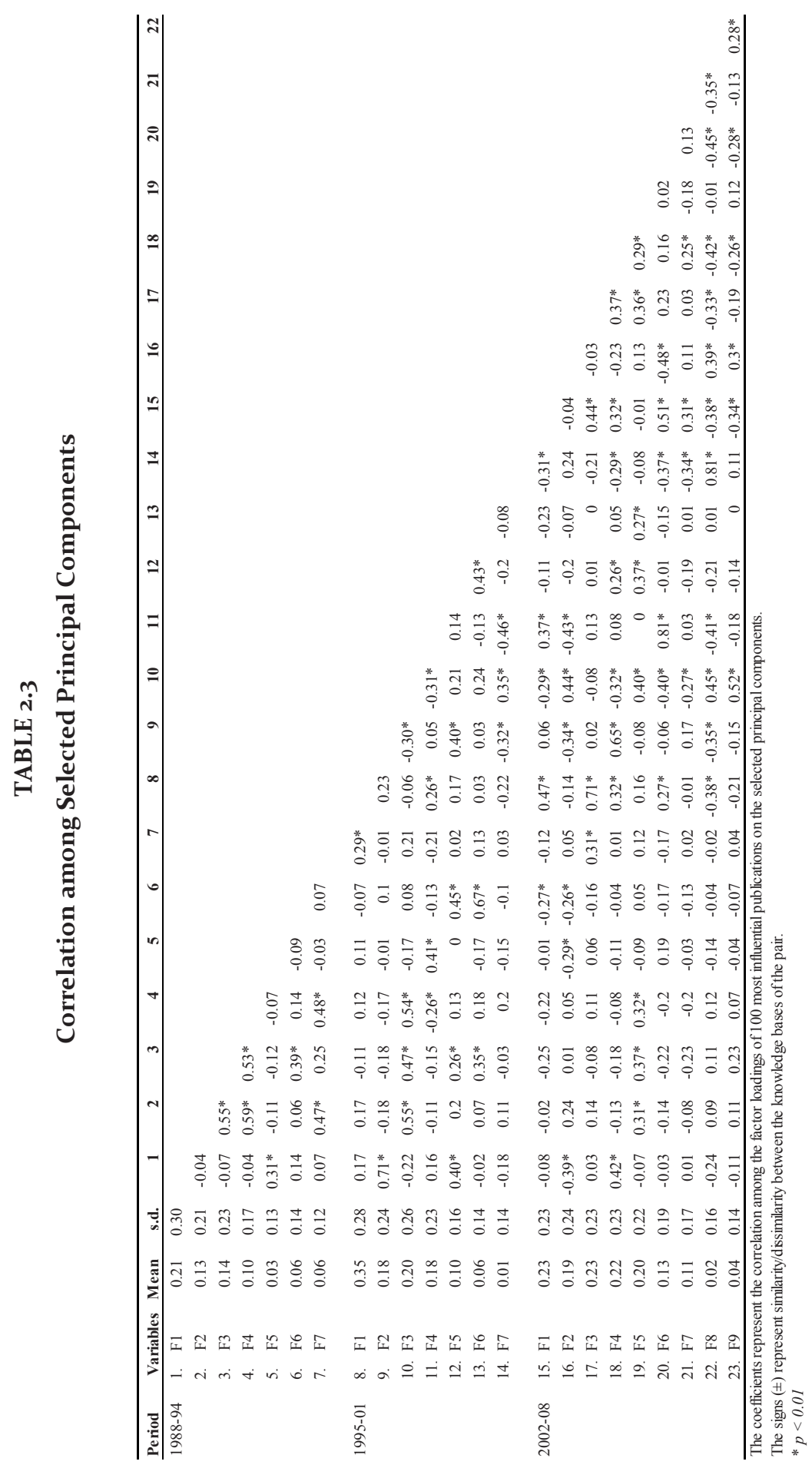




\section{TABLE 2.4}

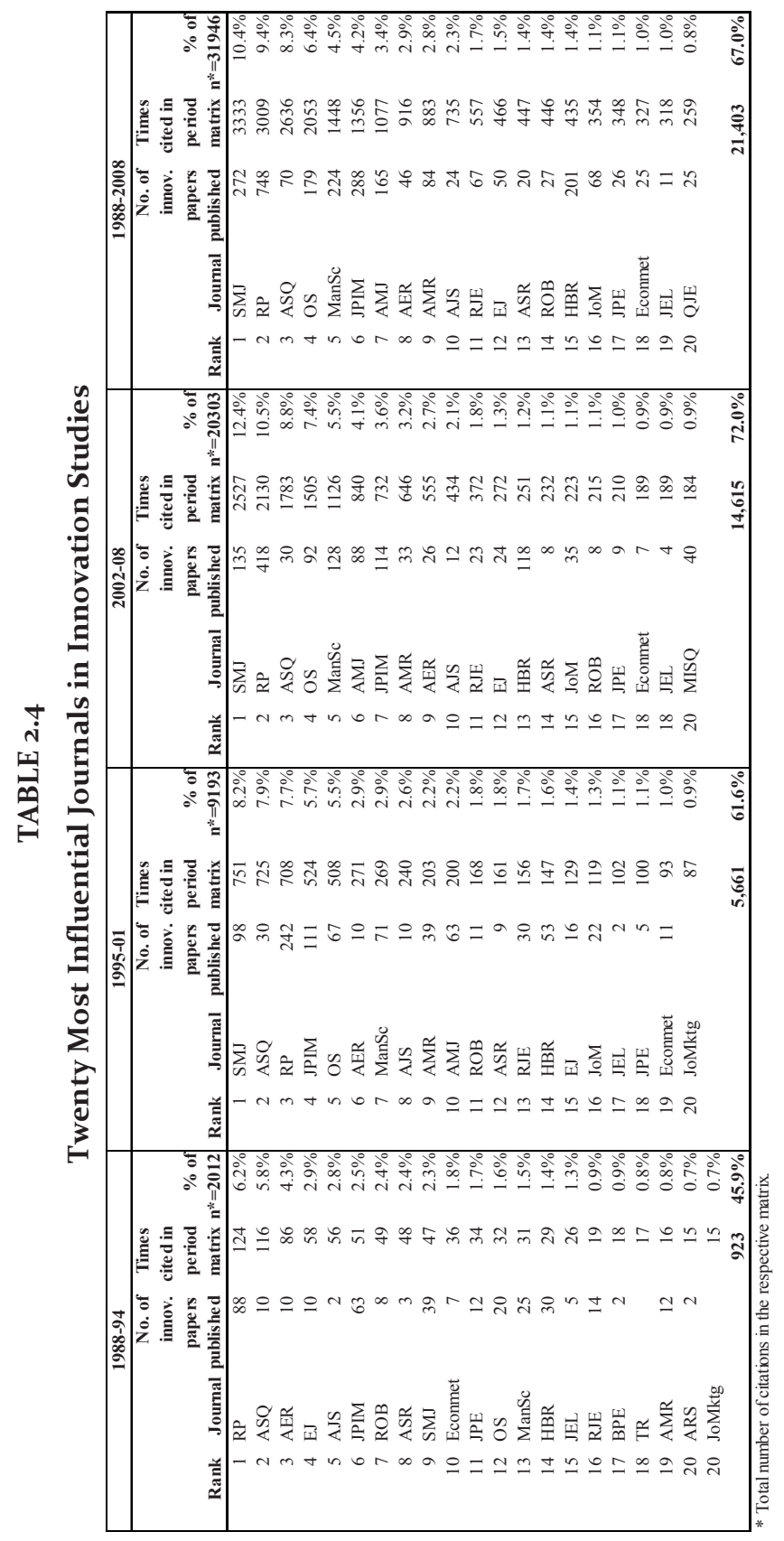

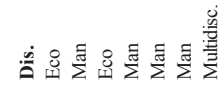

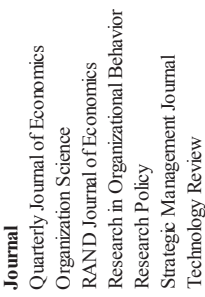

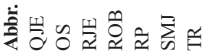

$\sum_{\frac{1}{2}}^{\frac{\infty}{4}}$

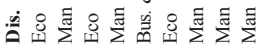

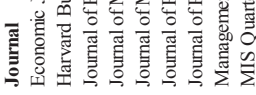

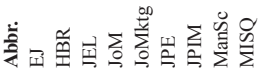

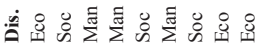

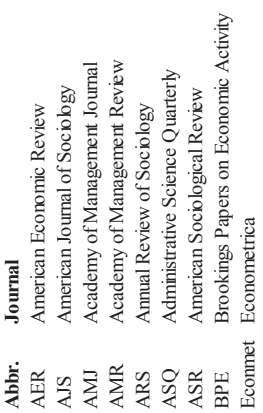


Finally, in order to measure and map the relationships among the knowledge bases of different traditions within and across three sub-periods, an affiliation matrix was constructed for the 100 most cited/influential publications and the 23 principal components. The correlation matrix of the affiliation matrix is a tabulation of the coefficients of similarity/dissimilarity among the knowledge bases of different traditions (McCain, 1990) (Table 2.3) and its weighted-line network is a visual representation of these relationships (Figure 2.A5 in Appendix 2.A). ${ }^{14}$

\subsection{ANALYSIS}

\subsubsection{Composition of the Knowledge Base}

This study uses two ad hoc measures - contribution and influence-to evaluate the knowledge base of innovation research. As noted earlier, disciplines are represented by journals. Thus, contribution of a discipline to a research field can be measured by the number of relevant papers published by respective journals as well as the books related to the field. On the other hand, influence of a discipline is measured by the number of citations received by the publications that belong to the discipline. Similarly, the contribution of a journal to a particular research field can be measured by the number of related articles published by the journal. However, while contribution is also a dimension of influence, the latter specifically involves the amount of knowledge that is contributed by a journal and actually used in the creation of further knowledge in the field. Therefore, although the term "influence" is relative, here it refers to the proportion of all citations that a publication/journal/discipline actually received during a given period. Accordingly, change in the influence can be measured via the change in the relative share in received citations during the period as following:

$$
\Delta_{t=\frac{x_{t}}{n_{t}}}-\frac{x_{t-1}}{n_{t-1}}
$$

Where $\Delta$ is percentage change over previous period, $t$ is the relevant base period, and $n$ is the total number of citations in the respective period

The statistics suggest that management and economics are two major contributors in the field (Table 2.1). However, the contribution of management journals has been consistently increasing from 79 percent in the first period to 84 percent in the $2^{\text {nd }}$, and 88 percent in the $3^{\text {rd }}$ period. On the other hand, the contri-

\footnotetext{
${ }^{14}$ The network was created by using network analysis software Pajek ${ }^{\circledR} 1.27$ (Nooy, Mrvar and Batagelj, 2005). The factors presented in this network correspond to the factors in relevant MDS maps and the thickness of connecting lines represents the degree of similarity/dissimilarity between the knowledge bases of different research traditions. This matrix/network is more comprehensive than the MDS maps because it accounts for the factor loadings of each publication on all the components which was precluded by the need for demarcation on the MDS maps.
} 
bution of mainstream economics journals steadily declined from 18 percent in the first period to 12 percent in the $2^{\text {nd }}$, and 9 percent in the $3^{\text {rd }}$ period. This may be an indication that researchers from different disciplines increasingly tended to publish their innovation-related research in management journals. It may also be that innovation-related research in economics was increasingly channeled via hybrid journals (e.g., Research Policy, Industrial and Corporate Change) or nonmainstream/specialized economics journals (e.g., Journal of Evolutionary Economics).

As regards the influence, the statistics about the 20 most influential journals-which represent 67 percent of the knowledge base of the field-indicate that management journals gradually ascended in their influence while the mainstream economics journals lost in relative influence (Table 2.4, Figure 2.1). During the whole study period (1988-2008), the top 20 journals included 12 from management (including Research Policy), six from economics, and two from sociology.

FIGURE 2.1

Influence of Top 20 Journals of Each Discipline

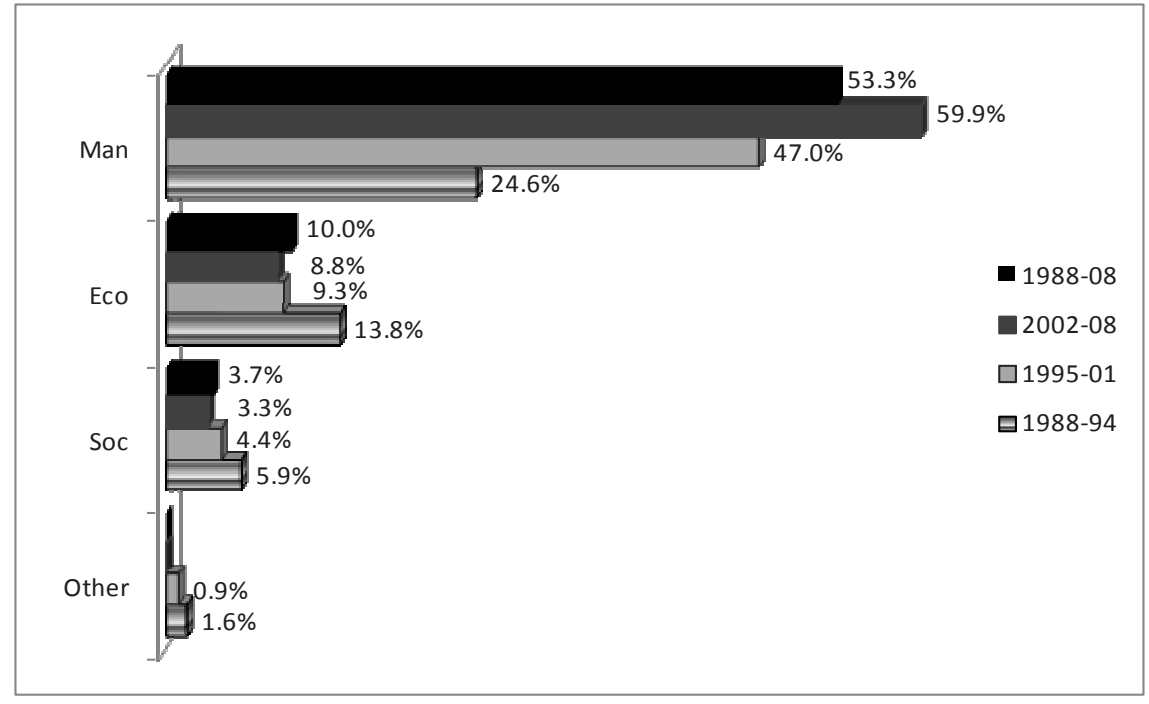

Similarly, the influence of individual publications can be measured. The 100 most influential publications in the whole study period represent 71 percent of all citations in the first period, 54 percent in the second period, 41 percent in the third period, and 46 percent in the cumulative period (Table 2.B1 in Appendix 2.B). This suggests that they constitute about a half of the knowledge base of innovation field, though this share has significantly decreased over time. As is typical of "normal science" (Kuhn, 1970; Latour, 1987), newer publications gradually replaced older ones which is an indication of healthy growth of the field (Figure 2.2). 
FIGURE 2.2

Changes in the Influence of 100 Most Cited Publications in the Knowledge Base of Innovation Research (1988-2008)

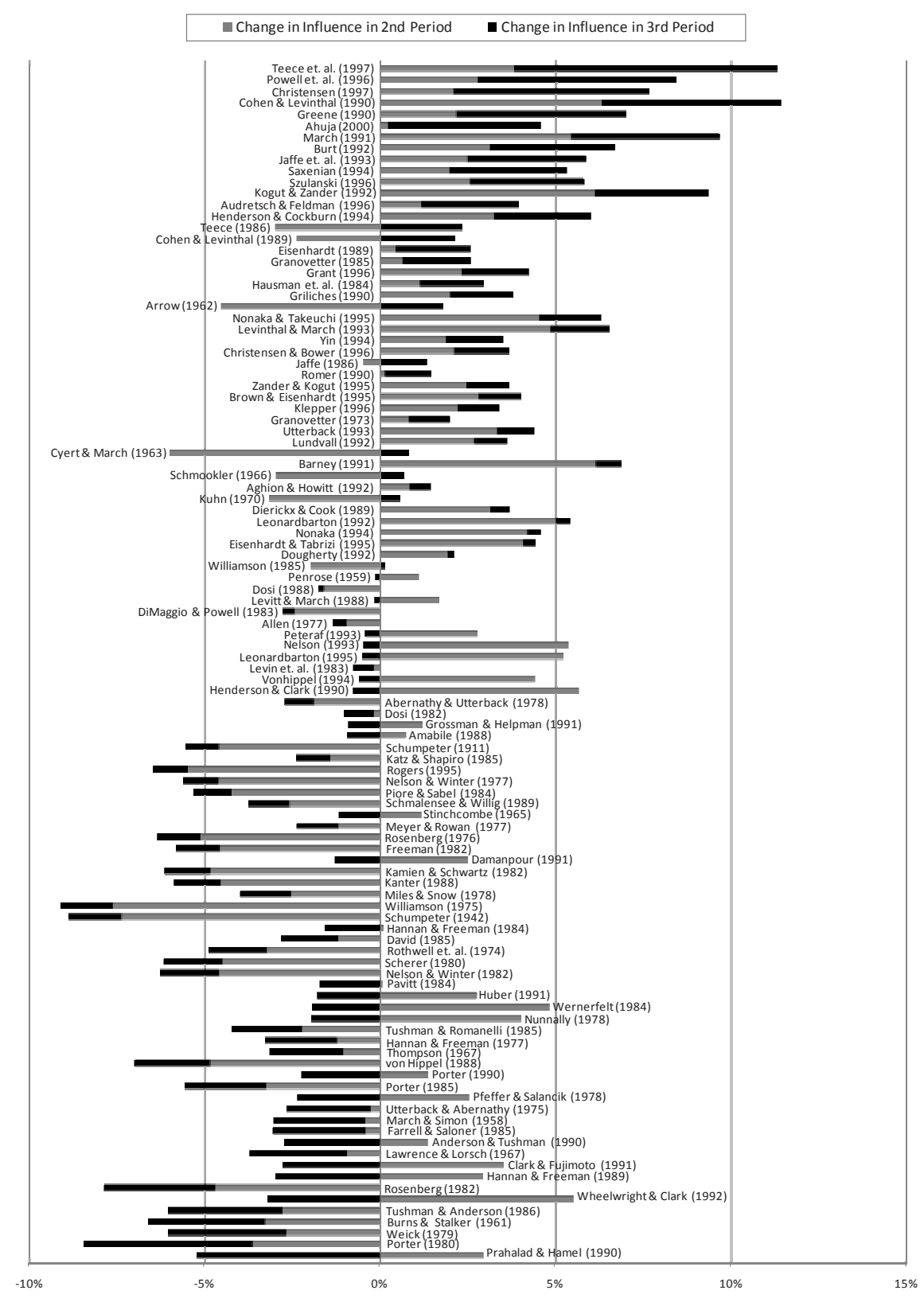


Moreover, the presence of some methodological publications-such as Greene (1990) and Yin (1994) — in this list indicates the use of quantitative as well as qualitative approaches, which is also a healthy sign.

The influence of journal papers compared to books has been steadily increasing from 51 percent in the first period to 68 percent in the second period and 79 percent in the third period (Table 2.1). This trend is accompanied by a steady increase in the influence of top 20 journals; from 46 percent in the first period to 62 percent in the second period and 72 percent in the third period (Table 2.4).

Besides publication type and the outlets, the distribution of all citations across disciplines indicates two major trends (Table 2.1). First, innovation research in each discipline has consistently become less multidisciplinary as measured by the proportion of citations in the journals of a discipline coming from outside the discipline. For instance, 53 percent of citations in management during the first period were from within the discipline, 23 percent from economics, and 12 percent from sociology. In the second period, this composition changed to 66 percent, 16 percent, and eight percent, respectively, which further deteriorated to become 73 percent, 15 percent, and six percent, respectively. This suggests that each discipline became more self-referential, hence more self-contained and increasingly detached from other disciplines. Second, sociology got closer to management in the knowledge space by drawing on the knowledge base of the latter while distancing from economics.

\subsubsection{Research Traditions and Their Interrelationship}

The complementary results of the MDS and PCA indicate the prevalence of several distinct research traditions during each period whereby each principal component assumingly represents a tradition encompassing several interrelated research fronts (McCain, 1990; Acedo et al., 2006; Nerur et al., 2008). The following analysis is based on the information derived from the structure of the MDS maps (Figures 2.A1-2.A4), content of the research traditions and their correlation (Tables 2.2 and 2.3, Figure 2.A5), and factor loadings of the publications (Tables 2. $\mathrm{B}_{2}-\mathbf{2} . \mathrm{B}_{5}$ ).

First period (1988-94). The analysis of factor loadings and MDS map for the first period suggests that the 'mainstream' of innovation research during this period was comprised of economics-based traditions as indicated by clustering of principal components F2 (Eco, Man \& Tech), F3 (Eco, Man \& Tech), and F4 (Eco) near the vertex (Figure 2.A1). It is also indicated by the fact that the most widely cited Nelson and Winter (1982) was located in close proximity to the 'mainstream' though it did not load significantly on any of the principal components noted here. It loaded almost equally on the first four components and loaded negatively on the fifth component (Man). The knowledge base of these economics-based 
traditions was related to $\mathrm{R} \& \mathrm{D}$, technological innovation, technical change, industrial dynamics, firm size, market structure, and innovation performance of firms.

On the other hand, while being major influencers of the field, management-related traditions, F1 (Man \& Soc) and F5 (Man) were more sociologyoriented and detached from economics-based research as indicated by their negative correlation with the former group. These traditions pertained to organizational learning and change with respect to external environments, product innovation, technological capabilities, competitive strategy, and theory of the firm. Straddling between the two groups but significantly tied to economics was F6 (Eco \& Man), which studied technological innovation, dominant designs, and network externalities from sociological and organizational theory perspectives. A small tradition, representing strategic management ( $\mathrm{F}_{7}$ : Man), also began to emerge in innovation field during this period. It is no surprise that due to its intellectual roots in economics and influence of Williamson (1985) and Porter (1985), it was significantly positively correlated with economics-based traditions, F2 (Eco, Man, \& Tech) and $\mathrm{F}_{4}$ (Eco).

Overall, this period in innovation research is marked by the detachment between the economics-based and organizational-theory-based approaches.

Second period (1995-01). This period witnessed more than three-fold increase in the number of published papers related to innovation and much of this research was contributed by management journals (Table 2.1). Due probably to this reason, the most noticeable development of this period was that the locus of 'mainstream' in innovation research migrated from economics to management as indicated by the position of management-related traditions F1 (Man, Eco \& Soc), $\mathrm{F}_{2}$ (Soc \& Man), F4 (Man\& Tech), and F5 (Man) on the MDS map (Figure 2.A2). Second noticeable development was the remarkable ascent of strategic management tradition from seventh place $\left(\mathrm{F}_{7}\right)$ in the previous period to the first place $\left(\mathrm{F}_{1}\right)$ in this period (Figure 2.A5). What makes it remarkable is its 'endogenous growth' as its knowledge base did not significantly draw from any other tradition in the previous period except its parent tradition. The dominance of this tradition is due mainly to the popularity of resource-based and dynamic capabilities perspectives during this period.

On the other hand, the organization theory tradition of the previous period (F1: Man \& Soc) split into two streams (F2: Soc \& Man and F4: Man \& Tech). One of these traditions, F2, seemed to focus more on the macro level by incorporating the social structural aspects of competition while shifting the emphasis from external factors to internal/organizational factors. The other tradition, $\mathrm{F}_{4}$, was more focused on internal environments and studied product innovation, dynamics of knowledge-creation, replication, and transfer. Moreover, a new tradition ( $\mathrm{F}_{5}$ : Man) emerged in organization theory by fusing knowledge from organization theory and economics-based traditions of the previous period (F1: Man \& 
Soc; F3: Eco, Man \& Tech; and F5: Man). It focused mainly on technological discontinuities and dominant designs. This was the only organization theory tradition that had significant positive correlation with a predominantly economicsbased tradition (F6: Eco). It is probably due to the reason that both were studying the dynamics of technological innovation and standard setting, though from different perspectives.

Third major development during this period was the convergence ${ }^{15}$ of three economics-based traditions of the previous period (F2: Eco, Man \& Tech; F3: Eco, Man \& Tech; and F4: Eco) and consequent emergence of one broad tradition (F3: Eco, Man \& Tech). This situation emerges when cross-fertilization across the knowledge bases of different traditions makes them homogeneous to such an extent that they become a consolidated domain which serves as a common field for creation of new knowledge. Not surprisingly, this tradition continued to build on the parent knowledge bases with noticeable emergence of a new research front-systems of innovation.

Fourth prominent change during this period was the appearance of a new island (F10: Eco) on the map asserting the "endogenous growth theory". It is no surprise that it is significantly positively correlated with its economics-based counterpart (F3: Eco, Man \& Tech), but significantly negatively correlated with organization theory traditions, F2 (Soc \& Man) and F4 (Man \& Tech).

A comparison of the MDS maps of the first and the second periods also indicates some other interesting developments during the second period. First, economics-based traditions exhibited a tendency of consolidation while the management-related traditions followed the path of diversification. Second, the discipline of management emerged as the largest contributor and influencer in the field. Third, sociological perspectives gained significant influence in innovation research as indicated by the emergence of three separate organization theory traditions and the location of F2 (Soc \& man) on the MDS map. All these developments indicate significant progress in the field of innovation research during the period 1995-2001.

Third period (2002-08). The innovation research continued to grow during this period and the discipline of management remained the major contrib-

\footnotetext{
15 Adapting the idea of Rosenberg (1963), the term "convergence" here refers to the overlap between the knowledge bases of different knowledge domains (research fronts, research traditions, academic fields, disciplines, etc.). It should not be confused with the concepts of merger or consolidation whereby participating entities form a larger whole and the participants lose their identiy. For instance, convergence between biology and chemistry would be a measure of the amount of their knowledge that is related/complementary. However, when the overlap among the knowledge bases of different domains reaches a threshold due to their interaction, convergence may result into the formation of hybrid sub-domains (for instance, biochemistry).
} 
utor and influencer (Table 2.1). The most prominent development that indicates increasing influence of management was the convergence of two traditions of the previous period (F1: Man, Eco \& Soc and F4: Man \& Tech) that bred a new organization theory tradition (F1: Man, Eco \& Psy) during this period. This influence seems to be the outcome of a general shift of focus from the external environments to the internal environments particularly towards the dynamics of knowledge creation, learning, and capability development in both organization theory and strategic management traditions.

However, externally-oriented branch of organization theory continued to grow alongside, as represented by $\mathrm{F}_{4}$ (Man \& Soc). Additionally, there appeared two other distinct traditions related to the organization theory, one focused more on product innovation management (F6: Man \& Commerce) and the other representing the emergence of social structural perspective of innovation and competition (F7: Soc, Man \& Tech). Another closely related but distinct tradition pertained to strategic management ( $\mathrm{F}_{3}$ : Man \& Eco). While the resource-based and dynamic capability perspectives remained a prominent influence in this tradition, it visibly incorporated the perspectives of technological competences and appropriability in its folds during this period.

On the other hand, consolidation of economics-based traditions during the previous period seems to have resulted in the emphasis on the dynamics of knowledge creation, its geography, and spillovers (F2: Eco, Man \& Tech). Furthermore, while the endogenous growth theory remained a niche in economics (F8: Eco), the systems of innovation perspective ascended from a research theme/front in the previous period to a distinct research tradition during this period (F9: Eco \& Tech).

Overall, the fragmentation between management and economics persisted-probably widened-during this period as indicated by significant negative correlations among their respective principal components and their positions on the MDS map (Figures 2.A3 and 2.A5). However, increasing focus on the role of knowledge is visible in almost all traditions of this period.

Cumulative period (1988-2008). An overview of the field for the whole study period indicates two prominent trends. First, as indicated by the share of variance explained and the coverage of the MDS map by different research traditions, management discipline has been the largest influencer in the field besides being the largest contributor to it (Table 2.1, Figures 2.1 and 2.A4). This finding is even more significant given the fact that the publications cited in management needed to have a minimum of 79 received citations in order to be included in the Base Matrix compared to 30 for Research Policy, 15 for economics, and seven for sociology. However, what is unexpected and disconcerting is the fact that innovation-related research in each discipline has been relying more and more on the internal knowledge base of its respective discipline (Table 2.1, Figure 2.1). This 
implies increasing fragmentation and compartmentalization which may undermine the prospects of innovation becoming a unified and/or coherent scientific field.

\subsection{DISCUSSION}

The aim of this research was to ascertain the subject matter of innovation as a field of research, delineate its intellectual structure by identifying the major research traditions that comprise it, and describe the disciplinary composition of their knowledge base. Based on the understanding that scientific communications within and across disciplines can be empirically measured through bibliometrics, the study used citation data of innovation-related papers published in 80 most influential journals of four major disciplines of social sciences during the period 1988-2008. Using some careful procedures on citation data matrices, 20 most influential journals and 100 most influential publications were identified that constituted 67 percent and 46 percent, respectively, of the knowledge base of the field during the period. Then, using these 100 publications as the core of the knowledge base and applying standard multivariate techniques, major research traditions and their constituent themes were identified for three sub-periods. Following that, relationships among these research traditions were identified using a correlation matrix and its network diagram. Consequently, this is probably the first systematic and comprehensive study that provides a 'global view' of the field from longitudinal and structural perspectives combined.

The research provides evidence supporting the idea that science normally progresses due to the dynamics of convergence (and divergence) among different knowledge domains (e.g., academic fields and disciplines). Convergence takes place due to the fusion and recombination of related knowledge across the boundaries of different knowledge domains. This phenomenon manifests in the emergence of relatively temporary sub-domains, such as "research fronts" and "research traditions". While the domains and sub-domains compete for resources (Merton, 1968), these tend to 'import' complementary knowledge from other domains and sub-domains for the creation of new knowledge. The knowledge 'trade' across the domains and sub-domains creates and expands the overlap among their knowledge bases. The greater the overlap among the knowledge bases of different domains and sub-domains, the closer they exist in the knowledge space and the greater the possibility of knowledge fusion across their boundaries. This seems to be a dynamic process-which is also likely to be self-reinforcing-that continuously feeds the growth of science.

On the other hand, certain domains or sub-domains may start exploring complementary knowledge in hitherto distant domains or sub-domains. Those which succeed in finding new reservoirs of complementary knowledge in distant regions may begin feeding more on that knowledge. This process may gradually 
distance them from their old neighbors in the knowledge space depending on the proportional changes in the composition of their knowledge bases over time. However, the process of divergence is likely to be slower than convergence due to the stickiness of existing knowledge base, linkages with existing communities of domains and sub-domains, and lack of knowledge about the new terrain(s). It also seems more likely that domains and sub-domains would move in packs rather than individually in the knowledge space.

This study provides some rudimentary evidence regarding the dichotomous phenomenon of knowledge convergence and divergence. For instance, due to increasing convergence among their knowledge bases, three economics-based traditions in the first period (F2: Eco, Man \& Tech; F3: Eco, Man \& Tech; and F4: Eco) bred a new tradition (F3: Eco, Man \& Tech) in the second period (Figure 2.A5). Then building on the consolidated knowledge base of this tradition, three distinct research traditions (F2: Eco, Man \& Tech; F5: Man \& Eco, and F9: Eco \& Tech) emerged in the third period.

Similarly, a small tradition in first period (F6: Eco \& Man) grew and split into two distinct traditions ( $\mathrm{F}_{5}$ : Man and F6: Eco) in the second period whereby one leaned towards organization theory $\left(\mathrm{F}_{5}\right)$ while the other tilted towards economics (F6). In this process, $F_{5}$ seems to be the outcome of management-related part feeding more on other management-related traditions, while F6 resulted from the economics-based part feeding more on the economics-based traditions. Due to the ongoing process of cross-fertilization with related traditions, the economics-based tradition (F6) morphed into another economics-based tradition ( $\mathrm{F}_{5}$ : Man \& Eco) while the management-related tradition $\left(\mathrm{F}_{5}\right)$ became part of the knowledge bases of $\mathrm{F}_{4}$ (Man \& Soc) and $\mathrm{F}_{5}$ (Man \& Eco) in the third period, both of which belong to organization theory. This phenomenon of convergence is present among other traditions as well.

The innovation field itself started as a research tradition in Schumpeterian economics. Over time, it became fairly multidisciplinary which is also indicated by the composition of cross-citations across different disciplines in the early period of the study. However, the evidence from this study suggests that innovation research is gradually losing this attribute. While psychology made very little contribution and influence in the field, the contribution of sociology increased slightly but its relative influence has been consistently decreasing. Consequently, innovation research seems to be getting compartmentalized between two major disciplines-management and economics - whereby each discipline exhibits the tendency of being inwardly focused and using less and less of the related knowledge outside its disciplinary boundaries (Table 2.1). This tendency of self-containment is disconcerting because it may hinder tapping the full potential of research in this innately multidisciplinary field. These findings have important implications for the future development of the field. 


\subsubsection{Implications}

This study constitutes an empirically grounded framework that can be used by any researcher to identify the opportunities for research contribution in the field according to the state of their expertise. Since the experts have greater qualitative knowledge, they may contribute reviews at various levels; research-fronts, research traditions, academic fields, and disciplines. The mid career researchers may do well by following the recommendations of the resource-based view of strategy. They may evaluate their existing knowledge base vis-à-vis the knowledge bases of various research traditions. If their expertise is concentrated in one tradition, they may consider the avenues for diversification through fusion of knowledge across related traditions. On the other hand, if their expertise is scattered across traditions, they may do well by narrowing their focus. Similarly, the beginners may do well by carefully evaluating the point of entry and "positioning" into the field. By matching their own goals and knowledge base with the knowledge bases of reasonably grounded and likely-to-emerge traditions, they may choose to specialize in one tradition or carefully diversify in a few closely related ones. Aside from serving as a compass for expertise-base research opportunities, the framework may also be used as an aid in problem-based research. For instance, locating the position of an issue in relation to research traditions may help spot related knowledge/literature within and across research traditions and disciplines.

\subsubsection{Limitations}

The study inherits several limitations that are typical of any sample-based research. The choice of the sample is the most important among these. Due to the purpose and nature of the study and availability of reliable data, the study was based upon the understanding of scale-free topology in scientific communication networks. Consequently, it focused upon four disciplines and twenty most influential journals from each discipline which supposedly represent the 'mainstream' of the respective discipline. Although the 100 most influential publications identified here and used as the basis of analysis have significant overlap with the core innovation literature identified by others, the differences suggest that the basis of the sample (e.g., journals vs. handbooks and ISI-listed vs. non-ISI-listed journals) may affect the results. Therefore, this study essentially pertains to the diffusion of Schumpeterian perspective of innovation in the 'mainstream' of each discipline and its integration with influential perspectives thereof. Consequently, it does not exhaustively cover all the innovation research or the whole field.

Second, the study used publications rather than persons as the unit of analysis. Due to the dilemmas of this dichotomy, this study did not take into account the disciplinary affiliation of authors of the publications. Unfortunately, both the approaches could not be simultaneously incorporated in a single study of this scale due to the inconsistencies in their methodological demands. It is quite 
possible that scholars from economics, sociology, and psychology disciplines may have been publishing their innovation-related research in management journals rather than the journals of their respective fields. In such a case, the contribution of management as proxied by its journals would be inflated and the impression of decreasing multidisciplinarity may be erroneous. However, it is expected that even the person-based approach may not produce drastically different results unless there is a compelling reason to believe that non-management scholars do not use the knowledge base of their parent disciplines when they publish in management journals.

Third, given the ever-increasing competition for space in top-tier journals, it is quite possible that some important research in innovation did not appear in the mainstream journals and diverted towards newer or more specialized journals which are not yet listed by the ISI. This seems plausible given the consistent decrease in the contribution of mainstream journals of economics which is the parent discipline of the field. Interestingly, if this is taken to be the case, then the innovation field may be seeking a distinct identity by establishing its own specialized journal(s) (Frickel \& Gross, 2005; Hambrick \& Chen, 2008).

Fourth, a significant part of research is published in books and handbooks which may have not been cited in journals due to increasing influence of electronic databases which provide instant access to electronic journals. Electronic access gives journals a decided advantage over books which are printed in limited number, are not included in commonly used electronic indexes, and do not reach every research institution.

Finally, this study is focused only on social science disciplines which means that it does not account for innovation-related research in science and technology fields. Therefore, it is related only to the economic, sociological, and management perspectives of innovation and leaves out the engineering and technological perspectives of the field. These disciplines and fields can be promising avenues for similar research.

\subsubsection{Future Directions}

The evidence that innovation research is getting increasingly fragmented and compartmentalized into different disciplines gives rise to a new set of interesting questions from the perspective of the theory of social intellectual movements which seek to establish a distinct identity as a field (Frickel \& Gross, 2005; Hambrick \& Chen, 2008). Although innovation-related research seems to be growing, it is fragmented and compartmentalized in different disciplines. Despite some indications of unification and coherence-such as the establishment of Technology and Innovation Management Division at the Academy of Management in the US and DRUID in Europe as well as several other fora focused on innovation-it is an open question whether innovation can be considered a unified, or at least a 
coherent, field. Whether it could be or should be a distinct scientific or academic field like, for instance, strategic management (cf. Hambrick \& Chen, 2008)? If so, why it could not attain such a status in more than half a century of active research that strategic management attained in a few decades? Multidisciplinary character of innovation as a research field is likely to be at the heart of all such issues.

\subsubsection{Conclusion}

Innovation involves the creation of new knowledge based on existing knowledge. The organization of knowledge in various domains or 'boxes' helps understand as well as create new knowledge. At various levels of aggregation, research traditions, academic fields and disciplines are few such 'boxes' in which scientific knowledge can be organized on the basis of their respective knowledge base. Correspondingly, every agent in any field has a certain knowledge base which determines their absorptive capacity as well as the creative capacity. The opportunities for knowledge creation, and hence, innovation within a domain and/or by an agent are dependent on the breadth, diversity, and external linkages of their knowledge base for the simple reason that greater variety of related and complementary knowledge increases the possibilities for newer combinations of knowledge. The scarcity of the linkages is indicative of self-containment, over-specialization, and possible stagnation. History of science suggests that it progresses through crossfertilization across various 'boxes'. Be it the adoption of biological theory of evolution in economics or incorporation of insights from military strategy in management, science has progressed through fusion, recombination, and reconfiguration of extant knowledge. By the same token, it can be reasonably expected that the evolution of technology fields is also driven by similar dynamics of knowledge creation that would essentially pertain to the linkages among different technology fields and/or the linkages across science and technology fields. 
APPENDIX 2.A

MAPS OF THE INTELLECTUAL STRUCTURE OF INNOVATION FIELD

FIGURE 2.A1

MDS Map of Period Co-Citation Correlation Matrix (1988-94)

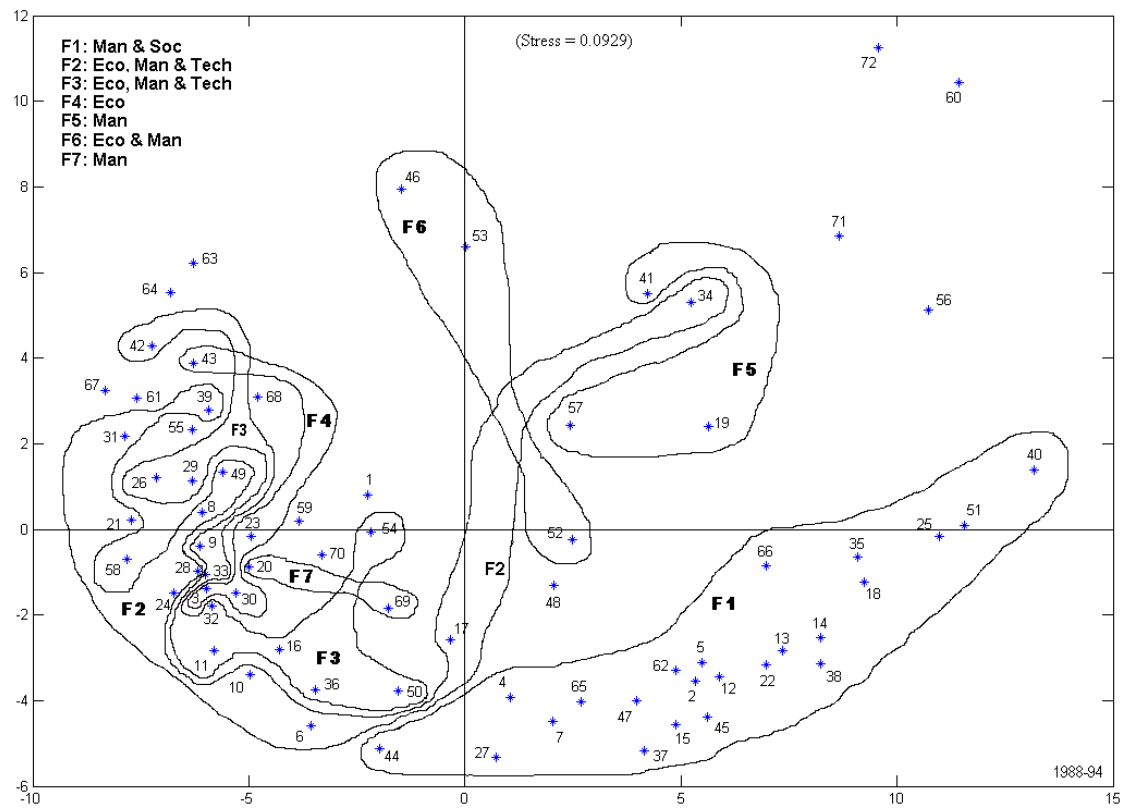

FIGURE 2.A2

MDS Map of Period Co-Citation Correlation Matrix (1995-2001)

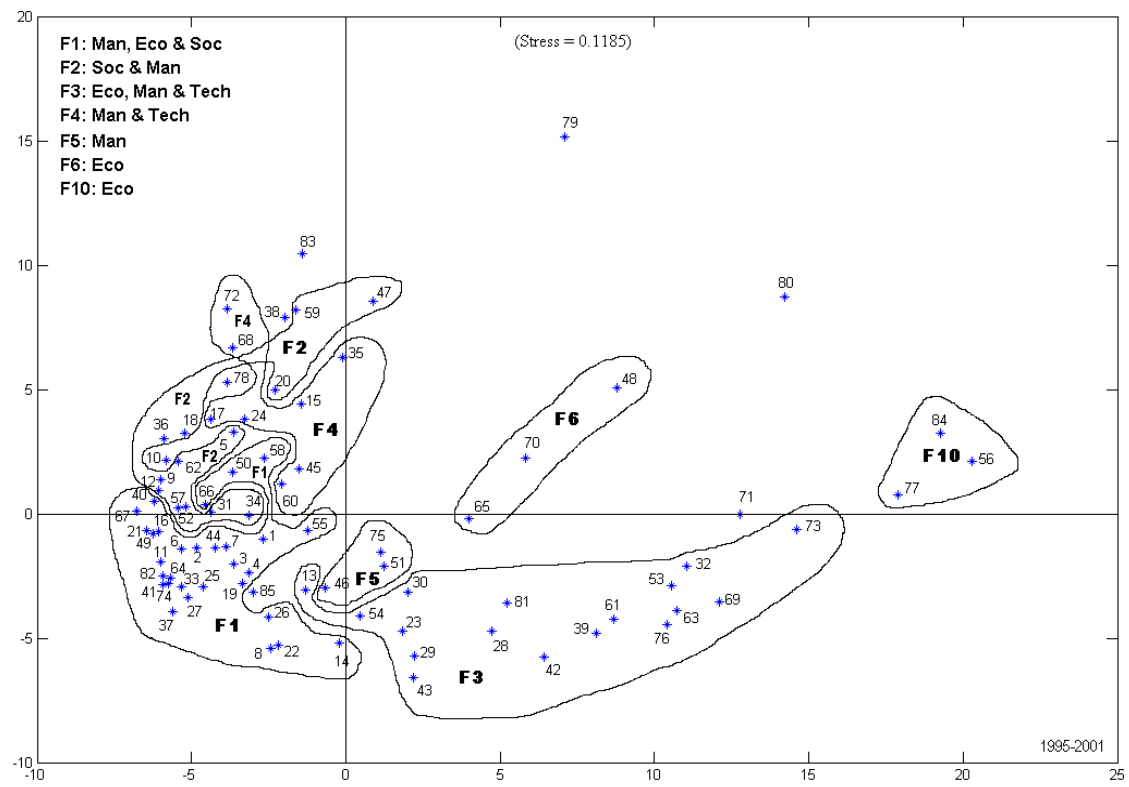


FIGURE 2.A3

MDS Map of Period Co-Citation Correlation Matrix (2002-08)

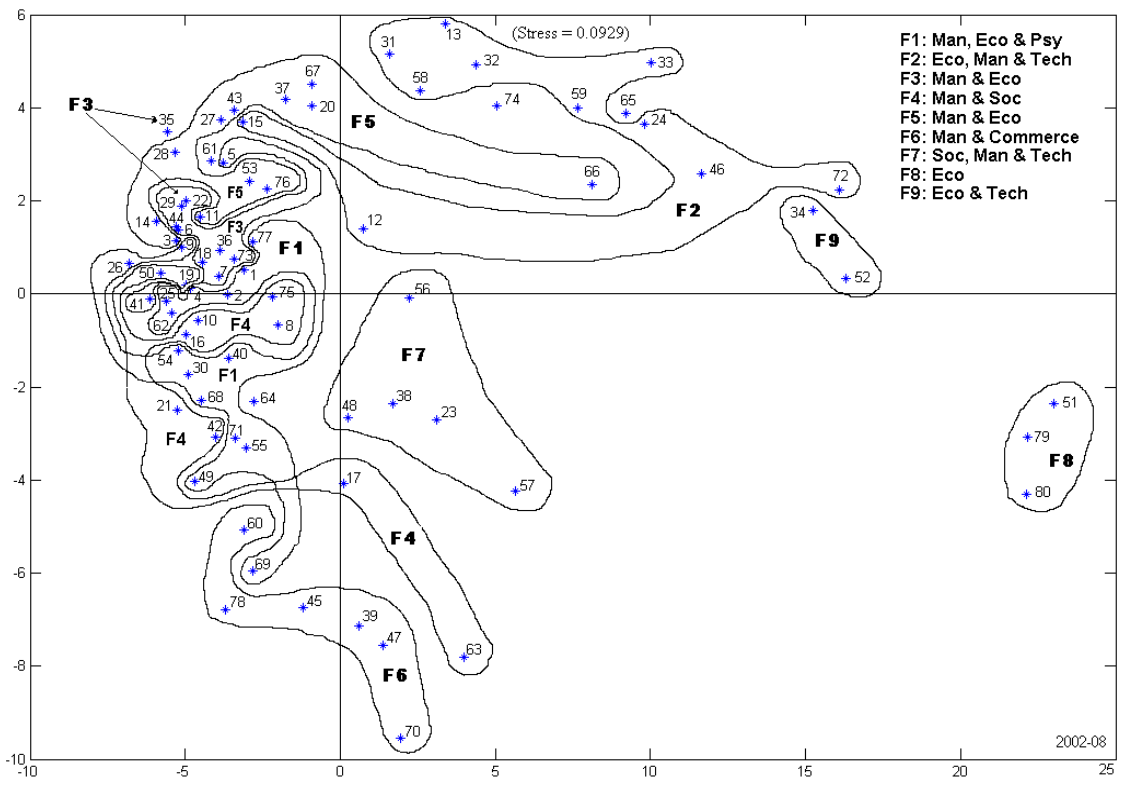

FIGURE 2.A4

MDS Map of Cumulative Co-Citation Correlation Matrix (1988-o8)

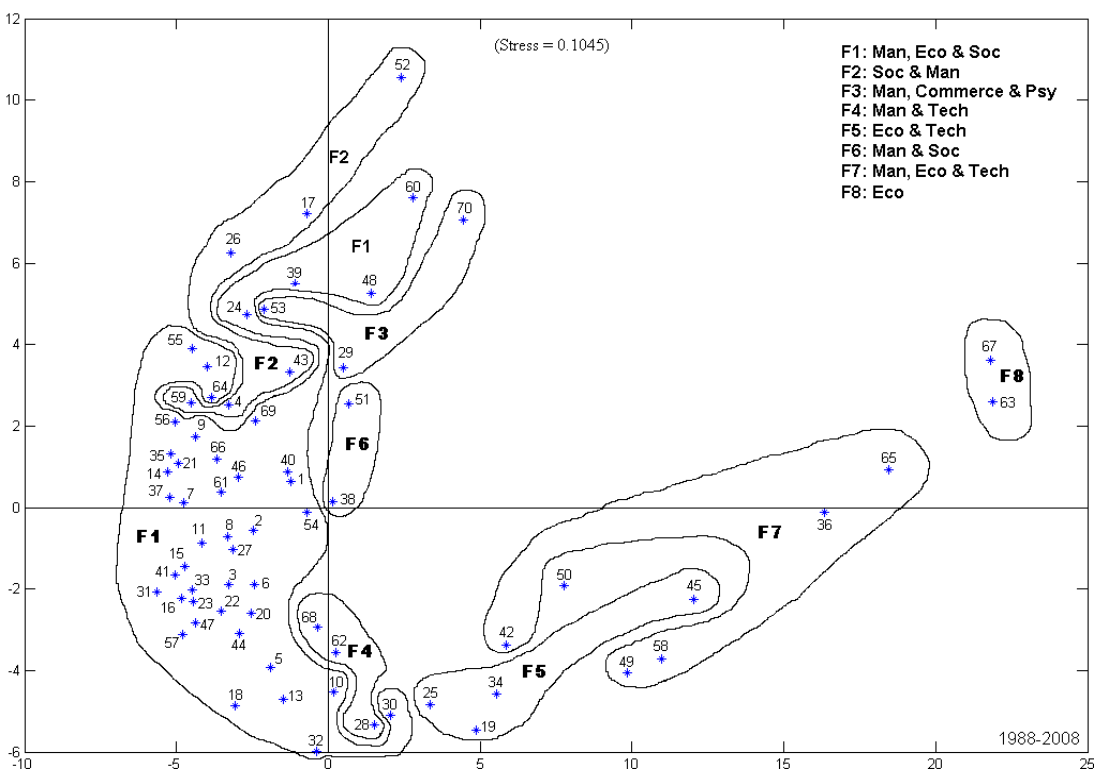




\section{FIGURE 2.A5}

Relationship Among the Research Traditions of the Three Periods

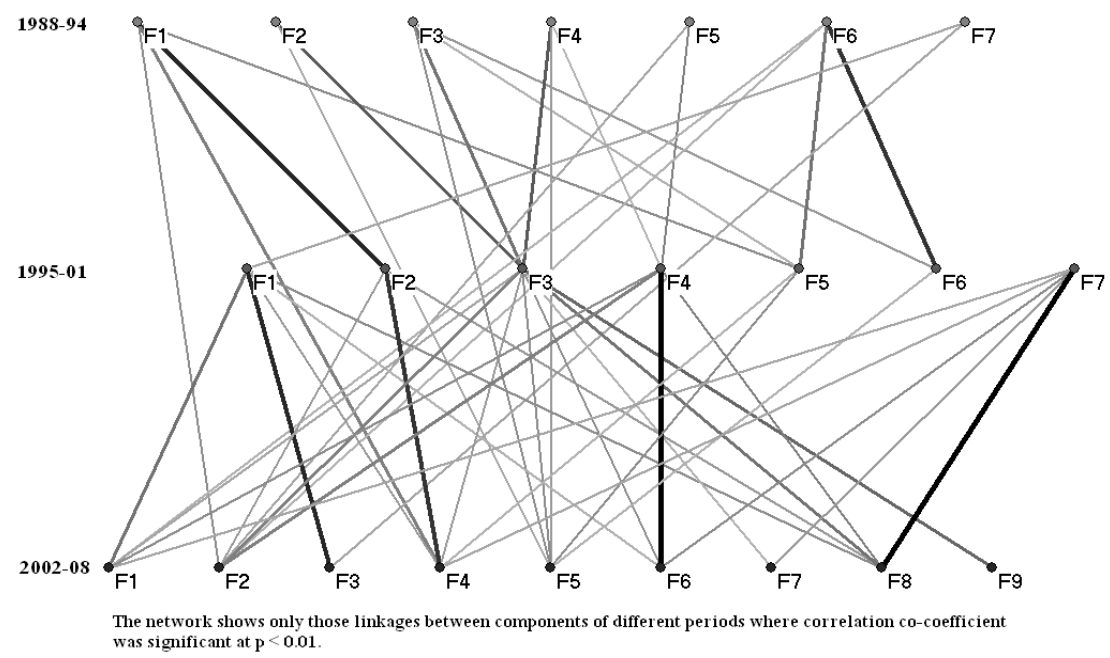




\section{APPENDIX 2.B: Tables}

\section{TABLE 2.B1}

\section{The 100 Most Influential Publications in Innovation Research (1988-20o8) ${ }^{\mathrm{a}}$}

\begin{tabular}{|c|c|c|c|c|c|c|c|c|c|c|c|c|c|c|c|c|c|c|c|c|}
\hline \multirow[b]{2}{*}{ 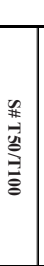 } & \multirow[b]{2}{*}{ Publication } & \multirow[b]{2}{*}{ 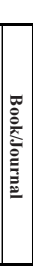 } & \multirow[b]{2}{*}{$\begin{array}{l}\stackrel{\check{g}}{\Xi} \\
\stackrel{\Xi}{\Xi}\end{array}$} & \multirow[b]{2}{*}{ 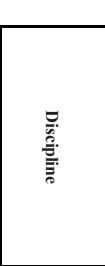 } & \multicolumn{4}{|c|}{ 1988-94 } & \multicolumn{4}{|c|}{$1995-2001$} & \multicolumn{4}{|c|}{ 2002-08 } & \multicolumn{4}{|c|}{ 1988-2008 } \\
\hline & & & & & 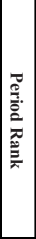 & 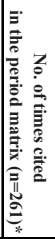 & $\begin{array}{l}\stackrel{0}{\circ} \\
\stackrel{0}{\sigma} \\
\stackrel{\pi}{\sigma}\end{array}$ & 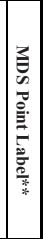 & 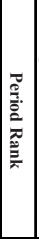 & 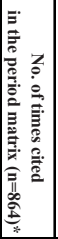 & 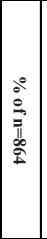 & 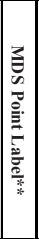 & 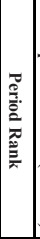 & 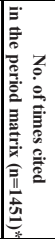 & 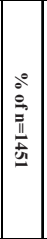 & 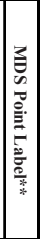 & 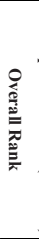 & 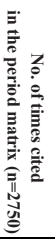 & 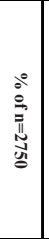 & 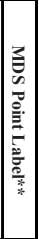 \\
\hline 1 & Nelson \& Winter (1982) & $\mathrm{B}$ & & Eco-Theory & 1 & 70 & $27 \%$ & 1 & 1 & 192 & $22 \%$ & 1 & 2 & 298 & $21 \%$ & 2 & 1 & 561 & $20 \%$ & 1 \\
\hline 2 & Cohen \& Levinthal (1990) & $\mathrm{J}$ & ASQ & Man & 16 & 24 & $9 \%$ & $\begin{array}{lll}0 & 17 \\
0\end{array}$ & 2 & 134 & $16 \%$ & 2 & 1 & 299 & $21 \%$ & 1 & 2 & 459 & $17 \%$ & 2 \\
\hline 31 & Henderson \& Clark (1990) & $\mathrm{J}$ & ASQ & Man & 25 & 20 & $8 \%$ & $\begin{array}{lll}0 & 27 \\
\end{array}$ & 3 & 115 & $13 \%$ & 3 & 3 & 182 & $13 \%$ & 3 & 3 & 317 & $12 \%$ & 3 \\
\hline 4 & Rogers (1995) & $\mathrm{B}$ & & Soc & 2 & 43 & $16 \%$ & $\begin{array}{ll}6 \\
0\end{array}$ & 5 & 95 & $11 \%$ & 5 & 8 & 145 & $10 \%$ & 8 & 4 & 296 & $11 \%$ & 4 \\
\hline 5 & Teece (1986) & $\mathrm{J}$ & $\mathrm{RP}$ & Man & 9 & 32 & $12 \%$ & 9 & 8 & 80 & $9 \%$ & 8 & 5 & 168 & $12 \%$ & 5 & 5 & 282 & $10 \%$ & 5 \\
\hline 6 & Tushman \& Anderson (1986) & $\mathrm{J}$ & ASQ & Man & 4 & 39 & $15 \%$ & 4 & 4 & 105 & $12 \%$ & 4 & 11 & 129 & $9 \%$ & 11 & 6 & 273 & $10 \%$ & 6 \\
\hline 7 & March (1991) & $\mathrm{J}$ & OS & Man & 88 & 7 & $3 \%$ & & 15 & 70 & $8 \%$ & 16 & 4 & 179 & $12 \%$ & 4 & 7 & 256 & $9 \%$ & 7 \\
\hline 8 & Barney (1991) & $\mathrm{J}$ & JOM & Man & 64 & 10 & $4 \%$ & 69 & 7 & 86 & $10 \%$ & 7 & 7 & 155 & $11 \%$ & 7 & 8 & 251 & $9 \%$ & 8 \\
\hline 9 & Cyert \& March (1963) & $\mathrm{B}$ & & Man & 5 & 38 & $15 \%$ & 5 & 12 & 74 & $9 \%$ & 12 & 10 & 136 & $9 \%$ & 10 & 9 & 249 & $9 \%$ & 9 \\
\hline 10 & Schumpeter (1942) & $\mathrm{B}$ & & PolEco & 3 & 41 & $16 \%$ & $\begin{array}{ll}0 & 3 \\
\end{array}$ & 14 & 72 & $8 \%$ & 14 & 20 & 99 & $7 \%$ & 20 & 10 & 216 & $8 \%$ & 10 \\
\hline 111 & Porter (1980) & $\mathrm{B}$ & & Man & 7 & 37 & $14 \%$ & $\begin{array}{ll}6 & 7 \\
0 & \end{array}$ & 6 & 91 & $11 \%$ & 6 & 41 & 83 & $6 \%$ & 41 & 11 & 212 & $8 \%$ & 11 \\
\hline 12 & Thom & $\mathrm{B}$ & & Man & 13 & 26 & $10 \%$ & 14 & 10 & 77 & $9 \%$ & 10 & 20 & 99 & $7 \%$ & 21 & 12 & 203 & $7 \%$ & 12 \\
\hline 13 & von $\mathrm{H}$ & $\mathrm{B}$ & & Eco-Hist & 8 & 35 & $13 \%$ & $\begin{array}{ll}6 & 8 \\
\end{array}$ & 12 & 74 & $9 \%$ & 13 & 27 & 93 & $6 \%$ & 27 & 12 & 203 & $7 \%$ & 13 \\
\hline 14 & March \& Simon (1958) & $\mathrm{B}$ & & Man & 15 & 25 & $10 \%$ & \begin{tabular}{|l|l}
6 & 15 \\
\end{tabular} & 9 & 79 & $9 \%$ & 9 & 25 & 95 & $7 \%$ & 25 & 14 & 200 & $7 \%$ & 14 \\
\hline 15 & Kogut \& Zander (1992) & $\mathrm{J}$ & OS & Man & 183 & 1 & $0 \%$ & & 32 & 56 & $6 \%$ & 33 & 9 & 141 & $10 \%$ & 9 & 15 & 198 & $7 \%$ & 15 \\
\hline 16 & Teece et. al. (1997) & $\mathrm{J}$ & SMJ & Man & & & & & 71 & 33 & $4 \%$ & 74 & 6 & 164 & $11 \%$ & 6 & 16 & 197 & $7 \%$ & 16 \\
\hline 17 & DiMaggio \& Powell (1983) & $\mathrm{J}$ & ASR & Soc & 13 & 26 & $10 \%$ & $\begin{array}{lll}0 & 13 \\
\end{array}$ & 20 & 65 & $8 \%$ & 20 & 17 & 104 & $7 \%$ & 17 & 17 & 196 & $7 \%$ & 17 \\
\hline 18 & Schumpeter (1911) & B & & Eco-Theory & 10 & 31 & $12 \%$ & $\begin{array}{ll}6 & 10 \\
0\end{array}$ & 22 & 63 & $7 \%$ & 22 & 28 & 92 & $6 \%$ & 28 & 18 & 187 & $7 \%$ & 18 \\
\hline 19 & Cohen \& Levinthal (1989) & $\mathrm{J}$ & EJ & Eco & 24 & 21 & $8 \%$ & $\begin{array}{lll}6 & 24 \\
\end{array}$ & 42 & 49 & $6 \%$ & 42 & 13 & 113 & $8 \%$ & 13 & 19 & 185 & $7 \%$ & 19 \\
\hline 201 & Levitt \& March (1988) & $\mathrm{J}$ & ARS & Soc & 42 & 15 & $6 \%$ & $\begin{array}{lll}0 & 47 \\
\end{array}$ & 21 & 64 & $7 \%$ & 21 & 16 & 105 & $7 \%$ & 16 & 20 & 184 & $7 \%$ & 21 \\
\hline 21 & Williamson (1985) & $\mathrm{B}$ & & Eco-Theory & 18 & 23 & $9 \%$ & \begin{tabular}{|l|l|}
0 & 20 \\
\end{tabular} & 26 & 59 & $7 \%$ & 26 & 18 & 101 & $7 \%$ & 18 & 20 & 184 & $7 \%$ & 20 \\
\hline 22 & Williamson (1975) & $\mathrm{B}$ & & Man & 5 & 38 & $15 \%$ & 6 & 25 & 60 & $7 \%$ & 25 & 44 & 79 & $5 \%$ & 44 & 22 & 177 & $6 \%$ & 22 \\
\hline 23 & Penrose (1959) & $\mathrm{B}$ & & Man & 42 & 15 & $6 \%$ & \begin{tabular}{|l|l|} 
& 44 \\
\end{tabular} & 26 & 59 & $7 \%$ & 27 & 22 & 97 & $7 \%$ & 22 & 23 & 171 & $6 \%$ & 23 \\
\hline 24 & Lawrence \& I & $\mathrm{B}$ & & Man & 18 & 23 & $9 \%$ & $\begin{array}{ll}6 & 18 \\
6\end{array}$ & 17 & 68 & $8 \%$ & 17 & 49 & 74 & $5 \%$ & 49 & 24 & 168 & $6 \%$ & 24 \\
\hline 25 & Levin et. al. & $\mathrm{J}$ & BPE & Eco & 31 & 18 & $7 \%$ & $\begin{array}{ll}6 & 31 \\
\end{array}$ & 28 & 58 & $7 \%$ & 28 & 31 & 89 & $6 \%$ & 31 & 25 & 167 & $6 \%$ & 25 \\
\hline 26 & Pfeffer \& Sal & $\mathrm{B}$ & & Man & 49 & 14 & $5 \%$ & \begin{tabular}{|l|l|}
6 & 51 \\
\end{tabular} & 17 & 68 & $8 \%$ & 18 & 42 & 80 & $6 \%$ & 42 & 26 & 163 & $6 \%$ & 26 \\
\hline 27 & Wernerfelt (1984) & $\mathrm{J}$ & SMJ & Man & 79 & 8 & $3 \%$ & & 17 & 68 & $8 \%$ & 19 & 36 & 86 & $6 \%$ & 36 & 27 & 162 & $6 \%$ & 27 \\
\hline 28 & Dosi (1982) & $\mathrm{J}$ & $\mathrm{RP}$ & Man & 31 & 18 & $7 \%$ & $\begin{array}{ll}6 & 32 \\
\end{array}$ & 28 & 58 & $7 \%$ & 29 & 37 & 85 & $6 \%$ & 37 & 28 & 161 & $6 \%$ & 28 \\
\hline 29 & Clark \& Fujimc & $\mathrm{B}$ & & Industry & 57 & 12 & $5 \%$ & \begin{tabular}{|l|l}
0 & 57 \\
\end{tabular} & 15 & 70 & $8 \%$ & 15 & 45 & 77 & $5 \%$ & 45 & 29 & 160 & $6 \%$ & 29 \\
\hline 30 & Leonardbarton (1992) & $\mathrm{J}$ & SMJ & Man & 138 & 3 & $1 \%$ & & 36 & 53 & $6 \%$ & 37 & 25 & 95 & $7 \%$ & 26 & 30 & 151 & $5 \%$ & 31 \\
\hline 31 & Rosenberg (1982) & $\mathrm{B}$ & & Eco-Hist & 10 & 31 & $12 \%$ & $\begin{array}{lll}0 & 11 \\
\end{array}$ & 23 & 62 & $7 \%$ & 23 & 67 & 58 & $4 \%$ & 67 & 30 & 151 & $5 \%$ & 30 \\
\hline 32 & Dierickx \& Cook (1989) & $\mathrm{J}$ & ManSc & Man & 88 & 7 & $3 \%$ & & 39 & 50 & $6 \%$ & 41 & 28 & 92 & $6 \%$ & 29 & 32 & 149 & $5 \%$ & 33 \\
\hline 33 & Dosi (1988) & $\mathrm{J}$ & JEL & Eco & 28 & 19 & $7 \%$ & $\begin{array}{ll}6 & 28 \\
2 & -1\end{array}$ & 42 & 49 & $6 \%$ & 43 & 42 & 80 & $6 \%$ & 43 & 32 & 149 & $5 \%$ & 32 \\
\hline 34 & Arrow (1962) & B & & Man & 18 & 23 & $9 \%$ & $\begin{array}{lll}0 & 21 \\
2 & \end{array}$ & 61 & 37 & $4 \%$ & 61 & 32 & 88 & $6 \%$ & 32 & 34 & 148 & $5 \%$ & 34 \\
\hline 35 & Hannan \& Freeman (1984) & $\mathrm{J}$ & ASR & Soc & 34 & 17 & $7 \%$ & $\begin{array}{ll}637 \\
\end{array}$ & 31 & 57 & $7 \%$ & 31 & 50 & 73 & $5 \%$ & 50 & 35 & 147 & $5 \%$ & 35 \\
\hline 36 & Nelson (1993) & $\mathrm{B}$ & & Technology & 138 & 3 & $1 \%$ & & 32 & 56 & $6 \%$ & 32 & 34 & 87 & $6 \%$ & 34 & 35 & 147 & $5 \%$ & 36 \\
\hline 37 & Levinthal \& March & $\mathrm{J}$ & SMJ & Man & 183 & 1 & $0 \%$ & & 49 & 45 & $5 \%$ & 49 & 19 & 100 & $7 \%$ & 19 & 37 & 146 & $5 \%$ & 37 \\
\hline 38 & Powell et. Al. (1996) & $\mathrm{J}$ & ASQ & Man & & & & & 98 & 24 & $3 \%$ & & 12 & 122 & $8 \%$ & 12 & 37 & 146 & $5 \%$ & 38 \\
\hline 39 & Allen (1977) & $\mathrm{B}$ & & Technology & 34 & 17 & $7 \%$ & $\begin{array}{ll}6 & 34 \\
\end{array}$ & 44 & 48 & $6 \%$ & 45 & 48 & 75 & $5 \%$ & 48 & 39 & 142 & $5 \%$ & 40 \\
\hline 40 & Burns \& Stalk & $\mathrm{B}$ & & & 2 & 27 & $10 \%$ & 12 & 24 & 61 & $7 \%$ & 24 & 78 & 54 & $4 \%$ & 78 & 39 & 142 & $5 \%$ & 39 \\
\hline 41 & Prahalad \& Hamel (1990) & $\mathrm{J}$ & HBR & Man & 42 & 15 & $6 \%$ & 48 & 11 & 75 & $9 \%$ & 11 & 86 & 50 & $3 \%$ & & 39 & 142 & $5 \%$ & 41 \\
\hline 42 & Porter (1990) & $\mathrm{B}$ & & Industry & 49 & 14 & $5 \%$ & 49 & 28 & 58 & $7 \%$ & 30 & 57 & 65 & $4 \%$ & 59 & 42 & 140 & $5 \%$ & 42 \\
\hline 43 & Granovetter (197 & $\mathrm{J}$ & A.JS & Soc & 64 & 10 & $4 \%$ & 66 & 53 & 40 & $5 \%$ & 55 & 38 & 84 & $6 \%$ & 38 & 43 & 134 & $5 \%$ & 43 \\
\hline 44 & Greene (1990) & $\mathrm{B}$ & & Eco-Theory & 183 & 1 & $0 \%$ & & 110 & 22 & $3 \%$ & & 15 & 107 & $7 \%$ & 15 & 44 & 133 & $5 \%$ & 44 \\
\hline 45 & Griliches (1990) & $\mathrm{J}$ & JEL & Eco & 96 & 6 & $2 \%$ & & 61 & 37 & $4 \%$ & 63 & 32 & 88 & $6 \%$ & 33 & 45 & 131 & $5 \%$ & 45 \\
\hline 46 & Nonaka \& Takeuchi (1995) & $\mathrm{B}$ & & Man & & & & & 57 & 39 & $5 \%$ & 58 & 30 & 91 & $6 \%$ & 30 & 45 & 131 & $5 \%$ & 46 \\
\hline 47 & Christensen (1997) & B & & Man & & & & & 131 & 18 & $2 \%$ & & 14 & 111 & $8 \%$ & 14 & \begin{tabular}{|l|}
47 \\
\end{tabular} & 130 & $5 \%$ & 47 \\
\hline 48 & Yin (1994) & $\mathrm{B}$ & & Soc Sc. (Gen) & 96 & 6 & $2 \%$ & & 65 & 36 & $4 \%$ & 66 & 38 & 84 & $6 \%$ & 39 & 48 & 128 & $5 \%$ & 48 \\
\hline 49. & Jaffe et. al. (1993) & $\mathrm{J}$ & QJE & Eco & 156 & 2 & $1 \%$ & & 81 & 28 & $3 \%$ & 81 & 24 & 96 & $7 \%$ & 24 & 49 & 126 & $5 \%$ & 50 \\
\hline 501 & Pavilt (1984) & $\mathrm{J}$ & $\mathrm{RP}$ & Man & 42 & 15 & $6 \%$ & 43 & 39 & 50 & $6 \%$ & 39 & 66 & 59 & $4 \%$ & 66 & 49 & 126 & $5 \%$ & 49 \\
\hline 51 & Burt (1992) & $\mathrm{B}$ & & Man & & & & & 83 & 27 & $3 \%$ & & 22 & 97 & $7 \%$ & 23 & 51 & 124 & $5 \%$ & 51 \\
\hline 52. & Meyer \& Rowan & $\mathrm{J}$ & AJS & Soc & 34 & 17 & $7 \%$ & 35 & 47 & 46 & $5 \%$ & 47 & 63 & 60 & $4 \%$ & 63 & 52 & 123 & $4 \%$ & 52 \\
\hline 53 & Nunnally (1978) & B & & Psy & 110 & 5 & $2 \%$ & & 38 & 51 & $6 \%$ & 38 & 71 & 57 & $4 \%$ & 71 & 53 & 121 & $4 \%$ & 53 \\
\hline 54 & Porter (1985) & $\mathrm{B}$ & & Man & 18 & 23 & $9 \%$ & 19 & 44 & 48 & $6 \%$ & 44 & 94 & 47 & $3 \%$ & & 54 & 119 & $4 \%$ & 54 \\
\hline 55 & Huber (1991) & $\mathrm{J}$ & OS & Man & 79 & 8 & $3 \%$ & & 39 & 50 & $6 \%$ & 40 & 67 & 58 & $4 \%$ & 68 & 55 & 116 & $4 \%$ & 56 \\
\hline
\end{tabular}


TABLE 2.B1 (Continued)

\begin{tabular}{|c|c|c|c|c|c|c|c|c|c|c|c|c|c|c|c|c|c|c|c|}
\hline 56 & Weick (1979) & $\mathrm{B}$ & & Soc & 18 & 23 & $9 \%$ & 22 & 36 & 53 & $6 \%$ & 36 & 106 & 40 & $3 \%$ & 55 & 116 & $4 \%$ & 55 \\
\hline 57 & Henderson \& Cockburn (1994) & $\mathrm{J}$ & SMJ & Man & & & & & 81 & 28 & $3 \%$ & 82 & 34 & 87 & $6 \% \quad 35$ & 57 & 115 & $4 \%$ & 57 \\
\hline 58 & Freeman (1982) & $\mathrm{B}$ & & Man & 16 & 24 & $9 \%$ & \begin{tabular}{c|}
16 \\
\end{tabular} & 53 & 40 & $5 \%$ & 53 & 89 & 49 & $3 \%$ & 58 & 114 & $4 \%$ & 58 \\
\hline 59 & Eisenhardt (1989) & $\mathrm{J}$ & AMR & Man & 88 & 7 & $3 \%$ & & 83 & 27 & $3 \%$ & & 47 & 76 & $5 \% \quad 47$ & 59 & 113 & $4 \%$ & 60 \\
\hline 60 & Hannan \& Freeman (1989) & $\mathrm{B}$ & & Man & 73 & 9 & $3 \%$ & & 34 & 55 & $6 \%$ & 34 & 89 & 49 & $3 \%$ & 59 & 113 & $4 \%$ & 59 \\
\hline 61 & Leonardbarton (1995) & $\mathrm{B}$ & & Man & & & & & 49 & 45 & $5 \%$ & 50 & 54 & 68 & $5 \% \quad 54$ & 59 & 113 & $4 \%$ & 61 \\
\hline 62 & Abernathy \& Utterback (1978) & $\mathrm{J}$ & TR & Multi & 34 & 17 & $7 \%$ & 36 & 53 & 40 & $5 \%$ & 54 & 75 & 55 & $4 \% \quad 76$ & 62 & 112 & $4 \%$ & 62 \\
\hline 63 & Szulanski(1996) & $\mathrm{J}$ & SMJ & Man & & & & & 110 & 22 & $3 \%$ & & 38 & 84 & $6 \% \quad 40$ & 65 & 106 & $4 \%$ & 66 \\
\hline 64 & Wheelwright \& Clark (1992) & $\mathrm{B}$ & & Commerce & 156 & 2 & $1 \%$ & & 35 & 54 & $6 \%$ & 35 & 99 & 44 & $3 \%$ & 70 & 101 & $4 \%$ & 70 \\
\hline 65 & Anderson \& Tushman (1990) & $\mathrm{J}$ & ASQ & Man & 61 & 11 & $4 \%$ & 62 & 44 & 48 & $6 \%$ & 46 & 104 & 41 & $3 \%$ & 71 & 100 & $4 \%$ & \\
\hline 66 & Farrell \& Saloner (1985) & $\mathrm{J}$ & RJE & Eco & 42 & 15 & $6 \%$ & 46 & 47 & 46 & $5 \%$ & 48 & 111 & 39 & $3 \%$ & 71 & 100 & $4 \%$ & \\
\hline 67 & Utterback \& Abernathy (1975) & $\mathrm{J}$ & Omega & Man & 49 & 14 & $5 \%$ & 52 & 51 & 44 & $5 \%$ & 51 & 111 & 39 & $3 \%$ & 74 & 98 & $4 \%$ & \\
\hline 68 & Saxenian (1994) & $\mathrm{B}$ & & Eco-Hist & & & & & 138 & 17 & $2 \%$ & & 45 & 77 & $5 \% \quad 46$ & 77 & 94 & $3 \%$ & \\
\hline 69 & Schmalensee \& Willig (1989) & $\mathrm{B}$ & & Industry & 34 & 17 & $7 \%$ & 39 & 69 & 34 & $4 \%$ & 69 & 106 & 40 & $3 \%$ & 81 & 91 & $3 \%$ & \\
\hline 70 & Katz \& Shapiro (1985) & $\mathrm{J}$ & AER & Eco & 49 & 14 & $5 \%$ & 53 & 69 & 34 & $4 \%$ & 70 & 100 & 43 & $3 \%$ & 81 & 91 & $3 \%$ & \\
\hline 71 & Schmookler (1966) & $\mathrm{B}$ & & Technology & 42 & 15 & $6 \%$ & 42 & 98 & 24 & $3 \%$ & & 86 & 50 & $3 \%$ & 81 & 91 & $3 \%$ & \\
\hline 72 & Hannan \& Freeman & $\mathrm{J}$ & AJS & Soc & 42 & 15 & $6 \%$ & 45 & 57 & 39 & $5 \%$ & 57 & 118 & 36 & $2 \%$ & 84 & 90 & $3 \%$ & \\
\hline 73 & David (1985) & $\mathrm{J}$ & AER & Eco & 49 & 14 & $5 \%$ & 54 & 65 & 36 & $4 \%$ & 65 & 115 & 37 & $3 \%$ & 87 & 87 & $3 \%$ & \\
\hline 74 & Tushman \& Roma & $\mathrm{J}$ & ROB & Man & 34 & 17 & $7 \%$ & 38 & 61 & 37 & $4 \%$ & 62 & 131 & 33 & $2 \%$ & 87 & 87 & $3 \%$ & \\
\hline 75 & Kamien \& Schw & $\mathrm{B}$ & & Eco-Hist & 23 & 22 & $8 \%$ & 23 & 76 & 31 & $4 \%$ & 76 & 131 & 33 & $2 \%$ & 89 & 86 & $3 \%$ & \\
\hline 76 & Miles \& & $\mathrm{B}$ & & Man & 40 & 16 & $6 \%$ & 40 & 76 & 31 & $4 \%$ & 78 & 135 & 31 & $2 \%$ & 90 & 82 & $3 \%$ & \\
\hline 77 & Kanter (1988) & $\mathrm{J}$ & ROB & Man & 25 & 20 & $8 \%$ & 25 & 83 & 27 & $3 \%$ & 83 & 160 & 26 & $2 \%$ & 93 & 77 & $3 \%$ & \\
\hline 78 & Kuhn (1970) & B & & Science (Gen) & 49 & 14 & $5 \%$ & 50 & 123 & 19 & $2 \%$ & & 106 & 40 & $3 \%$ & 95 & 75 & $3 \%$ & \\
\hline 79 & Nelson \& Winter (1977) & $\mathrm{J}$ & $\mathrm{RP}$ & Man & 28 & 19 & $7 \%$ & 29 & 102 & 23 & $3 \%$ & & 174 & 24 & $2 \%$ & 104 & 66 & $2 \%$ & \\
\hline 80 & Piore \& Sabel (1984) & $\mathrm{B}$ & & Industry & 31 & 18 & $7 \%$ & 33 & 102 & 23 & $3 \%$ & & 191 & 23 & $2 \%$ & 106 & 65 & $2 \%$ & \\
\hline 81 & Rothwell et. al. (1974) & $\mathrm{J}$ & $\mathrm{RP}$ & Man & 40 & 16 & $6 \%$ & 41 & 93 & 25 & $3 \%$ & & 257 & 18 & $1 \%$ & 106 & 65 & $2 \%$ & \\
\hline 82 & Rosenb & $\mathrm{B}$ & & Eco-Hist & 25 & 20 & $8 \%$ & 26 & 110 & 22 & $3 \%$ & & 240 & 19 & $1 \%$ & 116 & 61 & $2 \%$ & \\
\hline 83 & Scherer (1980) & $\mathrm{B}$ & & Industry & 28 & 19 & $7 \%$ & 30 & 98 & 24 & $3 \%$ & & 283 & 16 & $1 \%$ & 120 & 59 & $2 \%$ & \\
\hline 84 & Romer ( & $\mathrm{J}$ & JPE & Eco & 73 & 9 & $3 \%$ & & 76 & 31 & $4 \%$ & 77 & 51 & 71 & $5 \% \quad 51$ & 62 & 112 & $4 \%$ & 63 \\
\hline 85 & Stinchec & $\mathrm{B}$ & & Soc & 64 & 10 & $4 \%$ & 65 & 52 & 43 & $5 \%$ & 52 & 75 & 55 & $4 \% \quad 75$ & 64 & 108 & $4 \%$ & 64 \\
\hline 86 & Lundvall (1992) & $\mathrm{B}$ & & Eco-Hist & 138 & 3 & $1 \%$ & & 71 & 33 & $4 \%$ & 73 & 52 & 69 & $5 \% \quad 52$ & 65 & 106 & $4 \%$ & 65 \\
\hline 87 & Grossm: & B & & Eco-Hist & 73 & 9 & $3 \%$ & & 53 & 40 & $5 \%$ & 56 & 78 & 54 & $4 \%$ & 67 & 103 & $4 \%$ & 67 \\
\hline 88 & Nonak & $\mathrm{J}$ & OS & Man & & & & & 65 & 36 & $4 \%$ & 67 & 55 & 66 & $5 \% \quad 55$ & 68 & 102 & $4 \%$ & 69 \\
\hline 89 & Utterback (1993) & B & & Man & 183 & 1 & $0 \%$ & & \begin{tabular}{|l|}
75 \\
\end{tabular} & 32 & $4 \%$ & 75 & 52 & 69 & $\begin{array}{|lr|}5 \% & 53 \\
\end{array}$ & 68 & 102 & $4 \%$ & 68 \\
\hline 90 & Eisenhardt \& Tabr & $\mathrm{J}$ & ASQ & Man & & & & & 68 & 35 & $4 \%$ & 68 & 60 & 64 & $4 \% \quad 60$ & 73 & 99 & $4 \%$ & \\
\hline 91 & Peteraf(1993) & $\mathrm{J}$ & SMJ & Man & 120 & 4 & $2 \%$ & & 61 & 37 & $4 \%$ & 64 & 73 & 56 & $4 \%$ & 75 & 97 & $4 \%$ & \\
\hline 92 & Dougherty (1992) & $\mathrm{J}$ & OS & Man & 110 & 5 & $2 \%$ & & 71 & 33 & $4 \%$ & 72 & 67 & 58 & $\begin{array}{ll}4 \% & 69 \\
\end{array}$ & 76 & 96 & $3 \%$ & \\
\hline 93 & Vonhippel (1994) & $\mathrm{J}$ & ManSc & Man & & & & & 59 & 38 & $4 \%$ & 60 & 75 & 55 & $4 \% \quad 77$ & 77 & 94 & $3 \%$ & \\
\hline 94 & Hausman et. al. (1984) & $\mathrm{J}$ & Econmet & Eco & 120 & 4 & $2 \%$ & & 102 & 23 & $3 \%$ & & 57 & 65 & $4 \% \quad 58$ & 79 & 92 & $3 \%$ & \\
\hline 95 & Granovetter (1985) & $\mathrm{J}$ & AJS & Soc & 110 & 5 & $2 \%$ & & 110 & 22 & $3 \%$ & & 57 & 65 & $4 \% \quad 57$ & 79 & 92 & $3 \%$ & \\
\hline 96 & Aghion \& Ho & $\mathrm{J}$ & Econmet & $\mathrm{E}$ & 96 & 6 & $2 \%$ & & 83 & 27 & $3 \%$ & 84 & 78 & 54 & $4 \% \quad 80$ & 85 & 88 & $3 \%$ & \\
\hline 97 & Damanpour (199 & $\mathrm{J}$ & AMJ & $\mathrm{Ma}$ & 110 & 5 & $2 \%$ & & 59 & 38 & $4 \%$ & 59 & 96 & 45 & $3 \%$ & 85 & 88 & $3 \%$ & \\
\hline 98 & Brown \& & $\mathrm{J}$ & AMR & $\mathrm{M}$ & & & & & 98 & 24 & $3 \%$ & & 67 & 58 & $4 \% \quad 70$ & 90 & 82 & $3 \%$ & \\
\hline 99 & Grant (1996) & $\mathrm{J}$ & SMJ & Man & & & & & 119 & 20 & $2 \%$ & & 62 & 61 & $4 \% \quad 62$ & 92 & 81 & $3 \%$ & \\
\hline 100 & Jaffe (1986) & $\mathrm{J}$ & AER & Eco & 88 & 7 & $3 \%$ & & 123 & 19 & $2 \%$ & & 84 & 51 & $4 \%$ & 93 & 77 & $3 \%$ & \\
\hline 101 & Zander \& Kogut & $\mathrm{J}$ & OS & Man & & & & & 115 & 21 & $2 \%$ & & 82 & 53 & $4 \%$ & 96 & 74 & $3 \%$ & \\
\hline 102 & Amabile (1988) & $\mathrm{J}$ & ROB & Man & 96 & 6 & $2 \%$ & & 90 & 26 & $3 \%$ & & 140 & 30 & $2 \%$ & 97 & 71 & $3 \%$ & \\
\hline 103 & Christensen \& Bower (1996) & $\mathrm{J}$ & SMJ & Man & & & & & 131 & 18 & $2 \%$ & & 82 & 53 & $4 \%$ & 97 & 71 & $3 \%$ & \\
\hline 104 & Ahuja (2000) & $\mathrm{J}$ & ASQ & Man & & & & & 548 & 2 & $0 \%$ & & 55 & 66 & $5 \% \quad 56$ & 99 & 68 & $2 \%$ & \\
\hline 105 & Audretsch \& Feldman (1996) & $\mathrm{J}$ & AER & Eco & & & & & 230 & 10 & $1 \%$ & & 71 & 57 & \begin{tabular}{ll|}
$4 \%$ & 72 \\
\end{tabular} & 99 & 68 & $2 \%$ & \\
\hline 106 & Klepper (1996) & $\mathrm{J}$ & AER & Eco & & & & & 123 & 19 & $2 \%$ & & 89 & 49 & $3 \%$ & 99 & 68 & $2 \%$ & \\
\hline
\end{tabular}

${ }^{\mathrm{a}}$ First 83 publications represent the total set of 50 most influential studies in each period. The remaining $(84-106)$ publications are those which were not among top 50 in any period but are among the 100 most cited publications in the whole study period.

* Total number of citing publications in the respective matrix.

** The MDS point label of each publication for each period is unique and corresponds only to the MDS map of the respective period. 

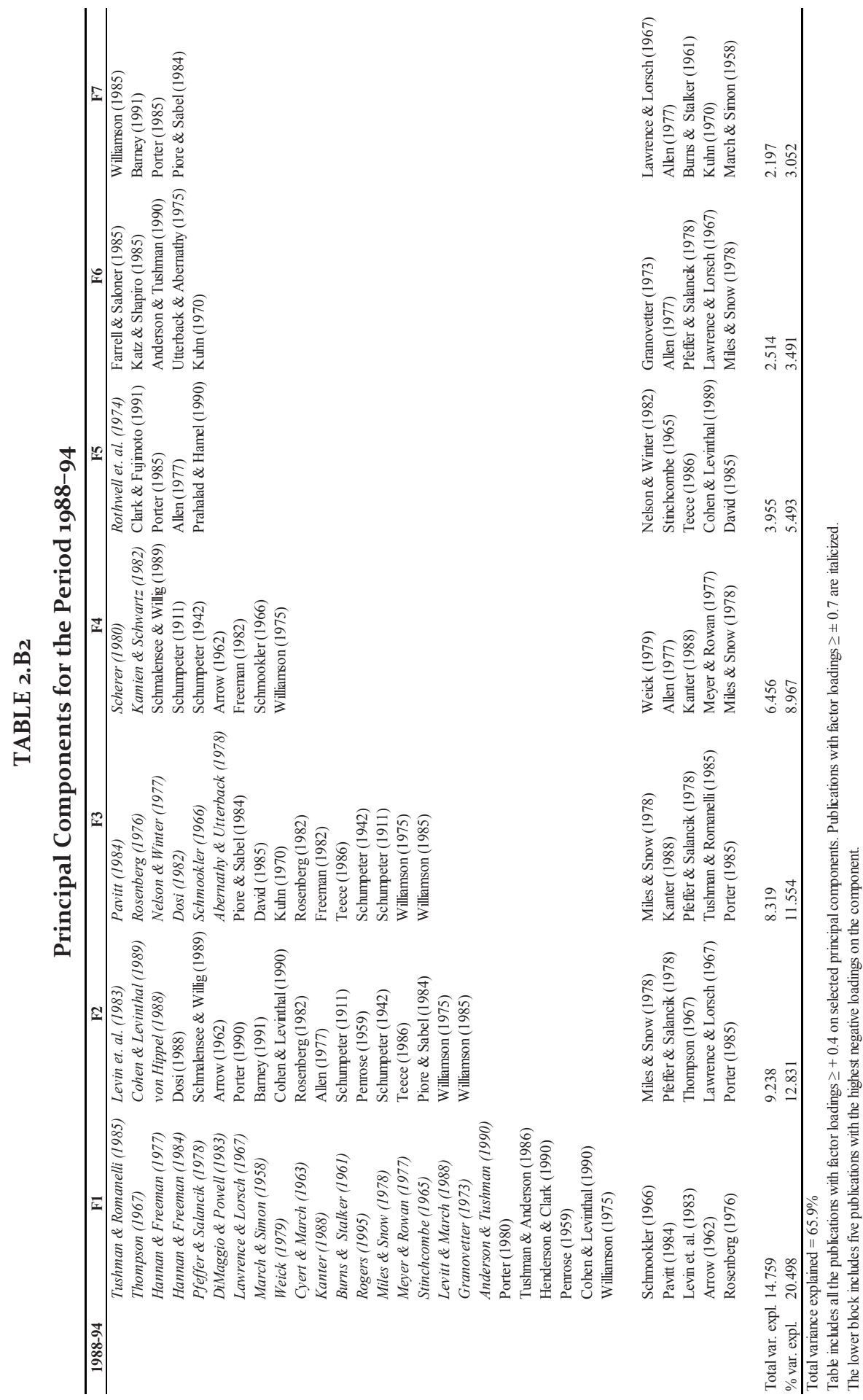


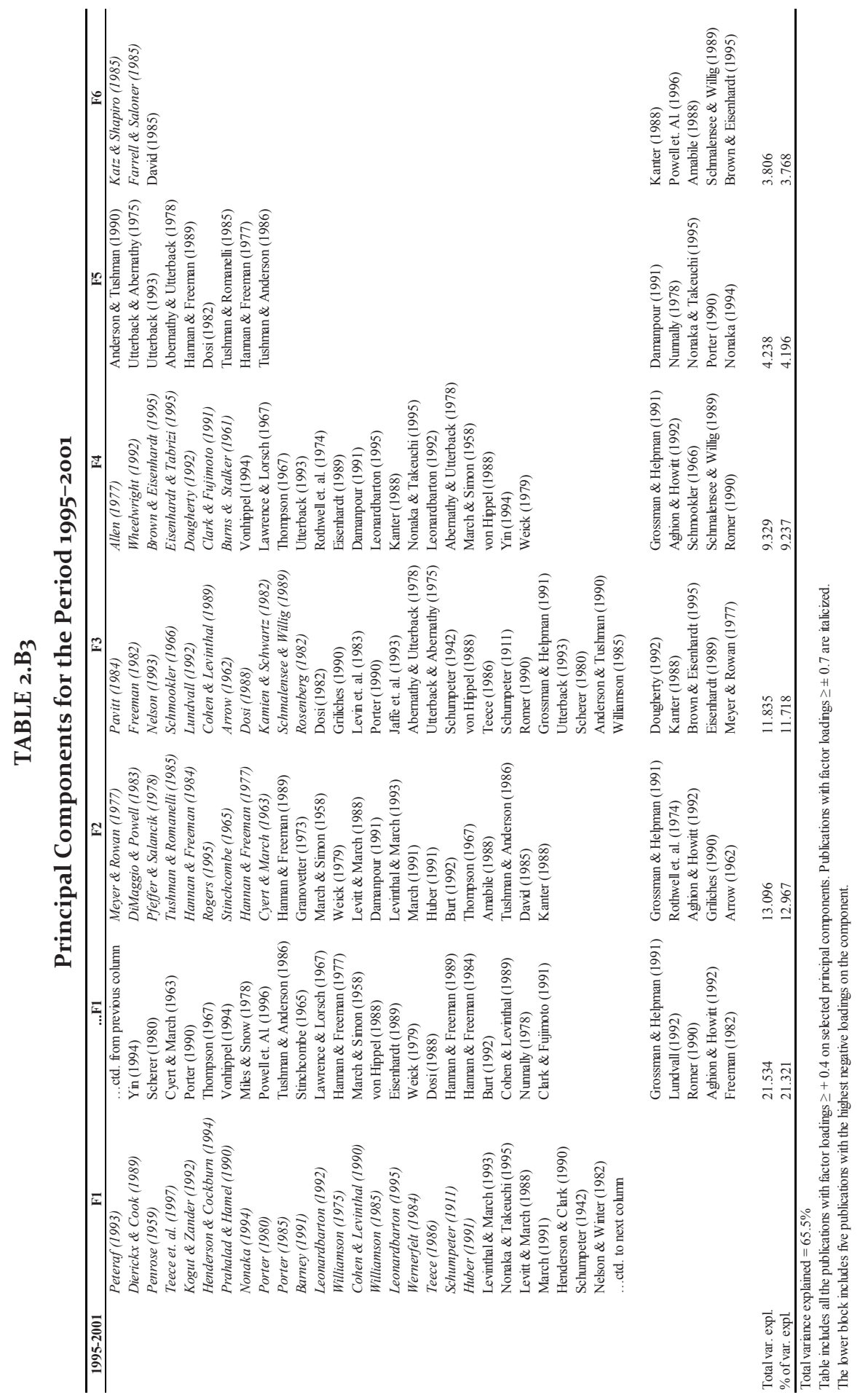




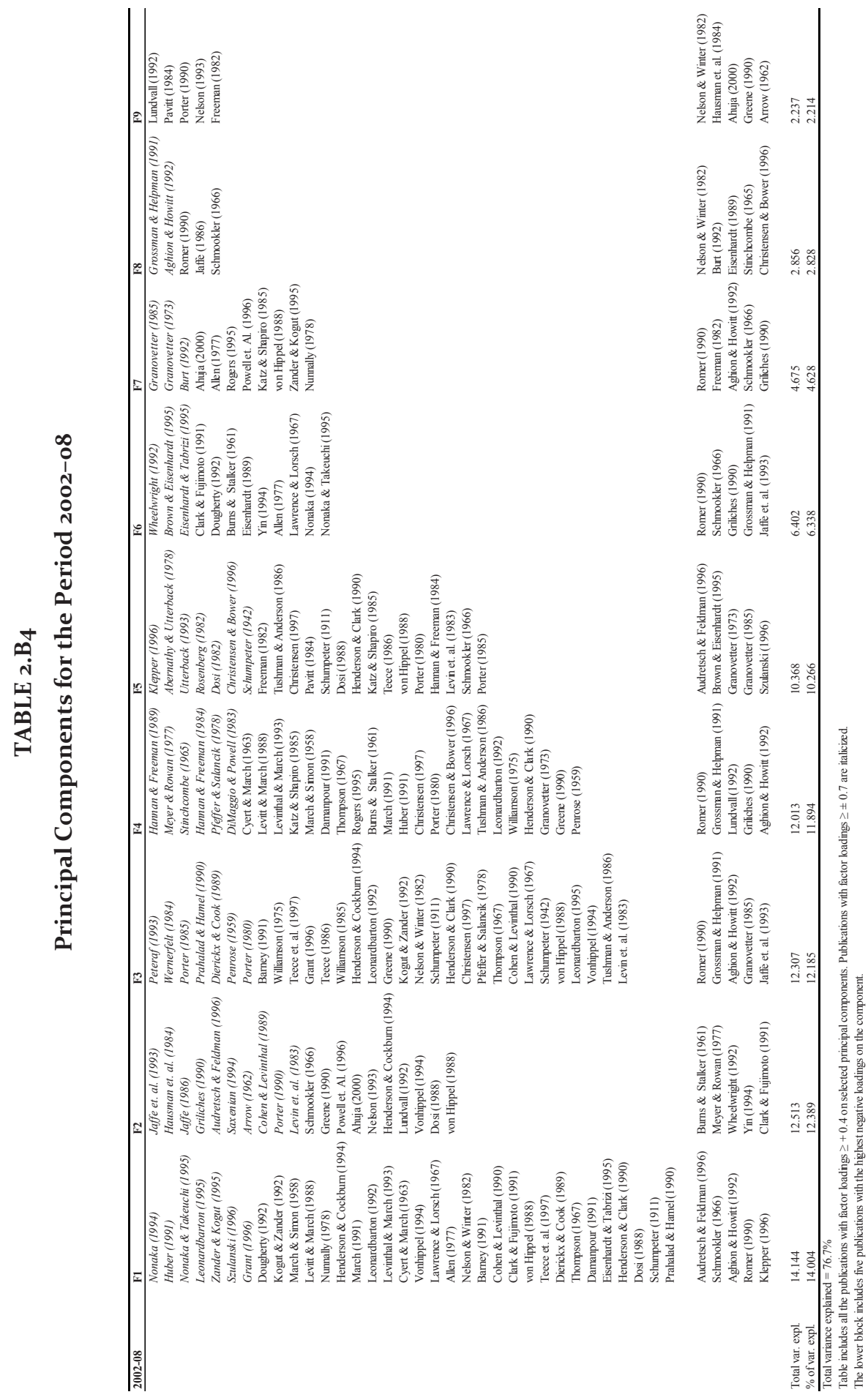




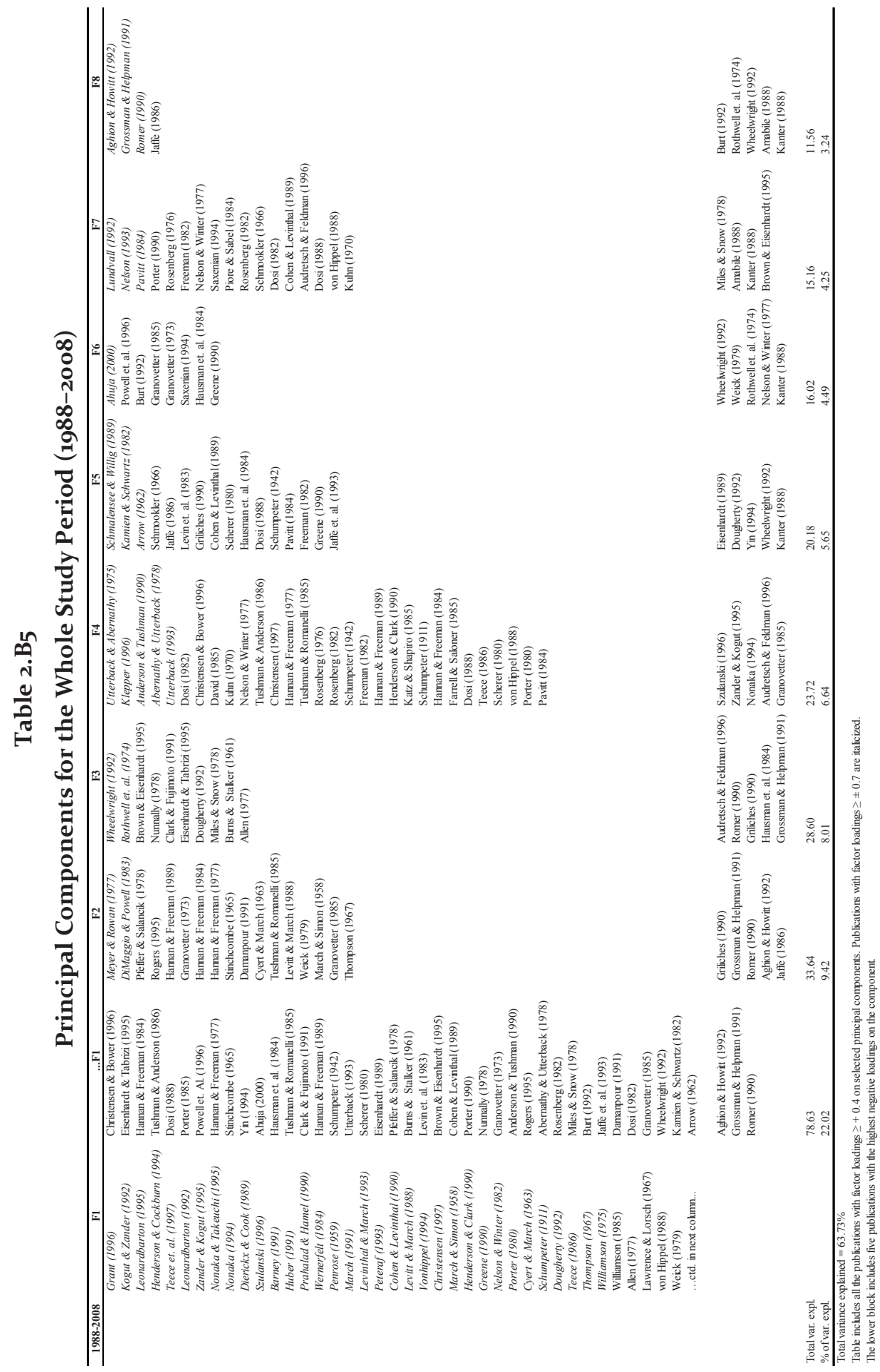




\title{
3 CO-EVOLUTION OF TECHNOLOGIES: A HISTORICAL PERSPECTIVE ON THE EMER- GENCE AND CONVERGENCE OF INFOR- MATION AND COMMUNICATION TECH- NOLOGIES
}

\begin{abstract}
To identify the locus and direction of technological change is one of the central problems in the scientific domain concerning economics and management of innovation and technological change. This problem arises due to the scatteredness of inventive activity in space and time as well as fusion and diffusion of technologies across multiple domains of science and technology. In order to understand the microdynamics of this phenomenon, we explore the origins and timing of discoveries and inventions related to information and communication technologies during the 18th and 19th centuries. The study suggests that inventive activity tends to be contextualized by the societal problems prevailing at a given time that are pursued in the domains of science and technology. The insights from the study are put in the context of Hebert Simon's idea of nearly decomposable hierarchical systems and Neo-Schumpeterian perspective of clusters of technologies. We find that the former is more practical from an artifact-based perspective of technology while the latter is more feasible from the knowledge-based perspective of technology. We conclude that the latter perspective can help solve the problem of measuring the rate and direction of technological change.
\end{abstract}




\subsection{INTRODUCTION}

One of the central aims of the scientific domain concerning economics and management of technological change is to measure the rate and direction of inventive activity and resulting technological change at the macro level (Nelson, 1962). This aim is important for at least two reasons. First, inventive activity involves creation as well as destruction (Schcumpeter, 1942, 1947) and brings about structural change in techno-economic system (Perez, 2010; Quatraro, 2012; Antonelli, 2014). Therefore, it is desirable for all stakeholders to be informed about such changes well in advance. Second, policymaking must be informed about the kind of societal needs and problems that must be addressed and the extent of contribution by science, technology, and industry in relation to these (Rosenberg, 1994).

Measuring the rate and direction of technological change, however, is a complicated task for at least two reasons: first, inventive activity and output tends to be scattered in space and time (e.g., Meyer, 1971), and second, technological developments in relation to one problem area may affect numerous other areas (Rosenberg, 1979). The latter tendency gives rise to a phenomenon termed as "technological convergence" (Rosenberg, 1963; Levinthal, 1998). It involves the emergence of new technologies due to the fusion of knowledge underlying different technologies (Levinthal, 1998) as well the diffusion of technical knowledge across different domains over time (Rosenberg, 1963). It seems that the solution to both problems resides in the neo-Schumpeterian conceptualization of technological change as the emergence, expansion, and contraction of clusters of technologies (Perez, 2010). In fact, it can reasonably be argued that the clusters of technologies emerge due to the dynamics of technological convergence. However, this requires theorizing based on microdynamics of technology creation and diffusion.

The purpose of this paper is twofold. First, to explicate the origination and co-evolution of technologies and technological convergence and emergence of the clusters of technologies in space and time. Second, to illuminate how the complexity arising out of these phenomena may actually be harnessed to measure the rate and direction of technological change at the macro level. In order to achieve both objectives we set the "context of discovery" (Swedberg, 2012) before theorizing about technological change and how it could be measured by taking stock of selected developments in key information and communication technologies during the $18^{\text {th }}$ and $19^{\text {th }}$ centuries. Therefore, we begin with a brief account of the developments in printing, photography, and mechanical telegraphy in order to contextualize more dynamic advancements related to information and communication technologies. Following that, electricity-related developments are presented in relation to communications and energy technologies. Then the technologies marking the beginning of electronic era are presented. Finally, based on the concurrent and consequent developments in these technologies we develop theoretical insights in the discussion section which is followed by the conclusion. 


\subsection{BEGINNING OF REVOLUTIONARY TECHNOLOGIES}

\subsubsection{Printing}

Perhaps the most important bridge between the stone age and the beginning of human civilization is the invention of the means to create, preserve, and transmit knowledge across the stretches of space and time. The construction of this bridge must have taken very time long time because it required the invention of language and the art and means of writing. The art of writing was developed as early as 3000 B.C. and various means were used as styluses (pens) and preservation materials (clay, stones, bronze, etc.) for the purpose of writing (Crompton, 2003). It is imaginable that clothing being the fundamental human need, the art of weaving fibres into textiles predates the art of writing. Historians have argued that cloth, particularly the one made of silk, was used as one of the preservation materials for permanent writing as early as 6th century B.C. in China (Tsuen-Hsuin, 1985). The sheets of textile fibers provided the base for the invention of paper which emerged as a "matted or felted sheet of fibres formed on a fine screen from a water suspension” (Tsuen-Hsuin, 1985, p. 35). However, after the invention of paper in China somewhere in the 1st century, it was initially used for non-literary purposes rather than writing. Eventually, paper became a popular medium for writing in China within a century because it was highly inexpensive compared to silk.

During the next few centuries, social and cultural needs for duplication and uniform distribution of writings and sketches prompted the need to mechanize the process of writing. This problem was solved by Chinese by combining the knowledge related to ancient engraving, inscription and stamping techniques with the paper and ink which manifested in the invention of wood-block printing technology somewhere in the 7 th century. The paper was introduced to Europe in the middle of 1oth century and the printing on paper started in Europe in the middle of the 15th century (Tsuen-Hsuin, 1985). The invention of printing press revolutionized almost all forms of learning in Europe and provided the fuel for many important revolutions on this continent (Eisenstein, 1980). Ever since, printing technology has been advancing due to the advancements and exchange of knowledge among several science and technology fields. Due to these advancements, printing is no longer confined to the creation of images on paper as the invention of three-dimensional printing technology has emerged with the aspiration to equate printing sketches and images with producing physical goods (Sachs, et al., 1993, 1994, 1998; Cima, et al., 1995; Bredt \& Anderson, 1999).

\subsubsection{Photography}

Besides the printing press, preservation of knowledge and its transfer in time and space was also facilitated by the invention of photography (Curley, 2010). The creative arts of sculpting, drawing, and sketching real or imaginary images via 
different means evolved in the ancient world to cater to the needs of illustration and decoration (van Dyke, 1894). However, the human desire to capture and store a real image was first materialized through the invention of ancient camera obscura or pinhole camera in which a dark room was used as 'camera' with a hole in one wall through which outside images were projected on the opposite wall. These principles were known to Chinese as well as Europeans. Aristotle is said to have known the principles of camera obscura (Curley, 2010). The camera obscura had to wait for several centuries for the invention of lens. The idea of using lens in camera obscura was put forth and elaborated by Italian scientist and writer Giambattista della Porta in 1533. It was followed by the principle of camera lucida, which means "light room", first described by William Hyde Wollaston in 1807. The camera lucida involved two types of devices, one type was based on reflective glass while the other was based on four-sided prism. In both types, the artist or draftsman would trace and copy the natural image on the paper (Okoroanyanwu, 2010, pp. 10-11). Thus, the invention of camera created a new area of application for glass and lens technologies and provided the necessary inducement for advancement in those technologies.

The art of glass-making had already been mastered in Venice in early $15^{\text {th }}$ century Europe (Frumkin, 1945; Berry, 1899). Spectacle-making and hence lensmaking was one of the various applications of glasses. One spectacle-maker of United Netherlands, Hans Lippershey, discovered in 1608 that the combination of lenses enabled distant objects to be seen as if they were near. Lippershey's lenses, used to be made of rock crystal rather than glass. He also applied for a patent for his instrument but the patent was not granted (Cajori, 1962). Nevertheless, the news of this invention reached the Italian mathematician and astronomer Galileo Galilei the following year who combined a convex lens with a concave lens in a tube and thus invented a telescope. The new instrument could obviously be used for viewing terrestrial as well as celestial objects. However, optical telescope attained a useful accuracy after John Dollond's achromatic object lens became available in 1757, one-and-a-half century after its invention (Beauchamp, 2001). The applications of telescope for military, entertainment, and scientific purposes are well known today but its contributions in astronomy--a well-developed science with its roots in earliest civilizations--are more important from the perspective of history of science and technology than economics of technological change (Berry, 1899). The invention of telescope gave impetus to scholarly interest in astronomy as well as the instruments used in astronomy, particularly telescope, and hence, optics (Dijksterhuis, 2004).

The two old arts, painting and printing, intermingled in late 18th century and gave birth to lithography that paved the way for the development of photographic technology. This mingling was necessitated by ever increasing demand for mechanical drawings of machines due to first industrial revolution, making the art of drawing a premium art of the time which offered artists and draftsmen lucrative 
economic rewards as well as upward social mobility (Okoroanyanwu, 2010). Lithography is a chemical process invented by German playwright Alois Senefelder in 1798 in which the artist draws a sketch on limestone which can be transferred on paper (Okoroanyanwu, 2010, pp. 12-13). It is worth remembering here that lithography is fundamental to modern integrated circuit technology. The invention of lithography allowed a common man not trained in the art of painting to draw the sketches of real images of nature on paper. Using the knowledge of lithography, a French, Nicéphore Niépce devised a method during 1822-26 by which oiled engravings could be copied on stone, glass, zinc, and pewter plates by exposing the setup to sunlight. He named this method "heliography" (meaning sun drawing). Later he used the pewter plate in camera obscura to be etched by means of heliography and used as printing plate. He succeeded to produce the first ever successful photograph from the nature in 1826-27 (Curley, 2010).

Another French, Louis-Jacques-Mandé Daguerre was a professional scene painter for the theatre who used to trace the sketches using camera obscura and camera lucida on translucent paper. In order to preserve the duplication of nature, Daguerre set up partnership with Nicéphore Niépce in 1829. After the death of Niépce, Daguerre succeeded in 1835 in forming latent image on a plate of iodized silver which could be "developed" later with the help of mercury vapour, and more importantly, with an exposure time reduced from eight hours to thirty minutes. However, the output from Daguerre's method would not last long. Daguerre solved the problem of temporariness of output in 1837 with the help of the solution of table salt! The invented process was called "the daguerreotype". In 1839, Niépce's son and Daguerre sold full rights of heliography and daguerreotype to the French government and full details of the processes were published (Curley, 2010, pp. 49-51). Thus the combination of selected knowledge from the fields of chemistry (painting and printing) and physics (light and optics) led to the invention of photography, a term which literally means "light drawing" (Osterman, 2007).

Photography had an inherent appeal and began to diffuse quickly in the industrializing world during 1840s. During 1850 os several photography journals, photographic societies, and photo-exchange clubs emerged which boosted the exchange of knowledge about the applied aspects of photography. Its increasing popularity and huge commercial potential led to numerous developments in the materials, processes, devices, and equipment used in professional and amateur photography. For instance, these developments were related to lenses, cameras, image storage, materials and methods for the development of negatives, specific paper to suit photographic needs, and commercial equipment for printing photographs etc. (Peres, 2007). In short, the invention of photography took place in relation to art and entertainment but it gave birth to numerous technologies and industries that catered to the numerous societal needs, particularly related to information, communication, and education such as publishing, theater, enter- 
tainment, and news, to mention a few. Accordingly, these technologies continuously interacted and co-evolved.

\subsubsection{Mechanical Telegraphy}

The advent of optical telescope also provided the key instrument for the first longdistance 'modern' communication technology, mechanical telegraphy. The mechanical telegraphy was essentially a signaling system connecting recognizable signaling structures that used to be built on tall hills known as "Telegraph Hills". The signals in the form of alphabets or ciphers used to be displayed by operating staff from the sending tower, viewed by optical telescope by the staff in the receiving tower, and then communicated to the next tower in the 'line of sight' in the same way. This system was initially built for military purposes but later it was also used to announce the arrival of ships on harbours. This technology diffused across Europe and Russia and it remained in use as late as 1856 (Beauchamp, 2001). Incidentally, this illustrates how one technology (e.g., optical telescope) may serve as the base for creating another entirely different and apparently unrelated technology (e.g., mechanical telegraph) not even imagined by the inventors of the base technology. However, mechanical telegraphy was costly, heavily dependent on weather, and mired by inaccuracies. Nevertheless, it demonstrated the need and potential applications, thus creating the incentive for a better substitute for longdistance communication.

\subsection{THE ELECTRIC REVOLUTION}

The magnetism and electricity gained the attention of scientists and became an important and active area of experimentation during the 16th century (Meyer, 1971). It emerged as a field of enquiry related to "sparks and shocks" (Hunt, 2010). This emerging field of experimentation was particularly stimulated by the publication of "De Magnete" written by British physician William Gilbert in 1600 who was the first to use the term "electricity". However, first machine for generating electricity was built in 1660 by Von Guericke who also demonstrated that electricity from his machine could be transmitted several feet over a piece of string (Meyer, 1971, p. 13). It was also discovered in late 1720 s by Stephen Gray that static electricity could also be transmitted (p. 15). In his successful experiments, he initially used a glass tube closed on both ends with corks. Later he used packthread to increase the distance of the transmission. He successfully transmitted the electrical charge upto 765 feet. Gray also discovered that some substances were conductors while others were not. Later, Charles Du Fay in Paris reported at the French Academy of Science in 1733-34 that a string was better conductor when it was wet and that he had successfully transmitted electric charge on such a line upto the distance of 1256 feet (p. 17). Subsequently, the invention of Leyden jar in 1745 provided impetus to the experiments in electricity transmission and the use of wires in these 
experiments became commonplace. The experiments regarding transmission of electricity using the Leyden jar and wires were taking place in France and England. In England, Sir William Watson and his team concluded in an experiment on August 5, 1748 on a 12276 feet long circuit that electricity is transmitted instantaneously. However, the electrical science so far had been concerned mostly with the electrical charges rather than electrical currents though it had accumulated significant amount of knowledge from the discoveries by numerous experimenters (Meyer, 1971; Hunt, 2010).

By the end of 18th century, the rediscovery of an important phenomena ignited a debate that led to a breakthrough invention. Luigi Galvani, a professor of anatomy who was also familiar with chemical and physical sciences, discovered during the dissection of a dead frog. When Galvani touched one of its exposed nerves with a scalpel, its legs contracted as if it kicked. Galvani published his observations in 1791 and concluded, based on the received wisdom, that it was the "animal electricity" that resided in nerves or muscles. Several scientists became interested in this phenomenon. However, Alessandro Volta, a physics professor, is the most notable among those who seriously explored this phenomenon. Volta theorized that the contraction had nothing to do with the "animal electricity", rather it arose from the fact that Galvani had used a combination of different metals. In order to test his theory, Volta carried out experiments which resulted in the revolutionary invention commonly known as "voltaic pile" or battery. He made his invention public in his letter to Royal Society of London in 180o. It was a stack of zinc and copper disks alternately arranged in a pile and separated by a nonconductor (such as felt, paper, or leather) soaked in a solution of salt or diluted acid. When the two ends of the pile were connected with a wire, it would produce spark. This invention not only proved Volta's theory but also provided the first means for producing steady current unlike the dissipating charge provided by Leyden jar or other electric machines that used to generate static electricity. It also provided the physicists essential means to measure quantitatively the conductivity of materials as well as the flow of current (Meyer, 1971; Hunt, 2010; Curley, 2010). This invention also led to the emergence of a new subfield, electrochemistry, which was founded on the theory that electric phenomenon of voltaic pile was due to the chemical processes intermediating the metals rather than mere combination of dissimilar metals themselves as Sir Humphry Davy proved within a year that electricity in voltaic pile was due to chemical action because the pile did not work with pure water.

Volta's invention not only complemented the ongoing experimentation related to electric signaling for long-distance communication but also provided the basis for thinking about electricity as a source of energy. For instance, it led to the construction of more powerful, and hence huge, batteries for producing electricity in the following decade which were used in fruitful experimentation. It also helped develop electromagnets which led many scientists to think that electricity 
could be generated through magnetism. Finally, Michael Faraday conclusively proved in 1831 that electricity could be generated from magnetism and that mechanical energy could be converted into electrical energy by means of electromagnetic induction. Faraday had already proven in 1821 that electrical energy could be converted into mechanical energy (Meyer, 1971; Hunt, 2010). In short, the knowledge accumulated in relation to electricity and magnetism not only helped in subsequent scientific and technological advancements related to charges, currents, circuits, and magnetic fields but also in several areas related to communication and energy (Meyer, 1971).

\subsubsection{Electricity and Communication}

\subsubsection{Electric telegraphy}

The idea of using electricity for telegraphy may have occurred to many at that time but probably the first attempt was made in 1746 by Johann Heinrich Winckler of the University of Leipzig (Meyer, 1971). This was the time when the 'line of sight' mechanical technology of telegraphy had taken hold and the governments of different countries in Europe were actively building the sights for telegraphic structures. However, the experiments to apply electrical means for solving long-distance communication problem continued (Beauchamp, 2001).

After the experiments of transmitting electric signals through electrostatic means, some experimenters turned to electrolytic approach. This approach had already led to the invention of electric battery by Volta in 1800 which became an important part of the experiments related to subsequent advancements in relation to electricity, such as electric telegraphy. One of the earliest electromechanical telegraphic devices built for military using electrolytic approach was a multi-wire electrolysis detector built by Samuel Thomas Sömmerring, a member of the Munich Academy of Sciences, in 1809. Similar experiments based on electrolysis were taking place in the USA at about the same time, which indicate the contemporaneous of ideas based on the accumulated knowledge at any given time. However, none of the electrostatic or electrolytic experiments could produce a workable electric telegraph device which could replace the mechanical semaphore which was the dominant telegraphic technology at the time. (Beauchamp, 2001)

In 1819, Hans Christian Oersted, professor of natural philosophy at the University of Copenhagen was demonstrating voltaic electricity in class when he discovered that the needle of a nearby compass oscillated with the opening and closing of the electrical circuit. Upon further experimentation, he found that electrically charged wire was deflected by magnet. He published this discovery in a Latin monograph in 1820 which led to the widespread replication of the experiment that brought many new insights regarding electromagnetism and the creation of magnets in 1820s (Meyer, 1971, p. 48). Particularly, these insights led to the 
invention of galvanometer by Schweigger in $1820 / 21$ as a device for measuring electric current. After the publication of Ampere's fundamental law governing the relationship between and electric circuit and a magnetic field in 1821, it became possible to construct an accurate galvanometer. It is worth noting that galvanometer was instrumental in Michael Faraday's discovery of electromagnetic induction during late 1820 s which was published in 1831. This discovery and the accompanying processes invented by Faraday induced a tremendous productive current among the scientific community active in the field worldwide as it conclusively proved that mechanical energy could be converted into electrical energy, and vice versa, and that practical machines could be built to do so (Meyer, 1971, p. 59).

At about the same time across the Atlantic Ocean, Joseph Henry was trying in the USA to construct electromagnet by following the ideas of his European contemporaries in the field. He demonstrated an electromagnet in 1829 that had a lifting power of many pounds. Further, he demonstrated in 1830 that magnets could be operated from a distance and suggested that a telegraph could be built and operated in the same way (Meyer, 1971, p. 64). He also discovered selfinduction; a property of an electric circuit that causes a counter electromotive force when the circuit is made or broken (Meyer, 1971, p. 65). In Europe, experiments regarding the transmission of electricity were also taking place alongside. For instance, two German scientists, Carl Gauss and Wilhelm Weber, used electromagnetic telegraph in 1833 in their experiments regarding transmission of electricity using double line of wires (Beauchamp, 2001, p. 25).

The experiments related to electric telegraphy continued for about a century starting from 1753 and took various forms such as electrostatic, electromechanical, magnetized needle, electromagnetic, electrochemical, and electrovoltaic type devices (Beauchamp, 2001, p. 26). However, the first completely developed telegraph system used for commercial purposes, was installed for the Great Western Railway in 1838 by Mr. Cooke and Professor Wheatstone who had secured a patent in 1837 (Beauchamp, 2001, p. 32). Later on, Cooke's company, the Electric Telegraph Company, also bought another patent of Edward Davy pertaining to telegraph relay, or 'electrical renewer' as it was called, which helped transmit the signals over long distances without leakage/weakening of the current. Electric telegraph network grew widely in Europe during 1840s owing to the growth of railway network because it provided valuable signaling system for railways, though a variety of telegraphic devices had been developed over time to solve the communication problems faced by railways. However, commercial telegraphy for public use could not gain ground in Europe during this period.

Across the Atlantic Ocean, Professor Morse, a well-known painter in the USA invented a 'recording electric telegraph' with a 'system of signs' (known as Morse code) and 'transmitting relay' in 1837 (Beauchamp, 2001, p.55). However, US 
Congress awarded a grant as late as 1842 to establish the first experimental line in America, between Washington and Baltimore, a distance of $64 \mathrm{~km}$ (Beauchamp, 2001, p.57). During the next few years, several companies were established to set up Morse's now well-established telegraph system, hence the birth of the telecommunication industry in the USA which prospered well but remained embattled in an unprecedented 'era of litigation' over patents related to telegraphy (Beauchamp, 2001, p.59). Due to the expanding commercial network of telegraphy, the US railroads began to use telegraphy in 1852 . It proved to be a symbiotic relationship between telegraphy industry and railroads because the former provided better traffic control while the latter provided protected route for communication wires.

In the USA, two further inventions were important in the development of the telegraphy. The House's printing telegraph was patented in 1846. It was comprised of three major components; print-wheel working in ratchet action, electromagnetic relay prompting hammer action, and piano-style keyboard for impulse selection. It would print the message on a strip of paper. The Bain's electrochemical printing telegraph was patented by a Scotsman, Alexander Bain, in 1846 and he brought it to the USA in 1848. It was comprised of a pre-prepared and perforated paper ribbon, conducting cylinder, electromagnet, and metal stylus. It was reputed to be faster than Morse's and House's printers (Beauchamp, 2001; Burns, 1993). A large number of telegraph companies adopted either House's or Bain's systems to secure freedom from Morse's patents (Beauchamp, 2001). However, Bain's system lost the commercial battle due to patent litigation in the USA and succumbed to Morse's system by early 1950s (Burns, 1993). Later the Huge's printing machine, invented in 1855 , became more popular alternative among the American telegraph companies (Beauchamp, 2001).

It is worth remembering here that electric telegraphy was used to transmit letters and symbols. However, Alexander Bain proposed in 1843 a way in which an identical image of a document could be transmitted via printing telegraph, though he did not build a working prototype (Burns, 1993). This idea was materialized by an Italian, Giovanni Caselli, who invented "pantelegraph" in mid 1850 using the knowledge related to printing and electric telegraphy. Pantelegraph was the forerunner of commercial facscimile/fax system, first introduced by Caselli in 1865 between Paris and Lion (Pelosi, 2010). The greatest advantage of facscimile/fax/photo-telegraphy technology was that it was independent of language symbols as it would transmit the identical copy of the image. This attribute made it much more attractive for non-English nations. The advancement related to photoelectric cell and hence photoelectric technology in the last quarter of the $19^{\text {th }}$ century paved the way for better scanning technology which was fundamental to facsimile. Eventually, photoelectric technology provided the base for invention of the apparatus for transmission of photograph via facsimile by a German, Dr. Arthur Korn, in 1902 (Coopersmith, 1993). It should also be noted here 
that the principles of transferring image as sequentially scanned lines as demonstrated by Korn in the facsimile were also used in the development of the cathode ray tube television that will be discussed later. Moreover, photoelectric technology served as a key ingredient in several other technologies such as camera, film projector, detectors and sensors, and optical storage media. Photoelectric science and technology also served as the base for the invention of solar cells in 1870 s which have a wide range of applications from pocket calculators and medical imaging to satellites (Hempstead, 2005; Fraas \& Partain, 2010).

In parallel to these developments in electric telegraphy, teletype technology also emerged by combining the knowledge from typewriting technology with that of electric telegraphy. This system, which was first introduced in 1910 between New York and Boston, involved a typewriter and a teleprinter which were separate technologies in their own right (Goodfox, 2005). However, the evolution and composition of these technologies are not discussed here in the interest of space.

In short, electric telegraphy gradually replaced mechanical telegraphy and became the dominant long-distance communication technology in 1840s. So much so, the growth of railways prompted the need for having 'standard time' instead of 'railway times', and here again it was electric telegraphy that provided the means to send time signals from observatories to synchronise the public clocks in the UK (Burns, 2004). The electromagnetic clock used for this purpose was invented by Alexander Bain, the inventor of printing telegraph noted earlier (Burns, 1993). Moreover, the idea of using submarine cable in telegraphy had been applied by Morse in the USA as early as 1842 . Submarine cable is yet another technology which was prompted by electric telegraphy and perfected for durable operation after several costly experiments. By 1900, the telegraph network had already spread most parts of the world via transoceanic submarine cables, making telegraphy the first global telecommunication technology (Meyer, 1971; Beauchamp, 2001). It is worth remembering here that due to the accumulation and fusion of knowledge across several science and technology fields, cable technology has advanced from originally copper-based technology to fiber optics technology during the $20^{\text {th }}$ century (Gambling, 2000; Solymar, 1999).

This discussion should not mislead the reader into thinking that electric telegraphy as a technology was merely about the apparatus for sending/receiving and interpreting signals via electric current or discoveries and inventions thereof. It prompted and absorbed technological developments in numerous other areas. Nor all the relevant developments took place only in relation to telegraphy. For instance, the material used as conductors and insulators, capacitance and resistance of wires, insulation and durability of cables, providing energy for the operation of the telegraphic equipment and so forth, are but a few major problems in the development and worldwide diffusion of electric telegraphy. It would be stating the obvious that the scientific and technical knowledge being developed 
and accumulated relevant to these problems was not used merely in telegraphy but in numerous other technologies developing alongside and subsequently. Telephone is one such example.

\subsubsection{Telephone}

The idea of transmitting live sound via pipe and the theory of sound had been touched upon by Aristotle (Cajori, 1962). However, the idea of transmitting sound over wire corresponded with the experiments related to magnetism, electricity, and electromagnetism during the 19th century (Meyer, 1971). While scientists at that time were mainly focused on experimenting about the possibility of electric telegraphy, some scientists also reflected on transmitting sound and speech over wire. In this regard, Professor Wheatstone suggested in a paper published in 1831 that it was possible to transmit musical sounds through solid linear conductors (Burns, 2004, p. 168). Similar work of American physicist William Charles Page in 1930 is notable. His experiments suggested that magnetization and demagnetization of metal rods corresponded with the generation of sound which he called 'galvanic music' (Burns, 2004; Mercer, 2006). This insight about the relationship between electromagnetism and sound later proved to be the key in the invention of telephone. Moreover, the realization of the idea that meaningful signals could be transmitted over wire and the success of electric telegraphy provided the "existential knowledge" which is not necessary in inventing but provides significant advantage for faithful and focused experimentation aimed at inventing the means to realize an idea or solve a given problem.

In 1854, publication of an article of Charles Bourseul of Paris envisioned a device for transmission of speech along telegraphic lines. It consisted of a transmitter, battery, and a receiver. The transmitter would be consisted of a stretched membrane which would vibrate with sound and thus open and close a circuit with the receiver which would be comprised of an electromagnet. Similar idea was pursued by Johann Philipp Reis, professor of physics in Germany in 1861. He developed a simple apparatus, that he called "telephone", in the shape of human ear. However, while it confirmed the effects produced by Philipp Reis, it did not reproduce human speech which was more a problem of frequency modulation than circuit making and breaking (Meyer, 1971).

It is worth remembering here that electric telegraphy was a booming industry at that time and one of its major technological problems that needed an urgent solution was the ability to transmit multiple messages (multiplexing) along a single telegraph line. This need of telegraph companies offered huge economic incentive for the invention of the solution. Therefore, inventive efforts were mostly aimed at creating a solution for multiplex telegraphy. The solution was considered to be a "harmonic-telegraph" which should replace Morse code signals with tones. Among those working on this problem, the efforts of two technologists are 
more illuminating. One of them, Elisha Gray, was a well-known inventor of electrical devices who had already secured several patents related to telegraphy. The other, Alexander Graham Bell, was knowledgeable about sound and speech and a teacher of the deaf and dumb who used the methods of 'visible speech' invented by his father. However, unlike Gray, Bell had no formal training or experience in the science of electricity except for his domestic experiments with electromagnets, tuning forks, electric telegraphy, and related devices and subjects which he carried out with the objective of generating vowel sounds artificially (Mercer, 2006; Meyer, 1971; Burns, 2004).

Gray invented the method for transmitting upto four telegraphs on a single transmission line and his method was successfully tried by Western Union Telegraph Company from Boston to New York, though it did not gain commercial success. Gray also invented in 1876 a telephone system by combining the principles of membrane vibration with the principles of conduction (metal rod and a poorly conducting fluid), resistance, electromagnet, and electric battery which reproduced the speech. He submitted his 'notice of invention' at the Patent Office the same day as Graham Bell submitted the complete and notarized specification of his invention of telephone (Burns, 2004).

Bell became professor of vocal physiology and elocution at Boston University in 1873 while he was conducting experiments in an attempt to build a harmonic telegraph. Due to his lack of technical knowledge needed to build a proper device embodying his findings, he hired Thomas A. Watson, in 1874, as his assistant who also became his lifetime friend. In 1874, he saw the demonstration of phonoautograph, a recent development at MIT. This apparatus was based on membrane diaphragms. Since this device was related to his field of teaching and also to his ongoing experiments related to harmonic telegraph, he tried to build a phonoautograph modeled on human ear. Probably, the combination of his experiments related to harmonic telegraph, phonoautograph, and knowledge of human ear led him to the idea that speech could be transmitted electrically (Meyer, 1971). Consequently, he submitted his caveats to the patent office regarding sound-based telegraphy in 1875 as noted in his famous US patent no. 174,465 granted for his application dated February 14, 1876. Later, Bell secured another key patent in 1877 (no. 186,787) regarding his method and apparatus pertaining to telephonic communication (Burns, 2004). Perhaps, it was Bell's intimacy with sound and speech and his hobby of experimenting with electric telegraphy provided just the right combination of knowledge needed to invent something like telephone which had more to do with sound than to electricity.

As regards commercial implementation of telephone, it is worth remembering that electric telegraphy had long provided the formal and informal knowledge as well as the infrastructure that helped implementation of telephonic communication. This also included the technologies related to wire as well as the 
knowledge of laying more efficient network of wires. Interestingly, by that time the insights from telegraphic network had also led to another industry which involved the burglar alarm and fire alarm networks that operated via telegraph lines (Mercer, 2006). After Western Union Telegraph-which had attained a monopoly in electric telegraphy-refused to buy Bell's patents dubbing telephone as an "electric toy", Bell started commercializing telephone through Bell Telephone Association which was later incorporated in Massachusetts as Bell Telephone Company (BTL) in 1878 and eventually became American Telephone and Telegraph Company (AT\&T) in 1885. Nevertheless, starting as a nascent technology in the face of established electric telegraphy, telephone quickly began to gain ground and rapidly grew alongside electric telegraphy. These two technologies, in combination with concurrent developments in science and other technologies, particularly photography, provided the needed knowledge base for teleprinting, facsimile and television technologies.

It is worth noting here that Bell System or AT\&T progressed in telecommunications technologies to such as extent that it established a separate research and development arm, Bell Telephone Laboratories Incorporated (Bell Labs) which started its operations on January 1 , 1925. On the date of its inception, it had a technical staff of 2,00o members which included physicists, chemists, metallurgists, mathematicians, and engineers (Burns, 2004). Since then, Bell Labs has made several revolutionary contributions (as evidenced by Nobel Prizes) in basic and applied sciences owing to its efficient and open system of pooling and fusing diverse knowledge. Perhaps, the most important of these contributions is transistor, which would bring about electronic revolution in the later half of $20^{\text {th }}$ century.

\subsubsection{Electricity, Light and Power}

As noted earlier, Michael Faraday proved in 1821 that mechanical energy could be converted into electrical energy. He also proved in 1831 that electrical energy could be converted into mechanical energy (Curley, 2010; Meyer, 1971). By then, electrical science had accumulated significant amount of knowledge related to electromagnetism, electromagnetic induction and self-induction which was necessary for producing electricity by mechanical means (Meyer, 1971). Consequently, the interdependent but clearly distinct development efforts in electrical science followed two tracks running in parallel, one aiming at converting electrical energy into mechanical energy while the other aiming at generating greater electric power. The former led to the development of electric motor while the latter led to the development of magnetos and dynamos. Although Faraday had discovered the principle of electric motor in 1821, the first electric motor was developed by Sturgeon in 1832. A more practical electrical motor was developed by Thomas Davenport in 1834 which he used to operate a printing press through electricity (Meyer, 
1971). However, commercially significant production of electric motors had to wait until the electric power was available.

On the other hand, after the Faraday's discovery of electromagnetic induction in 1831, the first machine was built by Hypolite Pixii of Paris in 1832 to produce electricity using coils and permanent magnet, thus known as magnetoelectric generator which did not need a battery. It produced alternating current which was converted into direct current using commutator. Using the same principles, several other experimenters built magneto-electric generators in the following years. An improved version of Pixii's machine was built with 32 permanent magnets by M. Nollet, a professor of physics in Brussels. A company known as Alliance Company was established in Paris to produce magneto-electric machines according to Nollet's design and of different sizes using upto 40 magnets. It was probably the first electrical manufacturing concern in the world (Hunt, 2010).

Alliance's machine was adapted in England for the purpose of arc lighting whereby steam engine was used for the motive power. Arc lighting had been invented as early as 1808 in which the electric spark between two carbon electrodes emitted a brilliant light (Curley, 2010). At that time, arc lights powered by huge batteries were already used in theaters in England and France (Hunt, 2010). Moreover, due to their enormous brightness and heavy use of electric power, carbonarc lighting was used only in lighthouses, train stations, and large buildings (Curley, 2010). Hence, Alliance's adapted machine was first used in British lighthouses (Meyer, 1971).

However, voltaic and magneto-electric currents were too expensive for most ordinary uses such as domestic lighting compared to the prevailing alternatives of gas and oil lamps (Hunt, 2010). In 1845, Professor Wheatstone, one of the inventors of electric telegraphy as noted earlier, suggested that electromagnets could be used in magnetos in place of permanent magnets. Following this suggestion, $\mathrm{H}$. Wilde of Manchester built the first machine in which a magneto was used as the exciter (Meyer, 1971). It involved a simple principle: starting with a magneto, the current was supplied to the field magnet which would become an electromagnet producing the alternating current, some of which would be fed back to the field magnet for continuing operation (Hunt, 2010). The success of Wilde's machine was followed shortly by self-exciting machines, hence called dynamoelectric machines, or dynamos, in contrast to the magneto-electric machines, or magnetos (Meyer, 1971). Thus dynamo was the first ever machine that could possibly convert mechanical energy into electrical energy at a very large scale (Hunt, 2010).

Although a wide variety of dynamos had been developed during 1860 s but they lacked steady current. This problem was solved by the dynamo design invented by a Belgian, Zenobe-Theophile Gramme, in 1870. Gramme’s design provided a steady alternating current which was suited to produce electrical energy and convert it into mechanical energy which could be converted back into electri- 
cal energy. Gramme's dynamo provided practical means for electrical arc lighting replacing the gas or oil lamps. Therefore, by the end of 1870s, arc lights were used to light streets and large buildings in many cities of the world. However, arc lights were too bright for lighting a room. Thomas Edison, a famous inventor of the USA who was known as "the Wizard of Menlo Park" at that time, was one of many who undertook to solve this problem by providing a domestic substitute for arc lights. An apparent solution was an incandescent lamp like the one invented by Frederick de Moleyns of England in 1841 based upon the idea of incandescence of platinum strips as demonstrated by English chemist Sir Humphry Davy in 1801. It essentially required solving two problems; creation of a vacuum tube and finding an appropriate filament (Hunt, 2010). Before turning to these issues, it is apposite to fill the notion of vacuum here.

The Latin word 'vacuum' means empty space or emptiness. Aristotle had argued in Physica around 330 B.C. that there could be no vacuum. The Italian, Galileo Galilei came to know from his experiments on air that water could be lift up in a vertical pipe with the help of suction pump upto the maximum height of 34 feet. Another Italian, Professor Evangelista Torricelli, conducted an experiment in 1644 with a glass tube filled with mercury and succeeded in creating a vacuum. This tube was used by Pascal and Descartes in France to measure air-pressure in 1648. Using this knowledge, Otto von Guericke in Germany built an air pump a few years later. In 1673, Huygens in the Netherlands, conceived the idea of using vacuum and atmospheric pressure to lift heavy weights. This vacuum technology was used and improved by scientist of Europe during the next two centuries. Thomas Newcomen carried this idea and knowledge further to build steam engine in early $18^{\text {th }}$ century which was widely used in England for pumping water (Jousten, 2008).

In 1855, Geissler in Germany designed a significantly better air pump which was further improved by Sprengel in 1873 using Torricelli's principles (Jousten, 2008). This mercury pump provided adequate vacuum needed for an incandescent lamp so the problem that remained was that of discovering or devising an appropriate filamentary material. Sir Humphry Davy had demonstrated arc lighting in 1801 using carbon rods, therefore carbon was a known element in relation to lighting and hence one of the earliest candidates as filamentary material for the lamp (Meyer, 1971; Brittanica; Hunt, 2010).

Edison succeeded in gathering inventors to establish Edison Electric Light Company in 1878 to develop an electric lighting system which would replace the prevalent gas lighting. Finally, carbon-filament bulb was developed independently by the English physicist Sir Joseph Wilson Swan in 1878 and Thomas Edison in the following year (Meyer, 1971; Brittanica). Since then, electric bulb has undergone many improvements in the filament as well as the vacuum tube used to seal this filament (Curley, 2010). Nevertheless, after the invention of incandescent 
lamp, Edison turned to establish an electricity supplying system for catering to both the potential uses of electricity, light and power, whereby the major electric source of power at that time was the electric motor which converted electrical energy into mechanical energy (Hunt, 2010; Curley, 2010; Meyer, 1971).

Edison modeled his centralized electricity generation and supply system on prevalent gas system which had centralized supply but user had control over the nature and timing of the use. He aimed to build a unified electromechanical system combining steam engines, dynamos, motors and transmission wires. Secondly, his system was based on a novel principle of parallel circuits in contrast to the series of circuits as prevalent in arc lighting at that time. Finally, he always preferred and used direct current (DC) as opposed to the alternating current (AC). Edison's first power plant comprised of jumbo dynamos driven by big steam engines was installed in Manhattan near well-known Wall Street which started supplying electricity in September 1882. While Edison's system demonstrated the practicality of electricity generation and supply at a large scale, his DC system eventually became a victim of the limitations inherent to the DC and lost to the $\mathrm{AC}$ system in what is known as the "War of the Currents" or "Battle of the Systems". Perhaps one of the most important events in this battle was the promulgation of Electric Lighting Act of $\mathbf{1 8 8 2}$ in Britain which was aimed at protecting the choice of customers regarding electric bulbs. This illustrates how institutions also co-evolve with technologies and industries.

The problem of adjusting various voltages of AC current offered by different companies was solved by Lucien Gaulard and John D. Gibbs who invented an adapter for varying AC voltage by the end users of light bulbs. Using the same principles, Gaulard and Gibbs also invented a transformer in 1883 which allowed the transmission of high-voltage alternating electric current at long distances that could be adapted near the point of use (Hunt, 2010). In the USA, the battle of currents was fought between Edison Electric Light Company and Westinghouse Electric Company in which the former contended for DC while the latter promoted AC. The transformer provided a decisive advantage to AC over DC because the latter could hardly be transmitted over a distance of a few miles due to the leakages of the current, a phenomenon experienced in electric-telegraphy as well. When the AC system clearly began to get ahead in the race, the American inventor Nikola Tesla invented the AC motor in 1888 that was taken by Westinghouse Electric Company for commercial production (Curley, 2010). During the last two decades of the 19th century, electricity diffused widely in the developed world spurring the growth of existing technologies as well as the development of new ones.

Apart from these technological developments, it is also worth mentioning here how academic disciplines of electrical engineering and physics co-evolved due to historical necessities of the $19^{\text {th }}$ century. Physics, popularly known as "natu- 
ral philosophy" at that time, was not an attractive discipline at all compared to chemistry and biology simply because of the virtual absence of professional career opportunities related to physics. Perhaps the only significant profession for physics graduates was teaching. Moreover, engineering was limited to civil and mechanical fields and engineers were trained, after initial schooling, through apprenticeship with a master engineer rather than formal education which was nonexistent. It was only due to the rise of submarine cable industry that physics laboratories in colleges and universities of Britain began to establish in 1850 os. Since the telegraph engineers were neither suitable enough for the needs of emerging electricity industry during 1880 nor were they in sufficient supply to meet the demand. The industry tried to meet its demand for electrical engineers through short-term in-house training. It was only then colleges and universities began to offer electrical engineering education. These courses were offered by physics departments where physicists would teach. Eventually, as the demand for enrollment in electrical engineering rose, the field of electrical engineering began to establish with separate departments at educational institutions. It was probably this coincidence of physics and electrical engineering that served both fields well and led to remarkable technological advancement at the intersection of both. At least, the field of electronics owes its development to this fortuitous historical necessity (Hunt, 2010).

In short, the discoveries and inventions related to electricity, electric telegraph, and telephone were going on in parallel and the new insights and techniques were applied across these technologies. The electricity-related efforts were aimed at generating and transmitting energy while the telegraphy- and telephone-related attempts were focused on solving the problem of long-distance communication. Therefore, these distinct technologies were co-evolving by drawing upon the accumulating technological knowledge base of each other as well as several other contemporary technologies (Burns, 2004). It is no surprise that the scientists and inventors working at the frontiers of these distinct technology fields carried some useful assortment of knowledge related to chemistry, physics, electricity, and engineering.

\subsection{THE ELECTRONIC REVOLUTION}

\subsubsection{Wireless Telegraphy}

The invention of voltaic electricity in 1800 had sparked and energized research in many areas of physics and chemistry, particularly in relation to electrical science. The discovery of electromagnetism by Oersted in 1820 and consequently the stipulation of elementary laws of electrodynamics by professor Andre Marie Ampere in 1821 led to the emergence of a new branch of physics. While repeating Oersted's 
and Ampere's experiments, Micheal Farady discovered the principle of electromagnetic rotation in 1821 which was practically the first electric motor converting electrical energy into mechanical energy. Due to his experiments related to electromagnetism, Faraday also discovered electromagnetic induction in 1831 and stipulated the fundamental laws of this phenomenon. Faraday also discovered in 1832 that electromagnetic force was circular in nature, forms an electromagnetic field in the space around the magnet and comprised of "lines of force", and propagates progressively in the form of waves comparable to "the vibrations upon the surface of disturbed water, or those of air in the phenomenon of sound,...and most probably to light" (Garratt, 1994).

Unfortunately, despite being a brilliant theorist that he was, Faraday was not academically trained scientist and could not formulate his theory in mathematical form which was considered as the only appropriate language for theorizing. Consequently, his ideas rarely got serious attention by the prestigious club of 'serious scientists' until James Clerk Maxwell-who was interested in the phenomena of electromagnetism and light-translated Faraday's theories into conventional mathematical form in 1855 . It is worth mentioning here that the physicists of that time believed that the forces between charges of electricity or between magnetic poles were the result of "action at a distance" like gravity, and hence considered distance as the only relevant factor. Later, Maxwell published a paper titled "A dynamical theory of the electro-magnetic field" in 1864 which made ample theoretical contribution to electrical science and electrical communications. Maxwell theorized that the electromagnetic waves were propagated through space with the same velocity as waves of light and that light itself consisted of electromagnetic waves. However, for about two decades Maxwell's theory remained a 'theory' lacking a demonstrable proof that could decisively refute the theory of action at a distance (Garratt, 1994).

Maxwell's formal theory of electromagnetism needed empirical proof which was independently supplied by two physical scientists-Heinrich Rudolf Hertz in Germany and Oliver Lodge in Britain-who were contemporaneously working on electrodynamics. Hertz was conversant with Maxwell's theory ever since he was a doctoral student. He had been urged by his professor, Helmholtz, to pursue the prize offered by Prussian Academy of Sciences (Berlin) in 1879 for a demonstrable proof or otherwise of Maxwell's theory (Burns, 2004). However, at that time Hertz believed that it was not possible to pursue the proof because neither electromagnetic waves of an appropriate frequency could be generated with available means, nor were there any means to detect such waves (Garratt, 1994; Burns, 2004). It is worth noting here that Henry had demonstrated as early as 1842 that the discharge of Leyden jar was oscillatory and FitzGerald had suggested in 1883, on mathematical grounds, that these oscillations emitted electromagnetic waves of radiation (Garratt, 1994). It was only when Hertz became a professor in 1885 and started experiments in the well-equipped laboratory of the university 
that he fortuitously found the means for overcoming these problems and studying electromagnetic waves. While examining an old piece of apparatus comprised of spiral coils in 1886, Hertz noticed short sparks. He quickly figured out that these sparks were due to oscillatory currents in the coils which generated electromagnetic waves of very high frequency. As a result of progression in his experiments, he replaced spiral coils with a rectilinear open wire to detect the electromagnetic waves (Garratt, 1994; Burns, 2004). This breakthrough invention is now known as half-wave antenna or aerial which is fundamental to all modern devices used in wireless communication. Consequently, in the course of experiments sparked by this invention, Hertz confirmed Maxwell's theory by demonstrating the dynamics of the reflection, refraction and polarisation of electromagnetic waves. These experiments of Hertz also bred a new branch of science, photo-electricity. Tragically, he died on $1^{\text {st }}$ January 1894 at an early age of 36 due to an infection in his jaw (Burns, 2004).

On the other hand, Oliver Lodge, who was professor of experimental physics, was working on lightning conductors. The practice of installing lightning conductors on high buildings had been established after the experiments by Benjamin Franklin in 1751. However, these conductors did not prove to be reliable (Garratt, 1994). The recommendations originating from a "lightning rod conference" resulted in the nomination of Lodge to examine the situation in late 188 os. Lodge demonstrated that lightning flash was oscillatory like the discharge of Leyden jar and that self-inductance of the conductor was far more important than its resistance whereas electricians of the time were focused on the latter. Lodge's paper on the subject of lightning conductors and dealing with oscillatory nature of current was published in 1888, only a few months after the publication of Hertz's first paper on the subject of electromagnetic waves. The main difference was that Hertz' experiments were related to unguided electromagnetic waves while those of Lodge pertained to guided electromagnetic waves (Burns, 2004). Later on, continuing his experiments on Hertzian waves, Lodge discovered that Edourd Branly's glass tube filled with metallic filings was an amazingly sensitive detector of electromagnetic waves. It is worth noting here that Branly had developed this tube for his experiments in relation to alternating electric current (Meyer, 1971). Lodge called this tube "coherer" which would later prove to be a key component in the systems of wireless telegraphy (Garratt, 1994).

A few months after the death of Hertz, Lodge delivered a memorial lecture on the work of Hertz in which he described in detail the relevant principles known so far and the application of his coherer. This lecture was published in a popular weekly journal, The Electrician. This lecture was important from at least two perspectives. First, one of the participants of the lecture, Dr Alexander Muirhead, an eminent telegraph engineer proposed to Lodge that Hertzian waves could be used for communication. Second, it led to wider dissemination of highly technical knowledge related to electromagnetic phenomena that had so far re- 
mained confined to a handful of scientists. Concurrently, Professor Righi of the University of Bologna, who was aware of the work of Hertz and Lodge, also wrote an obituary of Hertz followed by a paper describing and illustrating Hertz's work. Righi's article inspired a young Italian amateur, Guglielmo Marconi, to think of applying electromagnetic waves for wireless telegraphy, an application that was envisaged neither by Hertz nor by Lodge (Burns, 2004).

Marconi was the son of a prosperous landowner in Bologna and had a privileged childhood. He got some education in physics and chemistry through private tuition and enrollment in a technical institute but he failed the matriculation examination of University of Bologna and was refused admission. Nevertheless, Marconi had interest in experimentation related to electricity. Due to the influence of Marconi's mother, Professor Righi, who was their neighbor had kindly agreed to guide him and permitted him to use his laboratory and university library. After reading Righi's article on Hertzian waves, Marconi set out to work on the idea of wireless telegraphy in 1894 (Burns, 2004). The principal components of the needed equipment-the spark gap, the induction coil, the resonator and the coherer-were easy to construct or arrange (Beauchamp, 2001). Marconi attained the known ranges soon and continued his experiments by gradually extending the range during the next year. During these experiments, he discovered by chance that by earthing one end of the transmitting and receiving antennas while elevating the other end, the range of transmission increased upto a mile. Encouraged by these successes, his parents tried to secure some support for him. His father approached the Italian Government via their family physician but the response of the government was not encouraging. His mother contacted her relatives in London who encouraged them to travel to London. Consequently, Marconi and his mother moved to London in February 1896 (Burns, 2004).

Soon after arrival in London, Marconi applied for a patent on $5^{\text {th }}$ March 1896. However, he abandoned this patent due to some reason. Later, Marconi wrote to the Principal Secretary of State for War Affairs on $20^{\text {th }}$ May 1896 that he had made wireless electrical devices that could guide a self-propelled boat or torpedo from a distance of more than a mile. Furthermore, he expressed his willingness that if the devices were of interest to the War Office, he could demonstrate the devices at his own expenses and if the invention was not of military's interest, he would obtain a patent and apply it for commercial purposes. Later, Marconi submitted a second application for a patent on $2^{\text {nd }}$ June 1896 which was granted. This was the first patent related to wireless telegraphy ever granted (Garratt, 1994).

Marconi's cousin Colonel Jameson-Davis, who was a professional engineer, introduced him to an eminent electrical engineer, Campbell Swinton. Having seen the private demonstration of Marconi's equipment, Swinton introduced Marconi to William Preece, Chief Engineer of General Post Office (GPO). The 
GPO was already experimenting with the subject which was also the reason why the War Office had not deemed it appropriate to engage in the experiments of Marconi. However, the experiments by GPO were pursued based on the principles of induction or conduction rather than propagation of radio waves. Preece extended extraordinary help to Marconi in carrying out extended experiments and further refining his apparatus. As a result of these experiments supported by the GPO staff, Marconi significantly increased the range of transmission. Eventually, Marconi and his associates established the Wireless Telegraph and Signal Company Limited on 2oth July 1897 with the objective of commercializing the Marconi system. At that time, Marconi was only 23 years of age. This move, however, resulted in termination of support from GPO for his experiments.

The immediate application of the apparatus foreseen by Marconi was the ship-to-ship and shore-to-ship communication, particularly needed by Navy which had been carrying out experiments along similar lines under the charge of Captain H.B. Jackson. However, despite many successful demonstrations and free publicity by media, Marconi's system had to overcome many technical problems before he could commercially offer his system. This required scientific and technical knowledge. Therefore, Marconi began hiring academically trained scientists and engineers with the appointment of Dr J. Erskine Murray, an assistant professor of physics, as his principal experimental assistant in November 1898 (Burns, 2004). By 1900, the nascent company had developed a pool of highly talented scientists and engineers, including Lodge and Fleming acting as its consultants. Consequently, in the following years the company added many inventions to the pool of patents that comprised Marconi's system. Marconi also devised his own method of tuning for which he obtained a patent in 1900. In 1900, the company also initiated experiments for transatlantic wireless communication. The wireless telegraphy began to diffuse in Navies of different nations as well as the maritime industry (Garratt, 1994; Beauchamp, 2001; Susskind, 1970). Marconi was awarded 1909 Nobel Prize in physics together with Karl Ferdinand Braun (who had developed a transmitter and receiver rivaling Marconi's) for their contributions to the development of wireless telegraphy (Susskind, 1970).

The invention of Marconi's system of radiotelegraphy set the foundations of electronics as a new branch of technology and Wireless Telegraph and Signal Co. Ltd., established the same year to commercialize the system, marked the beginning of electronics industry. The company became Marconi's Wireless Telegraphy Company Ltd. in 1900. The industry initially included Marconi's company and two rival firms in Germany which later formed a single firm, Telefunkun, in 1903. It is worth noting here that neither of the major industries of the time-telegraph, cable, telephone, and electrical manufacturing-participated in the initial development of radiotelegraphy technology or industry (Susskind, 1970). 
Radiotelegraphy as a new breed of technology brought forth a new set of problems and opportunities which triggered numerous inventions that gave birth to the field of electronics. These inventions were related to detection and modification of electromagnetic signals. Marconi had initially used coherer as the detector as noted earlier. However, several other types of detectors were invented soon. Perhaps the most important step forward from hitherto electrical and electromechanical communication technologies (telephone and radiotelegraphy) towards electronics was taken by Sir John Fleming and De Forest in early 19oos (Hempstead, 2005, pp. 291-95). In a bid to craft a better detector, Fleming used Edison's experimental bulb (which had an extra wire in addition to the two wires supporting the filament) and invented in 1904 a diode which could serve as a detector as well as rectifier. Similarly, De Forest invented two-element and three-element vacuum tubes between 1904-06. De Forest called his triode tube "audion". The triode vacuum tubes served as the basis for the invention of method of amplification in 1911.

After the end of First World War, radio industry boomed and the demand for the tubes increased significantly. Moreover, due to need for operating radio receivers on alternating current rather than storage batteries, the alternatingcurrent tube was invented by Freeman and Wade of the Westinghouse Company in 1926. In a nutshell, the vacuum tubes played a key role in electronics by serving as detectors, rectifiers, amplifiers, and switching devices in numerous electronic systems of the time. The vacuum tube served as the key component of electronics till it was replaced by transistor, which was eventually also replaced by integrated circuits $^{16}$ (Hempstead, 2005; Meyer, 1971).

In short, the invention of wireless telegraphy, like electric telegraphy, emanated from the electricity-related research in physics which also drew upon the knowledge about the properties of light. However, while this account might give an impression that it was a linear progression of knowledge in science and its conversion into technology, a few facts need to be highlighted. First, it signifies the importance of cumulativeness of scientific and technical knowledge. Second, it signifies the importance of dissemination of knowledge which allows the contemporary scientists and engineers working at the frontiers of knowledge to exhaust the possibilities quickly without duplication of unpromising paths. Third, it signifies the importance of problem or opportunity identification in providing direction and focus to the research in science and/or development of technology. Despite being brilliant scientists, neither Hertz nor Lodge had thought of using the

\footnotetext{
${ }^{16}$ In fact, the term electronics was initially used to refer to the vacuum tubes (valves) because they function through the flow of electrons in a vacuum as opposed to electrical devices or components which function due to the movement of electric current via an electric circuit (Hempstead, 2005, pp. 292).
} 
knowledge of electromagnetic waves for solving any practical problem. It was an academically untrained amateur with entrepreneurial spirit who conceived, initiated, directed and enriched the efforts for putting emerging scientific knowledge into practical use simply because he was guided by a practical problem/opportunity. Fourth, it substantiates the view that technology is essentially a "useful" combination of existing knowledge whereby the "intended use" defines the nature and purpose of the technology as well as the paths of development that it takes. For instance, it took only a description of scientific developments and devices in an article written in memory of Hertz that an amateur with relevant interests was able to replicate that combination and refine it with the intent and aim to apply it for wireless telegraphy.

In retrospect, the application of electromagnetic waves for wireless/radio communication was a revolutionary development which opened up several new branches of science and bred numerous other technologies for military use (e.g., radar), sea and air-traffic control apparatus, mass communication (e.g., radio broadcasting), space exploration (e.g., survey and communication satellites), and personal communication (e.g., cellular phones), to mention a few. However, one of the most significant co-evolutionary developments in relation to wireless telegraphy were taking place in a separate domain of experimentation-long-distance transmission of images together with sound.

\subsubsection{Television}

As discussed earlier, the electrical science was progressing in different directions during the mid $19^{\text {th }}$ century. Consequently, scientific and technological knowledge accumulated regarding the transmission of electric current and electromagnetic signals manifested in such technologies as electric telegraphy and telephone by the end of 1870 s. Correspondingly, significant knowledge about the properties of light, photographic technology, and image scanning had also been accumulated. Sound recording technologies (phonograph, graphophone, gramophone, and polyphone) had already been invented by the end of 188 os while the efforts were underway to develop the technology for motion pictures as indicated by the invention of kinetograph, kinetoscope, praxinoscope, and zoopraxiscope etc. around 1880. In this environment, it is reasonable to expect that scientists and engineers as well as the knowledgeable persons would also think about recording and replaying the real-life combination of sound and image as well as transmitting this combination at a distance. The invention of telephone had particularly boosted such a fantastic possibility as indicated by the famous cartoon of 1878 which showed a girl in Ceylon speaking with her parents in the UK by means of an imaginary wide-screen telephonoscope expected from Bell and Edison (Magoun, 2007; Uricchio, 2008). The idea of telephonoscope also became part of popular science fiction of the time (Uricchio, 2008). However, the visions by practitioners of sci- 
ence and technology regarding such a "distant vision" technology that we know now as television varied a lot at that time (Garratt \& Mumford, 1952).

Perhaps the roots of the invention of television can be traced to the experiments related to photoelectricity using selenium, a non-metallic element that was first discovered by Berzelius in 1817 (Magoun, 2007; Burns, 2004; Garratt \& Mumford, 1952). A curious link between the non-conductivity and resistivity of this element had been discovered by Knox in 1837. Due to these properties of selenium, Willoughby Smith, a telegraph engineer used it in his experiments related to submarine cable and discovered its photoelectric or photoconductive properties in 1873. He discovered that its resistance changed in relation to the intensity of light. In 1878, Smith reported that with the help of telephone he had heard the action of a ray of light falling upon a bar of selenium. This discovery raised interest and research activity related to 'seeing by electricity'. Consequently, using selenium, A. G. Bell and his co-worker S. Tainter invented in 1880 a device called photophone which was one of the first attempts for optical telephony. During these experiments, Bell and Tainter devised a variety of selenium cells and a method of quickly transforming selenium into a required crystalline state as well as several methods of affecting polarized light (Burns, 2004).

Secondly, we have noted earlier that the idea of scanning is fundamental to image transmission (Garratt \& Mumford, 1952; Hempstead, 2005). The first scanning method was laid down by Alexander Bain, a Scottish clock and instrument maker in his British patent dated 27th November 1843 related to electric printing and telegraphy (Burns, 2004). After the discoveries related to selenium in 1870 , selenium was commonly used in experiments related to scanning and distant vision technology variously envisioned as "phototelegraphy", "visual telegraphy”, “telectroscope”, "telephonoscope”, “electric telescope”, etc. One stream of these efforts was aimed at what we know as facsimile technology while the other stream was focused on distant vision or television technology (Magoun, 2007; Meyer, 1971). The developments related to facsimile have been discussed earlier in connection with electric telegraphy, therefore, we shall focus here on televisionrelated developments.

Despite the popularity of selenium in experiments and technical proposals related to distant vision, it was established soon that selenium was not suitable for the purpose because of the time lag between its gaining and losing photoconductivity vis-à-vis exposure to light (Garratt \& Mumford, 1952; Magoun, 2007). This situation dampened the enthusiasm regarding distant vision technology but a long-standing laboratory instrument used by scientists of electricity and magnetism appeared as an alternative. This instrument was a special form of a vacuum tube built on the foundations of Edison's experimental bulb having three electrodes. As noted earlier, Maxwell's theory of electricity and magnetism was gaining increasing attention of scientists. In order to carry out the research related 
to electron, British J. J. Thomson invented a particular kind of vacuum tube in early 188 os that used electric or magnetic fields to deflect the electrons emitted from a cathode. Thomson announced the results of his study in 1897, the same year when a German Karl F. Braun invented oscilloscope using a similar tube. This tube came to be known as cathode-ray tube (CRT) and became commercially available in 1897 for laboratory experiments related to electric and radio circuits (Magoun, 2007; Meyer, 1971).

It was suggested by two Germans, Max Dieckmann and Gustav Glage, in a British patent in 1906 that CRT could be used to transmit written materials and drawings. The following year, Russian physicist Boris Rosing applied for a British patent for an electromechanical apparatus in which two rotating mirrors were used to scan an image and CRT was used to reconstitute the display by deflecting the beam of electrons (Magoun, 2007). This meant that CRT could be used as a receiving element in a system of remote electric vision (Garratt \& Mumford, 1952).

The "distant electric vision" involved two distinct problems: scanning a moving image and converting it into electronic display. It is worth noting here that a German, Paul Nipkow, had sought a patent in 1884 on electromechanical apparatus comprised of scanning, transmitting and receiving apparatus involving selenium cell and employing an ingenious method of light modulation. This apparatus may be considered as an electromechanical television (Garratt \& Mumford, 1952). However, the first comprehensive and all-electronic scheme was proposed by a Briton, Campbell Swinton (noted earlier in relation to electric telegraphy), in 1908 in a letter to the magazine Nature in which he stipulated a receiving apparatus comprising an electron beam, electromagnets, and a sensitive fluorescent screen. He elaborated his scheme in his presidential address to the Rontgen society in 1911 which provided the fundamental lines for the high-definition television that it became later (Magoun, 2007; Garratt \& Mumford, 1952).

The most practical demonstration of television was offered by a Briton, J. L. Baird, in 1925. In the following year, he gave a demonstration at Royal Institution whereby he showed moving images of human faces. His apparatus employed Nipkow's scanning system noted above. In the following two years, he demonstrated the transmission of low-definition images over telephone lines first between Glasgow and London and then between London and New York. The regular experimental transmission of television pictures (without sound) started in 1929 as a result of an arrangement between BBC and Baird Television Co. Later, sound was added to picture transmission in 1930. Although Baird's system was hugely dependent on mechanical process, it provided the stimulus needed for serious investment by others for further development of the technology and consequent developmental efforts ranged from creating better CRTs to high-definition display screens (Garratt \& Mumford, 1952; Herold, 1976). Again, subsequent developments in relation to television took place due to advancement in several scientific and 
technology fields, and correspondingly, these developments benefited the emergence and development of other technologies as well.

\subsection{DISCUSSION}

The above discussion is only a sketchy narration of the developments in a very small set of technologies and some important milestones thereof. However, it sets the context for theorizing about technology, technological change and the measurement of technological change. This discussion is organized from two interrelated but distinct perspectives of technology: artifact-based view of technology and knowledge-based view of technology.

\subsubsection{Technology as Physical Artifact}

Each of the technologies can be conceived as an organized, complex and nearly decomposable "hierarchical system" as defined by the Nobel Laureate, Herbert A. Simon (1962). In fact, from Simon's perspective any technology or technological artifact can be considered a technological system, whereby each subsystem is a technology in its own right having a unique purpose, configuration, and lineage (Arthur, 2007, 2009). For instance, glass was a technological system which served as a technological subsystem in optical lens, which in turn served as a subsystem in numerous other systems such as spectacles, telescope, microscope, and camera etc. Similarly, Senefelder's lithography, Volta's battery, Sturgeon's Electromagnet, Pixii's magneto, Bain's electrochemical printing telegraph, Edison's bulb, Bell's telephone, Baird's electromechanical television, etc. are such organized hierarchical systems which are comprised of technological subsystems and comprise higher order technological systems. Therefore, any artifact of individual or collective workmanship is an organized but complex hierarchical system having its own subsystems that may also serve as a component subsystem in several other systems.

In order to measure the rate and direction of technological change at the macro level, it is neither possible nor desirable to enumerate and inventorize all the technological systems and subsystems that may exist at any given point in time. However, Simon's construct offers not only a conceptual tool to understand technology but also provides the scaffolding that can be used to understand the dynamics of technological change.

Any society at any given point in time faces certain problems and needs of varying importance and complexity. Some of these needs and problems are apparent while the others are latent. Theoretically, all these needs and problems exist in a hypothetical "societal problem space". Given the availability of resources and perceived tractability of these problems, members of the society individually and collectively aim at solving some of these problems by creating different physical artifacts which are termed as technologies (Arthur, 2007, 2009). Theoretically, 
all the technologies that exist in any society at any given point in time also exist somewhere in a hypothetical "technology space" (cf. Fleming \& Sorenson, 2001).

The populations of societal problem space and technology space continuously interact with each other and co-evolve, thus jointly determine the societal progress. Society itself being a hierarchical system evolves and becomes increasingly more complex over time (Simon, 1962). Correspondingly, the societal problems and the technologies needed to address these problems also grow in number and complexity. Although there could be various ways and measures to gauge societal progress, perhaps a comprehensive measure would be the one that tells us about the change in the share of societal problems actually addressed during any given time period. Since it is impossible to calculate the population of the societal problem space, one has to resort to approximate the societal progress with the progress in the technology space because technologies are the means through which problems could be solved. In its simplest form, the progress can be measured as the change in the population of technology space between any two given points in time, assuming that qualitative change in technologies is constant. However, this approach poses a measurement problem in that even if all physical technologies created during any period may be enumerated, these are likely to be significantly different in terms of their relative importance and impact on society. Therefore, given our current state of knowledge and resources, measuring technological progress at the macro level is a complex problem.

As noted earlier, every technology can be conceived as an organized hierarchical system and may serve as a subsystem of numerous other systems, with or without some adaptation. For instance, vacuum tube was a technological system in its own right which served as a subsystem in numerous other systems such as air pressure measurement, steam engine, wireless telegraphy, television, etc. Therefore, we may consider it a special kind of general-purpose technology (GPT) in the sense that it could serve entirely different technological systems (cf. Helpman, 1998; Lipsey et. al, 2005). The same applies to its modern successor, the integrated circuit, which serves as subsystem in almost all modern electronic systems. Similarly, scanning technology not only made facsimile possible, it also helped build television, and over time it has enabled the creation of numerous technological systems ranging from optical character reader to ultrasonography.

This perspective of the network of technological systems based on common subsystems, during a given time period, is useful not only in ex-post analyses but also in ex-ante study. For instance, all the technological systems which included vacuum tube as their subsystem have certain overlap in their technological base in that they shared at least one technological subsystem. As transistor replaced vacuum tube due to the advancements in different science and technology fields, it not only helped advance all the technological systems of which vacuum tube was a part, but also opened up the opportunities for creating new technologi- 
cal systems, and hence new industries. Whereas vacuum tube or integrated circuit may be considered as GPTs of a sort, all technological systems which included these 'GPTs' as their subsystem may be termed as common-base technologies (CBTs). This phenomenon of different technological systems as CBTs sharing some subsystems is also a manifestation of technological convergence (Rosenberg, 1963; Levinthal, 1998). In other words, technological convergence may also refer to the technological overlap between any two or more technological systems. Since the growth of GPTs is dependent on the growth of the CBTs, technological convergence plays a key role in societal progress in terms of technological and economic progress.

The role and importance of GPTs is well-researched and documented (Helpman, 1998; Lipsey et. al, 2005). Similarly, the CBTs and hence technological convergence significantly impact the society in several ways. First, the growth of CBTs creates the need for specialization which stimulates the creation of new industries (e.g., Lécuyer and Brock, 2006; Orton, 2004, 2009). Second, CBTs as a group offer greater technological opportunities and hence attract more resources. Consequently, the rate of progress in CBTs tends to increase over time. Third, the advancements in component technologies have more widespread impact. Fourth, opportunities for inter-industry mobility of human capital increase that furthers their growth. Finally, the localized (co)adaptation of a technological subsystem in multiple contexts leads to the advancement of all relevant branches of science and technology, thus benefiting the entire supersystem. This attribute provides the incentive and the focus to the efforts aimed at invention and innovation. For instance, energy needs of various portable devices had different needs regarding the weight, size, and performance of batteries. These needs of different technological systems (e.g., cameras, portable lighting devices, cell phones, etc.) led to the advancements in all technological subsystems of battery as well as the focal technological systems. Similarly, increasing use of microprocessors in entirely different technological systems led to the advancements in microprocessor technology as well as its subsystems such as semiconductor materials, integrated circuit, lithography, etc. which benefited even those technological systems which do not use microprocessors but use its technological subsystems.

In this context, which is founded on the conception of artifact-based conceptualization of technology, the neo-Schumpeterian suggestion of measuring technological change in terms of clusters of technologies (Perez, 2010) loses appeal due to the lack of its feasibility in the face of complexity. If enumerating technological systems and subsystems at any given point in time was difficult, identifying their linkages with other systems, of which they are a part, makes the task even more complex. However, this suggestion may be useful from the knowledge-based perspective of technology. 


\subsubsection{Technology as Knowledge}

Every technology involves three essential elements: purpose, materials, and techniques (Arthur, 2007, 2009). First, the purpose or utility gives meaning to any artifact and in the absence of purpose any artifact can not be considered as technology. In fact, it is the purpose that guides the process of creation of technology though it is a frequent occurrence in the history of technology that some technological effect was discovered first and its utility was conceived later. Nevertheless, unless some utility is attached to an artifact it does not qualify as technology. For instance, vacuum tube was initially used for measuring air-pressure. After some time, it was adapted for electrical experiments and provided the base for the invention of electric bulb, and following that, it became a key component of electronic devices. Second, any technological artifact involves natural or synthetic materials or material components whose properties can be harnessed for certain purposes (Lécuyer \& Brock, 2006). For instance, copper is a natural element known for thousands of years but its use and superiority over other similar elements in relation to the transmission of electricity was discovered quite some time after the discovery of electricity. Similarly, selenium was an element known since 1817 but its photoelectric properties were discovered during experiments related to telegraphic cables in 1873 which made it appropriate for use in the experiments related to scanning technology. This suggests that it is the knowledge of materials and their properties, rather than materials per se, that is essential for creation of technology. Finally, it takes a specific configuration of known materials according to their known properties that can produce desired effects. This is a specific kind of knowledge that constitutes the art and craft that comes more from individual insights gained through experimentation and experience than from extant science. For instance, all materials and components used in telephone were known and available but it was the idea as well as the art of combining those elements that were conceived by Gray and Bell that enabled them to invent the telephone independently.

It is apparent from this analysis that every technological artifact is essentially knowledge in the form of idea or purpose, the knowledge of requisite materials, and the knowledge of how to combine those materials in order to produce desired effects. For instance, Professor Lodge did not invent wireless telegraphy because he did not have the complete assortment of knowledge needed for the technology. He had the scientific knowledge of materials and arranged and arrived at a rudimentary combination of materials and components needed for radiotelegraphy but he lacked the idea of the practical utility of his combination. On the other hand, an academically untrained enthusiast, Marconi, attained the necessary combination of knowledge-purpose, materials, and techniques-due to which he was able to invent the technology for wireless telegraphy. This suggests that the knowledge of requisite materials for a technology and the knowledge and ability 
of how to arrange those materials makes the materiality of materials immaterial and justifies to consider this element of technology as knowledge as well. Therefore, technology is essentially a useful configuration of knowledge, at least in the sense of a blueprint or code that can be replicated by anyone who is skilled in the relevant art (Romer, 1990; Mokyr, 2002).

If technology is knowledge, then creation of new technology is the act of creating a new combination of knowledge for a specific purpose (Griliches, 1957; Kuznets, 1962; Weitzman, 1998). For instance, Baird's invention of electromechanical television system was a combination of preexisting knowledge about the effects of artifacts such as Nipkow's scanning discs, neon lamp, a gas-filled potassium cell or CRT, telephone lines, etc. which had already been used and refined in relation to other technologies such as facsimile, audio recording and replay, and motion pictures, etc.

The knowledge-based perspective of technology and technological invention puts the notion of "technological convergence" in a new light and makes the task of studying our hypothetical "technology space" more tractable because it does not require enumerating all the technological systems and subsystems that emerge in the technology space and map increasingly complex networks of CBTs. In order to measure technological progress in this formulation, all that would be needed now is to devise a method to ascertain what purposes (societal or technological problems) are aimed at by those working at the frontiers of science and technology and what kind of knowledge is created in this process during any given period. This formulation also makes the neo-Schumpeterian suggestion of seeing technological change in the emergence, expansion, and contraction of clusters of technologies more practical because it makes the redundancies among artifactbased technological systems irrelevant and hence minimizes complexity (Perez, 2010).

For example, the historical account of the technologies presented above suggests that a significant number of scientists and engineers of the 19th century were working on electricity with an aim to use it for energy generation and transmission as well as long-distance communication. Further in long-distance communication, one aim was to transmit symbols and signals while the other was to transmit live sound over wires. Alongside, some scientists and engineers were aiming at transmission of symbols and images wirelessly by using the scientific and technical knowledge that was also being used for other purposes. Accordingly, accumulation of their contributions to knowledge eventually resulted in such technologies which could solve those societal problems as well as the technical problems arising along the way. This knowledge-based route can also help measure the rate and direction of technological change because there is a natural sequence and time lag between an invention, its translation into innovation for commercial application, and diffusion of the innovation. This requires systematic 
documentation and classification of all the scientific and technological content as soon as it is produced.

\subsection{CONCLUSION}

It is evident from our narration of technologies how one apparently small discovery over the experiment on a dead frog attracted the interest of scientists and engineers whose efforts and contribution accumulated over time and changed the life of humankind in fundamental ways. This discussion also suggests a few important insights about discovery, invention, and technological change. First, chance favours the prepared mind as it did in the serendipitous discoveries by Galvani and Oersted. Second, pursuit of solutions for practical problems is in fact a pursuit of technology. Third, pursuit of technology is actually the pursuit of knowledge. Fourth, knowledge is cumulative and the practitioners of knowledge draw upon the same pool of knowledge available at any given time and apply it to create new technologies. Fifth, technological advancement in any problem area depends upon the amount of intellectual resources it attracts. For instance, a significant proportion of the scientists and engineers of the $19^{\text {th }}$ century focused on the problems of energy (electricity), communication (printing, telegraphy, telephone, and radio) and entertainment (photography, television) which resulted in the development of relevant technologies. Sixth, knowledge and technologies created in relation to one problem area are often applicable to numerous other areas not even imagined by the original creators. For instance, the knowledge created in relation to electricity, communication, and entertainment provided valuable inputs for solving other apparently unrelated societal problems such as healthcare, accounting and computing, minerals exploration and extraction, space exploration, weather forecasting, and so forth. Seventh, there is a significant time lag between a discovery or invention and its commercialization, making it possible to predict the locus and direction of technological change. Finally, knowledgebased perspective of technology may be more useful than the artifact-based view of technology in the study of technological change. 


\title{
4 STRUCTURE OF TRANSFORMATIVE TECH- NOLOGICAL CHANGE
}

\begin{abstract}
Structural change is a matter of interest from the perspective of public policy as well as business strategy because it essentially involves what Schumpeter has famously termed as "creative destruction". Structural changes are always underway in one industry or the other at any given point in time but these become most important when these spread among a wide range of industries and transform the techno-economic system. These are conventionally measured ex post and with reference to the product space. However, Neo-Schumpeterians have attributed these changes to technological changes due to the fact that invention precedes innovation, and hence, technologies precede products. This paper extends this perspective and proposes that technology space is a better 'place' to locate transformative technological change (TTC) than the product space, more so because it can help identify transformative changes ex ante. Accordingly, a conceptual framework is proposed and illustrated with the help of all available US patent data. The evidence indicates three successive episodes of TTC during the 20 th century; the first took place around 1950, the second occurred around 1980, and the third took off around 2000 and it is currently underway. Important implications are also suggested for policy and strategy.
\end{abstract}

Keywords: Technology, innovation, technological change, structural change, co-evolution, technological diversification 


\subsection{INTRODUCTION}

Structural change has been an important topic in the fields of growth economics, industrial organization, and strategy for a long time (Quatraro, 2012; Antonelli, 2014). From the macroeconomic perspective, structural change refers to the change in relative contribution of different sectors in the economic system due to the emergence of new industries as the engine of growth and obsolescence or transformation of incumbent industries (Malerba, 2007; Perez, 2010; Krafft et al., 2014). In industrial organization and strategic management, structural change refers to the changes in the number, size, and market share of contestants in a given industry and the behaviour of entrants and incumbents thereof (Klepper, 1997; Klepper \& Simons, 1997, 2005; Sutton, 2001; Klepper \& Thompson, 2006). In relation to these macroeconomic and microeconomic structural changes, there are several important questions that are relevant to economics and management of innovation, such as, how these changes at various levels interconnected, to what extent these are local or global (Antonelli, 2008), and whether these can possibly be predicted.

There is a vast body of knowledge that informs about various dynamics of macro- and micro- level structural change from the perspective of each of the fields noted above. Central to this body of knowledge is the idea that changing environments continuously induce economic actors to introduce more effective and/or efficient solutions for ever-changing stock of societal needs and problems (Schumpeter, 1942, 1947). In other words, continuous interaction among societal needs and problems and the race to capitalize on these creates a co-evolutionary system that causes changes in the role and status of participating actors (Rosenberg, 1969; Tushman \& Anderson, 1986; Klepper \& Graddy, 1990; Utterback \& Suarez, 1993). Consequently, structural change (variation in the nature and composition of the contending actors) is considered to be related to the technological change (variation in the nature and composition of the solutions offered) (Quatraro, 2012). However, these processes of change co-evolve with numerous technological, social, and economic factors at various levels suggesting that these phenomena are systemic (e.g., Nelson, 2005).

Owing to the systemic, and hence co-evolutionary, nature of structural and technological changes, several systems- and co-evolutionary perspectives have emerged in the field of economics of innovation highlighting various facets of these complex phenomena. For instance, the most popular system perspectives include national innovation system (Nelson, 1993), sectoral innovation system (Malerba, 2002), socio-technical systems (Geels, 2004), technological systems (Carlsson \& Stankiewicz, 1995), and technological innovation systems (Bergek et al., 2008). Similarly, co-evolution of various important components of selection environments has been examined at different levels of analysis. For instance, Nelson (1994) studied the co-evolution of technology, industrial structure, and sup- 
porting institutions from sectoral perspective. In a similar vein, researchers have studied co-evolutionary dynamics in relation to particular technologies and industries. For instance, Murmann (2013a, 2013b) has studied the co-evolution of synthetic dye industry and the discipline of chemistry. Similarly, Sanderson and Simons (2014) have shown how lighting technologies emerged as a result of coevolution of several factors related to the light emitting diode (LED) technologies and led to the creation of solid-state lighting (SSL) industry.

However, almost all these perspectives suffer from the limitations of delimitation in terms of functional or geographical boundaries such as technology, industry, sector, or nation. While such delimitation is desirable from certain perspectives, it obscures important influences spanning all such boundaries which might be the key to ascertain global patterns of structural change. ${ }^{17}$ Scholars of technological change have already noted that delimitation along such lines is problematic. For instance, Rosenberg (1963, pp. 422) contended that "we cannot properly appraise important aspects of technological developments in the nineteenth century until we give up the Marshallian concept of an industry as the focal point of our attention and analysis."

The problem of delimitation has been worsening over time due to the fact that firms tend to be part of multiple technology and product domains (e.g., Granstrand, Patel \& Pavitt, 1997; Gambardella \& Torrisi, 1998; Brusoni, Prencipe \& Pavitt, 2001; Klepper \& Thompson, 2006), their technological linkages span sectoral and national boundaries (e.g., Hagedoorn, 2002), and they have become increasingly multi-national in their operations, especially in R\&D (e.g., Gerybadze \& Reger, 1999; Dunning \& Lundan, 2008). Moreover, universities have become increasingly important players in the process of creation and dissemination of technological knowledge for the benefit of entire system (Mowery \& Rosenberg, 1989; Leten, Landoni \& Van Looy, 2014). In short, while delimitation of analytical boundaries around technologies, industries, sectors, and nations serves well in highlighting the complexity of evolutionary dynamics within the chosen boundaries, it becomes a serious limitation in determining the locus, direction, and magnitude of technological and structural changes in the global techno-economic system. On the other hand, scholars have also cautioned that co-evolutionary and systems perspectives need to go beyond the generic statement that everything is changing with everything else (Malerba, 2007, pp. 694). This situation makes the

\footnotetext{
${ }^{17}$ We use the term 'global' to denote a level of analysis that represents a system of systems (i.e., a meta-system) that encompasses all kinds of social and technical systems. Although we do not intend to invoke the term in the sense of an international system comprising national systems but the term encompasses that sense as well, though not limited to it. We also feel that this level of analysis can be applied at the level of individual nations as well because national systems are, after all, comprised of a representative subset of these systems.
} 
study of co-evolution of technological and structural changes at higher levels of analysis a challenging task.

In order to help tackle this challenge, this paper proposes a conceptual framework based on the insights from multiple fields including economics, sociology, history of technology, and strategic management. The key insights underlying the framework include the idea that technology and product should be conceptually separated (Pavitt, 1998), technology is essentially knowledge (Mokyr, 2002; Dosi \& Grazzi, 2010), and technology and innovation are the result of recombination (Weitzman, 1998; Fleming \& Sorenson, 2001; Arthur, 2007). Moreover, it is well known that technologies take different trajectories during the process of diffusion in different areas of application (Dosi, 1982) and interrelated technologies form "domains" (Arthur, 2009) in the technology space. Furthermore, multiple actors tend to pursue same or similar technological problems at any given point in time (Boring, 1955; Simonton, 1979, 2004), they tend to operate in multiple technology and product domains simultaneously (Granstrand, Patel \& Pavitt, 1997; Gambardella \& Torrisi, 1998; Brusoni, Prencipe \& Pavitt, 2001; Klepper \& Thompson, 2006), and their inventive pursuits are limited to the extent of valuable technological opportunities available to them (Klevorick et al., 1995; Breschi, Malerba \& Orsenigo, 200o). These dynamics lead to the emergence of clusters of technologies and technological innovations in close temporal proximity which bring about transformative changes in the global techno-economic system (Ayres, 1990a, 199ob; Perez, 2010).

Transformative technological change (TTC) is important because it pertains to technological and structural change in broad swaths of technology and product domains at the global level (Perez, 2010). It occurs due to the changes in global technology space long before they manifest in the product space (Drucker, 1969). During this process, value and resources systematically migrate from maturing to emerging technology and product domains (cf. Slywotzky, 1996). The aim of this paper is to highlight and integrate the key drivers of TTC in a simple framework that may help explain this phenomenon more holistically and pave the way for predicting such technological and structural changes.

The paper is organized into six sections. The next section presents the historical and theoretical foundations of the concept of TTC and its usefulness for depicting as well as predicting structural changes in techno-economic system. The third section presents theory about the formation of technology domains and corresponding technological ecosystems as key components of the proposed framework. The fourth section details the methodology used in implementing the framework. The fifth section presents an analysis of the patterns in data. The final sections includes a discussion of the limitations of empirical study as well as the practical implications of the framework for theory and practice. 


\subsection{TRANSFORMATIVE TECHNOLOGICAL CHANGE}

Technological change as a subject of scientific inquiry emerged in relation to economic development, particularly as a result of Schumpeter's distinction between invention and innovation and his emphasis on the latter as the primary source of economic change (Rosenberg, 200o; McCraw, 2007). The neo-Schumpeterians connected innovation with invention and argued that "revolutionary" changes in the economic system emanate from technological innovations (Freeman \& Louçã, 2001; Perez, 2010). These changes are considered "revolutionary" or "transformative" because these are driven by the emergence of clusters of interrelated technologies which breed new industries and lead to the obsolescence or transformation of existing technologies and industries (Perez, 2010). Therefore, transformative technological change (TTC) brings about significant reallocation of resources in the techno-economic system as the new industries and sectors become "the engines of economic growth for a long period" (Perez, 2010, pp. 189). ${ }^{18}$ This reallocation happens due to migration of resources from the old technologies, industries and sectors to the new ones due to their relative growth potential and expected returns (cf. Slywotzky, 1996). Consequently, relative share of different industries and sectors in investment, employment and output also changes. Such a change in sectoral composition of techno-economic system as well as the composition of sectors and industries thereof is known as structural change (Quatraro, 2012).

Structural change is important not only from the perspective of economics but also from the perspective of sociology. Change in organization and deployment of resources to produce and deliver certain products and services is not only indicative of changing configurations of resources and capabilities within the system but also changing profile of societal needs and priorities (Rosenberg, 1969). It is the interplay of technological capabilities and societal demands that determines the direction of technological and structural changes in the long run (cf. Di Stefano, Gambardella, \& Verona, 2012).

Structural change is traditionally seen from two complementary perspectives: the composition of techno-economic system in terms of sectors and the composition of sectors and industries. The former typically uses the nature of activities to demarcate the composition of system such as agriculture, manufacturing, and services. The latter conventionally uses products as the basis of segmentation of the system such as textiles, electronics, automobiles etc. or specific product

\footnotetext{
${ }^{18}$ The term transformative technological change is used to depict essentially the same phenomenon that Perez (2010) has preferred to call "technological revolution". However, our choice of term also involves a slight departure from the original concept for two reasons. First, this change is essentially evolutionary, and second, it carries with itself the connotation of significant and widespread change across the techno-economic system.
} 
categories as distinct industries. Both these perspectives help depict the technological and structural changes in relation to past but it is difficult to see how these can possibly be used to predict the direction of technological change and corresponding structural changes in the system. This challenge can be addressed by combining two Schumpeterian perspectives.

Schumpeter (1947) argued that economic changes emanate from the creative and adaptive responses of actors. The evolutionary tradition dealing with micro foundations of economic change has extended this theme. This tradition suggests that the responses of actors manifest in the form of technologies and products but these are essentially rooted in path-dependent capabilities of the actors (Nelson \& Winter, 1982). On the other hand, neo-Schumpeterians argued that transformative technological change occurs due to the emergence of clusters of interrelated technologies (Perez, 2010). In order to bridge these two perspectives, we posit that actors contribute to and respond to transformative technological change by creating and using technologies. This view is based on the understanding that products are mere outcomes of technologies and technological capabilities whereby same technologies may be used to create different products by different actors. Products and industries appear and disappear (Klepper \& Simons, 1997, 2005) but technologies and technological knowledge underlying these continue to be used and reused in the techno-economic system (Hoetker \& Agarwal, 2007). What makes this integrative perspective useful is the fact that technologies appear in the technology space long before they manifest in the product space (Drucker, 1969; Rosenberg, 1994). Therefore, it may help not only depict but also predict TTC and resulting structural change.

In the following section, this perspective is developed into a conceptual framework that show the linkage between clusters of technologies and actors and how these linkages bring about TTC.

\subsection{TECHNOLOGY DOMAINS AND TECHNOLOGICAL ECO- SYSTEMS}

\subsubsection{What is Technology?}

The concept of technology is multifaceted and understood variously in various disciplines and fields (Faulkner, Lawson \& Runde, 2010). However, three perspectives of technology appear commonly in economics and management of technological change. Among these, perhaps the most common view is that of being a means for a particular end. For instance, each of the automobile, train, ship, and airplane, is a technology for transportation of material things from one place to another. Closely related to this perspective is the view of technology as an artifact-the embodiment of certain functionality in a physical structure by integrating other artifacts as components (e.g., Vermaas \& Houkes, 2006; Kroes, 2010; Arthur, 
2007, 2009). Finally, a perspective that encompasses and yet transcends these two perspectives is the view of technology as knowledge in the sense of technique or recipe (Mokyr, 2002; Dosi \& Grazzi, 2010). Building on the insights from these perspectives, we may define technology as:

An effective and replicable scheme or combination of ideas and means to produce a particular effect that can be used to create other useful ideasmeans-effects combinations (including the products).

This definition can be illuminated with reference to a breakthrough invention of the 19th century known as "Voltaic pile" (Meyer, 1971). Interestingly, this invention was the result of a popular scientific debate over the contractions in the muscles of a dead frog. Alessandro Volta conjectured that the contraction was somehow caused by the contact between dissimilar metals and was not due to animal electricity. In order to test his theory, he conducted a series of experiments to produce electric charge using dissimilar metals. Finally, he wrote a letter to the Royal Society of London in 1800 describing the scheme of construction of a particular pile of different metals whereby a spark would be produced when the two ends of the pile were connected through a wire. Following Volta's scheme, anyone having the relevant knowledge, skills, and resources could replicate the pile and produce the same effect, anywhere, anytime. Consequently, this invention quickly became a popular technology among the experimenters in the field of electricity and magnetism replacing the Leyden jar as a source of electric charge. From this perspective, the essence of technology is knowledge, at least in relation to know-what and know-how, if not the know-why (Carud, 1997; Mokyr, 2002; Dosi \& Grazzi, 2010). Moreover, a technology is a network or system of technical effects and the knowledge underlying these effects (Arthur, 2007; Mokyr, 2002).

This perspective is useful for thinking about technological change and related phenomena because it indicates the key elements of technology from the input perspective as well as the output perspective that are the roots of technological change. The input dimension of any given technology may be viewed in terms of complexity while the output dimension may be seen from the perspective of specificity. The former is related to the creation of a technology and the latter is linked to its diffusion.

Complexity refers to the variety of technical effects needed for the creation of a particular effect that is the defining characteristic of a given technology (Fleming \& Sorenson, 2001). ${ }^{19}$ The greater the variety of constituent effects, the more complex a technology is and the more diverse technological linkages it is likely to have with extant technologies. For instance, Kilby's scheme of integrated circuit (Kilby, 1964) was more complex than Volta's scheme because the former

\footnotetext{
${ }^{19}$ The notion of variety is also important from the perspective of technology as a system as well as the techno-economic system (cf. Ashby, 1956; Saviotti, 1996).
} 
involved integration of greater number of technical effects which, in turn, were also complex. Technological linkages of a given technology with other technologies stem from the component effects as well as the ideas and means underlying those effects. Accordingly, complexity and resultant diversity of technological linkages positively affect the possibilities of incremental changes in the focal technology. This is due to the reason that technological linkages provide the basis for awareness about advancements in component technologies that may take place anywhere in the technology space.

On the other hand, specificity refers to the variety of ultimate purposes for which a given technical effect can be used. The use of a technology for multiple purposes tends to give rise to different developmental trajectories of the same technology (Dosi, 1982; Levinthal, 1998). Consequently, the greater the variety of purposes relevant to a given technology are, the greater the possibilities for its diffusion as well as technological changes through combinations with other technical effects (Rogers, 2010). Accordingly, the less specific (or more generalpurpose) a technology, the greater its rate of technological change and technoeconomic impact (Lipsey, Carlaw \& Bekar, 2005). For instance, the rates of technological changes and techno-economic impact of integrated circuit technology are greater than that of cloning technology because the former has lower specificity than the latter.

In short, the knowledge-based view of technology presented here allows transcending the conventional conceptual boundaries and thinking about technological change from a global (meta-system) perspective. The following subsections explain how this perspective is useful in understanding, and possibly predicting, technological changes that manifest in significant structural changes in the global (worldwide) techno-economic system.

\subsubsection{Recombinant Invention, Knowledge Fusion, and For- mation of Technology Domains}

Technology comes into existence through a creative process that involves the production of a new technical effect that constitutes invention (Mokyr, 2002; Arthur, 2007). This process involves creative recombination and integration of existing effects in order to create the new effect that becomes the hallmark of new technology (Weitzman, 1998; Kodama, 1992; Fleming, 2001; Arthur, 2007). Integration of existing effects requires certain level of knowledge regarding the ideas and means related to the effects being integrated because the integration essentially takes place at the conceptual level prior to experimentation (Maggitti, Smith \& Katila, 2013). Therefore, invention essentially involves the creation of new technological knowledge using existing knowledge as the input. For instance, the Kilby's idea of miniaturized integrated circuit required technical knowledge related to conductive properties of various raw and fabricated materials, thermochemical 
processes and techniques such as oxidation and diffusion, electronic circuitry and circuit design, and important principles of engineering an electronic artifact, to mention a few (cf. Kilby, 1964; Huff, 2003). However, while the creative process involves experimentation and accumulation of knowledge about 'what works' as well as what does not, technology includes only that part of the knowledge concerned with 'what works' and that is what immediately becomes part of the universe of technologies that populate the technology space (cf. Mokyr, 2005). ${ }^{20}$

Dynamics of the creation and diffusion of what has been called "useful knowledge" (Mokyr, 2002, 2005) are usually studied as two separate provinces of knowledge, science and technology, whereby the former is primarily concerned with phenomenal explanation while the latter is concerned with practical application. The former is usually associated with basic research while the latter is related to applied research. Accordingly, the primary concern of science is to reveal what is presented by nature while the primary concern of technology is to create on purpose and by design. ${ }^{21}$ For instance, science primarily concerns itself with revealing the conductive properties of known materials while technology is concerned with fabrication of semiconductor material of a specific grade for specific purposes.

While this conventional segregation of useful knowledge has its own merits, it is also useful to recognize the fact that both provinces feed on each other for their development and growth. For instance, the "Voltaic pile" was the result of a scientific debate and it boosted experimentation related to the phenomena of electricity and magnetism but it also sparked the development of numerous technologies (Meyer, 1971). Similarly, a few scientific discoveries had prompted the invention of electric telegraphy which, in turn, stimulated research in the fields of chemistry and physics that supplied the inputs for creation of numerous information and communication technologies during the 2oth century (Burns, 2003). Thus, the fusion and diffusion of knowledge takes place not only within each province of science and technology (e.g., Uzzi et al., 2013; Kodama, 1992) but also across both provinces (Fleming \& Sorenson, 2004; Gruber, Harhoff \& Hoisl, 2013).

The fusion and diffusion of knowledge within and across the two provinces takes place due to several mechanisms such as documentation and dissemination of knowledge about technologies for educational purposes, scientific publi-

\footnotetext{
${ }^{20}$ The part concerning what does not work is not unimportant but we leave it here in the interest of our focus on technology. However, it seems that this is an important component of tacit knowledge because it largely remains unreported.

${ }^{21}$ One might argue that technology also involves revealing because the effect that characterizes a technology is also 'present' in that it was latent so it could be 'revealed'. A simple response to this point is that technology is the scheme--that produces (or reveals) the technical effect--that constitutes technology not the effect per se.
} 
cations and patents, mobility of scientists and engineers (Palomeras \& Melero, 2010), and collaborative interactions within and between academia and industry (Hagedoorn \& Wang, 2012; Breschi \& Catalini, 2010; Perkmann, M., et al., 2013). Therefore, science and technology tend to co-evolve (e.g., Mokyr, 2002, 2005; Murmann, 2013) though the pace of advancement in technology seems to be faster than science due to the differences in their approach toward knowledge processing as well as the nature of incentives in two provinces.

As mentioned earlier, every technology is a network or system of technical effects and thus embedded in a larger network of technologies that comprise the technology space. This is primarily due to the fact that technological knowledge is non-rivalours and imperfectly excludable (Romer, 1990). Non-rivalry means that a technology and/or its constituent ideas and means can be used in multiple technologies at the same time. Excludability refers to the extent to which the creator of the technology can predict its possible uses, identify its users and restrict its use to certain purposes or to certain actors. Consequently, all the ideas, means, and effects that are used in creation of a certain technology can also be used in various other technologies at the same time. Thus the focal technology is technologically linked not only to its constituent technologies but also to their input technologies as well as to the other technologies in which those are used. Similarly, on the output side, the focal technology is directly linked to those technologies in which it is used as an input as well those it is used in combination with. It is also indirectly linked to all those technologies in which these technologies are used as a component. Since these linkages are technological in nature, every technology is embedded in the network of extant technologies. Those technologies whose linkages are more active and more frequent tend to cluster in the technology space and co-evolve because the effects of changes in any one technology are likely to be transmitted to and impact other technologies via these linkages. In other words, technologies tend to form "domains" (Arthur, 2009) a la domains of scientific knowledge (cf. Börner, Chen \& Boyack, 2003).

A technology domain can be perceived as a cluster (or sub-cluster) of interrelated technologies in the technology space. If the invention of a technology is imagined as the addition of a new node in the extant network of technologies in the technology space, its 'place' in the technology space is determined by its linkages with extant technologies. Thus every technology is placed among those technologies where it has the highest number of important linkages. From this perspective, technological change can be ascertained by the appearance of new nodes in the network during any given period of time.

However, since technology is the manifestation of technological knowledge, a technology domain is a domain of technological knowledge a la domains of scientific knowledge as represented by scientific disciplines and fields (cf. Börner, Chen \& Boyack, 2003). Since knowledge can be applied for multiple 
purposes, technology domains tend to overlap in a manner similar to that of scientific domains. Accordingly, technology domains also emerge, grow, stagnate, and decline relative to each other like scientific domains do depending on the amount of resources and inventive activity attracted by them. These patterns of emergence and growth of technology domains carry important clues about the nature, locus, and direction of technological change in the global techno-economic system, particularly because of the fact that technological change manifests in the knowledge space well before it appears in the product space.

\subsubsection{Diversification, Technological Convergence, and For- mation of Technological Ecosystems}

Technological knowledge is created and used by social actors including individuals, institutions (such as universities), and firms. Actors seek technological knowledge in order to solve some technical problem or exploit some technological opportunity in relation to a certain area of their activity at a particular point in time (Rosenberg, 1969). Therefore, actors tend to have certain amount of prior knowledge related to the problem. Accordingly, their search and selection of useful knowledge is conditioned by its relevance to the problem on the one hand and its relatedness to the knowledge base of the actor, on the other (Fleming, 2001; Stuart \& Podolny, 1996). This is because of the fact that if the knowledge sought is unrelated to the knowledge base of the actor it will be difficult to absorb and integrate it with the existing knowledge of the actor (Cohen \& Levinthal, 1990). Therefore, actors tend to search for new knowledge in the light of their existing knowledge bases (Stuart \& Podolny, 1996; Rosenkopf \& Nerkar, 2001; Breschi, Lissoni, \& Malerba, 2003).

The knowledge base of actors is an important determinant of their productive (or creative) activities (Grant, 1996a, 1996b; Granstrand, 1998). Accordingly, the diversity of the knowledge base is an important determinant of their absorptive and creative capacities (Pavitt, 1998). In fact, a certain "requisite variety" (Ashby, 1956) in the knowledge base is necessary to operate in any productive (or creative) activity. Diversity is determined by the complexity of the activities and/or the number of activity areas an actor is engaged in. For instance, it is well known that firms operate in multiple product areas (multi-product firms) as well as in multiple technology areas (multi-technology firms) (Teece, Rumelt, Dosi \& Winter, 1994; Granstrand, Patel, \& Pavitt, 1997; Granstrand, 1998). Therefore, in case of complexity or diversity of activities, actors tend to need and search for relevant knowledge from multiple technology domains and this behaviour tends to reinforce diversity in their knowledge bases (Gambardella \& Torrisi, 1998).

Technological knowledge is an important resource and actors seek to exploit of their resource base to the extent possible (Montgomery \& Hariharan, 1991; March, 1991). Therefore, they tend to utilize their technological knowledge in 
all activities and activity areas they are engaged in and/or engage in new activities such as through product-market diversification (Kogut \& Zander, 1992). Since each area of productive (or creative) activity is likely to be populated by multiple actors, valuable knowledge discovered or created by any one actor tends to diffuse among other actors active in those areas due to the dynamics of competition (e.g., Cassidy \& Loree, 2001). Therefore, if an actor discovers or creates new knowledge that is novel and valuable, other actors also seek to acquire same or similar knowledge. Consequently, actors engaged in the same or similar set of productive (or creative) activities tend to draw their knowledge inputs from the same or closely related technology domains. Therefore, extant technologies and technological knowledge may be used by different actors in different areas of activity, depending on the specificity of the knowledge as discussed earlier (Kogut \& Zander, 1992).

For instance, Rosenberg (1963) pointed out that apparently different industries such as bicycles, firearms, and sewing machines involved significant overlap in their technological bases and termed this phenomenon as "technological convergence". This indicates that any give technology domain may supply technological inputs to diverse areas of activity within the techno-economic system. Therefore, apparently different technology domains and different domains of activity (e.g., industries) are technologically interconnected (Rosenberg, 1979). This means that there exist multiplex technological relationships among the technology domains, among activity domains such as industries, and among technology domains and activity domains.

While this network of technological linkages provides the medium for transmission of technological knowledge across the techno-economic system, the multiplexity of these linkages makes the study of technological change at higher levels of analysis a complex task. This complexity is hard to capture but difficult to ignore because the sources of creation and diffusion of technological change are embedded in this network of linkages. Therefore, perhaps the best solution to tackle this complexity is to harness it.

One possible way of harnessing this complexity is to focus the analysis on cohorts of technologies on the one hand and the cohorts of actors who create and use these, on the other. As discussed in the previous subsection, the cohorts of technologies (technology domains) are determined by the linkages among their knowledge bases. Similarly, cohorts of actors can be determined by technological linkages among their knowledge bases. A cohort of actors may be termed as "technological ecosystem" and defined as a set of social actors involved in the creation and application of interrelated technologies. These actors may be working in entirely different kinds of productive activities (e.g., industries and academic institutions), may be located anywhere, and may even be unaware of each other, but are nevertheless interconnected technologically. In the light of this conceptual 
framework, TTC may be defined as the process of emergence of new technology domains which involves systematic migration of inventive activity from established to the new domains and corresponding change in the configuration of technological ecosystems.

This view of techno-economic system comprised of technology domains on the one hand and technological ecosystems on the other captures a large part of the complexity and provides a useful framework to think about various dynamics of technological and structural change (Figure 4.1). Since technological changes appear in the form of new technologies in the technology space well before their manifestation in the product space, technological changes and corresponding structural changes in the techno-economic system may be studied via changes in technology domains, technological ecosystems, and the linkages among these.

\section{FIGURE 4.1}

\section{Technology Domains and Technological Ecosystems}

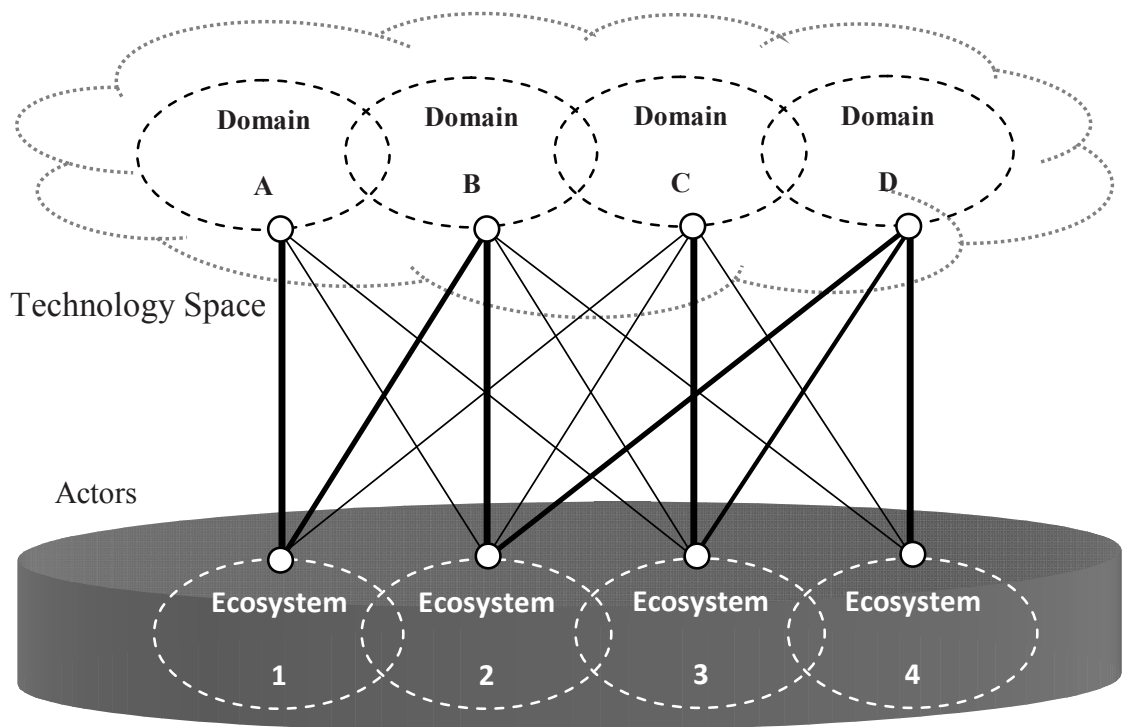

\subsection{DATA AND METHODS}

\subsubsection{Data}

Technology is fundamental to the understanding of technological change, and hence, to our framework. Patents are widely used as a valid proxy for technology, technological capabilities of actors, and indicators of technological change (e.g., Fleming \& Sorenson, 2001; Granstrand, 1998; Sanderson \& Simons, 2014). We used 
the patent record of USPTO taken from PATSTAT (v. 4.10, 2010) because PATSTAT provides global information about the patents. We used only patents of innovation and design patents and ignored the utility models (or "petty patents"). Since the object of study was to analyze inventions, we used DOCDB family as the unit of analysis whereby each family is represented by its oldest member. Accordingly, we used the earliest filing date in the family because it allows temporal sequencing of inventions. As a result of this procedure, a total of 9,415,358 inventions were identified till 31-Dec-2009. Further, we divided the data for the period 1881-2009 into 5-year periods whereby all years before 1880 were treated as one period. Pattern of growth in total inventive output on yearly and 5-yearly basis is given in Figure 4.2.

\subsubsection{Identifying Technology Domains}

Clusters of interrelated technologies are what we call technology domains (cf. Perez, 2010). In order to measure changes in different technology domains, mutually exclusive groups of interrelated technologies are needed as a stable frame of reference for the whole study period. Unfortunately, international patent classification (IPC) cannot serve this purpose because the categories at the highest level of IPC (section) are not technologically mutually exclusive. Consequently, patents are bound to be classified in multiple sections and their subtrees. Therefore, such hierarchical classifications of inventions may involve significant endogeneity in patent-based measures of similarities and differences (McNamee, 2013). Due to this reason, we reclassified all the patents of 634 major IPC subclasses using a four-stage process based on network theoretic methods (see Appendix 4.A). First, we constructed $634^{*} 634$ co-classification matrices for each 5 -year period. Since these matrices were highly sparse and the variability among weights was also very high, we extracted the backbone of each matrix using the "multiscale backbone" method (Serrano, Boguñá, \& Vespignani, 2009). Second, from these network backbones, we extracted overlapping communities of IPC subclasses using the hierarchical link clustering method (Ahn, Bagrow, \& Lehmann, 2010). Third, using the spectral clustering method (Newman, 2006; Rubinov \& Sporns, 2010), we extracted three non-overlapping spectral clusters (SC) of inventions- $\mathrm{SC}_{1}, \mathrm{SC}_{2}$, and $\mathrm{SC}_{3}-$ that accounted for more than $99 \%$ of inventions in the whole study period (Table 4.A1). The size and pattern of growth of these three clusters, in terms of number of inventions, is shown in Figure 4.3. Form each of these clusters, we obtained subclusters using the same method (Table 4.A2). This resulted in a hierarchy of clusters and sub-clusters which can be extended to several levels, though this analysis is limited to three levels only-clusters, sub-clusters, and subclasses (For relative share of major sub-clusters see Table $4 . \mathrm{A}_{3}$ and their growth pattern see Figure 4.A3). Fourth, we ascertained the content of these clusters and sub-clusters using the co-word analysis of titles of inventions contained in the most central subclasses (cf. Callon, Courtial, \& Laville, 1991). 


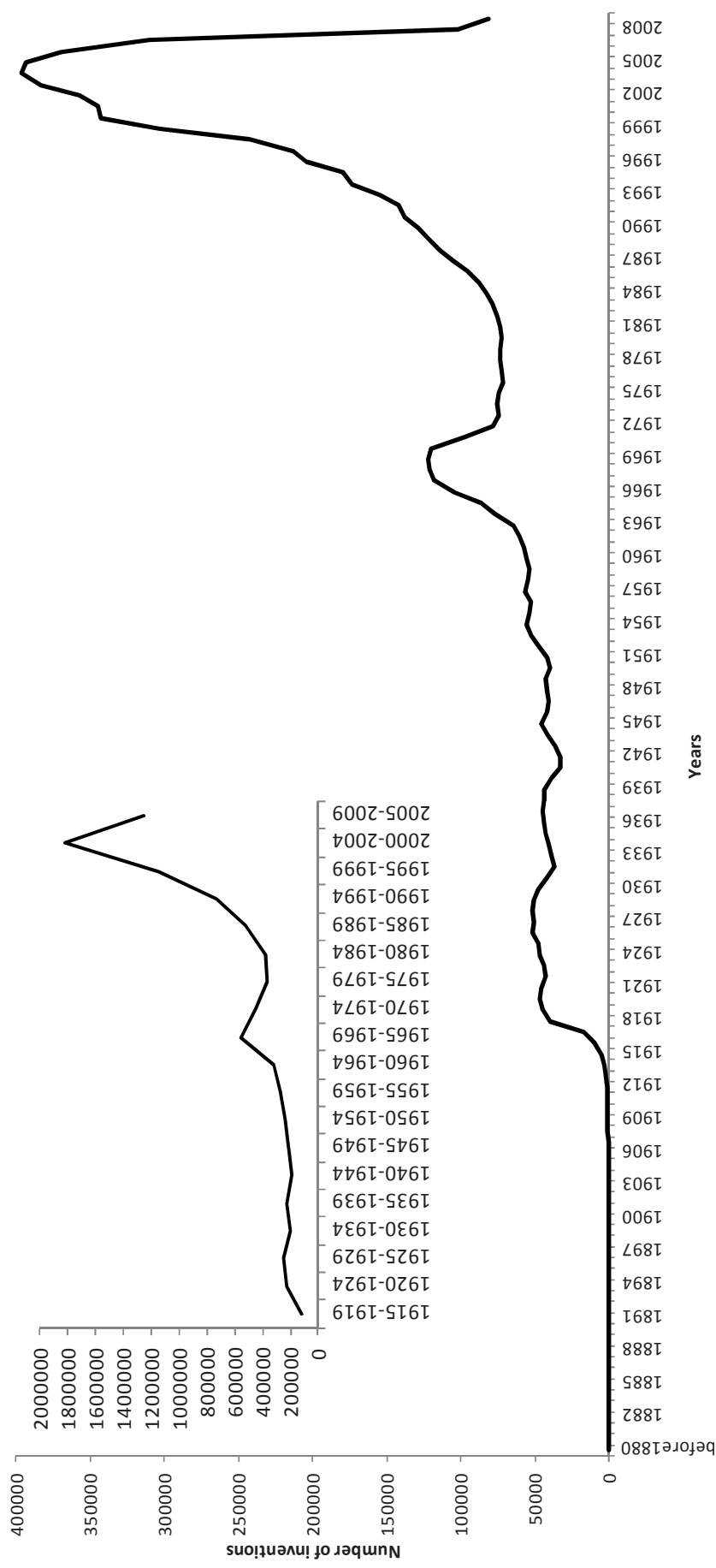


These clusters (technology domains) can be described as following:

SC1: Chemical engineering, metallurgy, textiles and paper

SC1_1: Separation and purification of liquids, solids, and gases

$\mathrm{SC}_{1} \_$2: Organic chemistry and chemical engineering

$\mathrm{SC}_{1 \_3}$ : Materials engineering and metallurgy

SC2: Communication, computing, and electronics

SC2_2: Telecommunications and computing

$\mathrm{SC}_{2}$ 3: Wireless communication

$\mathrm{SC}_{2}$ 4: Detection, diagnosis, and measurement

SC2_5: Automatic control, monitoring, and vending

$\mathrm{SC}_{3}$ : Mechanical-, thermal-, and aerospace engineering and weapons

$\mathrm{SC}_{3}$ 1: Automobile engineering

$\mathrm{SC}_{3}$ 5: Firearms, heating, refrigeration and propulsion

$\mathrm{SC}_{3 \_23:}$ Packaging and dispensing

FIGURE $4 \cdot 3$

Growth Pattern of Major Technology Domains

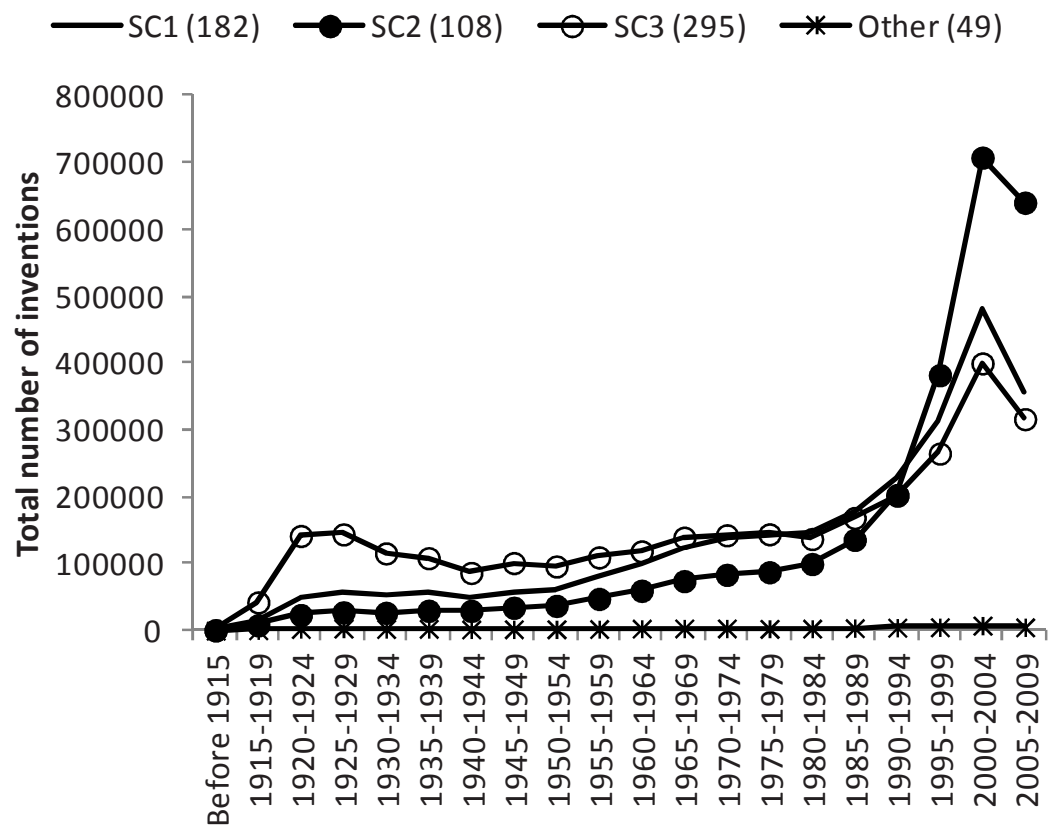




\subsubsection{Overlap among technology domains}

As discussed in section 3.1, a technology may be related to several technologies from its input side as well the output side, it may be used in multiple domains. Therefore, technologies domains tend to overlap. In order to measure overlap, we constructed the overlap matrices for various levels of IPC hierarchy as well as the spectral clusters and sub-clusters. From these matrices, we computed average overlap as following:

$$
\text { Average Overlap }=\frac{\sum \mathrm{S}}{\mathrm{N}} \times 100
$$

where $\mathrm{S}$ is the total number of shared inventions between each pair of domains in the matrix and $\mathrm{N}$ is total number of inventions in the respective period

The overlap among different domains at any given level of a classification is a useful indicator from two perspectives. First, it indicates the robustness of the classification; the lesser the overlap the greater the robustness. Second, it indicates the extent to which different domains at any given level interact and produce new technologies and technological content of the output.

On account of the first, our spectral classification is more robust than the IPC classification because it has significantly reduced the overlap. For instance, the overlap at the second level of spectral classification is significantly lower than the second level of IPC (3-digit classes) (Figure 4.4). On account of the second, the data indicates that there is greater cross fertilization among the domains of the same family than across different families (Figure 4.5).

\subsubsection{Identifying Technological Ecosystems}

Technologies are created and used by social actors in creating technologies as well as products. We refer to those actors who create and use interrelated technologies as technological ecosystem. In other words, those actors who create or use technologies related to a given technology domain constitute a technological ecosystem. Accordingly, technological knowledge bases of the actors linked with a given technology domain affect and affected by the domain. Therefore, changes in the structure and performance of technology domains can be understood better by identifying the actors associated with these and examining the changes in their technological bases.

The most important characteristic of a technological ecosystem is the diversity. This is because of the fact that diversity positively affects not only the quantity but also the quality (radicalness) of the inventive output in the ecosystem. The greater the diversity, the greater is the probability of new knowledge combinations, and vice versa (Schoenmakers \& Duysters, 2010; Datta \& Jessup, 2013). Technological diversity of an ecosystem is determined by the diversity 
among the knowledge bases of actors as well as within the knowledge bases of individual actors. The former is conventionally measured in terms of technological similarity among technological portfolios of actors while the latter is conventionally measured in terms of diversity within the technological portfolios of different actors.

FIGURE 4.4

\section{Average Overlap among IPC and Spectral Domains}

(a) IPC entities

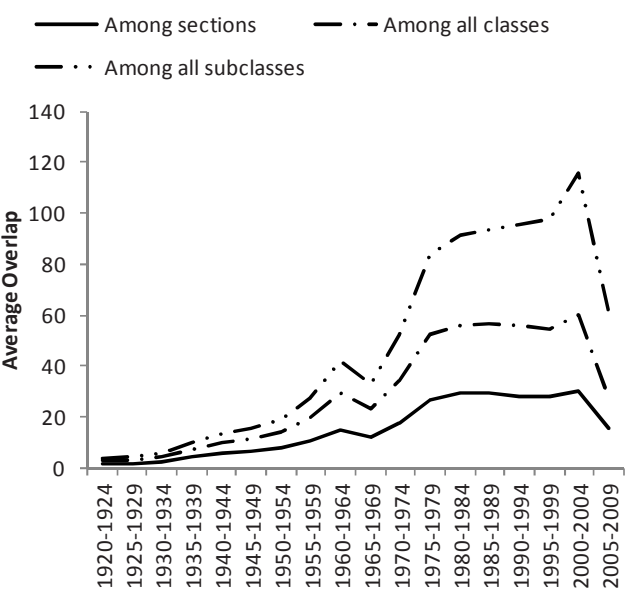

(b) Spectral clusters and sub-clusters

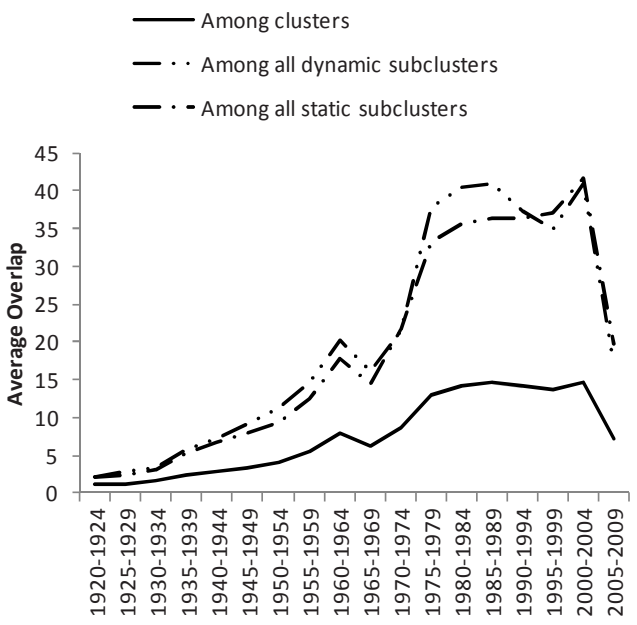


FIGURE 4.5

\section{Average overlap between and within clusters}

(a) Average overlap between domains
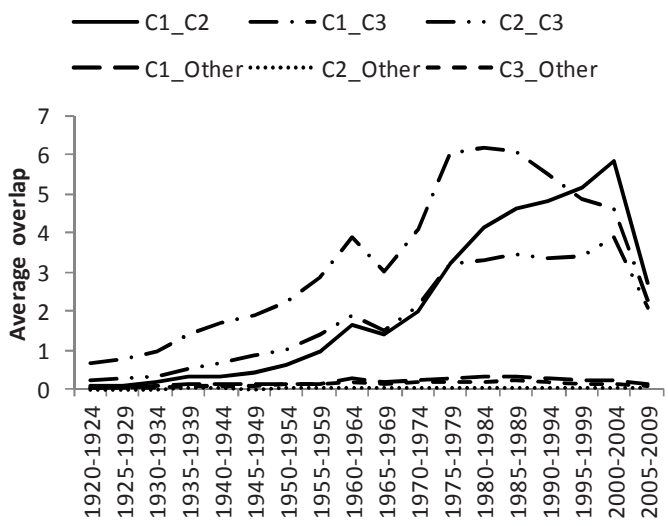

(b) Average overlap among sub-domains

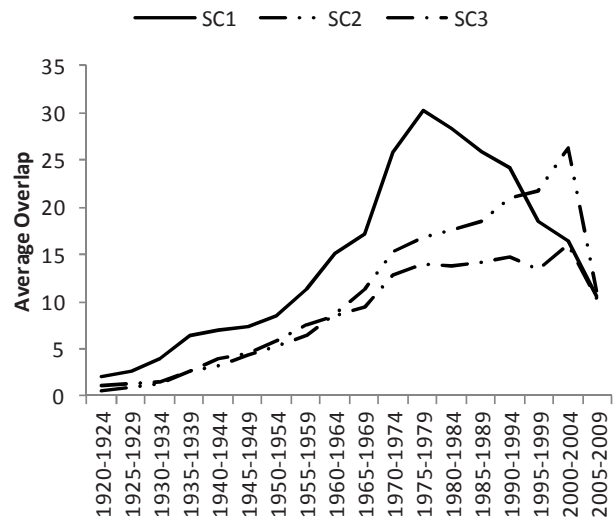

In order to ascertain technological ecosystems, we focused on large producers of inventions because inventive activity has been largely institutionalized during the 2oth century and the role of lone inventors has been gradually decreasing (Mowery \& Rosenberg, 1999; Mokyr, 2002, 2005; Singh \& Fleming, 2010; Conti, Gambardella, \& Mariani, 2013). Accordingly, we identified top 1000 applicants in terms of number of applications in each 5 -year period. ${ }^{22}$ Then we identified the

\footnotetext{
${ }^{22}$ It is worth mentioning here that we used extensive text analysis to standardize the names of assignees by removing typographical variations. However, during the final analysis it was found
} 
domains they belonged to by measuring the share of their patent portfolio in relation to each domain. An actor was considered as part of a technological ecosystem if the largest number of its patents belonged to a particular technology domain. ${ }^{23,24}$ The size of major ecosystems in terms of the number of actors (from among the top 1000) is shown in Figure 4.6.

Following the identification of technological ecosystems with respect to the major technology domains, we measured their technological diversity in terms of technological similarity among their members as well as diversity within the technological portfolios of individual members.

FIGURE 4.6

Size of Major Ecosystems

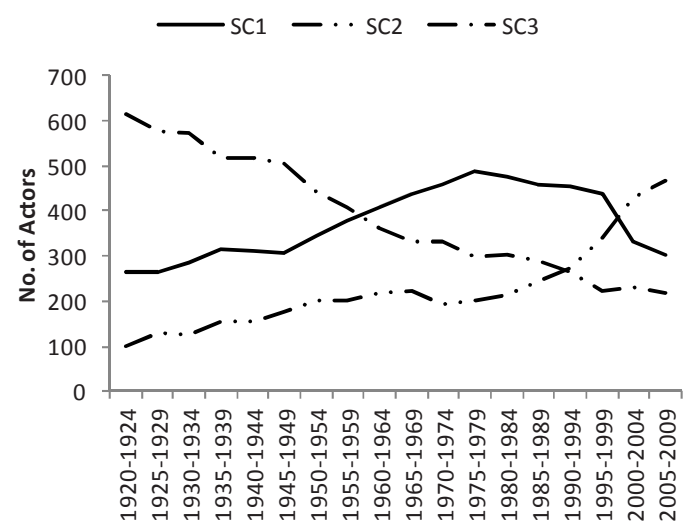

that some entities appeared separately due to variations in their names in the record. For instance, "DuPont" and "Du Pont" appeared separately despite the processing. However, we assume that such happenstances cannot be completely avoided and may be ignored.

${ }^{23}$ There are two possible ways to identify a technological ecosystem. One is to select the actors whose technological activity belongs mainly to a particular technology domain while the other is to identify a subset of all known actors on the basis of certain degree of similarity among their technological bases. We adopted the former because technology domain provides better demarcation among firms than an arbitrary threshold of technological similarity.

${ }^{24}$ There were few cases in certain periods where the actor(s) had equal number of patents in two domains. Such cases were dropped in order to minimize the noise caused by them. 


\subsubsection{Technological ecosystems and diversity of ac- tors}

In order to measure technological similarity among technological profiles of actors, we used the well-known index of cosine similarity (ICS) at various levels of the spectral classification (McNamee, 2013; Breschi, Lissoni, \& Malerba, 2003).

$$
\operatorname{ICS}_{(\mathrm{a}, \mathrm{b})}=\frac{\sum_{\mathrm{i}(1)}^{\mathrm{i}(\mathrm{n})}\left(\mathrm{f}_{\mathrm{ai}}\right)\left(\mathrm{f}_{\mathrm{bi}}\right)}{\sqrt{\sum_{\mathrm{i}(1)}^{\mathrm{i}(\mathrm{n})}\left(\mathrm{f}_{\mathrm{ai}}\right)^{2}} \sqrt{\sum_{\mathrm{i}(1)}^{\mathrm{i}(\mathrm{n})}\left(\mathrm{f}_{\mathrm{bi}}\right)^{2}}}
$$

where $\mathrm{f}_{\mathrm{ai}}$ is the total frequency of classification of inventions of a person $a$ in a subclass $i, \mathrm{f}_{\mathrm{bi}}$ is the total frequency of classification of inventions of a person $b$ in the subclass $i$, and $\mathrm{n}$ is the total number of subclasses.

Patent-based measures of similarity and diversity are often used at any one level of some hierarchical classification scheme (such as 3-digit IPC classes or 4-digit subclasses) assuming that all domains at the level are equally different from each other. It has been pointed out that this assumption is unrealistic and may produce inaccurate results (McNamee, 2013). In reality, entities belonging to the same parent are more related/similar than those descending from a different parents. This means that the similarity measure at any given level needs to account for similarities at higher level as well. Due to this reason, we chose to compute composite similarity using all levels of our spectral classification scheme above the chosen level.

Then, following the logic of varying significance of similarity/difference at various levels of classification hierarchy as argued earlier, a Composite Index of Cosine Similarity (CICS) can be computed by incorporating all levels above the level of interest as following:

$$
\operatorname{CICS}_{(a, b)}=\sqrt[k]{\operatorname{ICS}_{(a, b) 1}^{\frac{1}{k}} \cdot \operatorname{ICS}_{(a, b) 2}^{\frac{1}{k-1}} \cdot \operatorname{ICS}_{(a, b) 3}^{\frac{1}{k-2}} \ldots \operatorname{ICS}_{(a, b) k}^{\frac{1}{k-m}}}
$$

where ICS is the conventional index of cosine similarity between two firms $a$ and $b$ at a given level 1, 2, ...k and measured as a non-zero value between $0-1$, and $k$ represents the level of interest in the hierarchy and ranges from 1-n.

For instance, CICS for a classification involving three levels is computed as:

$$
\operatorname{CICS}_{(a, b)}=\sqrt[k]{\operatorname{ICS}_{(a, b) 1}^{\frac{1}{3}} \cdot \operatorname{ICS}_{(a, b) 2}^{\frac{1}{2}} \cdot \operatorname{ICS}_{(a, b) 3}}
$$

The pattern of change in technological diversity among members of different ecosystems over time is presented in Figure 4.7(a). 


\section{FIGURE $4 \cdot 7$}

Average Technological Diversity of Ecosystems And Actors

(a) Technological diversity of ecosystems

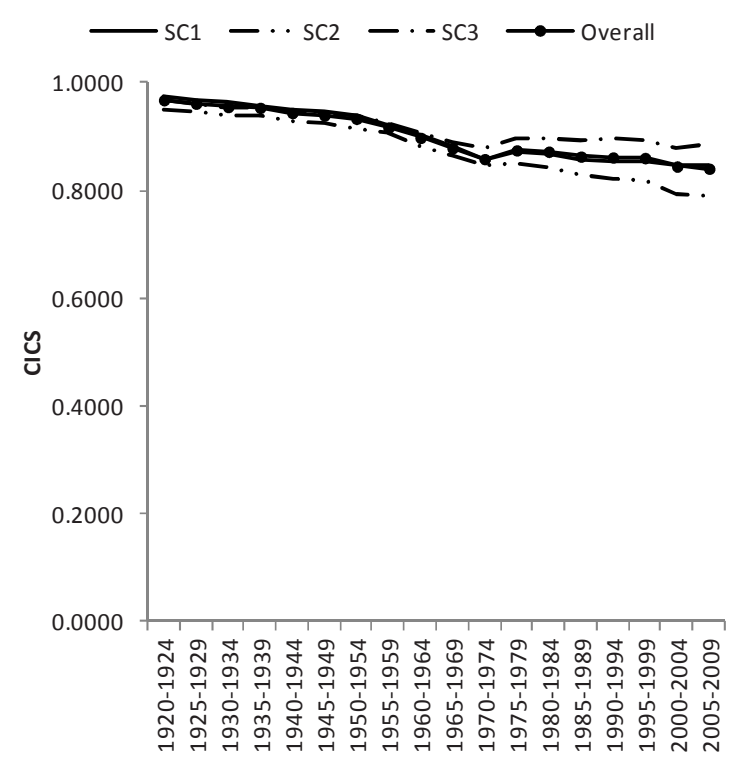

(b) Technological diversification of actors

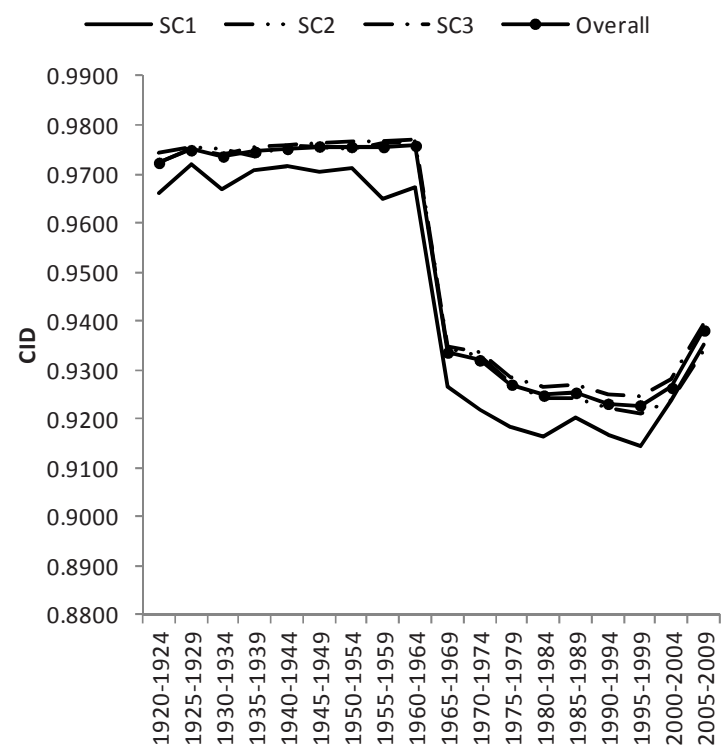




\subsubsection{Technological ecosystems and technological di- versification of actors}

Technological ecosystems overlap because actors operate in multiple technology and product domains (e.g., Granstrand, Patel \& Pavitt, 1997; Brusoni, Prencipe \& Pavitt, 2001). Therefore, diversification plays a key role in creation and diffusion of technologies. Here we limit the discussion to the role of technological diversification only.

Technological diversification is conventionally measured using Herfindahl-Hirschman Index (HHI) (e.g., Gambardella \& Torrisi, 1998; QuintanaGarcía, \& Benavides-Velasco, 2008). This index is not only simple but also has an important advantage that it measures the diversification of a given actor independently of other actors. Since HHI is a measure of concentration, it is used to compute Herfindahl Index of Diversification (HID) as:

$$
\mathrm{HID}=1-\mathrm{HHI}=1-\frac{\sum P_{\mathrm{i}}^{2}}{\mathrm{n}}
$$

where $\mathrm{P}_{\mathrm{i}}^{2}$ is the proportion of a firm's inventions in a technology field/domain $i$ and $n$ is the total number of technology fields in the reference group.

This index is conventionally used at any one level of a patent classification scheme (usually 3-digit IPC classes or 4-digit subclasses). We have already noted in section 4.3.1. the limitations of using a single level as the reference of measurement. Therefore, we devised a multi-level Composite Index of Diversification (CID) to compute diversification as following:

$$
\mathrm{CID}=\sqrt[k]{\operatorname{HID}_{\mathrm{k}}^{\frac{1}{\mathrm{k}}} \cdot \operatorname{HID}_{\mathrm{k}-1}^{\frac{1}{\mathrm{k}-1}} \cdot \operatorname{HID}_{\mathrm{k}-2}^{\frac{1}{\mathrm{k}-2}} \ldots \operatorname{HID}_{\mathrm{k}-\mathrm{m}}^{\frac{1}{\mathrm{k}-\mathrm{m}}}}
$$

where HID is a non-zero value between o-1 indicating diversification at a given level in the classification hierarchy, and $k$ represents the level of interest in the hierarchy between a range of 1 and $m$.

For instance, diversification of a firm $i$ at third level of a given classification scheme is computed as following:

$$
\mathrm{CID}=\sqrt[3]{\operatorname{HID}_{3}^{\frac{1}{3}} \cdot \operatorname{HID}_{2}^{\frac{1}{2}} \cdot \mathrm{HID}_{1}}
$$

Using HID and CID, we computed technological diversification of each actor in the sample of top 1000 actors in each 5 -year period. The average technological diversification of actors in each ecosystem is presented in Figure 4.7(b).

\subsubsection{Technological ecosystems and product domains}

Actors create technologies and products using existing technologies in order to solve some problem facing the society at a particular point in time (Rosenberg, 1969; Christensen \& Rosenbloom, 1995). This implies that creation of technologies and products involves diffusion of existing technologies as discussed in section 3.1. 
Creation of a new technology may give birth to a radically new product/industry and/or may affect many existing products/industries. The focal technology and industry may further branch out and create new technologies and industries which, in turn, may lead to creation of new technologies and industries and reformation of existing ones (Dosi, 1982; Levinthal, 1998). Thus, changes in the technology space eventually manifest in the product space, though with varying time lag. From a macro perspective, this also means that extant technologies and products form a complex and evolving network. In this context, a question arises: where the effects of changes in a technology domain are likely to manifest? It is, indeed, a complex question which has three major facets. First, technological linkages of the new technologies with other technologies in the technology space. Second, technological linkages of the actors, who effectuated the technological changes, with technology space on the one hand and with the product space, on the other. Third, technological linkages of the relevant technology domain with product domains. The first facet concerns the structure of technology domains, the second is related to the structure of technological ecosystems, and third is connected with the structure of the product space in terms of technological knowledge underlying extant products.

Technology being the essential content of every product, all extant products can possibly be grouped on the basis of their technological content. Moreover, given the fact that a technology may be used in different kinds of products, or product domains, it is reasonable to expect that different product domains have strong technological linkages (Rosenberg, 1963, 1979). In order to determine the technological structure of the product space, we linked the concordances among the classification schemes of United States Patent Classification System (USPCS 2008), North American Industrial Classification System (NAICS 2002), and IPC. From these matrices, we extracted significant positive linkages among the pairs of technology domains and product domains. Technological linkages among major technology domains and product domains are presented in Figure 4.8 and described in Table 4.1.

\subsubsection{Robustness}

In order to ascertain the robustness of the clustering method and the measures based on these, we computed 1000 random matrices for each of the 18 periods using the maximum and minimum number of inventions in the sample of the 1000 largest contributors in each period. From these matrices, we computed the correlation between the vectors of total inventive output and HHI. It was found that $100 \%$ of these correlation coefficients were larger than actual coefficients for 15 periods whereas this ratio was $99.5 \%, 99.9 \%$, and $99.5 \%$ for the first, second, and last periods, respectively. We also applied this method to the correlation coefficients of HIDs and found that $100 \%$ of the coefficients of random HIDs were 
smaller than the actual coefficients in 16 periods whereas this ratio was $99.4 \%$ and 99.8\% for the first and the last period, respectively. These results suggest that observed HIDs are non-random and so are the CIDs based on these.

TABLE 4.1

Description of Major Clusters in Terms of Product Domains

\begin{tabular}{|c|c|c|c|}
\hline Cluster & Description & Major Technology Areas & NAICS Product Fields \\
\hline $\mathrm{SC}_{1}$ & $\begin{array}{l}\text { Chemical engineer- } \\
\text { ing, metallurgy, } \\
\text { textiles and paper }\end{array}$ & $\begin{array}{l}\text { Chemical engineering, } \\
\text { textiles, and metallurgy as } \\
\text { well as paper and food } \\
\text { processing }\end{array}$ & $\begin{array}{l}\text { Machinery, chemical prod- } \\
\text { ucts, plastic and rubber } \\
\text { products, basic chemicals, } \\
\text { fabricated metal products, } \\
\text { nonmetallic mineral prod- } \\
\text { ucts; electrical equipment, } \\
\text { appliances and components; } \\
\text { instruments, textiles and } \\
\text { leather, etc. }\end{array}$ \\
\hline $\mathrm{SC}_{2}$ & $\begin{array}{l}\text { Electronics, compu- } \\
\text { ting, and communi- } \\
\text { cations }\end{array}$ & $\begin{array}{l}\text { This cluster largely belongs } \\
\text { to the cohort of technolo- } \\
\text { gies that are recognized by } \\
\text { OECD (2008) as ICTs }\end{array}$ & $\begin{array}{l}\text { Navigational and control } \\
\text { instruments, semiconductors } \\
\text { and other electronic compo- } \\
\text { nents; electrical equipment, } \\
\text { appliances and components; } \\
\text { computer and peripheral } \\
\text { equipment, machinery, } \\
\text { communications equipment, } \\
\text { and other computer and } \\
\text { electronic products etc. }\end{array}$ \\
\hline $\mathrm{SC}_{3}$ & $\begin{array}{l}\text { Mechanical-, ther- } \\
\text { mal-, and aerospace } \\
\text { engineering and } \\
\text { weapons }\end{array}$ & $\begin{array}{l}\text { Mechanical engineering, } \\
\text { thermal engineering, land } \\
\text { and air transport systems, } \\
\text { and machine tools }\end{array}$ & $\begin{array}{l}\text { Machinery, fabricated metal } \\
\text { products; electrical equip- } \\
\text { ment, appliances and com- } \\
\text { ponents; navigational and } \\
\text { control instruments, plastics } \\
\text { and rubber products, aero- } \\
\text { space products and parts, and } \\
\text { other transportation equip- } \\
\text { ment, etc. }\end{array}$ \\
\hline
\end{tabular}




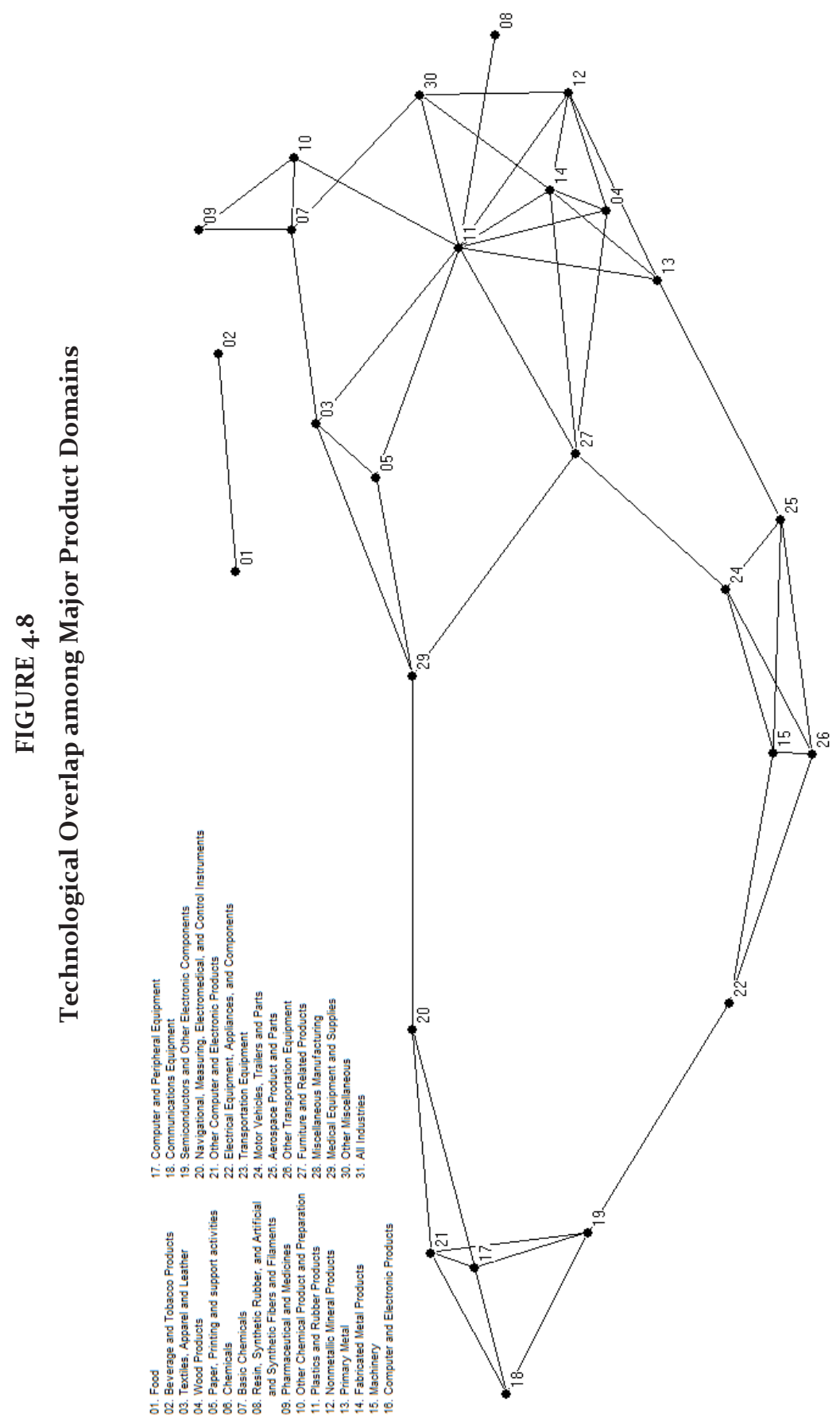




\subsection{ANALYSIS}

\subsubsection{Growth of Technological Knowledge and Structural Change}

Applications for patenting of inventions remained less than 1000 per year till 1911, crossed the mark of 5000 in 1915, and approached 50000 in 1926 (Figure 4.2). Between 1926 and 1950, number of applications per year fluctuated around the mean of about 4200o. Starting 1951, the growth picked up and yearly output reached the peak at a little above 122000 mark in 1969 before it started to decline in 1970. It remained around the average of 76500 per year between 1971 and 1980. Starting from 1981, it began to increase at an accelerated pace and reached the peak of about 396000 in 2004. It started to decline in 2005 and fell down to about 82000 by the end of 2009 .

The pattern of changes in the quantity of inventive output may be of interest from several perspectives. However, what may be more interesting is the qualitative changes in the nature and amount of technological knowledge that manifested in these inventions and how it influenced the performance and structure of techno-economic system. It is, perhaps, an obvious but a potentially interesting question whether the consistent increase in inventive output during 1950 s and 6os, its decrease during 1970s, resurgence and accelerated growth during 1980 s and 9os, and beginning of decline at the dawn of 21st century mean that inventive activity is cyclical? If so, is the increase and decrease uniform across all technology- and product domains? How it is linked to economic performance of techno-economic system? These are certainly well known questions in Schumpeterian tradition and are still open.

In this connection, it is well known that the decline in inventive (and economic) output during 1970s was lamented. However, it is possible that this situation arose due to some kind of structural change in the techno-economic system that paved the way for growth in the following two decades. If this was the case, then the slowdown and decline in inventive and economic output at the beginning of the 21st century might be the sign of beginning of another round of structural change in the system. Exploration of these qualitative changes in the techno-economic system is the focus of our analysis.

\subsubsection{Structural Change in Technology Domains}

Data suggest that mechanical engineering and related technologies were major focus of inventive activity during the first quarter of the zoth century, particularly during 1920 s (Figures 4.3 and 4.A1). The automobiles-related inventions (SC3_1) appear to be among the most popular area during this period. Although mechanical engineering-related inventions $\left(\mathrm{SC}_{3}\right)$ continued to contribute major share in 
inventive output till 196os, relative share of this domain, particularly that of automobile engineering, started to decline in 1930 .

In the meantime, domain of chemical engineering and related fields $\left(\mathrm{SC}_{1}\right)$ also started to emerge as important contributor to inventive output. Within this domain, two sub-domains were particularly noticeable: organic chemistry and chemical engineering $\left(\mathrm{SC}_{1} \_2\right)$ on the one hand and materials engineering and metallurgy ( $\left.\mathrm{SC}_{1} \_3\right)$, on the other. The former grew more rapidly than the latter and overtook the domain of automobile engineering ( $\mathrm{SC}_{3}{ }_{1}$ ) during 1940s. The pace of technological developments in these two sub-domains gained momentum, particularly during 1950s, and consequently, chemical engineering-related domain (SC1) became major contributor to inventive activity and output. The stagnation of mechanical engineering-related domain $\left(\mathrm{SC}_{3}\right)$ and growth of chemical engineering-related domain $\left(\mathrm{SC}_{1}\right)$ suggest that the locus of inventive activity migrated from the former to the latter during 1950 .

In parallel, significant technological developments had also started during 1920 in the domain of communications, computing, and electronics (SC2), though it had a relatively low share in total inventive output. The leading subdomain in this area was related to detection, diagnosis, and measurement of various physical and electrical phenomena (SC2_4). Following this were two other sub-domains, wireless communication $\left(\mathrm{SC}_{2}{ }_{3}\right)$ and telecommunications and computing (SC2_2). Growth in $\mathrm{SC}_{2} \_4$ and $\mathrm{SC}_{2} \_3$ gained momentum during $1950 \mathrm{OS}$ and 6os while SC2_2 lagged behind till it began to catch up during 1980s. Overall, the domain SC2 started to grow faster than other domains during 1980s, and consequently, the locus migrated from $\mathrm{SC}_{1}$ to $\mathrm{SC}_{2}$ during this period.

The pattern in data suggests that inventive activity at any given time may be distributed among multiple technology domains and their sub-domains. However, those technology domains and sub-domains grow faster which present greater opportunities and expected returns, thus attracting greater resources. As the opportunities begin to diminish or returns begin to level off, resource flows are diverted from the maturing domains to emerging domains that have gained legitimacy and present greater opportunities and returns. The self-reinforcing effects of resource migration begin to appear as the dominant domains face increasing stagnation and emerging domains begin to progress faster. While the maturing domains continue to supply knowledge, the locus of inventive activity and output systematically migrates to the emergent domain, as it happened during 1950 s and then in 1980s. However, it seems that the duration of transition from the domain to the emergent domain as a successor has decreased over time.

It is also apparent that the dominant technology domain of the time also affects and affected by other technology domains by exchanging technological knowledge. The emergent/catching up domains tend to exchange technological knowledge with the leading domain of the time which contributes to an increase 
in the legitimacy, resource attraction, and technological opportunities of the former while sustaining the leadership of the latter for some time. For instance, mechanical engineering-related domain $\left(\mathrm{SC}_{3}\right)$ was dominant during the first half of 2oth century followed by chemical engineering-related domain ( $\left.\mathrm{SC}_{1}\right)$. Consequently, there was greater interaction and overlap among these two domains which continued till 1980s despite the fact the former started to lag behind in growth in 1950 s (Figure 4.5(a)). Similarly, telecommunications-related domain (SC2) was in its infancy during the first half of zoth century and exchanged knowledge with $\mathrm{SC}_{3}$. Growth of SC2 during 1970 s and onwards also indicates reciprocal influence between the leading and catching-up domains.

The results also corroborate extant theory that inventive activity sustains itself largely by recombining knowledge from related technology domains. This means that inventive activity at any given level of hierarchy of domains tends to be sustained by knowledge combinations across the sub-domains that descend from the same parent domain (Figure 4.5(b)). For instance, the growth of $\mathrm{SC}_{1}$ started to accelerate in 1950 s and reached the maximum in mid-1970s when it started to lag behind telecommunications-related domain ( $\left.\mathrm{SC}_{2}\right)$ in terms of growth (Figure 4.3). A large part of this growth of SC1 was due to the utilization of knowledge across its sub-domains (Figure 4.5(b)) than across other domains (Figure 4.5(a)). Perhaps the growth of SC1 stagnated during 1970s because the technological opportunities had diminished within the domain or their attractiveness relative to the catching-up domain ( $\left.\mathrm{SC}_{2}\right)$ had diminished as indicated by subsequent decline in knowledge combinations across its sub-domains.

\subsubsection{Structural Change in Technological Ecosystems}

Data suggest that technological ecosystems also change in size in terms of number of participating actors (Figure 4.6). Size is likely to be an important determinant of changes in growth prospects of an ecosystem because it indicates not only the perceived availability and attractiveness of technological opportunities linked to it but also the amount of resources attracted by the ecosystem. Accordingly, an ecosystem attracts greater number of participants when it offers greater technological opportunities and returns, and vice versa. Therefore, resources tend to migrate from the ecosystems when opportunities and returns associated with it begin to stagnate to those ecosystems which offer better opportunities and returns.

The stagnation of dominant technology domain, $\mathrm{SC}_{3}$, during the first half of 2 oth century seems to be linked to a persistently declining number of actors associated with it (Figures 4.3, 4.6). On the other hand, the growth of other two domains, $\mathrm{SC}_{1}$ and $\mathrm{SC}_{2}$, corresponds with the increase in the number of actors. Rapid increase in the size of ecosystem corresponding to $\mathrm{SC}_{1}$ after mid-1940 corresponds with accelerated increase in inventive output in that technology domain. 
However, number of actors active in SC1 began to decrease during 1980 s while this number began to increase in the emergent domain $\mathrm{SC}_{2}$ which corresponds with the stagnation of the former and accelerated growth in the latter.

The ecosystems remained fairly diverse in terms of technological profiles of actors, though this diversity has been decreasing over time (Figure 4.7(a)). This suggests that actors have been drawing knowledge from diverse sets of technology domains and sub-domains. On the other hand, average diversity within the technological profiles of individual actors showed a cyclical pattern (Figure 4.7(b)). The extent to which actors in a technological ecosystem tend to specialize or diversify their knowledge base provides important clues about the quantity and quality of inventive output in corresponding technology domains. For instance, it is well known that actors tend to exploit their technological resources in their existing domains of activity. When technological opportunities within existing domains begin to diminish, they tend to explore in relatively distant domains. This tendency translates into technological specialization during exploitation and diversification during exploration. Accordingly, exploitation and specialization result in greater but incremental inventive output. On the other hand, exploration and diversification tend to be accompanied by lower but more radical inventive output. These tendencies are apparent in our data.

For example, as the ecosystem corresponding to $\mathrm{SC}_{3}$ began to stagnate and decline during 1920 (Figures 4.3, 4.6), actors increasingly diversified their technological knowledge base (Figure $4.7(\mathrm{~b})$ ), largely in connection with the emerging domain $\mathrm{SC}_{1}$ (Figure 4.5(a)). On the other hand, technological ecosystem corresponding to $\mathrm{SC}_{1}$ grew by bouts of specialization and diversification during 1930 and 40s. As the specialization in SC1 began to increase during 1950s, its inventive output began to increase at an accelerated rate. As the returns of specialization in this ecosystem began to stagnate during 1980s, actors started diversifying their technological bases mainly in connection with $\mathrm{SC}_{2}$ which had started to emerge as the new leader. The revival of $\mathrm{SC}_{1}$ in 1990 is due, perhaps, to the tendency of technological diversification of actors in its corresponding ecosystem. Similarly, growth of SC2 was sustained by the bouts of specialization and diversification of actors in its corresponding ecosystem till 1960s. As the actors in this ecosystem began to specialize in 1970s, the inventive output began to increase in the domain that picked up pace during 1980s due to the participation of increasingly specialized set of actors. However, this also means that a large part of this inventive output is likely to be incremental. This trend has continued till the dawn of the $21^{\text {st }}$ century.

Overall, it appears that the era of specialization started in 1970 which sustained the growth during 1980 s and 9os. However, increasing technological diversification in all ecosystems since the beginning of the 21st century might be an indication that technological opportunities have dried up within existing tech- 
nology domains. The tendency of increasing technological diversification also suggests that new configurations are likely to take place in the technology domains, technological ecosystems, and product domains.

\subsubsection{Structural Change in Product Domains}

In the absence of relevant data, it is difficult to demonstrate here how the technological changes noted above may have affected the product domains. Indeed, industrial organization economics informs that inventive activity and technological change not only give birth to new industries but also affects existing industries (e.g., Klepper \& Simons, 1997, 2005). While these insights stimulate reasonable temptation to speculate about the effects of changes in technology domains on product domains, the complexities of the level of analysis dealt here prohibit doing so. Instead, a few questions may illuminate better what is involved in such an expedition.

Keeping in view the lag between invention and innovation, our data suggest that the technology domain $\mathrm{SC}_{3}$ (mechanical engineering etc.) stagnated in terms of inventive output during 1930 and 40 (Figure 4.3). Does this mean that the industries in the product domains associated with $\mathrm{SC}_{3}$ (Table 4.1) were maturing during this period? Does this indicate that the inventions related to this domain were mainly sustaining existing industries rather than stimulating the creation of new ones? On the other hand, inventive output related to $\mathrm{SC}_{1}$ (chemical engineering etc.) began to increase during 1940 and 50 . Does this mean that $\mathrm{SC}_{1}$ offered more attractive opportunities than $\mathrm{SC}_{3}$ and resources migrated from the former to the latter? Does this indicate that technological developments in this domain helped create new industries in the product domains connected to it? Similarly, is the accelerated increase in inventive output in the technology domain SC2 (ICTs) during 1980s and 9os due largely to the creation of new industries or expansion of existing industries? These questions are important and need to be addressed if the link between technological change and structural change in the techno-economic system is to be understood and harnessed.

However, any consideration of such questions must take into account the fact that technological developments in one domain may affect multiple domains (Figure 4.8). For instance, technological developments in relation to semiconductors and other electronic components may stimulate innovations in computers, communications equipment, appliances, and electrical equipment, to mention a few. Similarly, inventions related to basic chemicals may stimulate innovations in textiles and leather on the one hand and pharmaceuticals and medicines, on the other. 


\subsection{DISCUSSION}

\subsubsection{Summary}

Technological change is an important phenomenon because it is the source of new technologies as well as new products. The latter implies the creation of new industries which also affect existing industries, thus bringing about certain level of structural change in concerned industries as well as in the techno-economic system as a whole. Transformative technological change is a special kind of technological change which causes structural change of great magnitude and scope in the techno-economic system.

Technological changes occur due to the creation of new technologies that happens through the recombination of existing technological knowledge. Therefore, every technological change has direct and indirect linkages with numerous other technologies and the effects of the change are likely to be transmitted to all those technologies and products in which these interrelated technologies are used. Accordingly, transformative technological change involves the emergence of clusters of new technologies in close temporal proximity which bring about significant structural changes in the techno-economic system.

Conventionally, the research regarding technological change not only uses the product space as the frame of reference but also uses various kinds of technological, functional, and geographical boundaries to delimit the scope of inquiry. This approach may be useful for depicting the technological change and corresponding structural change ex post, but it is unlikely to be helpful in predicting the direction and magnitude of technological or structural change ex ante due to the fact that technological change occurs in the technology space well before it manifests in the product space. Moreover, a single technological change may stimulate changes in numerous technologies and products.

In this essay, we proposed that technological change needs to be identified and measured at source, that is, in the technology space rather than the product space where it ultimately manifests. To this end, a conceptual framework was proposed and illustrated using the US patent data for the $20^{\text {th }}$ century. It was found that mechanical engineering and related technologies were major focus of inventive activity during the first quarter of the 2oth century, particularly during 1920s. The stagnation in inventive activity in mechanical engineering-related domain and growth of chemical engineering-related domain during 1950s suggest that the locus of inventive activity migrated from the former to the latter during this period. The locus of inventive activity migrated again during 1980 s from the chemical engineering-related domain to the domain of communications, computing, and electronics. It can be reasonably expected that these structural changes in the technology space, which we refer to as TTC, must have brought about corresponding structural changes in the product space. 
Thus the proposed shift from the product space to technology space as the 'place' for inquiry and measurement of structural changes in the former via structural changes in the latter may not only help depict the macro-level technological changes but also predict such changes. Accordingly, the proposed shift may have far-reaching implications for management of technology and innovation from the perspective of public policy as well as business strategy.

\subsubsection{Implications}

Creative destruction is a challenging phenomenon from the perspective of public policy as well as business strategy. It is a paradoxical phenomenon because its creative part is desirable and its destructive part is inevitable. The destructive part of the phenomenon is more harmful when structural changes in the technoecosystem linger on for longer periods. Therefore, the best policy to manage creative destruction would be to provide necessary lubrication for swifter and smoother transition from the existing state to the new state. This is possible with the help of right framework conditions as well as timely intelligence to the actors so that uncertainty is reduced. The framework conditions have already received ample attention but it is the provision of intelligence that may be more effective for stimulating the creative part and managing the destructive part. Since the source of transformative changes in the techno-economic system is the structural change in the technology space, accurate and timely intelligence about changes in the latter is a vital input for managing the former. Therefore, provision of such intelligence needs to be incorporated in the agenda of public policy, more so because policymakers need such intelligence more than anyone else.

As regards business strategy, firms continuously need to meet twin objectives of survival and growth in competitive environments. The ability of firms to meet these objectives depends upon their capability to innovate in order to deliver competitive offerings in their existing product-markets and to create new productmarkets. The resource-based perspective of strategic management suggests that firms accomplish this through their resource- and capability base whereby knowledge is the key element of this base (Grant, 1996a, 1996b). Since maintaining requisite variety in their technological knowledge base is necessary for innovation, the key challenge is to determine the nature and composition of this variety. It is well known that existing knowledge base of the firm is the major determinant of the choice of new knowledge because it determines the costs of acquiring, absorbing, and integrating new knowledge with existing knowledge of the firm (Cohen \& Levinthal, 1990). Accordingly, it is often suggested that the existing knowledge base of firms should be extended by acquiring "related" knowledge (cf. Miller, 2006; Makri, Hitt, \& Lane, 2010). However, it is difficult to determine what technological knowledge should be considered "related". 
Technological ecosystem perspective proposed in this paper extends this perspective and helps with this conceptual problem of "relatedness". It helps identify the actors who are technologically linked to the same technology domain regardless of the product domains they operate in and the way they use that knowledge. Once all the actors in the focal actor's ecosystem are known, it becomes easier to identify the portfolio of their technologies, the underlying knowledge base, and various uses of the technology. From this information, it becomes easier to identify which other technologies are used elsewhere in combination with the technologies that are part of the technology portfolio of the focal actor. Accordingly, the focal actor may choose from among those technology areas according to their fit with existing technological base and technology strategy of the focal firm.

Moreover, technological ecosystem perspective opens up new technological opportunities for the focal actor. Keeping abreast of different uses and corresponding advancements of a particular technology may provide the opportunities for innovation for the existing product-markets, help identify new productmarkets where the technology is relevant, and create entirely new productmarkets by collaborating with or acquiring relevant members of the ecosystem. Therefore, unlike the industry-centric paradigm of strategizing that tends to trap the firms into a Red Queen race of incremental innovation (cf. Derfus et al., 2008), the perspective of technological ecosystems provides a much broader portfolio of strategic choices and allows simultaneous pursuit of exploitation and exploration (cf. March, 1991; Frankort, Hagedoorn, \& Letterie, 2012).

\subsubsection{Limitations}

Patents are the best available record of inventions and inventive activity, and hence, frequently used to measure inventive output and technological developments. We observed due caution against the known problems associated with the use of patents (e.g., Benner \& Waldfogel, 2008). Nevertheless, the empirical results of this paper need to be interpreted with due consideration to certain limitations arising out of our assumptions as well as the treatment of data. First of all, it is well known that all inventions are not patented, all patents are not equally important, and all important inventions in the world are not necessarily patented in the US. Second, changes in regulations and policies may have affected the rate of patenting in general and that of non-US applicants in particular. Third, we used IPC subclasses to identify the clusters of inventions. Accordingly, our clusters may have inherited some of the overlap from the hierarchy of IPC system. Fourth, concordances are imperfect representations of correspondence between patent classification and industrial classification. Fifth, the identity of firms may change over time due to change in company name, mergers and acquisitions etc. We did not account for such variations and used the name of assignee as unique identifier. 
Finally, it is well established that science and technology co-evolve and technological knowledge is disseminated not merely through patents but also through other means. Therefore, patents provide only a limited view of changes in the technology space.

\subsubsection{Future Directions}

The perspective presented in this paper may be explored further from macro as well as micro perspectives. From the macro perspective, two important avenues seem worth exploring. First concerns the correspondence between changes in technology domains and corresponding product domains. It is expected that there is a time lag between evolution of technology domains and corresponding product domains but it may be interesting to see the nature of correspondence between the rate and direction of changes in both kind of domains. Second, this perspective suggests the possibility of linkage between technological change and long waves (cf. Rosenberg \& Frischtak, 1984; Kleinknecht, 1990; Ayres, 1990a, 199ob; Geroski \& Walters, 1995; Korotayev, Zinkina, \& Bogevolnov, 2011). For instance, when growth of major product domains in the techno-economic system begins to stagnate due to the exhaustion of technological opportunities in corresponding technology domains, it may negatively affect investment, employment, and output. In order for new product domains to emerge as the engines of growth, there need to be relevant technological developments. This may entail significant resource reallocation among technology domains as well as product domains and the process continues till the time new domains gain critical mass and their growth begins to gain momentum. Since this transformative process is likely to affect broad swaths of industries, it may give rise to a pattern of cyclical movements in investment, employment, and output in the techno-economic system.

From the microeconomic and strategic management standpoint, the broad questions arising out of this perspective concern how actors sense and respond to structural changes in technology space. For instance, what kind of actors play more important role in different phases of evolution of a technology domain and its corresponding ecosystems (cf. Carroll, Bigelow, Seidel \& Tsai, 1996; Bergek \& Onufrey, 2014; Bergek et al., 2013), what role does existing knowledge base of actors play in this regard (cf. Makri, Hitt, \& Lane, 2010; Sears \& Hoetker, 2014; Colombelli, Krafft, \& Quatraro, 2014), how actors decide when to switch between exploitation and exploration or create a balance between the two (cf. Mudambi \& Swift, 2014; Stettner \& Lavie, 2014), and how does their technological diversification affect their ability to sense and respond?

Finally, from the perspective of policy and governance, the most important but perhaps the most difficult avenue is the nature, design, development, and implementation of the global intelligence system that can provide accurate and timely information about the changes in technology space. At the very least, 
this requires a patent system designed for the purpose, technology-based product classification system, classification and indexing of scientific output, and correspondence among these classification systems. Such a system is expected to boost inventive activity through greater utilization of knowledge and increased collaboration which are necessary conditions for invention and innovation. Above all, this system will help learn about and solve the complex and big world problems, including the TTC. 


\section{APPENDIX 4.A: SUPPLEMENTARY MATERIAL}

\section{Identifying Technology Domains}

Link clustering. Hierarchical Link Clustering method identifies communities of links rather than nodes, thus allowing nodes to be part of multiple communities with 3 or more members. We found no link communities for matrices before 1915. From the incidence matrices of subclasses-communities for remaining periods between 1915-2009, we extracted binary correlation matrices whereby those pairs of subclasses that were significantly positively correlated $(p<0.01)$ were treated as related (1), otherwise unrelated (o).

Spectral clustering. In order to obtain clusters of technologically related inventions, we prepared a symmetric partitioned matrix using the binary correlation matrices of individual periods as blocks/submatrices. These blocks were arranged in chronological order starting from the ninth period. This inverted-Lshaped arrangement of blocks set the horizontal and vertical dimensions of the square partitioned matrix in which remaining blocks were set to zero. Thus the resulting partitioned matrix was a symmetric matrix as following:

\begin{tabular}{|l|l|l|l|}
\hline $\mathrm{B}_{1}$ & $\mathrm{~B}_{2}$ & $\mathrm{~B}_{3}$ & $\mathrm{~B}_{4}$ \\
\hline $\mathrm{B}_{2}$ & $\mathrm{o}$ & $\mathrm{o}$ & $\mathrm{o}$ \\
\hline $\mathrm{B}_{3}$ & $\mathrm{o}$ & $\mathrm{o}$ & $\mathrm{o}$ \\
\hline $\mathrm{B}_{4}$ & $\mathrm{o}$ & $\mathrm{o}$ & $\mathrm{o}$ \\
\hline
\end{tabular}

From this partitioned matrix we extracted non-overlapping clusters using the spectral clustering method of Newman (2006) because it automatically determines the optimal number of clusters on the basis of modularity in data points (Rubinov \& Sporns, 2010). This method produced two types of clusters of subclasses: first, static clusters of the vectors of first block which contained complete linkage profile of subclasses in all periods, and second, dynamic clusters for each period on the basis of the vectors of each block corresponding to a given period. Due to our interest in longitudinal analysis, we focused on static clusters because they provided a stable frame of reference for all periods.

Out of a total of 10 static clusters (Table 4.A1), three spectral clusters (SC) - $\mathrm{SC}_{1}, \mathrm{SC}_{2}$, and $\mathrm{SC}_{3}$-accounted for more than $99 \%$ of inventions in the whole study period. Since other clusters were very small and mainly represented technologies related to "low-tech" sectors (OECD, 2011), we treated them as one cluster, henceforth referred as "Other".

These four clusters represent the highest level of dendrogram of spectral classification hierarchy and are equivalent to 1-digit IPC sections. Subsequently, we applied the same spectral clustering procedure on each of the three major static clusters. As a result, we obtained 6 static sub-clusters from $\mathrm{SC}_{1}, 6$ from $\mathrm{SC}_{2}$, 
and 25 from $\mathrm{SC}_{3}$ (Table 4.A2). These sub-clusters represent the second level of the dendrogram equivalent to 3 -digit IPC classes.

Describing spectral clusters and sub-clusters. In order to determine what kind of technologies these clusters and sub-clusters represented, we identified the largest sub-clusters from each spectral cluster $\mathrm{SC}_{1}, \mathrm{SC}_{2}$, and $\mathrm{SC}_{3}$. The chosen sub-clusters accounted for about $91.4 \%$ of all inventions during the whole study period. From the chosen sub-clusters, we identified the most central subclasses in terms of degree centrality to represent each sub-cluster. We extracted the text of titles of all inventions from these subclasses.

Further, we assumed that the core of each cluster and sub-cluster remains fairly stable for a period of 20 years as it is not only the official life of a patent (TRIPs Agreement, Article 33) but also the estimated life of a zeitgeist (Simonton, 2003). Therefore, we divided the text data into four 20-year periods and performed co-word analysis (Callon, Courtial, \& Laville, 1991) of these titles using Rapidminer $^{\circledast}$. On the basis of co-word analysis, major clusters and sub-clusters were described.

Overlap among technology domains. In order to measure technological overlap among technology domains, we constructed the overlap matrices for various levels of IPC hierarchy as well as the spectral clusters whereby the main diagonal represents the total number of inventions in each domain during each period and the off-diagonal elements represent the overlap between each pair of the domains. In order to attain a comparable statistic for matrices across different periods and levels, we measured average overlap at each level as the ratio of total overlap among all pairs of domains over total number of inventions during the period.

The results suggest that a large part of overlap in IPC classification is due to the design of its classification hierarchy. For instance, average overlap measured as geometric mean for all 18 periods at first level of IPC (Sections) was about $10.5 \%$ whereas the same is about $6 \%$ in spectral classification. At the second level, it was $19.4 \%$ in IPC compared to $13.2 \%$ in spectral scheme.

Technological overlap among product domains. From the official concordance between North American Industrial Classification System (NAICS 2002) and the United States Patent Classification System (USPCS 2008), we computed the matrix of similarity among product fields whereby those product domains that were significantly positively correlated $(p<0.01)$ were treated as technologically similar/related (1), otherwise not (o).

Technological ecosystems. In order to ascertain the pattern of change in technological diversification of actors over time, we selected a sample of top 1000 assignees of inventions in each 5-year period. To this end, first we identified all 'persons' in the database who had ten or more inventions to their credit. In order to avoid the risk of duplicate counting of inventions and consequent 116 
endogeneity, we used only the first assignees of inventions as the sample. Then we cleaned the names of persons for typographical variations and standardized them. Finally, we counted the total number of inventions associated with each unique 'person'. From this list of all persons, we selected the top 1000 contributors to inventive output in each 5 -year period.

Technological diversification. We computed the conventional HIDs at three levels and corresponding CIDs for each of the actors in the sample.

$$
\begin{aligned}
& \text { HID_1: Across the four spectral clusters ( } \mathrm{SC}_{1}, \mathrm{SC}_{2}, \mathrm{SC}_{3} \text {, and Other) } \\
& \text { HID_2: Across all spectral sub-clusters } \\
& \text { HID_3: Across all subclasses }
\end{aligned}
$$

The CID ranges between o-1 like the HID and it is self-adjusting because its value decreases with the increase in number of levels, and vice versa. This behavior is consistent with the fact that the greater the number of levels in the classification, the greater the specialization. Accordingly, composite index is computed on the basis of relative weight of diversification at each level. Moreover, since the CID at any given level is designed to include the information about the magnitude of diversity at all levels above the level of interest, all entities at the level of interest can be reasonably considered as equally different from each other regardless of their lineage. The sample average for each index in each period and corresponding statistics are presented in Table 4.A3.

\section{FIGURE 4.A1}

\section{Growth Pattern of Major Sub-Domains of Technology}

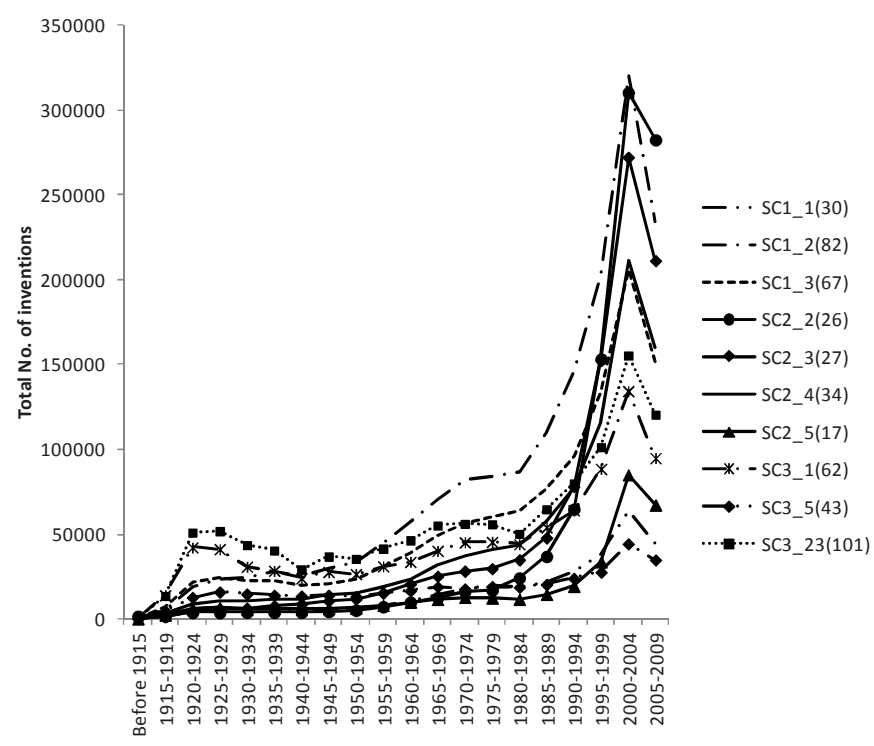


TABLE 4.A1

Static Spectral Clusters (1915-2009)

\begin{tabular}{|c|c|c|}
\hline $\begin{array}{l}\stackrel{P}{E} \\
\frac{a}{0} \\
\frac{0}{0}\end{array}$ & 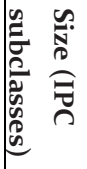 & IPC Subclasses \\
\hline $\mathrm{SC}_{1}$ & 182 & $\begin{array}{l}\text { Ao1H,Ao1K,Ao1L,Ao1N,Ao1P,A23C,A23G,A23J,A23K,A23L,A24B,A41B,A43D,A } \\
\text { 45D,A46D,A47H,A47L,A61K,A61L,A61P,A61Q,A62C,A62D,A63H,Bo1B,Bo1D,B } \\
\text { o1F,Bo1J,Bo1L,Bo3B,Bo3C,Bo3D,Bo4C,Bo5C,Bo5D,Bo7B,Bo9B,B21B,B21H,B22C } \\
\text {,B22D,B22F,B23H,B23K,B24D,B27K,B28C,B29B,B29C,B32B,B41C,B41F,B41,,B4 } \\
\text { 1K,B41M,B41N,B43K,B44C,B44F,B63B,B68B,B68C,Co1B,Co1C,Co1D,Co1F,Co1G } \\
\text {,Co2F,Co3B,Co3C,Co4B,Co5B,Co5C,Co5G,Co6B,Co7B,Co7C,Co7D,Co7F,Co7 } \\
\text { G,Co7H,Co7J,Co7K,Co8B,Co8C,Co8F,Co8G,Co8H,Co8J,Co8K,Co8L,Co9B,Co } \\
\text { 9C,Co9D,Co9F,Co9G,Co9J,Co9K,C10B,C10G,C10J,C10K,C10L,C10M,C11B,C11C, } \\
\text { C11D,C12C,C12M,C12N,C12P,C12Q,C12S,C13D,C13K,C14C,C21B,C21C,C21D,C22 } \\
\text { B,C22C,C22F,C23C,C23D,C23F,C23G,C25B,C25C,C25D,C25F,C3oB,C4oB,Do1 } \\
\text { D,Do1F,Do1H,Do2G,Do2J,Do3D,Do4B,Do4H,Do5C,Do6B,Do6C,Do6J,Do6L, } \\
\text { Do6M,Do6N,Do6P,Do6Q,D21C,D21D,D21G,D21H,D21J,Eo2B,Eo3F,Eo5B,F16B, } \\
\text { F17C,F23C,F23G,F25J,F26B,F27B,F27D,Go2C,Go3C,Go3D,Go3F,Go3G,G21C,G2 } \\
\text { 1F,Ho1B,Ho1C,Ho1F,Ho1G,Ho1M,Ho1R,Ho1S,Ho1T,Ho2G,Ho5K }\end{array}$ \\
\hline $\mathrm{SC}_{2}$ & 108 & $\begin{array}{l}\text { A61B,A61D,A63F,Bo6B,B41B,B42D,B43L,B62C,B81B,B81C,Do3C,Eo5G,Fo3H,F1 } \\
\text { 5C,F21H,Go1B,Go1C,Go1D,Go1F,Go1G,Go1H,Go1J,Go1K,Go1L,Go1M,Go1N,Go1P } \\
\text {,Go1Q,Go1R,Go1S,Go1T,Go1V,Go1W,Go2B,Go2F,Go3B,Go3H,Go4B,Go4C,Go4 } \\
\text { D,Go4F,Go4G,Go5B,Go5F,Go6C,Go6E,Go6F,Go6G,Go6J,Go6K,Go6M,Go6N, } \\
\text { Go6Q,Go6T,Go7B,Go7C,Go7D,Go7F,Go7G,Go8B,Go8C,Go8G,Go9B,Go9C,G } \\
\text { o9G,G10H,G10K,G10L,G11B,G11C,G12B,G21G,G21H,G21K,Ho1H,Ho1J,Ho1L,Ho1 } \\
\text { P,Ho1Q,Ho2B,Ho2H,Ho2J,Ho2M,Ho2N,Ho2P,Ho3B,Ho3C,Ho3D,Ho3F,Ho3G } \\
\text {,Ho3H,Ho3J,Ho3K,Ho3L,Ho3M,Ho4B,Ho4H,Ho4J,Ho4K,Ho4L,Ho4M,Ho4N, } \\
\text { Ho4Q,Ho4R,Ho4S,Ho4W,Ho5G,Ho5H }\end{array}$ \\
\hline $\mathrm{SC}_{3}$ & 295 & 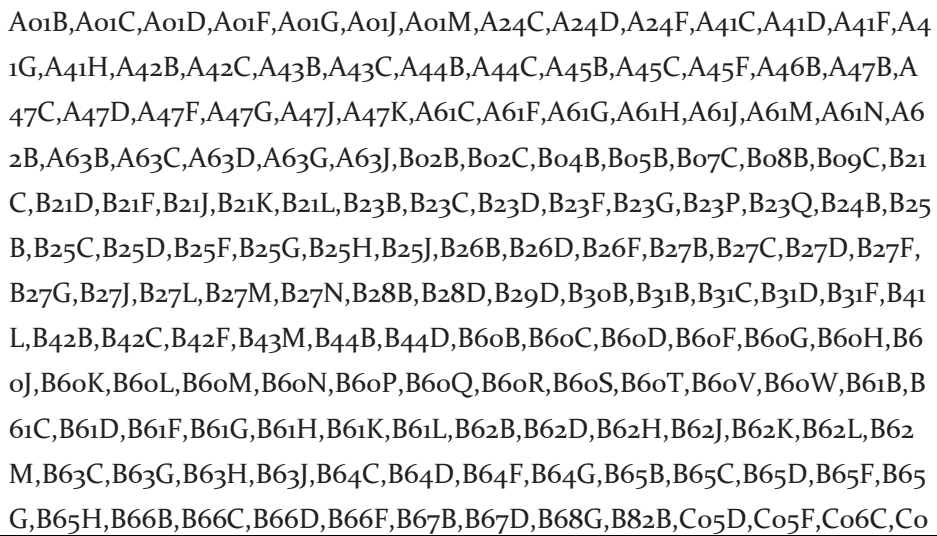 \\
\hline
\end{tabular}




\begin{tabular}{|c|c|c|}
\hline & & 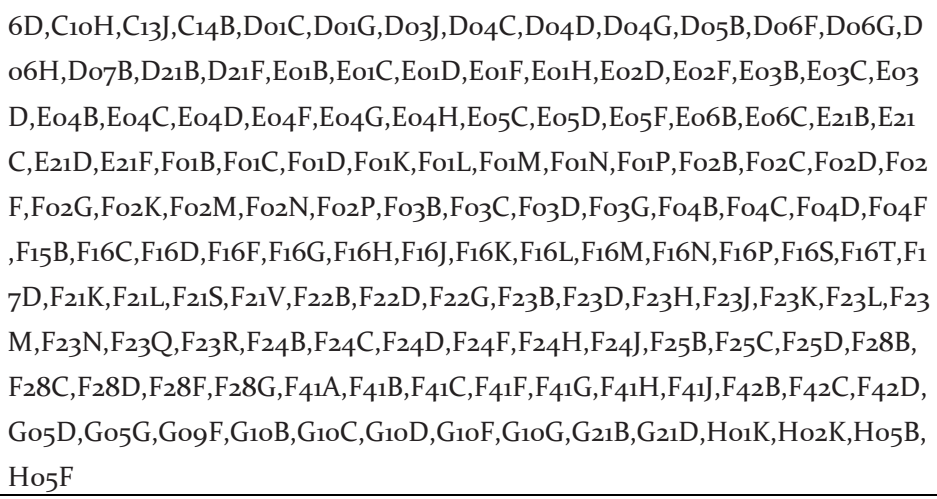 \\
\hline $\mathrm{SC}_{4}$ & 27 & $\begin{array}{l}\text { A63K,A99Z,B21G,B41D,B41G,B61J,B68F,B99Z,Co9H,C10F,C12F,C12J,C12L,C13G } \\
\text {,C13 H,C99Z,Do1B,Eo2C,E99Z,F17B,F99Z,Go6D,Go9D,G21J,G99Z,Ho5C,H99Z }\end{array}$ \\
\hline $\mathrm{SC}_{5}$ & 1 & $\mathrm{C}_{13} \mathrm{C}$ \\
\hline SC6 & 13 & $\mathrm{~A}_{21} \mathrm{~B}, \mathrm{~A} 21 \mathrm{C}, \mathrm{A} 21 \mathrm{D}, \mathrm{A} 22 \mathrm{~B}, \mathrm{~A} 22 \mathrm{C}, \mathrm{A} 23 \mathrm{~B}, \mathrm{~A} 23 \mathrm{D}, \mathrm{A} 23 \mathrm{~F}, \mathrm{~A} 23 \mathrm{~N}, \mathrm{~A}_{23} \mathrm{P}, \mathrm{C}_{12} \mathrm{G}, \mathrm{C} 12 \mathrm{H}, \mathrm{C}_{13} \mathrm{~F}$ \\
\hline $\mathrm{SC}_{7}$ & 2 & $\mathrm{~B} 67 \mathrm{C}, \mathrm{Co} 6 \mathrm{~F}$ \\
\hline SC10 & 2 & C10C,C10C \\
\hline $\mathrm{SC}_{18}$ & 1 & $\mathrm{~F}_{15} \mathrm{D}$ \\
\hline $\mathrm{SC}_{21}$ & 2 & $\mathrm{~B}_{24} \mathrm{C}, \mathrm{B} 27 \mathrm{H}, \mathrm{B} 64 \mathrm{~B}$ \\
\hline
\end{tabular}

TABLE 4.A2

Static Spectral Sub-clusters (1915-2009)

\begin{tabular}{|c|c|c|}
\hline $\begin{array}{l}\text { Sub- } \\
\text { Cluster }\end{array}$ & 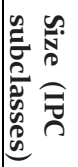 & IPC Subclasses \\
\hline SC1_o1 & 30 & 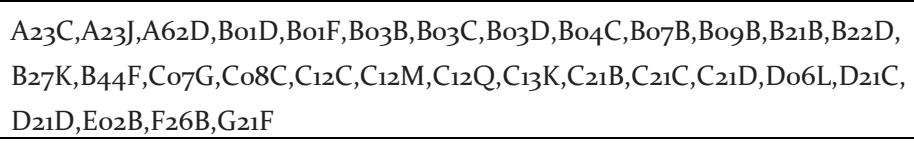 \\
\hline SC1_02 & 82 & $\begin{array}{l}\text { Ao1H,Ao1K,Ao1L,Ao1N,A23G,A23K,A24B,A41B,A43D,A45D,A46D,A47H,A61 } \\
\text { K,A61L,A61Q,A62C,Bo1L,Bo5C,Bo5D,B22C,B24D,B29C,B32B,B44C,B68B,B6 } \\
\text { 8C,Co5C,Co6B,Co7B,Co7C,Co7D,Co7F,Co7H,Co7J,Co7K,Co8B,Co8F,Co8G, } \\
\text { Co8J,Co8K,Co8L,Co9B,Co9D,Co9F,Co9J,Co9K,C10L,C10M,C11B,C11C,C11D, } \\
\text { C12N,C12P,C14C,C23F,C23G,C4oB,Do1D,Do1F,Do1H,Do2G,Do2J,Do3D,Do4 } \\
\text { B,Do4H,Do5C,Do6B,Do6C,Do6J,Do6M,Do6N,Do6Q,D21G,D21H,D21J,Eo5B } \\
\text { „F17C,Go2C,Go3C,Go3F,Go3G,Ho1S }\end{array}$ \\
\hline $\mathrm{SC}_{1} \_03$ & 67 & $\begin{array}{l}\text { Ao1P,A23L,A47L,A61P,Bo1B,Bo1J,B21H,B22F,B23H,B23K,B28C,B29B,B41C,B4 } \\
\text { 1F,B41J,B41K,B41M,B41N,B43K,Co1B,Co1C,Co1D,Co1F,Co1G,Co2F,Co3B,Co3C } \\
\text {,Co4B,Co5B,Co5G,Co8H,Co9C,Co9G,C10B,C10G,C10J,C10K,C12S,C13D,C22 B }\end{array}$ \\
\hline
\end{tabular}




\begin{tabular}{|c|c|c|}
\hline & & $\begin{array}{l}\text {,C22C,C22F,C23C,C23D,C25B,C25C,C25D,C25F,C3oB,Do6P,F16B,F23C,F23G } \\
\text {,F25J,F27B,F27D,Go3D,G21C,Ho1B,Ho1C,Ho1F,Ho1G,Ho1M,Ho1R,Ho1T,Ho2 } \\
\text { G,Ho5K }\end{array}$ \\
\hline SC1_o8 & 1 & $\mathrm{Eo}_{3} \mathrm{~F}$ \\
\hline $\mathrm{SC}_{1 \_12}$ & 1 & $\mathrm{~B} 63 \mathrm{~B}$ \\
\hline $\mathrm{SC}_{1 \_14}$ & 1 & $\mathrm{~A}_{3} \mathrm{H}$ \\
\hline $\mathrm{SC} 2 \_\mathrm{O} 1$ & 3 & B43L,Go1),G12B \\
\hline $\mathrm{SC} 2 \_02$ & 26 & $\begin{array}{l}\text { B41B,B62C,Do3C,Eo5G,F21H,Go3H,Go5B,Go6C,Go6F,Go6J,Go6K,Go6N,Go } \\
\text { 6T,Go7G,Go8C,G1oL,G11B,Ho3M,Ho4H,Ho4J,Ho4K,Ho4L,Ho4M,Ho4Q,Ho } \\
\text { 4S,Ho4W }\end{array}$ \\
\hline $\mathrm{SC}_{2} \_03$ & 27 & 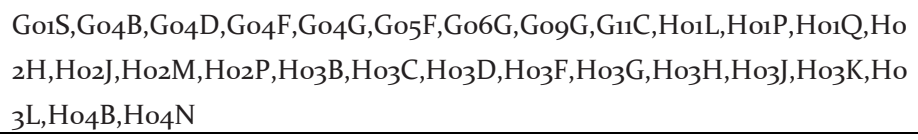 \\
\hline $\mathrm{SC}_{2} \_\mathrm{O} 4$ & 34 & $\begin{array}{l}\text { A61B,Bo6B,B81B,B81C,Fo3H,F15C,Go1B,Go1D,Go1F,Go1G,Go1H,Go1K,Go1L,G } \\
\text { o1M,Go1N,Go1P,Go1Q,Go1R,Go1T,Go1V,Go1W,Go2B,Go2F,Go3B,Go4C,G1oK } \\
\text {,G21G,G21H,G21K,Ho1J,Ho2N,Ho4R,Ho5G,Ho5H }\end{array}$ \\
\hline SC2_O5 & 17 & $\begin{array}{l}\text { A63F,B42D,Go1C,Go6E,Go6M,Go6Q,Go7B,Go7C,Go7D,Go7F,Go8B, Go8G,G } \\
\text { o9B,Go9C,G10H,Ho1H,Ho2B }\end{array}$ \\
\hline SC2_o6 & 1 & $\mathrm{~A} 61 \mathrm{D}$ \\
\hline $\mathrm{SC}_{3 \_\mathrm{O} 1}$ & 62 & $\begin{array}{l}\text { Ao1B,Ao1D,Ao1F,A42B,A43C,A61J,A61M,B6oB,B6oD,B6oG,B6oK,B6oL,B6oR } \\
\text {,B6oS,B6oT,B6oW,B61H,B61L,B62B,B62D,B62J,B62K,B62M,B63G,B63H,B64 } \\
\text { F,B66D,Do6F,Do7B,Eo2F,Fo1B,Fo1C,Fo1L,Fo1M,Fo1N,Fo1P,Fo2B,Fo2D,Fo2F, } \\
\text { Fo2G,Fo2M,Fo2N,Fo2P,Fo3B,Fo3C,Fo3G,Fo4B,Fo4C,Fo4F,F15B,F16C,F16D,F } \\
\text { 16F,F16H,F16J,F16K,F16M,F16N,F16T,F42D,Go5G,Ho2K }\end{array}$ \\
\hline $\mathrm{SC}_{3 \_\mathrm{O} 2}$ & 1 & $\mathrm{~B} 62 \mathrm{~L}$ \\
\hline $\mathrm{SC}_{3} \_\mathrm{O} 4$ & 12 & B21L,B27J,B82B,C10H,C13J,Do1C,Do6G,E21B,E21C,E21D,F16L,F17D \\
\hline $\mathrm{SC}_{3} \_05$ & 43 & 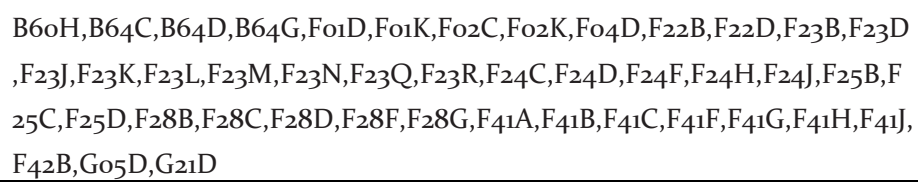 \\
\hline $\mathrm{SC}_{3} \_\mathrm{o6}$ & 18 & 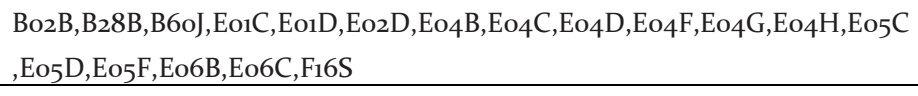 \\
\hline $\mathrm{SC}_{3} \_\mathrm{o} 8$ & 1 & $\mathrm{~B} 6 \mathrm{oC}$ \\
\hline $\mathrm{SC}_{3} \_12$ & 1 & $\mathrm{Bo} 4 \mathrm{~B}$ \\
\hline $\mathrm{SC}_{3} \_20$ & 2 & A63J,B63J \\
\hline $\mathrm{SC}_{3 \_23}$ & 101 & $\begin{array}{l}\text { Ao1C,Ao1G,Ao1J,Ao1M,A24C,A24F,A41F,A41G,A41H,A44B,A44C,A45C,A45F, } \\
\text { A47 B,A47C,A47D,A47F,A47G,A47J,A47K,A62B,A63B,A63C,A63D,Bo5B,Bo7 }_{\text {C,Bo8B,Bo9C,B21D,B21F,B25J,B26D,B26F,B27D,B27N,B29D,B31B,B31C,B31D, }} \\
\text { B31F,B41L,B42B,B42C,B42F,B43M,B44B,B6oF,B6oN,B6oP,B6oQ,B6oV,B61B, } \\
\text { B61C,B61D,B61F,B61G,B61K,B63C,B65B,B65C,B65D,B65F,B65G,B65H,B66C, }\end{array}$ \\
\hline
\end{tabular}




\begin{tabular}{|c|c|c|}
\hline & & $\begin{array}{l}\text { B66F,B67B,B67D,B68G,Co5D,Co5F,Co6C,Co6D,C14B,Do1G,Do4D,Do4G,D } \\
\text { o5B,Do6H,D21B,D21F,Eo1B,Eo1F,Eo1H,E03B,Eo3C,E03D,E21F,Fo3D,F16G,F16 } \\
\text { P,F21K,F21S,F21V,F22G,F23H,Go9F,G1oB,G1oD,Ho1K,Ho5B }\end{array}$ \\
\hline $\mathrm{SC}_{3} 33$ & 1 & GioF \\
\hline $\mathrm{SC}_{3} 34$ & 1 & $\mathrm{~B} 44 \mathrm{D}$ \\
\hline $\mathrm{SC}_{3} \_42$ & 9 & $\mathrm{~A}_{41} \mathrm{C}, \mathrm{A}_{41} \mathrm{D}, \mathrm{A}_{42} \mathrm{C}, \mathrm{A}_{43} \mathrm{~B}, \mathrm{~A} 61 \mathrm{C}, \mathrm{A} 61 \mathrm{~F}, \mathrm{~A} 61 \mathrm{G}, \mathrm{A} 61 \mathrm{H}, \mathrm{A} 61 \mathrm{~N}$ \\
\hline $\mathrm{SC}_{3} \_46$ & 4 & $\mathrm{~B}_{21} \mathrm{C}, \mathrm{B} 21 \mathrm{~J}, \mathrm{~B} 21 \mathrm{~K}, \mathrm{~B} 23 \mathrm{P}$ \\
\hline $\mathrm{SC}_{3} \_49$ & 1 & $\mathrm{~F}_{42} \mathrm{C}$ \\
\hline $\mathrm{SC}_{3}{ }_{5} 1$ & 22 & $\begin{array}{l}\mathrm{B}_{22} \mathrm{C}, \mathrm{B} 23 \mathrm{~B}, \mathrm{~B} 23 \mathrm{C}, \mathrm{B} 23 \mathrm{D}, \mathrm{B} 23 \mathrm{~F}, \mathrm{~B} 23 \mathrm{G}, \mathrm{B} 23 \mathrm{Q}, \mathrm{B} 24 \mathrm{~B}, \mathrm{~B} 25 \mathrm{~B}, \mathrm{~B} 25 \mathrm{C}, \mathrm{B} 25 \mathrm{D}, \mathrm{B} 25 \mathrm{~F}, \mathrm{~B} 25 \mathrm{G}, \\
\mathrm{B}_{25} \mathrm{H}, \mathrm{B} 26 \mathrm{~B}, \mathrm{~B}_{27} \mathrm{~B}, \mathrm{~B} 27 \mathrm{C}, \mathrm{B}_{27} \mathrm{~F}, \mathrm{~B}_{27} \mathrm{G}, \mathrm{B} 27 \mathrm{~L}, \mathrm{~B} 27 \mathrm{M}, \mathrm{B} 28 \mathrm{D}\end{array}$ \\
\hline $\mathrm{SC}_{3-52}$ & 1 & $\mathrm{~A}_{4} 6 \mathrm{~B}$ \\
\hline $\mathrm{SC}_{3} 53$ & 1 & $\mathrm{~A} 24 \mathrm{D}$ \\
\hline $\mathrm{SC}_{3} 54$ & 1 & $\mathrm{~F}_{21} \mathrm{~L}$ \\
\hline $\mathrm{SC}_{3} 55$ & 1 & $\mathrm{~F}_{24} \mathrm{~B}$ \\
\hline $\mathrm{SC}_{3}{ }_{5} 6$ & 1 & $\mathrm{~B} 62 \mathrm{H}$ \\
\hline $\mathrm{SC}_{3-57}$ & 1 & B66B \\
\hline $\mathrm{SC}_{3} 5_{5} 8$ & 1 & $\mathrm{Ho}_{5} \mathrm{~F}$ \\
\hline $\mathrm{SC}_{3} 62$ & 1 & B6oM \\
\hline $\mathrm{SC}_{3} 6_{4}$ & 1 & $\mathrm{G}_{21} \mathrm{~B}$ \\
\hline $\mathrm{SC}_{3} 65$ & 7 & $\mathrm{~A}_{45} \mathrm{~B}, \mathrm{~A} 63 \mathrm{G}, \mathrm{B} 30 \mathrm{~B}, \mathrm{D}_{3} \mathrm{~J}, \mathrm{Do}_{4} \mathrm{C}, \mathrm{G} 10 \mathrm{C}, \mathrm{G} 10 \mathrm{G}$ \\
\hline
\end{tabular}


TABLE 4.A3

Relative Share of Major Sub-Clusters

\begin{tabular}{|c|c|c|c|c|}
\hline $\begin{array}{c}\text { Major } \\
\text { Sub- } \\
\text { clusters }\end{array}$ & $\begin{array}{c}\text { No. of } \\
\text { subclasses }\end{array}$ & $\begin{array}{c}\text { No. of } \\
\text { Inventions }\end{array}$ & $\begin{array}{l}\text { Share in } \\
\text { parent } \\
\text { cluster }\end{array}$ & $\begin{array}{c}\text { Share in } \\
\text { total } \\
\text { inventions }\end{array}$ \\
\hline $\mathrm{SC}_{1 \_1}$ & 30 & 329,045 & $12.3 \%$ & $4.4 \%$ \\
\hline $\mathrm{SC}_{1 \_2}$ & 82 & $1,627,842$ & $60.7 \%$ & $21.6 \%$ \\
\hline $\mathrm{SC}_{1} \_3$ & 67 & $1,123,145$ & $41.9 \%$ & $14.9 \%$ \\
\hline $\mathrm{SC}_{2} \_2$ & 26 & 968,174 & $35 \cdot 3 \%$ & $12.8 \%$ \\
\hline $\mathrm{SC}_{2} \_3$ & 27 & 973,282 & $35 \cdot 5 \%$ & $12.9 \%$ \\
\hline $\mathrm{SC}_{2} \_4$ & 34 & 903,109 & $32.9 \%$ & $12.0 \%$ \\
\hline $\mathrm{SC}_{2}-5$ & 17 & 332,819 & $12.1 \%$ & $4.4 \%$ \\
\hline $\mathrm{SC}_{3 \_1}$ & 62 & 911,257 & $30.6 \%$ & $12.1 \%$ \\
\hline $\mathrm{SC}_{3-5}$ & 43 & 361,116 & $12.1 \%$ & $4.8 \%$ \\
\hline $\mathrm{SC}_{3 \_23}$ & 101 & $1,129,167$ & $37.9 \%$ & $15.0 \%$ \\
\hline Total* & 489 & $6,904,578$ & & $91.5 \%$ \\
\hline
\end{tabular}




\title{
5 EXPLOITATION, EXPLORATION, OR EX- CURSION? WHEN AND HOW TECHNOLOG- ICALLY DIVERSIFIED FIRMS BENEFIT FROM TECHNOLOGICAL MERGERS AND ACQUISITIONS
}

\begin{abstract}
Technological mergers and acquisitions (TM\&As) are important part of strategic repertoire of technology-based firms (TBFs) that populate high-tech sectors and serve as the major source of technological changes due to their R\&D. Owing to their ever-increasing popularity, performance outcomes of TM\&As have attracted scholarly interest and it is now established that they positively contribute to the technological output of the acquirers. However, recent research to identify the drivers of post-acquisition performance has frequently used resource-based and organizational learning theories by assuming that organizational search is deliberate and driven by the strategic intent to use existing capabilities of the firm or develop new capabilities. Accordingly, it is also assumed that organizational search through TM\&As and the performance outcomes thereof either constitute exploitation or exploration. We argue that these assumptions need to be revisited because exploitation and exploration can be understood better by (i) changing the frame of reference from capabilities to opportunities and (ii) isolating the emergent part of organizational search that constitutes excursion. We explicate and illustrate these ideas using 160 TM\&A deals of large TBFs from global information and communication technology sector during a 21-year period and measuring the post-acquisition inventive output of acquirers. Empirical evidence suggests that excursion is a sizeable contributor to the post-acquisition inventive output of TBFs. Results of negative binomial regression analysis of the panel data suggest that technological diversity of the acquirer negatively effects post-acquisition exploitative and explorative output, exploitative output is negatively affected by technological history of the acquirer, and technological similarity between acquirer and target negatively affects explorative output.
\end{abstract}

Keywords: R\&D, mergers and acquisitions, technological diversification, technological opportunity, absorptive capacity. 


\subsection{INTRODUCTION}

High-tech sectors are an important part of the knowledge economy (Powell \& Snellman, 2004) and significant contributors to global economic and social changes. These sectors are characterized by their high R\&D intensity and technologybased competition (Pavitt, 1984; Hagedoorn, 2002). Accordingly, firms that drive these sectors are known as technology-based firms (TBFs) (Granstrand, 1998). TBFs tend to grow and diversify, hence becoming multi-product and multitechnology enterprises (Granstrand \& Sjölander, 1990; Patel \& Pavitt, 1997; Gambardella \& Torrisi, 1998). Thus, TBFs face increasingly dynamic environments (Uotila et al., 2009), particularly due to increasing technological convergence on the one hand (Gambardella \& Torrisi, 1998) and frequent technological changes (Tushman \& Anderson, 1986), on the other. Due to the dynamism of their environments, these TBFs need to exploit their existing technological capabilities before those become obsolete and develop new technological capabilities before their competitors (Wernerfelt, 1984; Sirmon, Hitt \& Ireland, 2007; Chen et al., 2010). Since technological capabilities are difficult to develop in the short run (Cohen \& Levinthal, 1989, 1990), mergers and acquisitions (M\&As) are an important component of the strategic repertoire of TBFs (Graebner, Eisenhardt \& Roundy, 2010; Cloodt \& Hagedoorn, 2012) because M\&As serve as relatively quick means for internalizing valuable resources and capabilities through the market for corporate control (Dierickx \& Cool, 1989; Hitt et al., 1996; Ranft \& Lord, 2002; Grimpe \& Hussinger, 2014).

Due to the ever-increasing popularity of M\&As as a strategic tool, their effects on acquirer's performance have been an important area of scholarly interest (Cartwright \& Schoenberg, 2006; Cloodt \& Hagedoorn, 2012). Accordingly, strategy scholars have long be interested in investigating the performance outcomes of technological M\&As (e.g., Ahuja \& Katila, 2001; Cloodt, Hagedoorn, \& Van Kranenburg, 2006). Since TBFs engage in M\&As in order to acquire valuable technological resources and capabilities of target firms, the impact of such technological M\&As is expected to contribute towards increase in post-acquisition technological output of the acquirers (Chaudhuri \& Tabrizi, 1999). Empirical research has established that technological M\&As positively affect the inventive output of the acquirers (e.g., Cloodt et al., 2006).

This stream of research has been extended along the lines of theory of organizational learning (March, 1991; Levinthal \& March, 1993) suggesting that firms engage in technological M\&As in order to utilize their existing technological knowledge and capabilities or acquire new knowledge and capabilities that they lack (Phene, Tallman \& Almeida, 2012). This view is based on the popular understanding that exploitation and exploration are mutually exhaustive modes of organizational learning (Stettner \& Lavie, 2014). We argue that this understanding needs to be refined for several reasons. 
The first and foremost problem with the notions of exploitation and exploration concerns the conceptual ambiguity surrounding their definition and connotations (Gupta, Smith, \& Shalley, 2006; Lavie, Stettner \& Tushman, 2010). According to the original-and by far the most popular-formulation of the constructs, exploitation essentially refers to the use of knowledge that the firm already possesses whereas exploration refers to the search for knowledge that is new to the firm. However, every activity involves use of existing knowledge of the actor as well as well as some learning, at least in the form of new insights (Gupta et al., 2006). Therefore, application of these concepts in theory and practice of strategic management is difficult partly because of the ambiguity of these concepts and partly because of the difficulty in determining what constitutes organizational knowledge and what kind of organizational knowledge is more relevant for organizational performance (cf. Nonaka, 1994; Grant, 1996a). This problem becomes more complex in the context of TBFs because these firms tend to operate in multiple technology domains as well as multiple product domains and these two kinds of domains are interlinked through multiplex relationships (Granstrand \& Sjölander, 1990; Patel \& Pavitt, 1997; Gambardella \& Torrisi, 1998).

This point can be illustrated by the fact that technology-based firms may use their existing technological knowledge to enter other domains that are new to them, or seek out new knowledge in order to innovate in their existing domains. However, firms are likely to know less about the domains new to them and more about their existing domains. The prevalent conception-that is based on the content of knowledge-suggests that the use of existing technological knowledge in new-to-the-firm domains constitutes exploitation and search for new knowledge for innovating in existing domains of the firm constitutes exploration for the focal firm. However, one can argue in the opposite direction as well using the domains as the context where knowledge is generated and used. This situation highlights the conceptual tension between the content and context of the knowledge as the frame of reference. Such confusion hinders applying these concepts in understanding the strategic behaviour of firms, particularly TBFs.

Strategic behaviour of TBFs can be understood in terms of product domains (so called industries) as well as technology domains (Granstrand \& Sjölander, 1990; Patel \& Pavitt, 1997; Gambardella \& Torrisi, 1998). These domains serve as the context of opportunities and threats that direct the strategic behaviour of firms. It is a well-known fact that firms seek to maximize profits and their actions are driven by the quest for competitive advantage and guided by certain strategic intent (Hamel \& Prahalad, 1989). Therefore, TBFs do not learn for the sake of learning but to generate and exploit opportunities and avert possible threats. This suggests that the context that engenders opportunities and threats may serve as a useful frame of reference for the strategic intent as well as the content of the response to those opportunities and threats. Hence, domains as the context and opportunities as the content of organization search provide an unam- 
biguous way of differentiating between exploitation and exploration (Klevorick et al., 1995; Foss, Lyngsie \& Zahra, 2013). That is, if the firm seeks opportunities in its current domains of activity, the search constitutes exploitation whereas exploration involves search for opportunities somewhere outside its current domains.

The second problem concerns the ambiguity caused by exploitationexploration dichotomy itself that raises the question whether exploitation and exploration are two ends of a continuum (Gupta et al., 2006). This question is particularly relevant to the search behaviour of TBFs. The theory of invention suggests that search for invention is a costly and complex process (Arthur, 2007; Fleming, 2001; Maggitti, Smith, \& Katila, 2013), hence a purpose-driven and goaldirected activity. Therefore, whether firms seek exploitation or exploration of technological opportunities or capabilities, they need to focus on a small number of domains due to the constraints of resources and capabilities (Cohen \& Levinthal, 1990). Such a focus is also necessary due to the need for consistency and coherence in search (Nesta \& Saviotti, 2005) so that exploitation and exploration are "transitive" (Lavie et al., 2010) and feed on each other. This transitivity is necessary because, in the long run, neither exploitation nor exploration is sustainable without the other (Levinthal \& March, 1993) particularly due to the fact that every capability tends to have a lifecycle (Helfat \& Peteraf, 2003). Therefore, the dichotomy gives rise to the tension between content and context of knowledge as competing frames of reference for defining relevance and coherence of knowledge.

Finally, the exploitation-exploration dichotomy is problematic also because the search for technological opportunities involves significant amount of uncertainty (Arthur, 2007; Maggitti et al., 2013; Fleming, 2001). It involves successes and failures in planned pursuits as well as the emergence of unexpected insights and opportunities due to serendipity or unintended consequence of search (Shapiro, 1986; Roberts, 1989; Kantorovich \& Ne'eman, 1989; Van Andel, 1994; Austin, 2003; Seymore, 2009; de Rond, 2014). Extant theory of organizational learning and strategic management has either neglected such pursuits altogether or implicitly subsumed these under exploration. However, organizational search through $R \& D$ is a costly activity which can hardly be left to chance. Therefore, exploration is more likely to be directed by strategic intent than by serendipity. The latter is the emergent aspect of the conduct of search (Mintzberg \& Waters, 1985) that needs to be separated from exploration in order to understand the role and dynamics of exploration more clearly by isolating the contribution of chance and serendipity. Therefore, we propose that organizational search actually involves three dimensions: exploitation, exploration, and excursion.

The main purpose of this paper is to explicate the role of technological M\&As in exploitation and exploration by TBFs and the factors that affect the postacquisition exploitative and explorative output of the acquirer. Our study departs from prior research in three important aspects: it focuses on the attributes of the 
acquirer rather than the target, it uses opportunities as the focus of analysis rather than capabilities, and it examines exploration by explicitly separating it from excursion. Our research is guided by the following question: "To what extent does a TBF benefit from technological M\&As, given its technological history and capability base, and when do these benefits tend to accrue?" In order to address this question, we develop hypotheses by drawing upon theory of organizational learning (March, 1991; Cohen \& Levinthal, 1990; Levinthal \& March, 1993), theory of technology-based firm (Patel \& Pavitt, 1997; Granstrand, 1998), and resourcebased theory of firm (e.g., Wernerfelt, 1984; Prahalad \& Hamel, 1990; Grant, 1996a). We test these hypotheses in the context of technological M\&As in the global information and communication technology (ICT) sector between 1985 and 2005. We chose this empirical setting for two important reasons. First, M\&As are strategic initiatives which involve significant organizational commitment. Therefore, every M\&A deal is likely to be based on certain "strategic intent" (Hamel \& Prahalad, 1989) that requires acquiring certain resources and capabilities that are useful for the acquirer to operate in particular technology and/or product domains and that are expected to be possessed by the M\&A target. Consequently, M\&As are reliable identifiers of the domains targeted by the acquirer, thus making the identification and separation of exploitation, exploration, and excursion feasible and reliable. Second, firms in this sector are typical of technology-based firms (Granstrand, 1998; Granstrand \& Sjölander, 1990; Patel \& Pavitt, 1997; Gambardella \& Torrisi, 1998) and M\&As have been an important feature of the high-tech sectors (Ranft \& Lord, 2002; Cloodt \& Hagedoorn, 2012). Therefore, their strategic moves, particularly technological M\&As, are a reflection of technology-based competition in their current domains of activity.

We present theory and hypotheses in the next section followed by empirical analysis and results. Then we discuss the contributions, implications, and limitations of our research in the final section.

\subsection{THEORY}

\subsubsection{Differentiating among Technological Opportunities: Exploitation, Exploration, and Excursion}

From an evolutionary perspective, a TBF typically originates due to an invention and hence technology is part of the DNA of such firms. Owing to the cyclical nature of technology and hence technological obsolescence (Anderson \& Tushman, 1990), TBFs continually search for new technological opportunities for their survival and growth (Suárez \& Utterback, 1995; Christensen, Suárez \& Utterback, 1998). A technological opportunity is defined as a possibility of technological advance, given the current state of technology (Klevorick et al., 1995, pp. 188). TBFs usually sense and respond to technological opportunities through research-and- 
development (R\&D) as an institutionalized function within the firm (Cohen \& Levinthal, 1989, 1990). R\&D helps create new technologies and products that can be commercialized via technology-markets or product-markets (Teece, 1986; Rosenberg, 1990; Dutta, Narasimhan \& Rajiv, 1999; Arora \& Gambardella, 2010). Moreover, having an institutionalized R\&D subsystem not only helps TBFs create inventions and innovations but also endows them with the absorptive capacity (Cohen \& Levinthal, 1989, 1990) to benefit from external sources of knowledge, such as M\&As (Hagedoorn \& Wang, 2012). Consequently, R\&D helps TBFs incrementally advance their existing technologies and products on the one hand, and helps them expand and diversify their technology and product portfolios over time, on the other (Patel \& Pavitt, 1997; Granstrand, 1998; Gambardella \& Torrisi, 1998).

How do technology and product portfolios of TBFs emerge and why do TBFs differ in terms of their portfolios are important questions not only from the micro perspective of theory of TBFs but also from the macro perspective of technological change. Accordingly, from the evolutionary and resource-based perspectives (e.g., Nelson \& Winter, 1982; Cohen \& Levinthal, 1990; Helfat \& Peteraf, 2003), answers to these questions reside, at least partly, in how their R\&D subsystems realize new technological opportunities. This is because of the fact that adaptation to technological changes as well as technology-based growth sprouts from realizing new technological opportunities (Klevorick et al., 1995) and R\&D is the principal mechanism through which TBFs sense and respond to technological opportunities (Cohen \& Levinthal, 1989, 1990). This implies that TBFs actually seek technological opportunities as the ends that direct their search for technological capabilities as the means.

Development of a technological capability is a costly process, therefore it is reasonable to expect that search for a capability is a purposeful and non-random process that is directed by the strategic intent of the firm (Hamel \& Prahalad, 1989). Therefore, search for new technological capabilities is directed by the nature of technological opportunities intended by the firm. Since technological opportunities are the end and capabilities are the means to that end, we suggest that the opportunities are better frame of reference than the capabilities for studying the learning behavior of the TBFs. This can also help solve the conceptual problems related to the exploitation-exploration dichotomy (Gupta et al., 2006; Lavie et al., 2010). Exploitation can be defined as the systematic pursuit of those technological opportunities that belong to the firm's existing domains of experience and exploration as the systematic pursuit of those technological opportunities that belong to those domains where the firm does not have sufficient prior experience. This definition is consistent with extant understanding of exploitation (use of existing capabilities) and exploration (search for new capabilities) (March, 1991; Levinthal \& March, 1993) but it suggests using technological opportunities as the frame of reference rather than technological capabilities. 
History of science and technology, however, suggests that discoveries and inventions may also result from chance and serendipity (Shapiro, 1986; Roberts, 1989; Kantorovich \& Ne'eman, 1989; Austin, 2003; Austin, Devin \& Sullivan, 2012). For instance, electromagnetism, X-rays, penicillin, sugar, dynamite, and phonograph are known to be unintended discoveries. Apart from serendipitous discovery of opportunities that are not deliberately sought for (Van Andel, 1994; Seymore, 2009; de Rond, 2014) other search activities also take place in the firm that are not in line with or part of the organization's strategic intent, and hence, constitute the "white space" (Maletz \& Nohria, 2001) and "intrapreneurship" (Fry, 1987; Lechevalier, Nishimura \& Storz, 2014). This phenomenon has also been acknowledged in strategic management as the evolutionary and emergent dimension of strategy (Mintzberg \& Waters, 1985). Therefore, from the perspective of strategic management, such pursuits can not be considered part of organizational exploration for the simple reason that these are neither guided by the strategic intent nor do these involve organizational commitment (e.g., Burgelman \& Grove, 1996, 2007; Austin et al., 2012). Instead, we suggest examining all such technological opportunities constitute a distinct category that can be termed as excursion. Accordingly, excursion can be defined as the pursuit of occasional and peripheral technological opportunities that fall outside the current domains of core technological activities of TBFs (cf. Hamel \& Prahalad, 1989; Prahalad \& Hamel, 1990; Patel \& Pavitt, 1997). The incentive for pursuing such opportunities may arise due to several reasons (Somaya, 2012). For instance, these opportunities may be particularly feasible for the firm given its existing resource- and capability-base (March, 1991; Helfat \& Peteraf, 2003), inventions resulting from these opportunities may serve as a strategic option for the future (McGrath \& Nerkar, 2004), generate additional revenue through markets for technology (Arora \& Gambardella, 2010), contribute to the reputation and goodwill of the firm (Levitas \& Chi, 2001), and provide leverage in negotiations for corporate deals (Blind, Cremers \& Mueller, 2009).

In short, technological opportunities pursued by TBFs not only involve exploitation and exploration but also include excursion. Acknowledging excursion as a pursuit of opportunities distinct from exploration may help refine our understanding of strategic behavior of TBFs in terms of exploitation and exploration.

\subsubsection{Search for New Technological Opportunities through M\&As}

Technological opportunities available in a given domain and accessible to individual TBFs tend to deplete fairly rapidly due to the internal demands from R\&D subsystem (such as increasing R\&D output) as well as the external challenges posed by the competition, particularly due to the Red Queen race (Derfus et al., 2008) in technology-intensive industries. Thus the TBFs continuously need to 
search for new technological opportunities not only within the existing domains of their activity but also in other domains that are new to them. Since the development of technological capabilities is a costly and lengthy process, TBFs tend to use $M \& A s$ as a strategic tool to acquire new technological capabilities quickly. Consequently, researchers have sought to identify the conditions in which technological M\&As are more successful, particularly in terms of post-acquisition inventive output of the acquirer (e.g., Ahuja \& Katila, 2001; Cloodt et al., 2006; Makri, Hitt \& Lane, 2010). This research tradition has identified several characteristics of the acquiring and acquired firm that affect the post-acquisition performance of the acquirer. These include various attributes of the knowledge stocks of the acquirer and the acquired and technological similarity between their knowledge bases prior to the M\&A deal. More recently, this tradition has been extended to investigate the conditions that make technological M\&As effective vehicles for exploitation and exploration (Phene et al., 2012). We build on this research to disentangle the effects of technological M\&As on exploitation and exploration.

In short, technological M\&As are important external source of technological knowledge and capabilities of TBFs and their post-acquisition inventive output (Ahuja \& Katila, 2001; Cloodt et al., 2006; Makri et al., 2010). Firms may use M\&As to exploit technological opportunities in their existing domains or explore new technological opportunities in other domains that are new to them (cf. Stettner \& Lavie, 2014). Assuming that technological capabilities of the acquirer and the target have a certain core, technological opportunities emanating from M\&As can be divided into three categories from the perspective of the acquirer. First, new technological capabilities acquired via the M\&A can make some opportunities in acquirer's existing core domains more accessible to the acquirer. Second, technological opportunities in the core domains of the target, that are new to the acquirer, become more accessible to the acquirer. Finally, substitutabilities and complementarities arising out of the combination of technological bases of the acquirer and the target can open up unexpected and unintended opportunities beyond the core domains of both the firms. As suggested earlier, due to the locus of new technological opportunities vis-a-vis core competencies of the acquirer, first category constitutes exploitation, second comprises exploration, and the third involves excursion. In the following, we explain how various attributes of the acquirer and the target-technological history, technological diversity, and technological similarity-affect exploitation and exploration keeping aside the outcomes that constitute excursion. 


\subsubsection{Technological History of the Acquirer and Post- Acquisition Search for Opportunities}

Evolutionary perspective of organizational learning suggests that the absorptive capacity of firms is determined by their R\&D history (Cohen \& Levinthal, 1989, 1990; Levinthal \& March, 1993). The R\&D history concerns which areas of knowledge the firm has invested in over time and determines the level of its absorptive capacity vis-a-vis different domains of knowledge. However, absorptive capacity has two dimensions: potential absorptive capacity (PACAP) and realized absorptive capacity (RACAP). The former refers to the ability of the firm to value and acquire external knowledge while the latter refers to the capacity to leverage the acquired knowledge (Zahra \& George, 2002, p. 190). Therefore, PACAP helps determine the nature of technological search by the TBF whereas RACAP manifests in the technological output, particularly the inventive output of the TBF. Thus the quantity and quality of the inventive output of a TBF during any given period reflects its RACAP. We use the term technological history to depict both the aspects of absorptive capacity, PACAP and RACAP, that emanate from the R\&D history.

Both components of technological history affect the search for and realization of new technological opportunities through technological M\&As. Due to the constraints of PACAP, TBFs tend to search for new technological opportunities in those domains of knowledge that are related to its existing core (Helfat, 1994; Stuart \& Podolny, 1996; Rosenkopf \& Nerkar, 2001; Bergek \& Onufrey, 2013). Hence, the choice of target for technological M\&As is affected by PACAP. On the other hand, RACAP indicates the extent to which a TBF has already exploited valuable technological opportunities available to it and manifests in the inventive output. It is reasonable to expect that technological M\&As not only increase the technological opportunities accessible to acquiring TBF but also expand its PACAP. However, as the TBF exploits the most valuable and accessible technological opportunities emanating from M\&As, its RACAP increases but the rate of increase in the post-acquisition total inventive output tends to slows down and eventually falls. This is because of the fact that technological opportunities accessible to it diminish with the increase in RACAP and pursuing more distant opportunities become increasingly difficult and costly. Therefore,

Hypothesis 1a. Technological history of acquirer has a curvilinear (inverted-

$U)$ effect on post-acquisition total inventive output of the acquirer.

Technological history, however, has varying effects on post-acquisition exploitative and explorative technological opportunities available to the acquiring TBF. The total post-acquisition inventive output of the acquiring TBF is determined by the realization of these distinct types of technological opportunities. As argued earlier in this section, we refer to those technological opportunities that are located within the acquirer's existing core domains as exploitative opportunities. Ac- 
cordingly, the inventions resulting from the exploitation of these opportunities is referred here as exploitative output. Greater pre-acquisition RACAP implies that the TBF has already exploited greater proportion of exploitative opportunities available to it and the unrealized opportunities in these domains are more difficult or costly. Therefore, the greater the pre-acquisition RACAP, the lesser the opportunities for post-acquisition exploitative invention, and vice versa. Hence,

Hypothesis 1 b. Technological history of acquirer negatively affects the postacquisition exploitative output of the acquirer.

On the other hand, assuming that the TBF selects the M\&A target on the basis of its PACAP, technological M\&As make the technological opportunities outside the core domains of the acquiring TBF more accessible to it. We consider those technological opportunities that are located in the core domains of activity of the target as explorative opportunities and, hence, corresponding inventions are referred as explorative output.

Since technological history of the acquiring TBF includes its PACAP and RACAP, it also affects the post-acquisition explorative output of the acquirer. This is because of the fact that M\&A deal provides the acquirer access to the technological opportunities located in the core domains of the target that were hitherto inaccessible to it, hence increasing the possibilities for explorative output. Moreover, combination of the technological bases of the acquirer and the target not only increases the PACAP of the acquirer but also creates new technological opportunities due to the substitutabilities and complementarities arising out of the combined technological base of the two firms (Makri et al., 2010; Hagedoorn \& Wang, 2012). A significant portion of these opportunities is likely to fall outside the existing core domains of the acquirer but within the core domains of the target, hence increasing the possibilities of explorative output. Therefore,

Hypothesis 1c. Technological history of acquirer positively affects the postacquisition explorative output of the acquirer.

\subsubsection{Technological Diversity of the Acquirer and Post- Acquisition Search for Opportunities}

Technological diversity of a firm refers to the variety of technologies or technology domains in which the firm is operating at any given time (Gambardella \& Torrisi, 1998; Quintana-García \& Benavides-Velasco, 2008). The greater the variety in the technological base of the TBF, the greater its technological diversity, and vice versa. Technological diversity affects the firm's PACAP because the knowledge about greater number of technologies better enables a TBF to identify and pursue technological opportunities both within and outside its existing core domains. Accordingly, prior research has shown that technological diversity positively affects innovative competencies of the firm (Quintana-García \& Benavides-Velasco, 2008). 
Technological M\&As are expected to increase the diversity of the acquirer because the core competencies of the target are likely to be different from those of the acquirer. However, acquirer can benefit from target's competencies when technological base of the two are integrated and resulting substitutabilities and complementarities of technological knowledge are utilized (Ranft \& Lord, 2002; Makri et al., 2010; Hagedoorn \& Wang, 2012). Integration requires reconfiguration of existing search and experimentation routines in the R\&D subsystem of the acquirer as well as the target (Karim \& Mitchell, 200o; Ranft \& Lord, 2002; Lewin, Massini \& Peeters, 2011). However, the more diverse the acquirer's technological base, the greater the complexity and uncertainty, and the greater the disruption in routines is likely to be. Hence, it is expected that higher pre-acquisition technological diversity of the acquirer leads to lower post-acquisition total inventive output. Therefore,

Hypothesis 2a. Technological diversity of acquirer negatively affects the post-acquisition total inventive output of the acquirer.

The effects of technological diversity of acquirer, however, differ vis-a-vis exploitative and explorative capabilities, opportunities, and outputs. Greater diversity in technological base of the acquirer means greater PACAP (Zahra \& George, 2002) as well as greater number of relevant technological opportunities available to it both within and outside its core domains (Klevorick et al., 1995). Since acquirer TBF is likely to have substantial knowledge about it core domains, it would need relatively lesser amount of new but complementary knowledge in order to access and exploit the available opportunities in its core domains. Technological M\&As may provide the needed knowledge relatively quickly and enable the acquirer to exploit those opportunities. However, greater diversity in technological base also means a lack of focus and depth in competencies as well as greater costs of search and coordination due to greater complexity (Nesta \& Saviotti, 2005). Hence, technological diversity beyond certain optimal level is likely to undermine the ability of the acquirer to find and utilize fruitful complementarities with the target's technological base and exploit the existing opportunities within its own core domains or explore new opportunities in the core domains of the target. Therefore,

Hypothesis $2 b$. Technological diversity of acquirer has a curvilinear (inverted-U) effect on post-acquisition exploitative output of the acquirer.

Hypothesis 2c. Technological diversity of acquirer has a curvilinear (inverted-U) effect on post-acquisition explorative output of the acquirer.

\subsubsection{Technological Similarity and Post-Acquisition Search for opportunities}

Technological similarity refers to the degree of commonality or extent of comparability between the technological bases of the acquirer and the target. Earlier research suggests that technological similarity is an important predictor of quanti- 
ty of post-acquisition inventive output of the acquirers (Ahuja and Katila, 2001; Cloodt et al., 2006; Colombo \& Rabbiosi, 2014). However, others have found that it does not have significant impact on post-acquisition total inventive output (Makri et al., 2010) or exploitative and explorative output (Phene et al., 2012). Nevertheless, as these studies have suggested, a moderate amount of technological similarity is necessary because it facilitates the appreciation, assimilation, and integration of the technological bases of the two firms (Grant, 1996b; Ranft \& Lord, 2002). Too low or no similarity hinders integration and exploitation of technological bases whereas too high similarity causes unproductive redundancies and lack of new technological opportunities. Therefore,

Hypothesis 3a. Technological similarity between the acquirer and the target has a curvilinear (inverted-U) effect on post-acquisition total inventive output of the acquirer.

The effects of technological similarity between the acquirer and target, however, tend to differ vis-a-vis exploitative and explorative search (Phene et al., 2012). Greater technological similarity implies that the PACAP and RACAP of both firms relates to the same technology domains and similar (if not the same) technologies and that both firms are likely to have already exploited a significant portion of technological opportunities available to them separately. Consequently, higher technological similarity means that the merger or acquisition does not significantly expand the acquirer's ability to access those technological opportunities in its existing domains of activity that were already inaccessible to it. Therefore,

Hypothesis $3 b$. Technological similarity between the acquirer and the target negatively affects post-acquisition exploitative output of the acquirer.

As noted earlier, it is reasonable to assume that the acquirer is likely to benefit more when it has a moderate amount of technological similarity with the target but the core technological competencies of the two firms span different technology domains. This is because of the fact that moderate similarity facilitates the integration of technological bases of the two firms and the difference in competencies affords the acquirer access to new technological opportunities in one or more new technology domains via the target. Hence, moderate similarity allows the acquirer to utilize the substitutabilities and complementarities with target's technological base for exploring untapped opportunities in the target's core domains. On the other hand, greater similarity implies that the acquirer already possesses a significant level of technological competencies for operating in target's core domains and the target may have already tapped a large part of the valuable technological opportunities relevant to its own technological base. Therefore,

Hypothesis 3c. Technological similarity between the acquirer and the target has a curvilinear (inverted-U) effect on post-acquisition explorative output of the acquirer. 
The hypothesized effects of independent variables on dependent variables are summarized in Figure 5.1.

\section{FIGURE 5.1}

\section{Hypothesized Effects of Independent Variables*}

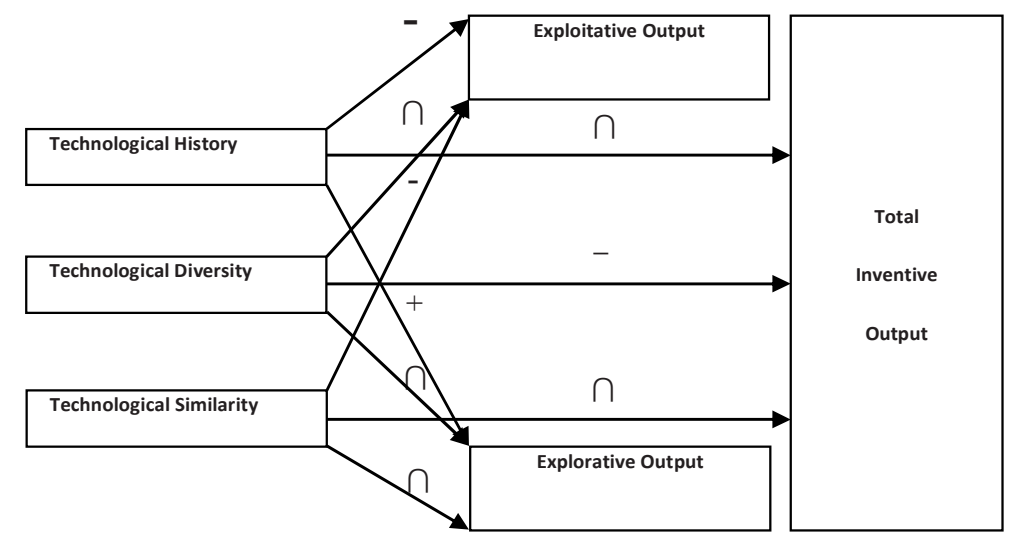

* The signs +, -, and $\cap$ indicate positive, negative, and inverted-U effect, respectively.

\subsection{EMPIRICAL ANALYSIS}

\subsubsection{Empirical Design, Data, and Sample}

We began the study with a set of 65 technology-based firms that have a long history of patenting in information and communication technologies and identified all their M\&A transactions between 1985 and 2009 from SDC Platinum. We found 4316 corporate transactions of various types related to these firms during the period. Due to our interest in "technological" acquisitions, we limited the analysis to only those transactions where the target had at least one patent application to its credit during the 5 years before the acquisition date. Further, we restricted the analysis to only those transactions in which a firm acquired $50 \%$ or more of the target and eliminated all other transactions, including those in which a firm acquired partial stake before and/or after it had already acquired at least 50\% stake in the target. We also excluded transactions involving joint ventures. Finally, in order to ascertain the post-acquisition patenting activity for a reasonable amount of time, we restricted the analysis to the period 1985-2005. Our final sample is comprised of 42 firms from 4 countries, 8 different industries (2-digt SIC) as their primary area of business, and 160 technological M\&A transactions by these firms during the 21-year period. 
We used the patent applications of sample firms ${ }^{25}$ filed in the US as the indicator of technological output and obtained these data from PATSTAT (Sep2010 version). However, we used inventions rather than patents as the unit of measurement whereby DOCDB family was considered as a representation of an invention regardless of the number of the patents in the family. In doing so, we used earliest filing date in the family as the reference date for temporal sequencing of inventions.

We obtained financial information about our sample firms from Standard \& Poor's Compustat.

Frame of reference. We used M\&A transaction as the frame of reference. Hence, all the measures were computed in relation to each transaction and independent of other transactions in the sample.

Period of analysis. We used 3-year period for pre- and post-acquisition analysis from the effective date of acquisition. However, for post-acquisition analysis, we consider first year as the lag period for the effects of acquisition to manifest in patent data. Therefore, the 3-year post-acquisition period starts at the end of the first year after the date of transaction.

Deflation index. In order to control for increasing propensity of patenting over time, we deflated all the measures involving quantity of inventive output (Almeida \& Phene, 2004; Phene et al., 2012). The deflator index was calculated for each transaction separately as the total number of inventions in the 121 IPC classes related to our sample during the post-acquisition period of analysis divided by the total number of inventions in those classes during the pre-acquisition period of analysis.

\subsubsection{Measurement: Dependent Variables}

We tested our hypotheses in two steps. In the first step, we used post-acquisition inventive output as the dependent variable. In the second step, we used exploitation, exploration, and excursion as dependent variables.

\subsubsection{Post-Acquisition Total Inventive Output}

Inventive output refers here to the total number of inventions by a firm whereby each invention is either a singleton or represents a distinct patent family. A patent

\footnotetext{
${ }^{25}$ Theoretically, patent profile of a firm includes the patents of the focal firm as well as those of its subsidiaries. However, in order to be certain about the profile, we included only those patents in the sample whereby the name of our sample firm was part of the name of patent applicant. Moreover, we excluded those patents that belonged to a joint venture of the firm. For instance, we considered all the patents belonging to Siemens whereby "Siemens" was part of the name of applicant while excluding the patents where name of applicant was "Nokia-Siemens".
}

136 
family includes more than one patent that are variations of a single invention. We used patent family rather than patents per se as the measure of inventive output because we sought to measure those inventions that are new to the firm as well as new to the world. Use of patent family as a measure of inventive output helps control for the increase in quantity of patents by the firms that are due to incremental changes in their existing inventions or due to strategic motives such as gaining leverage in negotiations or blocking the competitors from entering particular technologies (Blind et al., 2006; Blind et al., 2009).

We measured the inventive output of the acquirer for the pre- and postacquisition periods separately as the total number of inventions during the respective 3-year period from the effective date of acquisition. However, post-acquisition output was measured for the 3-year period starting from the second year after the date of acquisition. This is because of the fact that first year after acquisition is likely to constitute a period during which $R \& D$ processes of the acquirer and the target are integrated before the effects of their integrated knowledge can possibly manifest in the post-acquisition inventive output of the acquirer (Paruchuri, Nerkar \& Hambrick, 2006; Puranam, Singh \& Chaudhuri, 2009; Graebner et al., 2010).

Post-acquisition inventive output of the acquirer can be partitioned into three components in relation to the pre-acquisition technological competencies of the acquirer and the target: the invention may be the result of existing technological competencies of the acquirer, of the technological competencies of the target, or new technological competencies that emerged due to the acquisition. We refer to these as exploitative output, explorative output, and excursive output, respectively.

\subsubsection{Exploitative and Explorative Output}

Exploitation refers to the pursuit of technological opportunities in those technology domains of which the firm already possesses significant amount of technological knowledge and expertise. In other words, technology domains in which the firm has already been active and frequent contributor of new technological knowledge represent core technological competencies of the firm and hence the pursuit of technological opportunities in those domains constitutes exploitation. This is because of the fact that such a pursuit tends to be based primarily on the technological knowledge that the firm already possesses.

In order to measure exploitation, first we identified the core technology domains of the acquirers and the targets as those classes in which the firm had above-average number of inventions with reference to all the classes in which the focal firm had at least one invention during pre-acquisition period (cf. Phene et al., 2012). That is, the average was computed as the total number of inventions by a given firm divided by the number of classes in which the firm had at least one 
invention. We used the core of each firm in pre-acquisition period as the frame of reference for measuring changes in the nature of post-acquisition output of the acquirers. Following Phene et al. (2012), we measured exploitative output as the increase in total number of inventions in core classes of the acquirer during postacquisition period, deflated by the index, while no-increase and decrease in contribution of core classes are treated as zero increase.

On the other hand, exploration refers to the pursuit of technological opportunities in those technology domains of which the firm does not possesses but deliberately seeks to acquire the knowledge and develop the expertise. Firms can aim at a limited number of such domains due to the complexities of search process of invention, constraints of absorptive capacity, and the costs of managing diversity in R\&D project portfolio. Accordingly, we measured explorative output as the post-acquisition increase in the number of inventions of acquirer, deflated by the index, in those classes that comprised the core of the acquisition target and that were not part of the core of the acquirer during the pre-acquisition period.

\subsubsection{Measurement: Independent Variables}

\subsubsection{Acquirer's Technological History}

Technological history refers to a firm's prior record of inventive output. We operationalized history as pre-acquisition inventive output of the acquirer as the total number of inventions by the acquirer during the 3 -year period before the effective date of acquisition. It is worth noting here that inventive output has also been used previously as a proxy of the size of the "knowledge stock" of the firm (e.g., Roper \& Hewitt-Dundas, 2015). However, since this measure essentially quantifies the technological history of the firm, we used it as a measure of history.

\subsubsection{Acquirer's Technological Diversity}

Technological diversity refers to the degree of variety within the technological knowledge base of the firm. Technological diversity has been commonly measured using either Jacquemin-Berry entropy measure or Herfindahl index. We chose Herfindahl index because it is simpler as well as well-known (Quintana-García \& Benavides-Velasco, 2008; Gambardella \& Torrisi, 1998). It is based on the idea that greater the concentration of a firm's patents in a few technology domains the lesser the firm's technological diversification and vice versa. This index ranges between o and 1 whereby technological diversity is higher when the index value is closer to 1 and vice versa. However, existing implementation of this index is possible only at one level of the patent classification hierarchy that involves an unrealistic assumption that all categories at that level are equidistant in the technology space. This assumption is likely to result in imprecise and possibly misleading measurement of technological diversity. Therefore, we used Herfindahl index to 
create a new multilevel composite index of diversification (CID) for any given firm $i$ at three levels: IPC section (level 1), classes (level 2), and subclasses (level 3).

$$
\mathrm{CID}_{i}=\sqrt[m]{\operatorname{HID}_{\mathrm{k}}^{\frac{1}{\mathrm{k}}} \cdot \operatorname{HID}_{\mathrm{k}-1}^{\frac{1}{\mathrm{k}-1}} \cdot \operatorname{HID}_{\mathrm{k}-2}^{\frac{1}{\mathrm{k}-2}} \ldots \operatorname{HID}_{\mathrm{k}-\mathrm{m}}^{\frac{1}{\mathrm{k}-\mathrm{m}}}}
$$

Where $\mathrm{m}$ is the number of measurement levels in classification hierarchy, $\mathrm{k}$ represents the lowest level thereof, and

$$
\mathrm{HID}=1-\mathrm{HHI}=1-\frac{\sum \mathrm{P}_{\mathrm{j}}^{2}}{\mathrm{n}}
$$

Where $P$ is the proportion of a firm's inventions in a technology field/domain $j$ and $n$ is the total number of technology domains at a given level.

Using the CID, we measured the pre-acquisition diversity of the acquirers on the basis of their total inventive output during the 3-year period prior to the effective date of each M\&A transaction.

\subsubsection{Technological Similarity}

Technological similarity refers to the degree of overlap between the technological knowledge bases of two firms. Prior research suggests that it plays an important role in determining the extent to which acquirer can benefit from the knowledge of the target (e.g., Ahuja \& Katila, 2001; Cassiman et al., 2005; Cloodt et al., 2006; Makri et al., 2010; Phene et al., 2012; Colombo \& Rabbiosi, 2014; Sears \& Hoetker, 2014). Accordingly, various patent-based measures of similarity have been used in the literature. Since we were interested in the degree of similarity between the core technological competences of the acquirer and target, we measured technological similarity as the total number of inventions of acquirer in those technology classes which were part of the core of the acquirer as well as the target.

\subsubsection{Measurement: Control Variables}

\subsubsection{Target's Technological History}

Technological history refers to a firm's prior record of inventive output. Like the acquirers, targets' technological history may affect the contribution of their inventive capabilities to the inventive output of the acquirer (Ahuja \& Katila, 2001; Cloodt et al., 2006; Phene et al., 2012). Since different targets are likely to differ in terms of their inventive capabilities, we controlled for their history measured as the total number of inventions in its core classes during three years before the effective date of acquisition.

\subsubsection{Acquirer's Size}

Size of the firm is known to be associated with organizational inertia and slack resources (Hannan \& Freeman, 1984; Audia \& Greve, 2006). The former is likely to 
induce exploitation whereas the latter is likely to stimulate exploration. Moreover, size of the acquirer may significantly affect the scale and scope of R\&D (Cohen \& Levinthal, 1990), and hence inventive output. Therefore, we controlled for acquirer's size measured as the log of its total assets in the year prior to the year of acquisition (Phene et al., 2012).

\subsubsection{Acquirer's RED Intensity}

It is well known that the size of R\&D expenditures affects the inventive output of the firm (Jaffe, 1986; Acs \& Audretsch, 1988). Firms differ in terms of their R\&D expenditures (Baysinger \& Hoskisson, 1989; Chen \& Miller, 2007). This fact is particularly relevant in the context of M\&As because R\&D inputs as well as the outputs significantly vary during the pre- and post-acquisition periods (Hitt et al., 1991; Szücs, 2014). Therefore, we controlled for R\&D intensity measured as total $R \& D$ expenditure of the acquirer divided by its total revenue in the year prior to the year of acquisition (Phene et al., 2012).

\subsubsection{MEA Propensity}

M\&As are important vehicles for time compression in extending the stock of resources and capabilities and access to new technological opportunities (Dierickx \& Cool, 1989; Ranft \& Lord, 2002). While technological M\&As involving majority stake are expected to impact the inventive capabilities of the acquirer directly, technological M\&As involving minority interest are also likely to affect these capabilities through access to new technological opportunities as well as spillovers (Cohen \& Levinthal, 1990). Besides, non-technological M\&As may also affect the inventive capabilities of the acquirer indirectly through access to new productmarkets as well as their impact on the scale and scope of firm's operations. Moreover, more frequent acquirers leverage the technological capabilities of the targets better than their less experienced acquirers (Puranam \& Srikanth, 2007). Therefore, M\&A propensity, defined as the frequency of a firm's involvement in M\&As during a certain period, may affect the technological opportunities available to it as well as its inventive capabilities. We controlled for M\&A propensity measured as the number of all M\&A transactions by an acquirer during the 3-year period prior to the effective date of each transaction.

\subsubsection{Joint Ventures}

Joint ventures (JVs) are a peculiar kind of inter-firm partnerships in which two or more firms create, own, and control a semi-independent entity (Hagedoorn, 2002). These are often used as an alternative to M\&As (Hennart \& Reddy, 1997). Technology-based firms usually engage in R\&D joint ventures (Hagedoorn, 2002). The engagement in joint ventures may affect the awareness of and access to technological opportunities as well as inventive capabilities of the firms through vari- 
ous mechanisms (Hagedoorn \& Wang, 2012) such as human recourse mobility and social networks across the JV and parent firms (Sampson, 2007). Therefore, we controlled for the effects of joint ventures by including the total number of joint ventures by the acquirer during three years before the effective date of each $M \& A$ transaction.

\subsubsection{Localness}

Geographic location of firms and their spatial and cultural proximity not only affect their access to knowledge but also their ability to share and integrate their knowledge and capabilities in a timely fashion (Jaffe, Trajtenberg \& Henderson, 1993; Weber, Shenkar \& Raveh, 1996). These effects tend to be more pronounced and clearer at the country level. In keeping with the prior research (Ahuja \& Katila, 2001), we controlled for these affects by using a binary categorical variable, localness, that differentiated whether the acquirer and the target in an acquisition transaction belonged to the same or different country.

\subsubsection{Business Relatedness}

Mergers and acquisitions may be used for product-market diversification and/or technological diversification (Montgomery, 1994; Cassiman et al., 2005; Miller, 2006). In both cases, coherent diversifiers tend to benefit more than unrelated diversifiers due to similarities and complementarities among relevant resources and capabilities (Teece et al., 1994; Breschi, Lissoni \& Malerba, 2003; Nesta, 2008; Makri et al., 2010). Accordingly, those technological M\&As whereby acquirer and target operate in the same or related business domains are likely to share, integrate, and leverage their knowledge assets more effectively than those belonging to unrelated business domains. Therefore, we controlled for the effect of business relatedness using a binary categorical variable whereby the acquisition was considered as related and coded as 1 if the acquirer and target belonged to the same 2digit code of Standard Industrial Classification (SIC), otherwise it was considered as unrelated and coded as o.

\subsubsection{Industry}

Industries differ in terms of environmental dynamism, technological opportunities, inventive activities, and productivity of R\&D (Lant \& Mezias, 1992; Klevorick et al., 1995; Lach, 1995; Fung, 2004). However, firms having larger stock of knowledge and technological output tend to be highly diversified (Patel \& Pavitt, 1997; Gambardella \& Torrisi, 1998) and it is difficult to determine which industry such a firm primarily belongs to or which industry mainly affects its strategic initiatives and responses (Sharp, Bergh \& Li, 2013). One possible solution to this boundary problem of diversified firms is to use the broad business domain they operates in. Therefore, we used 2-digit SIC as the basis of the dummy variable to 
control for industry/sectoral differences in R\&D productivity and inventive output.

\subsubsection{Time}

Time affects the prospects and behaviour of firms in numerous and complex ways (Mosakowski \& Earley, 200o). For instance, the availability and value of technological opportunities and strategic responses of firms are usually determined by the macroeconomic rhythms (Amit \& Livnat, 1988) and sequence of different M\&A initiatives by a firm may affect the post-acquisition performance of the acquirer (Shi \& Prescott, 2012). Therefore, such effects need to be controlled for in order to increase the accuracy of analysis. Although time is a continuous variable and it is hard to determine which unit of time is most relevant to the relationships among our chosen set of variables (Mitchell \& James, 2001), we used a dummy variable for time in our analysis using the calendar year of the transaction as the unit of time.

\subsubsection{Standardization of variables}

In order to control for the apparent overdispersion due to the scales of different variables (Hilbe, 2011), non-linear relationships between dependent variables and independent variables, non-essential collinearity among IVs due particularly to the polynomial terms (e.g., Dalal \& Zickar, 2012), and improve the model convergence, we standardized all independent variables. We used one standard deviation for standardizing variables rather than two standard deviations because our primary goal at this stage was to ascertain the significance and direction of the effects of the independent variables rather than the precise magnitude of their effects (cf. Gelman, 2008).

\subsubsection{Model}

Our analysis of M\&A activity spanned 21 years, and the sample firms differed in terms of number of M\&A transactions, hence the data constituted an unbalanced panel. Since our dependent variables were count data, Poisson regression and negative binomial regression were two possible alternatives to models the data. However, the variances of the dependent variables were very high compared to means indicating that the data was overdispersed. The likelihood ratio test of dispersion also confirmed overdispersion. In case of overdispersed count data, negative binomial model is typically recommended (Hausman, Hall \& Griliches, 1984; Hilbe, 2011) and several studies in the research tradition of technological M\&As have used this model on similar grounds (e.g., Cloodt et al., 20o6; Phene et al., 2012). Nevertheless, we also compared goodness of fit of Poisson model and Negative Binomial in terms of Pearson dispersion, deviance, Akaike information criterion (AIC), and Bayesian information criterion (BIC) using generalized linear models (GLM) to our data. The results suggested that the negative binomial mod- 
el managed overdispersion in the data better than the Poisson model. Therefore, we used the former. Further, in order to choose between random-effects and fixed-effects, we used Hausman test which determines whether the unique errors are correlated with the regressors. Some of our models did not converge for fixedeffect model. For others, Hausman test suggested that random-effects model was a better fit. Therefore, we used random-effects negative binomial model for regression analysis.

Our analysis involves two steps. In the first step, we regress the postacquisition inventive output using exploitation, exploration, and excursion together with history, diversity, and similarity as independent variables. We also regress the post-acquisition inventive output using history, diversity, and similarity and excluding exploitation, exploration, and excursion as independent variables. In the second step, we regress exploitation, exploration, and excursion separately using the other three as independent variables.

\subsubsection{Robustness}

In order to eliminate apparent overdispersion from the data (Hilbe, 2011), we eliminated all the outliers in relation to each dependent variable to arrive at our final sample of 42 firms with 160 M\&A transactions from the initial sample.

Since many of our variables are significantly correlated, multicollinearity was a matter of some concern. In order to evaluate the magnitude of multicollinearity, we used two conventional tests on each regression model. First, we calculated the variance inflation factor (VIF) for each model. The highest mean VIF among our models is 6.99. We found that control variables were major contributors to the VIF. This is evident not only from the base models $1,6,11$, and 16 but also from the share of control variables in total VIF of full models. Control variables account for $88 \%$ of total VIF of full Model 5, 94\% of full Model 10, and $92 \%$ of full Model 15. A high VIF which is due to control variables can be safely ignored. Nevertheless, the VIFs of all our regression models are below the recommended threshold of 10 (Chatterjee \& Hadi, 2012). Second, we also applied the collinearity diagnostic routine of Stata, called Coldiag, that examines the conditioning of the matrix of independent variables using the procedures of Belsley, Kuh, and Welsch (1980). The condition numbers of our full models are far below the threshold of 30 as recommended by Belsley et al. These two tests suggest that multicollinearity in our models is within the acceptable limits.

\subsection{RESULTS}

The descriptive statistics, as reported in Table 5.1, suggest that the sample firms are highly technology-intensive as indicated by two variables: post-acquisition total inventive output and acquirer's technological history. Both these variables measure the patent applications for inventions filed by the firms during a 3-year 
period before and after the acquisition, respectively. On the other hand, the target firms had much smaller number of filings. Moreover, the sample firms were highly technologically diversified as indicated by the variable "technological diversity", the mean value of which is close to 1 .

Our first hypothesis concerned the role of technological history of the acquirers in the post-acquisition total inventive output (Hypothesis 1a), exploitative output (Hypothesis 1b), and explorative output (Hypothesis 1c) as mutually exhaustive components of post-acquisition total inventive output. We predicted that acquirer's technological history curvilinearly (inverted-U) affects postacquisition total inventive output (Hypothesis 1a). An inverted-U relationship exists when the linear term of the variable is positive and significant while its quadratic term is negative and significant (Haans, Pieters, \& He, 2015). Our Model 5 (Table 5.2) shows support for our hypothesis as the co-efficient of quadratic term of technological history is negative and significant $(\beta=-0.06, \mathrm{p}<0.01)$ and that of the linear term is positive and significant $(\beta=0.16, \mathrm{p}<0.05)$. We predicted a negative effect of acquirer's technological history on exploitative output (Hypothesis 1b). Our Model 10 (Table 5.3) shows support for our hypothesis $(\beta=-2.43$, $\mathrm{p}<0.001)$. On the other hand, we predicted that acquirer's technological history positively affects post-acquisition explorative output (Hypothesis 1c). However, our Model 15 (Table 5.4) shows that this hypothesis is not supported ( $\beta=-0.46$, $\mathrm{p}>0.05)$.

Our second hypothesis concerned the role of technological diversity of the acquirer in the post-acquisition total inventive output (Hypothesis 2a) as well as exploitative output (Hypothesis 2b) and explorative output (Hypothesis 2c). We predicted that acquirer's technological diversity negatively affects post-acquisition total inventive output (Hypothesis 2a). Our Model 5 (Table 5.2) shows support for our hypothesis as the co-efficient of the linear term of technological diversity is significant and negative $(\beta=-0.51, \mathrm{p}<0.001)$. We predicted a curvilinear (inverted$\mathrm{U})$ effect of acquirer's diversity on post-acquisition exploitative output (Hypothesis 2b). Our Model 10 (Table 5.3) shows partial support for our hypothesis as both the co-efficients of linear term $(\beta=-1.49, \mathrm{p}<0.001)$ and quadratic term of technological diversity $(\beta=-1.02, p<0.01)$ are negative and significant suggesting that technological diversity negatively affects post-acquisition exploitative output. Similarly, we predicted a curvilinear (inverted-U) effect of acquirer's diversity on explorative output (Hypothesis 2c). Our Model 15 (Table 5.4) shows partial support for our hypothesis as the co-efficient of the quadratic term of technological diversity is negative and significant $(\beta=-0.56, \mathrm{p}<0.05)$ but the co-efficient of the linear term is not significant. This indicates an overall negative effect of acquirer's diversity on explorative output.

Our third hypothesis concerned the role of technological similarity between the acquirer and target in the post-acquisition total inventive output (Hy- 
pothesis 3a) as well as the exploitative output (Hypothesis $3 \mathrm{~b}$ ) and explorative output (Hypothesis 3c). We predicted a curvilinear (inverted-U) effect of technological similarity on post-acquisition total inventive output (Hypothesis za). As our Model 5 (Table 5.2) shows, we did not find support for this hypothesis $(\beta=0$, $\mathrm{p}>0.05)$. We also predicted that technological similarity negatively affects postacquisition exploitative output (Hypothesis 3b). As our Model 10 (Table 5.3) shows, we did not find support for our hypothesis $(\beta=0.31, p>0.05)$. On the other hand, we predicted a curvilinear (inverted-U) effect of technological similarity on post-acquisition explorative output (Hypothesis 3c). Our Model 15 (Table 5.4) shows partial support for this hypothesis as indicated by its negative and significant quadratic term $(\beta=-0.76, \mathrm{p}<0.05)$ whereas the linear term is positive but not statistically significant, suggesting an overall negative effect.

Finally, the results of some of our control variables are also worth noting. First, acquirer's size significantly positively affects the post-acquisition total inventive output (Table 5.2: $\beta=0.45, \mathrm{p}<0.01$ ) and exploitative output (Table 5.3: $\beta=$ 2.84, $\mathrm{p}<0.001$ ) but it has no significant effect on explorative output (Table 5.4: $\beta=$ $0.38, \mathrm{p}>0.05)$. Second, acquirer's R\&D intensity negatively affects the postacquisition total inventive output (Table 5.2: $\beta=-0.18, \mathrm{p}<0.01$ ) but it has no significant effect on exploitative or explorative output. Third, acquirer's M\&A propensity, frequency of joint ventures, and localness of M\&As do not have any significant effect on post-acquisition total inventive output, exploitative output or explorative output. Finally, business relatedness of the acquirer and target significantly positively affects the exploitative output (Table 5.3: $\beta=0.84, \mathrm{p}<0.05$ ) but has no significant effect on explorative output or post-acquisition total inventive output.

The results of analysis in relation to all hypotheses are summarized in Table 5.5.

\subsection{DISCUSSION}

Prevailing theory suggests that firms tend to favour exploitation over exploration because the latter involves uncertainty and remoteness of returns in terms of time as well as the locus of organizational activity (March, 1991; Levinthal \& March, 1993; Lavie et al., 2010). Our research confirms this theory but we propose that this understanding can be refined further. TBFs ultimately search for technological opportunities and seek to develop capabilities in view of those opportunities. Therefore, the technological opportunities as the content of organizational search and domains as the context of search serve as a better frame of reference than capabilities per se. 


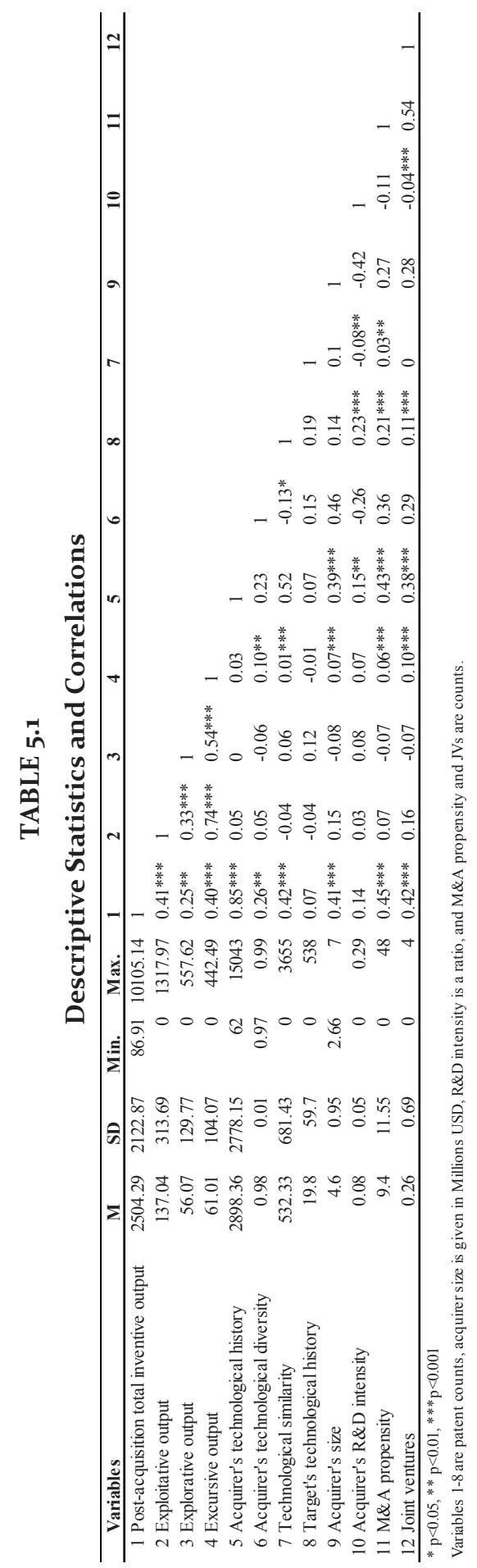




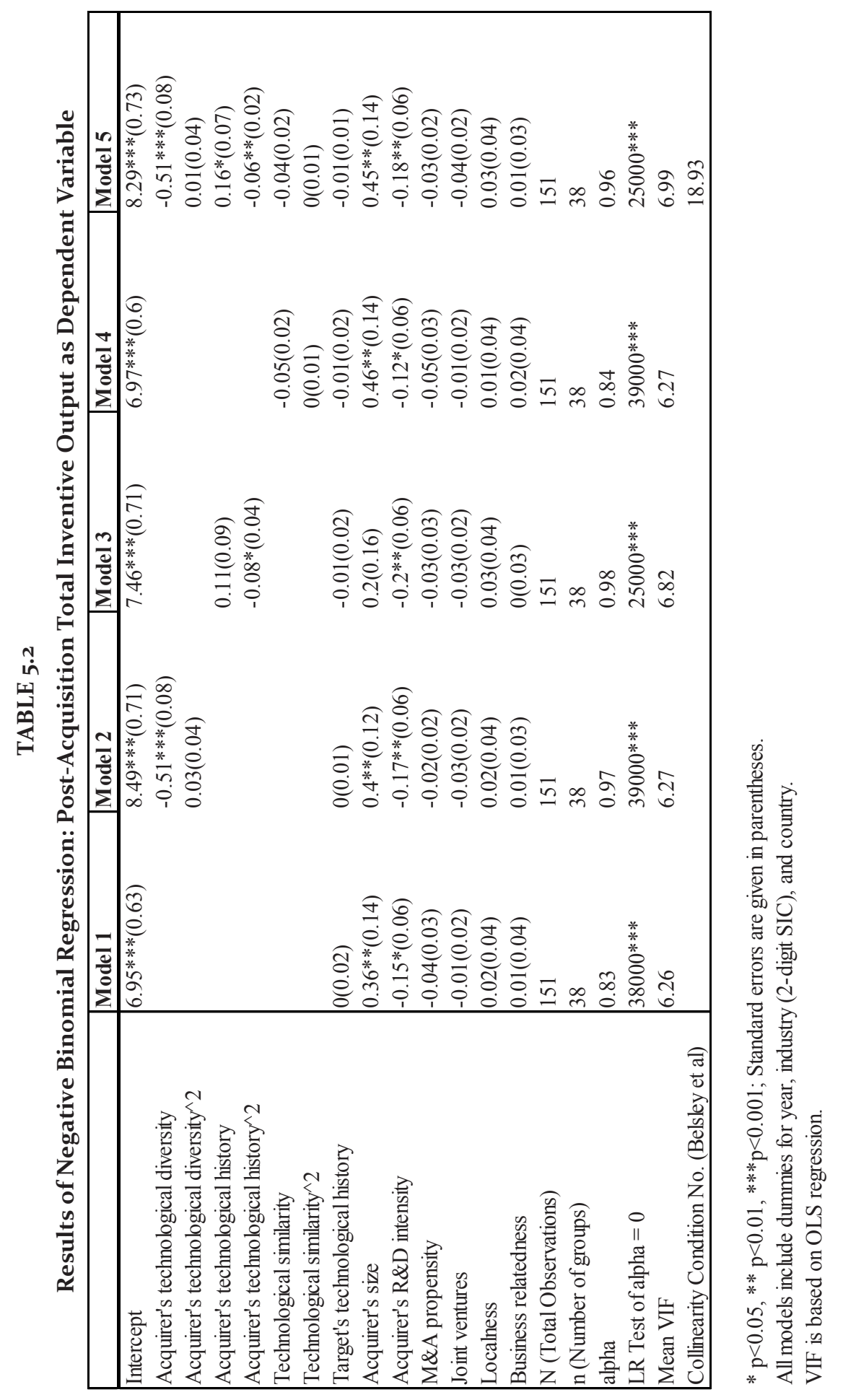




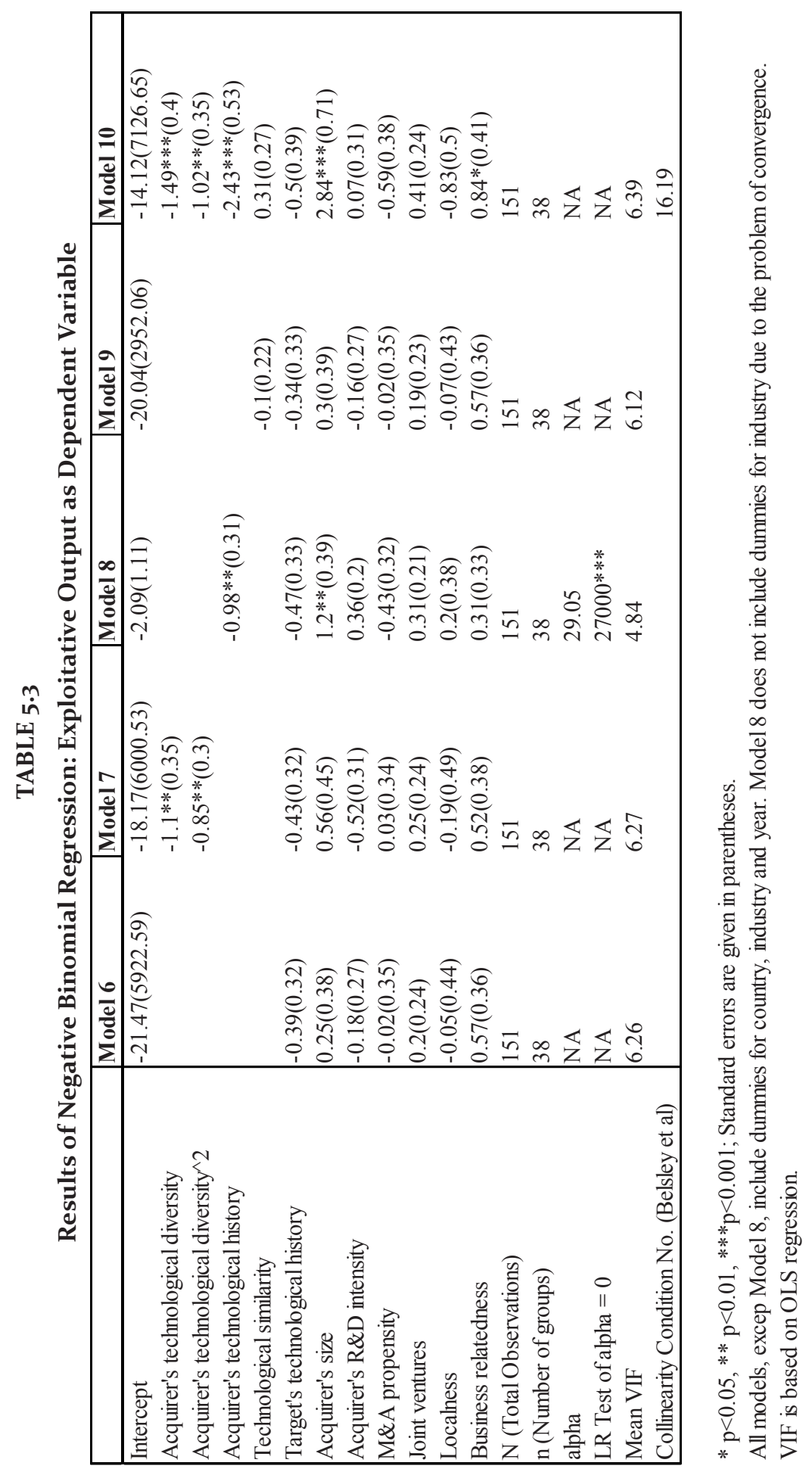




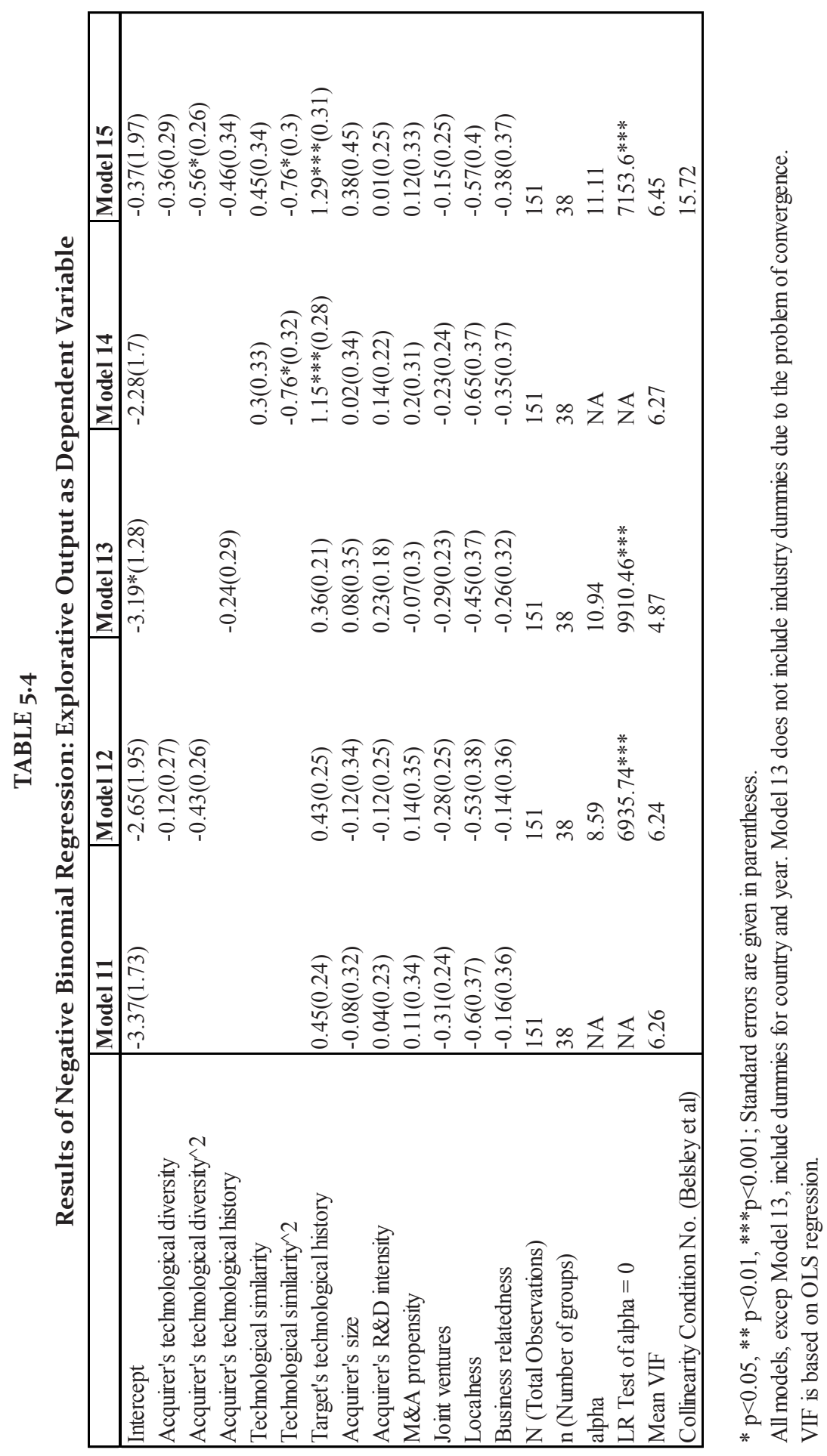




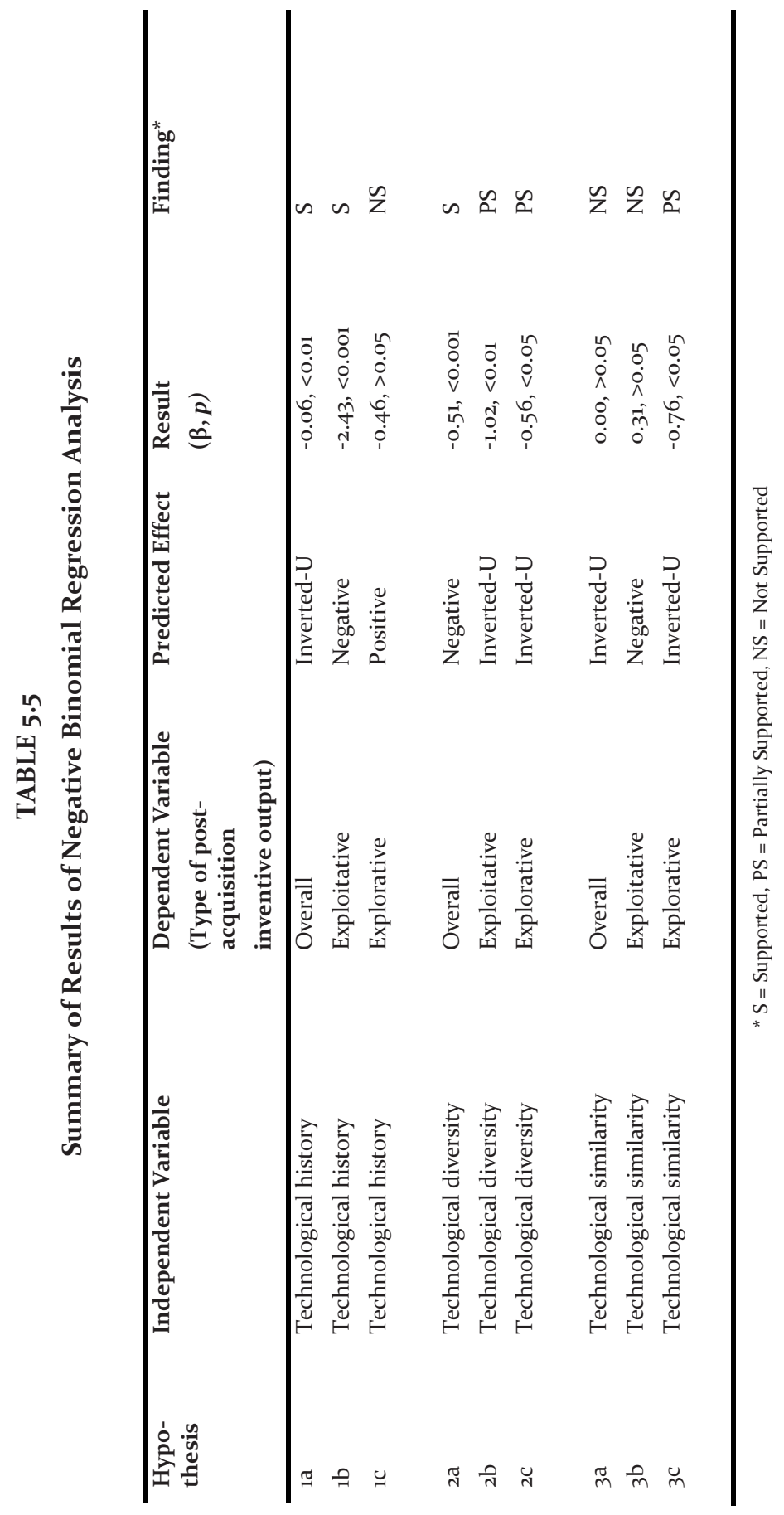


Extant theory also suggests that the size of existing knowledge base of the firm is an important determinant of its absorptive capacity (Cohen \& Levinthal, 1990) and hence the ability to explore and exploit technological opportunities. Accordingly, prior research on M\&As has conventionally used the stock of its patents as an indicator of the stock of its knowledge (e.g., Makri et al., 2010; Phene et al., 2012; Roper \& Hewitt-Dundas, 2015). However, in theory, knowledge stock should have positive effect on exploration of new technological opportunities and inventive output. Our research suggests that the knowledge stock measured in terms of prior inventive output has no significant effect on post-acquisition explorative output, negatively affects exploitative output, and curvilinearly (inverted-U) affects total inventive output. This suggests that prior stock of inventions is a representation of firm's "realized absorptive capacity" rather than the "potential absorptive capacity" (Zahra \& George, 2002). Therefore, prior stock of inventions is an indicator of technological history of the firm in that it indicates the extent to which the firm has already exploited the technological opportunities available to it given its capabilities.

Prior research suggests that large TBFs tend to be technologically highly diversified (e.g., Patel \& Pavitt, 1997) and enjoy cumulative advantage (Malerba \& Orsenigo, 1995; Bergek et al., 2013) by systematically diversifying their technological base in related areas (Stuart \& Podolny, 1996; Rosenkopf \& Nerkar, 2001; Quintana-García \& Benavides-Velasco, 2008), particularly through technological M\&As (Makri et al., 2010). Our research suggests that greater technological diversification helps TBFs benefit from technological M\&As to a limited extent in terms of exploitative and explorative output but the overall effect is negative in terms of post-acquisition total inventive output. This leaves us with the speculation that greater technological diversity is linked with excursion that, in turn, may be stimulated and guided by technological imperatives in existing product domains of the TBF (cf. Gambardella \& Torrisi, 1998; Miller, 2006) or complementarities that emerge due to the combination of acquirer's and target's capability bases (Makri et al., 2010; Hagedoorn \& Wang, 2012; Yu, Umashankar \& Rao, 2015). This could be an interesting avenue for further research.

The case of technological similarity is intriguing. We found support for only one hypothesis that concerns its effect on explorative output. It corroborates extant theory that some degree of similarity is necessary for integrating the knowledge bases of the acquirer and the target and accessing technological opportunities in the latter's core domains (Cloodt et al., 2006). For other hypotheses, we also used a hierarchical index of similarity constructed on the basis of same principles that we used in our composite index of diversity (CID). The results of those regressions were similar to the ones reported here. This situation leads us to the conclusion that the lack of support for our other hypotheses actually supports the recent theory that technological complementarities are more important than the 
similarities and substitutabilities for realizing new technological opportunities (Makri et al., 2010; Hagedoorn \& Wang, 2012; Yu et al., 2015).

In short, our research suggest that large TBFs benefit from technological M\&As for realizing new technological opportunities. However, TBFs seem to face an important challenge. As they exhaust the low-hanging fruits of their technological capabilities, their inventive output increases but the technological opportunities available to them in their own domains as well as the targets' domains deplete. Moreover, only part of the increase in post-acquisition total inventive output accrues due to technological similarities between the technological bases of the acquirer and the target, and that too, because similarities and substitutabilities may allow the acquirer to tap new technological opportunities in the core domains of their targets (Hagedoorn \& Wang, 2012; Dibiaggio, Nasiriyar \& Nesta, 2014). This gives us a reason to speculate that a large part of the increase in postacquisition output accrues because of the technological complementarities between the technological bases of the acquirer and target as already suggested by researchers (Makri et al., 2010; Hagedoorn \& Wang, 2012; Yu et al., 2015). Therefore, investigating the source of complementarities and their role in the realization of technological opportunities may be a fruitful avenue for further research.

\subsubsection{Contribution}

Our research makes theoretical and empirical contribution to the management theory from three perspectives. First, it paves the way for better incorporation of theory of organizational learning in strategic management research by clarifying the ambiguity surrounding the dichotomous notions of exploitation and exploration (Gupta et al., 2006). It highlights the boundary problem caused by the use of content of knowledge or capabilities as the basis for demarcation between the two. Instead, we suggest that knowledge and capabilities are not the end but the means to identify and exploit opportunities (Klevorick et al., 1995; Foss et al., 2013). Therefore, we suggest that the locus or context of opportunities is better frame of reference for understanding organizational search, particularly through R\&D. This perspective may be particularly helpful in understanding excursion (Shapiro, 1986; Roberts, 1989; Kantorovich \& Ne'eman, 1989; Van Andel, 1994; Seymore, 20o9; de Rond, 2014).

Second, our study contributes to the theory of large technology-based firms. Prevailing theory suggests that large TBFs tend to be highly diversified with regards to technology domains and hence they have "distributed" rather than "distinctive" core competencies (Patel \& Pavitt, 1997; Granstrand, Patel \& Pavitt, 1997), though their core competencies are identifiable in terms of their focus on product domains (Gambardella \& Torrisi, 1998). In line with prior research (e.g., Helfat, 1994; Stuart \& Podolny, 1996; Rosenkopf \& Nerkar, 2001; Breschi et al., 2003; Miller, 2006), this study sheds more light on how TBFs diversify technologi- 
cally-through interaction among exploitation, exploration, and excursion-while maintaining their core strategically.

Finally, our research also contributes to increasingly rich and active research tradition of resource-based theory of firm growth through technological M\&As (Ahuja \& Katila, 2001; Cloodt et al., 2006; Makri et al., 2010; Phene et al., 2012; Yu et al., 2015). Prior research is justifiably founded on resource-based theory and hence used acquirer's knowledge stock as the frame of reference. However, surprisingly, the analysis is often focused on the attributes of the target. Our study helps correct this imbalance by focusing on the key attributes of the acquirer. In doing so, we also propose a modification in the operationalization of the "knowledge stock". Empirical evidence suggests that prior stock of inventions is either negatively or curvilinearly (inverted-U) related to the inventive output and it seems counterintuitive that increase in the stock or resource-base leads to decrease in output. Therefore, we propose that the stock of inventions is an indicator of the "realized absorptive capacity" (Zahra \& George, 2002), or more broadly, technological history, rather than the knowledge stock.

\subsubsection{Practical Implications}

Our research has implication for management practice in pre-acquisition as well as well as post-acquisition periods. In M\&A decisions, selection of the target for technological acquisition is one of the key challenges, particularly when acquirers have highly diversified technological base. Our research suggests that technological acquisitions are more useful when the strategic intent is to search for technological opportunities beyond the existing technological core of the acquirer. This is because of the fact that if acquiring firm's technological base is already broad and diverse, M\&As may not contribute much to the existing core. Therefore, technological M\&As tend to be more useful for exploration than for exploitation, particularly when technological base of the acquirer is highly diverse. Hence, those targets are more promising whose technological competencies belong to those domains that are related to but significantly different from existing domains of the acquirer. Moreover, targets with greater realized absorptive capacity tend to be better in terms of quantity of explorative output. However, caution is due with regards to the technological diversity of the target. The evidence from our research suggests that targets of explorative acquisitions having too low or too high technological diversity do not contribute significantly to the post-acquisition total inventive output.

As the post-acquisition total inventive output increases, the managers can rightfully claim the success of the strategic decision of acquisition and its implementation. However, they need to remind themselves that, given the technological history and capability of their firm, reservoirs of technological opportunities tend to be limited and deplete with exploitation. Therefore, they need to 
closely watch the rate of increase in inventive output due to a given acquisition. As soon as the rate begins to slow down, they need to take stock of the technological opportunities available to the firm in its current domains of activity. Needless to say that they should welcome the unintended and emergent technological opportunities all along with due consideration to their impact on expected returns on R\&D.

\subsubsection{Limitations and Future Directions}

This research is about multi-technology multi-product TBFs which is a complex phenomenon. Consequently, we have taken a small slice of the whole phenomenon of TBFs. In doing so, we also focused only on technological aspect, and hence invention. Consequently, we have ignored the product-market aspect, that is innovation. However, it cannot be overemphasized that technology strategy and technological performance of such firms is determined by the dynamics of pushand-pull across their technology and product domains (Di Stefano, Gambardella \& Verona, 2012) because technologies, firms, and industries co-evolve (Nelson, 1994; Stuart \& Podolny, 1996; Grodal, Gotsopoulos \& Suarez, 2014). Besides, firms may use several possible combinations of exploitation and exploration across technology and product domains. For instance, a firm may explore in one technology domain and exploit its technological capabilities in other technology or product domain. Or else, it may exploit and explore in the technology domains in connection with its exploitation and exploration strategy in the product domains, and vice versa.

The phenomenon of excursion seems to be a promising avenue for further investigation. For instance, we need to learn about how excursion sprouts, how it is sustained, and how it becomes part of espoused strategic intent and exploration (cf. Fry, 1987; Maletz \& Nohria, 2001; Burgelman \& Grove, 1996, 2007; Lechevalier et al., 2014). Moreover, we need to learn how firms benefit from excursive inventions. This may be particularly interesting because we found that R\&D intensity had a significant positive effect on excursive output while it had no significant effect on exploitative or explorative output. This suggests that a significant portion of R\&D of technologically diversified firms goes to excursive output making technological diversification a self-reinforcing phenomenon. Additionally, we conjecture that firms that exhibit higher levels of excursion tend to have greater opportunities for targeted exploration. Likewise, we expect that exploratory initiatives of firms are directed towards those domains wherein their excursions are greater. It is worth noting here that we also performed the same analysis on excursive output as dependent variable but we did not find any of the independent variables in our set to be significantly related to it. Nevertheless, it seems to us that excursion is an interesting and promising avenue for future research, at least in the context of technological M\&As. 


\subsubsection{Concluding Remarks}

This research presented in this paper was largely shaped by serendipitous discovery of excursion as a distinct facet of $R \& D$. This discovery sprouted from the fact that our initial research design was based on prevalent understanding of exploitation and exploration as mutually exhaustive phenomena. However, the results of our initial analysis did not fit well with our understanding of the theories of technological change (evolutionary theory), firm (resource-based theory and knowledge-based theory), firm growth (multi-product multi-technology firms, diversification, corporate coherence, and M\&As), organizational learning (exploitation-exploration and local search), competition (Red-Queen races), invention (recombination theory), and innovation (appropriability, push-pull). Forced by this situation, we revisited the extant theory about the motivations and constraints of acquirers regarding technological M\&As. This helped us see the extant theory of organizational learning and R\&D strategies of TBFs in a new light. Consequently, we learned that excursion may provide useful insights about several aspects of management theory. However, caution is due because excursion does not work in isolation; it goes hand in hand with exploitation and exploration. 



\section{CONCLUSION}

Technological change has been a subject of interest in sociology, economics, and management for a long time. It is central topic of the multidisciplinary scientific field of inquiry referred as economics and management of innovation, or simply, innovation studies. Technological change can be studied at various levels ranging from a single technical effect, such as transmitting a message over long distance, to a gestalt effect that changes the configuration of productive activities in a society or civilization in a given era. From this perspective, the highest level of technological change involves aggregation of numerous technological changes at lower levels and their accumulative impact not only changes the structure of productive activities but also relative contribution of various activities in total output. Determining the locus and direction of such aggregate technological change is one of the central problems in economics and management of innovation and we endeavored to address this problem through a doctoral research project. This $\mathrm{PhD}$ thesis presents the rationale and findings of this project.

Technological changes emanate from the complex interactions and coevolution of social, technical, and economic factors. We conceived that these interacting factors form a gestalt that we term as socio-techno-economic system (STES). It is essentially a social system and it evolves due to the interactions among the factors and forces endogenous to it. The gestalt effect of accumulated technological changes in a given era manifests in the structural changes in this system, part of which manifestly appears in structural changes in the well-known industrial sub-system in the form of emergence of new industries and decline of the old. We refer to this gestalt effect as transformation technological change (TTC). In this context, the big question is: does there exist an 'epicenter' of TTC in the STES, and if so, is it possible to locate that epicenter in order to understand the change, and ideally, predict one? Due to the enormous scope of this question, we adopted a trans-disciplinary approach to comprehend various aspects of this system in parts as well as a whole.

Location of an epicenter involves the examination of certain 'place' or an objective space that contains the epicenter as well as the affected zone. Conventionally, innovation scholars have used product space (industries or sectors) as the place of inquiry for examining technological changes. This approach may be useful to depict technological change because that is where the effects of technological changes become manifestly visible. However, it is highly doubtful that this approach can help predict technological changes. Due to this reason, we followed Peter Drucker's suggestion to locate the origins of technological changes in the knowledge space, or the universe of knowledge. Therefore, from a sociological perspective of evolution, we consider knowledge as the DNA of the STES and ideas as the 'genes' of this system. Technological changes sprout in the form of ideas 
and knowledge in the knowledge space long before it manifests in the product space. Therefore, the former can serve as better 'place' of inquiry for depicting and predicting the nature of technological changes. We posit that structural change in the STES follows structural change in the knowledge space.

The universe of knowledge is composed of two well-known socially constructed domains, science and technology, and each domain has a certain structure in the form of sub-domains that vary in age and size. Due to the dynamics of aging and cross-fertilization within and across these domains and sub-domains, not only the size but also the number of sub-domains change within each domain. The structure of the universe of knowledge in terms of domains and sub-domains represents the input as well as the output sides of knowledge production process because these domains represent the reservoirs of scientific and technological knowledge. The producers of knowledge use extant knowledge from these domains and sub-domains as part of their inputs to produce new knowledge that flows back into these knowledge domains and sub-domains. These producers include universities and technology-based firms (TBFs) as two institutional groups. These two sets of producers significantly differ in terms of their motivations and conduct to produce knowledge. In general, TBFs tend to be more effective and efficient in sensing and responding to the needs of useful knowledge in a timely fashion due to the unforgiving accountability mechanism of the market as the arena of their performance. Since TBFs are major contributors to technological knowledge, we focused on these as an important producer group.

We attempted to capture important aspects of the input and output sides of knowledge production as well as the motives and conduct of the producers of knowledge. We began with the examination of the input/output sides through two separate studies. First we studied how scientific domains and sub-domains emerge and co-evolve. To this end, we took the scientific subfield of innovation studies as a case of an emerging domain and used a scientometric approach to examine the changes in intellectual structure of the field during a 21-year period. In this study, presented in the first essay, contrary to our expectation of increasing interdisciplinarity in the field, we found that it is becoming increasingly compartmentalized between economics and management disciplines and each segment is becoming increasingly self-contained. Then we examined how technology domains and sub-domains emerge and co-evolve. In this study, presented in the second essay, we used history approach to explore the origins and timing of the discoveries and inventions related to information and communication technologies (ICTs) during the 18th and 19th centuries. We found that inventive activity tends to be contextualized by the societal and technological problems prevailing at a given time that are pursued by scientists and engineers working in the domains of science and technology. We found that the knowledge-based perspective of technology is more useful than the artifact-based view of technology in the study of technological change. Moreover, there is a significant time lag between a 
discovery or invention and its appearance in the product space, making it possible to predict the locus and direction of technological change. We also found that knowledge and technologies created in relation to one problem area are often applicable to numerous other areas not even imagined by the original creators, causing the diffusion of knowledge across domains and sub-domains and hence co-evolution.

Regarding the producers of knowledge, we also conducted two separate studies. In one study, presented in the third essay, we examined how emergence and co-evolution of scientific and technology domains lead to structural changes in the STES. In this study, we conceived the universe of technological knowledge as represented by extant stock of discoveries and inventions. Then using the network theoretic approach and methods we examined all available US patent data till 2009. We identified clusters of technologies on the basis of their similarities in terms of the areas of their application or use. As a result, we identified three successive episodes of TTC during the 2oth century; the first took place around 1950 (shift of locus from mechanical-engineering related technologies to chemicalengineering related technologies), the second occurred around 1980 (shift of locus from chemical-engineering related technologies to ICT-related technologies), and the third took off around 2000 that is currently afoot (seemingly away from ICTrelated technologies). This study also suggests that the pattern of technological diversification of TBFs may be an important determinant and a leading indicator of TTC.

In the second study concerning the producers of knowledge, as presented in the fourth essay, we followed up on the insights from the preceding study by focusing on the TBFs' search for new technological opportunities through technological mergers and acquisitions (M\&As). The extant research on technological M\&As has frequently used resource-based and organizational learning theories, suggesting that TBFs seek to exploit their existing technological capabilities or explore new capabilities. We departed from conventional understanding of exploitation-exploration duality and posited that the dynamics of organizational learning on both these fronts can be more clearly understood by modifying extant theory from two perspectives. First, TBFs ultimately search for technological opportunities as the ends and need technological capabilities as the means to those ends. Therefore, opportunities are better frame of reference than capabilities for understanding organizational search behavior. Second, extant research implicitly assumes that organizational search is deliberate and intended, while the emergent and unintended aspect of search is either subsumed under exploration or neglected altogether. We refer to the pursuit of such opportunities as excursion and suggest that this needs to be separated from exploration in order to understand the latter more clearly. We tested our hypotheses using 160 TM\&A deals of large TBFs from global information and communication technology sector during a 21-year period and measuring the post-acquisition inventive output of acquirers. Results 
suggest that technological diversity of acquirer negatively affects the postacquisition exploitative and explorative output, technological history of acquirer curvilinearly affects the post-acquisition total inventive output and negatively affects the exploitative output, whereas technological similarity between acquirer and target negatively affects the explorative output.

Our research suggests that TTC can be understood by taking a holistic perspective that encompasses the producers of knowledge as well as the origins of knowledge inputs and destinations of knowledge outputs. TTC is a desirable phenomenon from the perspective of advancement of STES but it involves significant costs. Arguably, a significant part of these costs is associated with the uncertainty triggered by the shift in the locus of technological activity. The greater the uncertainty and the longer it stays, the greater will be the costs. Perhaps the best way of managing TTC is to develop an integrated global intelligence system in order to monitor structural changes in the universe of knowledge. This system will require purpose-specific indexing of scientific knowledge and classification of technological output. With this understanding, we end this research project and hope that this thesis will serve as a useful base for new beginnings. 


\section{BIBLIOGRAPHY}

\section{A}

Acedo, F. J., Barroso, C., \& Galan, J. L. 2006. The resource-based theory: dissemination and main trends. Strategic Management Journal, 27(7): 621-636.

Acs, Z. J., \& Audretsch, D. B. 1988. Innovation in large and small firms: An empirical analysis. The American Economic Review, 78(4): 678-69o.

Agarwal, R., \& Hoetker, G. 2007. A Faustian bargain? The growth of management and its relationship with related disciplines. Academy of Management Journal, 50(6): 1304-1322.

Ahn, Y. Y., Bagrow, J. P., \& Lehmann, S. 2010. Link communities reveal multiscale complexity in networks. Nature, 466 (7307), 761-764.

Ahuja, G., \& Katila, R. 2001. Technological acquisitions and the innovation performance of acquiring firms: A longitudinal study. Strategic Management Journal, 22(3): 197-220.

Almeida, P., \& Phene, A. 2004. Subsidiaries and knowledge creation: The influence of the MNC and host country on innovation. Strategic Management Journal, 25(8/9): 847-864.

Altman, D. G. 1995. Sustaining interventions in community systems: on the relationship between researchers and communities. Health Psychology, 14(6): 526536.

Amit, R., \& Livnat, J. 1988. Diversification strategies, business cycles and economic performance. Strategic Management Journal, 9(2): 99-110.

Anderson, N., De Dreu, C. K. W., \& Nijstad, B. A. 2004. The routinization of innovation research: a constructively critical review of the state-of-the-science. Journal of Organizational Behavior, 25(2): 147-173.

Anderson, P., \& Tushman, M. L. 1990. Technological discontinuities and dominant designs: A cyclical model of technological change. Administrative Science Quarterly, 35: 604-633.

Antonelli, C. 2014. The economics of innovation, new technologies and structural change. Routledge.

Antonelli, C., 2008. Localised technological change: Towards the economics of complexity. Routledge, London.

Arora, A., \& Gambardella, A. 2010. Ideas for rent: An overview of markets for technology. Industrial and Corporate Change, 19(3): 775-803.

Arthur, B., 2009. The nature of technology: What it is and how it evolves. Simon \& Schuster, Free Press, New York.

Arthur, W. B. 2007. The structure of invention. Research Policy, 36(2): 274-287.

Arthur, W. B. 2009. The nature of technology: What it is and how it evolves. NY: Free Press.

Arundel, A. 2001. The relative effectiveness of patents and secrecy for appropriation. Research Policy, 30(4), 611-624.

Ashby, W. R. 1956. An introduction to cybernetics (Vol. 2). London: Chapman \& Hall.

Astley, W. G. 1985. The two ecologies: Population and community perspectives on organizational evolution. Administrative Science Quarterly, 224-241.

Audia, P. G., \& Greve, H. R. 2006. Less likely to fail: Low performance, firm size, and factory expansion in the shipbuilding industry. Management Science, 52(1): 83-94.

Austin, J. H. 2003. Chase, chance, and creativity: The lucky art of novelty. MIT Press. 
Austin, R. D., Devin, L., \& Sullivan, E. E. 2012. Accidental innovation: Supporting valuable unpredictability in the creative process. Organization Science, 23(5): 1505 $-1522$.

Ayres, R. U. 1990a. Technological transformations and long waves. Part I. Technological Forecasting and Social Change, 37(1): 1-37.

Ayres, R. U. 199ob. Technological transformations and long waves. Part II. Technological Forecasting and Social Change, 37(2): 111-137.

B

Balsiger, P. W. 2004. Supradisciplinary research practices: History, objectives and rationale. Futures, 36(4): 407-421.

Barabási, A-L. 2003. Scale-free networks. Scientific American, 288: 60-69.

Bargh, J. A., \& McKenna, K. Y. A. 2004. The Internet and social life. Annual Review of Psychology, 55: 573-590.

Basalla, G., 1988. The evolution of technology. Cambridge University Press, Cambridge.

Baysinger, B., \& Hoskisson, R. E. 1989. Diversification strategy and R\&D intensity in multiproduct firms. Academy of Management Journal, $32(2): 310-332$.

Belsley, D., Kuh, E., \& Welsch, R. 1980. Regression Diagnostics: Identifying influential data and sources of collinearity. New York: Wiley.

Benner, M., \& Waldfogel, J. 2008. Close to you? Bias and precision in patent-based measures of technological proximity. Research Policy, 37(9): 1556-1567.

Bergek, A., \& Onufrey, K. 2013. Is one path enough? Multiple paths and path interaction as an extension of path dependency theory. Industrial and Corporate Change, 23(5): 1261-1297.

Bergek, A., \& Onufrey, K. 2014. Is one path enough? Multiple paths and path interaction as an extension of path dependency theory. Industrial and Corporate Change, 23(5): 1261-1297.

Bergek, A., Berggren, C., Magnusson, T., \& Hobday, M. 2013. Technological discontinuities and the challenge for incumbent firms: Destruction, disruption or creative accumulation? Research Policy, 42 (6): 1210-1224.

Bergek, A., Jacobsson, S., Carlsson, B., Lindmark, S., \& Rickne, A. 2008. Analyzing the functional dynamics of technological innovation systems: A scheme of analysis. Research policy, 37(3): 407-429.

Bernal, J. D. 1969. Science in history: The scientific and industrial revolutions (Vol. 2). England: Penguin Books.

Berry, A. 1899. A short history of astronomy. NY: Charles Scribner's Sons.

Bijker, W., 1995. Of bicycles, bakelite, and bulbs: Toward a theory of socio-technical change. MIT Press, Cambridge, MA.

Blind, K., Cremers, K., \& Mueller, E. 2009. The influence of strategic patenting on companies' patent portfolios. Research Policy, 38(2): 428-436.

Blind, K., Edler, J., Frietsch, R., \& Schmoch, U. 2006. Motives to patent: Empirical evidence from Germany. Research Policy, 35(5): 655-672.

Borgman, C. L., \& Furner, J. 2002. Scholarly communication and bibliometrics. Annual Review of Information Science and Technology, 36: 2-72.

Boring, E. G. 1955. Dual role of the Zeitgeist in scientific creativity. The Scientific Monthly, 8o: 101-106.

Börner, K., Chen, C. M., \& Boyack, K. W. 2003. Visualizing knowledge domains. Annual Review of Information Science and Technology, 37: 179-255.

Boyack, K. W., Klavans, R., \& Börner K. 2005. Mapping the backbone of science. Scientometrics, 64(3): 351-374. 
Braun, E \& MacDonald, S., 1982. Revolution in miniature: The history and impact of semiconductor electronics. Cambridge University Press.

Bredt, J. F., \& Anderson, T. 1999. "Method of three dimensional printing." U.S. Patent 5,902,441, issued May 11, 1999.

Breschi, S., \& Catalini, C. 2010. Tracing the links between science and technology: An exploratory analysis of scientists' and inventors' networks. Research Policy, 39(1), 14-26.

Breschi, S., Lissoni, F., \& Malerba, F. 2003. Knowledge-relatedness in firm technological diversification. Research Policy, $32(1): 69-87$.

Breschi, S., Malerba, F., \& Orsenigo, L. 200o. Technological regimes and Schumpeterian patterns of innovation. The Economic Journal, $110(463): 388-410$.

Brusoni, S., Prencipe, A., \& Pavitt, K. 2001. Knowledge specialization, organizational coupling, and the boundaries of the firm: why do firms know more than they make? Administrative science quarterly, 46(4): 597-621.

Burgelman, R. A., \& Grove, A. S. 1996. Strategic dissonance. California Management Review, 38(2): 8-28.

Burgelman, R. A., \& Grove, A. S. 2007. Let chaos reign, then rein in chaos-repeatedly: Managing strategic dynamics for corporate longevity. Strategic Management Journal, 28(10): 965-979.

Burns, R. W. 1993. Alexander Bain, a most ingenious and meritorious inventor. Engineering Science and Education Journal, 2(2):85-93.

Burns, R. W., 2003. Communications: An international history of the formative years. The Institution of Engineering and Technology, London.

Burns, R. W., 2004. Communications: An international history of the formative years. The Institution of Engineering and Technology, London.

C

Cajori, F., 1962. A history of physics. Dover Publications, Inc, NY.

Callon, M., Courtial, J. P., \& Laville, F. 1991. Co-word analysis as a tool for describing the network of interactions between basic and technological research: The case of polymer chemistry. Scientometrics, 22(1): 155-205.

Carlsson, B., \& Stankiewicz, R., 1995. On the nature, function and composition of technological systems. In B. Carlsson, (Ed.), Technological systems and economic performance: The case of factory automation: 21-56. Kluwer Academic Publishers, Dordrecht.

Carroll, G. R., Bigelow, L. S., Seidel, M. D. L., \& Tsai, L. B. 1996. The fates of de novo and de alio producers in the American automobile industry 1885-1981. Strategic Management Journal, 17S1: 117-137.

Cartwright, S., \& Schoenberg, R. 2006. Thirty years of mergers and acquisitions research: Recent advances and future opportunities. British Journal of Management, $17\left(\mathrm{~S}_{1}\right)$ : S1-S5.

Carud, R. 1997. On the distinction between know-how, know-why, and knowwhat. Advances in Strategic Management, 14: 81-101.

Cassidy, C.M., \& Loree, D. 2001, Dynamics of knowledge transfer among multimarket competitors (141 - 174). In Joel A.C. Baum \& Henrich R. Greve (Eds) Multiunit organization and multimarket strategy (Advances in Strategic Management, Vol. 18), Emerald Group Publishing Limited.

Cassiman, B., Colombo, M. G., Garrone, P., \& Veugelers, R. 2005. The impact of M\&A on the R\&D process: An empirical analysis of the role of technological-and market-relatedness. Research Policy, 34(2): 195-220. 
Chandler, A. D. \& Hikino, T. 1997. The large industrial enterprise and the dynamics of modern economic growth (24-57) In A. D. Chandler, F. Amatori, \& T. Hikino (Eds) Big business and the wealth of nations. Cambridge University Press.

Chandler, A. D. \& Hikino, T. 2004. Scale and scope: The dynamics of industrial capitalism. Harvard University Press.

Chandler, A. D. 1977. The visible hand: The managerial revolution in American business. Harvard University Press.

Chandler, A. D. 2005. Shaping the industrial century: The remarkable story of the evolution of the modern chemical and pharmaceutical industries. Harvard University Press.

Chatterjee, S. \& Hadi, A. S. 2012. Regression analysis by example (5th ed.). NJ: John Wiley \& Sons, Inc.

Chaudhuri, S., \& Tabrizi, B. 1999. Capturing the real value in high-tech acquisitions. Harvard Business Review, 5: 123-130.

Chen, E. L., Katila, R., McDonald, R., \& Eisenhardt, K. M. 2010. Life in the fast lane: Origins of competitive interaction in new vs. established markets. Strategic Management Journal, 31(13): 1527-1547.

Chen, W. R., \& Miller, K. D. 2007. Situational and institutional determinants of firms' R\&D search intensity. Strategic Management Journal, 28(4):369-381.

Christensen, C. M., \& Rosenbloom, R. S. 1995. Explaining the attacker's advantage: Technological paradigms, organizational dynamics, and the value network. Research Policy, 242: 233-257.

Christensen, C. M., Suárez, F. F., \& Utterback, J. M. 1998. Strategies for survival in fastchanging industries. Management Science, 44(12-part-2), S207-S220.

Cima, M., et al. 1995. "Three-dimensional printing techniques." U.S. Patent 5,387,380, issued February 7, 1995.

Cloodt, M., \& Hagedoorn, J. 2012. Mergers and acquisitions and firm performance (391404). In Michael Dietrich, Jackie Krafft (Eds) Handbook on the economics and theory of the firm. Cheltenham, UK: Edward Elgar.

Cloodt, M., Hagedoorn, J., \& Van Kranenburg, H. 2006. Mergers and acquisitions: Their effect on the innovative performance of companies in high-tech industries. Research Policy, 35(5): 642-654.

Cohen, W. M., \& Levinthal, D. A. 1989. Innovation and learning: The two faces of R\&D. The Economic Journal, 99(397): 569-596.

Cohen, W. M., \& Levinthal, D. A. 1990. Absorptive capacity: A new perspective on learning and innovation. Administrative Science Quarterly, 35(1): 128-152.

Colombelli, A., Krafft, J., \& Quatraro, F. 2014. High-growth firms and technological knowledge: Do gazelles follow exploration or exploitation strategies? Industrial and Corporate Change, 23(1): 261-291.

Colombo, M. G., \& Rabbiosi, L. 2014. Technological similarity, post-acquisition R\&D reorganization, and innovation performance in horizontal acquisitions. Research Policy, 43(6): 1039-1054.

Conti, R., Gambardella, A., \& Mariani, M. 2013. Learning to be Edison: Inventors, organizations, and breakthrough inventions. Organization Science, 25(3): 833849 .

Coopersmith, J. 1993. Facsimile's false starts. IEEE Spectrum, February Issue, 46-49.

Cottrill, C. A., Rogers, E. M., \& Mills, T. 1989. Co-citation analysis of the scientific literature of innovation research traditions: diffusion of innovations and technology transfer. Knowledge: Creation, Diffusion, Utilization, 11(2): 181-208. 
Cowan, R., \& Foray, D. 1997. The economics of codification and the diffusion of knowledge. Industrial and Corporate Change, 6(3): 595-622.

Culnan, M. J., Oreilly, C. A., \& Chatman, J. A. 1990. Intellectual structure of research in organizational-behavior, 1972-1984: a cocitation analysis. Journal of the American Society for Information Science, 41(6): 453-458.

Curley, R. (Ed) 2010. Turning points in history: The Britannica guide to inventions that changed the modern world. Britannica Educational Publishing, New York.

D

Dalal, D. K., \& Zickar, M. J. 2012. Some common myths about centering predictor variables in moderated multiple regression and polynomial regression. Organizational Research Methods, 15(3): 339-362.

Datta, A., \& Jessup, L. M. 2013. Looking beyond the focal industry and existing technologies for radical innovations. Technovation, 33(10-11): 355-367.

de Rond, M. 2014. The structure of serendipity. Culture and Organization, 20(5): 342358.

Derfus, P. J., Maggitti, P. G., Grimm, C. M., \& Smith, K. G. 2008. The Red Queen effect: Competitive actions and firm performance. Academy of Management Journal, 51(1): 61-80.

DeWitt, R. 2010. Worldviews: An introduction to the history and philosophy of science. Wiley-Blackwell.

Di Stefano, G., Gambardella, A., \& Verona, G. 2012. Technology push and demand pull perspectives in innovation studies: Current findings and future research directions. Research Policy, 41(8): 1283-1295.

Dibiaggio, L., Nasiriyar, M., \& Nesta, L. 2014. Substitutability and complementarity of technological knowledge and the inventive performance of semiconductor companies. Research Policy, 43(9): 1582-1593.

Dierickx, I., \& Cool, K. 1989. Asset stock accumulation and sustainability of competitive advantage. Management Science, 35(12): 1504-1511.

DiMaggio, P. J. 1995. Comments on "What theory is not". Administrative Science Quarterly, 40(3): 391-397.

Dosi, G. \& Grazzi, M. 2010. Technology and Economics. On the nature of technologies: knowledge, procedures, artifacts and production inputs. Cambridge Journal of Economics, 34(1): 173-184.

Dosi, G. 1982. Technological paradigms and technological trajectories: a suggested interpretation of the determinants and directions of technical change. Research policy, 11(3): 147-162.

Drucker, P. F. 1969. The age of discontinuity: Guidelines to our changing society. London: Cox \& Wyman Ltd.

Dunning, J. H., \& Lundan, S. M. 2008. Multinational enterprises and the global economy. Edward Elgar Publishing.

Dutta, S., Narasimhan, O., \& Rajiv, S. 1999. Success in high-technology markets: Is marketing capability critical? Marketing Science, 18(4): 547-568.

E

Eigenfactor Project 2009. Ranking and mapping scientific knowledge. Bergstrom Lab in the Department of Biology at the University of Washington. http://www.eigenfactor.org [13 August 2009].

Eisenstadt, S. N. 1964. Social change, differentiation and evolution. American Sociological Review, 29(3): 375-386.

Eisenstein, E. L. 1980. The printing press as an agent of change. NY: Cambridge University Press. 
Eisenstein, E. L. 1980. The printing press as an agent of change. NY: Cambridge University Press.

Esfeld, M. 2001. Holism in philosophy of mind and philosophy of physics. Kluwer Academic Publishers.

$\mathbf{F}$

Fagerberg, J., \& Verspagen, B. 2009. Innovation research: the emerging structure of a new scientific field. Research Policy, 38(2): 218-233.

Faulkner, P., Lawson, C., \& Runde, J. 2010. Theorising technology. Cambridge Journal of Economics, 34(1): 1-16.

Fleming, L. 2001. Recombinant uncertainty in technological search. Management Science, 47(1): 117-132.

Fleming, L., \& Sorenson, O. 2001. Technology as a complex adaptive system: evidence from patent data. Research policy, 30(7), 1019-1039.

Fleming, L., \& Sorenson, O. 2004. Science as a map in technological search. Strategic Management Journal, 25(8-9), 909-928.

Fortunato, S. 2010. Community detection in graphs. Physics Reports, 486(3-5): 75-174.

Foss, N. J., Lyngsie, J., \& Zahra, S. A. 2013. The role of external knowledge sources and organizational design in the process of opportunity exploitation. Strategic Management Journal, 34: 1453-1471.

Fraas, L., Partain, L. (Eds) 2010. Solar cells and their applications (2nd ed.). John Wiley \& Sons: NJ.

Frable, D. E. S. 1997. Gender, racial, ethnic, sexual, and class identities. Annual Review of Psychology, 48: 139-162.

Frankort, H. T., Hagedoorn, J., \& Letterie, W. 2012. R\&D partnership portfolios and the inflow of technological knowledge. Industrial and Corporate Change, 21(2): 507-537.

Freeman, C. \& Louçã, F. 2001. As time goes by : From the industrial revolutions to the information revolution. Oxford University Press.

Freeman, C. 1994. The economics of technical change. Cambridge Journal of Economics, 18(5): 463-514.

Frickel, S., \& Gross, N. 2005. A general theory of scientific/intellectual movements. American Sociological Review, 70(2): 204-232.

Frumkin, M. 1945. The origin of patents. Journal of the Patent Office Society, 27 (3): 143149 .

Fry, A. 1987. The post-it note: An intrapreneurial success. SAM Advanced Management Journal, 52(3): 4 .

Fung, M. K. 2004. Technological opportunity and productivity of R\&D activities. Journal of Productivity Analysis, 21(2): 167-181.

G

Gambardella, A., \& Torrisi, S. 1998. Does technological convergence imply convergence in markets? Evidence from the electronics industry. Research policy, 27(5): 445-463.

Gambling, W. A., 200o. The rise and rise of optical fibers. IEEE Journal on Selected Topics in Quantum Electronics, 6(6): 1084-1093.

Garfield, E. 1979. Is citation analysis a legitimate evaluation tool? Scientometrics, 1: 359-375.

Garratt, G. R. M., \& Mumford, A. H. 1952. The history of television. Proceedings of the IEE - Part IIIA: Television, 99(17): 25-40. 
Geels, F. W. 2004. From sectoral systems of innovation to socio-technical systems: Insights about dynamics and change from sociology and institutional theory. Research policy, 33(6), 897-920.

Gelman, A. 2008. Scaling regression inputs by dividing by two standard deviations. Statistics in Medicine, 27(15): 2865-2873.

Geroski, P. A., \& Walters, C. F. 1995. Innovative activity over the business cycle. The Economic Journal, 916-928.

Gerybadze, A., \& Reger, G. 1999. Globalization of R\&D: Recent changes in the management of innovation in transnational corporations. Research policy, 28(2): 251-274.

Godin, B. 2010. Innovation without the word: William F. Ogburn's contribution to the study of technological innovation. Minerva, 48(3), 277-307.

Gopalakrishnan, S., \& Damanpour, F. 1997. A review of innovation research in economics, sociology and technology management. Omega-International Journal of Management Science, 25(1): 15-28.

Graebner, M. E., Eisenhardt, K. M., \& Roundy, P. T. 2010. Success and failure in technology acquisitions: Lessons for buyers and sellers. The Academy of Management Perspectives, 24(3): 73-92.

Granstrand, O. 1998. Towards a theory of the technology-based firm. Research Policy, 27: 465-489.

Granstrand, O., \& Sjölander, S. 1990. Managing innovation in multi-technology corporations. Research Policy, 19(1): 35-60.

Granstrand, O., Patel, P., \& Pavitt, K. 1997. Multi-technology corporations: Why they have "distributed" rather than" distinctive core" competencies. California Management Review, 39(4): 8-25.

Grant, R. M. 1996a. Toward a knowledge-based theory of the firm. Strategic Management Journal, $17\left(\mathrm{~S}_{2}\right)$ : 109-122.

Grant, R. M. 1996b. Prospering in dynamically-competitive environments: Organizational capability as knowledge integration. Organization Science, 7(4): 375387.

Greve, H. R. 2007. Exploration and exploitation in product innovation. Industrial and Corporate Change, 16(5): 945-975.

Griffith, B. C., Small, H. G., Stonehill, J. A., \& Dey, S. 1974. The structure of scientific literature II: The macro- and micro-structure of science. Science Studies, 4: 339-365.

Griliches, Z., 1957. Hybrid corn: An exploration in the economics of technological change. Econometrica, 25: 501-522.

Grimpe, C., \& Hussinger, K. 2014. Resource complementarity and value capture in firm acquisitions: The role of intellectual property rights. Strategic Management Journal, 35(12): 1762-1780.

Grodal, S., Gotsopoulos, A., \& Suarez, F. 2015. The Co-evolution of Technologies and Categories during Industry Emergence. Academy of Management Review, $40(3): 423-445$.

Gruber, M., Harhoff, D., \& Hoisl, K. 2013. Knowledge recombination across technological boundaries: scientists vs. engineers. Management Science, 59(4): 837-851.

Gupta, A. K., Smith, K. G., \& Shalley, C. E. 2006. The interplay between exploration and exploitation. Academy of Management Journal, 49(4): 693-706. 
$\mathbf{H}$

Haans, R. F. J., Pieters, C. \& He, Z.-L. 2015. Thinking about U: Theorizing and testing U- and inverted U-shaped relationships in strategy research. Strategic Management Journal. doi: 10.1002/smj.2399

Hagedoorn, J. 2002. Inter-firm R\&D partnerships: An overview of major trends and patterns since 1960. Research Policy, 31(4): 477-492.

Hagedoorn, J., \& Wang, N. 2012. Is there complementarity or substitutability between internal and external R\&D strategies? Research Policy, 41(6): 1072-1083.

Hambrick, D. C., \& Chen, M. J. 2008. New academic fields as admittance-seeking social movements: the case of strategic management. Academy of Management Review, 33(1): 32-54.

Hamel, G., \& Prahalad, C. K. 1989. Strategic intent. Harvard Business Review, 67(3): 6376.

Hannan, M. T., \& Freeman, J. 1984. Structural inertia and organizational change. American Sociological Review, 49(2): 149-164.

Hauser, J. R., Tellis, G. J., \& Griffin, A. 2006. Research on innovation: a review and agenda for Marketing Science. Marketing Science, 25(6): 687-717.

Hausman, J., Hall, B., \& Griliches, Z. 1984. Econometric models for count data with an application to the patents-R\&D relationship. Econometrica, 52: 909-938.

Helfat, C. E., \& Peteraf, M. A. 2003. The dynamic resource-based view: Capability lifecycles. Strategic Management Journal, 24(10): 997-1010.

Helfat, C. E., 1994. Evolutionary trajectories in petroleum firm research-anddevelopment. Management Science, 40(12): 1720-1747.

Hempstead, C.A. (Ed) 2005. Encyclopedia of $20^{\text {th }}$-century technology (Vol. 1) (332-334). NY: Routledge.

Hennart, J. F., \& Reddy, S. 1997. The choice between mergers/acquisitions and joint ventures: The case of Japanese investors in the United States. Strategic Management Journal, 18(1): 1-12.

Herold, E.W., 1976. A history of color television displays. Proceedings of The IEEE, 64(9): 1331-1338.

Hilbe, J. M. 2011. Negative binomial regression (2nd ed). New York: Cambridge University Press.

Hitt, M. A., Hoskisson, R. E., Ireland, R. D., \& Harrison, J. S. 1991. Effects of acquisitions on R\&D inputs and outputs. Academy of Management Journal, 34(3): 693-706.

Hitt, M. A., Hoskisson, R. E., Johnson, R. A., \& Moesel, D. D. 1996. The market for corporate control and firm innovation. Academy of Management Journal, 39(5): 1084-1119.

Hodgson, G. 1998. On the evolution of Thorstein Veblen's evolutionary economics. Cambridge Journal of Economics, 22(4): 415-431.

Hoetker, G., \& Agarwal, R. 2007. Death hurts, but it isn't fatal: The postexit diffusion of knowledge created by innovative companies. Academy of Management Journal, 5o(2): 446-467.

Hoffman, D. L., \& Holbrook, M. B. 1993. The intellectual structure of consumer research: a bibliometric study of author cocitations in the 1st 15 years of the Journal of Consumer Research. Journal of Consumer Research, 19(4): 505-517.

Huff, H. R. 2003. From the lab to the fab: Transistors to integrated circuits (pp. 3-39). In American Institute of Physics International Conference Proceedings, CP683.

Hunt, B.J. 2010. Pursuing power and light: Technology and physics from James Watt to Albert Einstein. The Johns Hopkins University Press. Baltimore, USA. 
Jaffe, A. 1986. Technological opportunity and spillovers of R\&D. American Economic Review, 76: 984-1001.

Jaffe, A. B., Trajtenberg, M., \& Henderson, R. 1993. Geographic localization of knowledge spillovers as evidenced by patent citations. The Quarterly Journal of Economics, 108(3): 577-598.

Jefferson, T. 1972. The life and selected writings of Thomas Jefferson, Koch A and Peden W (eds). The Modern Library: New York.

Jousten, K. (Ed) 2008. Handbook of vacuum technology. WILEY-VCH Verlag GmbH \& Co. KGaA, Weinheim.

K

Kantorovich, A., \& Ne'eman, Y. 1989. Serendipity as a source of evolutionary progress in science. Studies in History and Philosophy of Science (Part A), 20(4): 505529.

Karim, S., \& Mitchell, W. 200o. Path-dependent and path-breaking change: reconfiguring business resources following acquisitions in the US medical sector, 19781995. Strategic Management Journal, 21(10-11): 1061-1081.

Kilby, J. S. 1964. Miniaturized electronic circuits. U.S. Patent No. 3138743 . Washington, DC: U.S. Patent and Trademark Office.

Kleinknecht, A. 1990. Are there Schumpeterian waves of innovations? Cambridge Journal of Economics, 14(1): 81-92.

Klepper, S. 1997. Industry life cycles. Industrial and Corporate Change, 6(1): 145-182.

Klepper, S., \& Graddy, E. 1990. The evolution of new industries and the determinants of market structure. The RAND Journal of Economics, 21(1): 27-44.

Klepper, S., \& Simons, K. L. 1997. Technological extinctions of industrial firms: an inquiry into their nature and causes. Industrial and Corporate Change, 6 (2): 379-46o.

Klepper, S., \& Simons, K. L., 2005. Industry shakeouts and technological change. International Journal of Industrial Organization, 23 (1-2): 23-43.

Klepper, S., \& Thompson, P. 2006. Submarkets and the evolution of market structure. The RAND Journal of Economics, 37(4): 861-886.

Klevorick, A. K., Levin, R. C., Nelson, R. R., \& Winter, S. G. 1995. On the sources and significance of interindustry differences in technological opportunities. Research Policy, 24(2): 185-205.

Kodama, F. 1992. Technology fusion and the new R\&D. Harvard Business Review, 70: $70-78$.

Kogut, B., \& Zander, U. 1993. Knowledge of the firm and the evolutionary theory of the multinational corporation. Journal of International Business Studies, 24(4): 625-645.

Korotayev, A., Zinkina, J., \& Bogevolnov, J. 2011. Kondratieff waves in global invention activity (1900-2008). Technological Forecasting and Social Change, 78(7): 1280-1284.

Kroeber, A. L. 1917. The superorganic. American Anthropologist, 19(2): 163-213.

Kuhn, T. S. 1970. The structure of scientific revolutions (2d ed.). University of Chicago Press: Chicago.

Kuznets, S. 1965. Economic growth and structure. NY: W.W. Norton.

Kuznets, S. 1962. Inventive activity: Problems of definition and measurement (19-52). In: The Rate and Direction of Inventive Activity: Economic and Social Factors. NBER, Princeton University Press. 
L

Lach, S. 1995. Patents and productivity growth at the industry level: A first look. Economics Letters, 49(1): 101-108.

Lant, T. K., \& Mezias, S. J. 1992. An organizational learning model of convergence and reorientation. Organization Science, 3(1): 47-71.

Latham, G. P., \& Pinder, C. C. 2005. Work motivation theory and research at the dawn of the twenty-first century. Annual Review of Psychology, 56: 485-516.

Latour, B. 1987. Science in action: How to follow scientists and engineers through society. Harvard University Press: Cambridge.

Lavie, D., Stettner, U., \& Tushman, M. L. 2010. Exploration and exploitation within and across organizations. The Academy of Management Annals, 4(1): 109-155.

Lawrence, R. J., \& Després, C. 2004. Futures of transdisciplinarity. Futures, 36(4): 397405 .

Lechevalier, S., Nishimura, J., \& Storz, C. 2014. Diversity in patterns of industry evolution: How an intrapreneurial regime contributed to the emergence of the service robot industry. Research Policy, 43(10): 1716-1729.

Leten, B., Landoni, P., \& Van Looy, B. 2014. Science or graduates: How do firms benefit from the proximity of universities? Research Policy, 43(8): 1398-1412.

Levinthal, D. A. 1998. The slow pace of rapid technological change: Gradualism and punctuation in technological change. Industrial and corporate change, $7(2)$ : 217-247.

Levinthal, D. A., \& March, J. G. 1993. The myopia of learning. Strategic Management Journal, 14(S2): 95-112.

Levitas, E., \& Chi, T. 20o1. A real option perspective on the market valuation of a firm's technological competence. In Academy of Management Proceedings, 1: F1-F6, Academy of Management.

Lewin, A. Y., Massini, S., \& Peeters, C. 2011. Microfoundations of internal and external absorptive capacity routines. Organization Science, 22(1): 81-98.

Lievrouw, L. A. 1989. The invisible college reconsidered: Bibliometrics and the development of scientific communication-theory. Communication Research, 16(5): 615-628.

Lipsey, R. G., Carlaw, K. I., \& Bekar, C. T. 2005. Economic transformations: general purpose technologies and long-term economic growth. Oxford University Press.

M

Machlup, F. 1958. An economic review of the patent system (No. 15). US Government Printing Office.

Machlup, F. 1962. The production and distribution of knowledge in the United States (Vol. 278). Princeton university press.

Maggitti, P. G., Smith, K. G., \& Katila, R. 2013. The complex search process of invention. Research Policy, 42(1): 90-100.

Magoun, A. B. 2007. Television: The life story of a technology. Greenwood Press, Wesport, USA.

Makri, M., Hitt, M. A., \& Lane, P. J. 2010. Complementary technologies, knowledge relatedness, and invention outcomes in high technology mergers and acquisitions. Strategic Management Journal, 31(6): 602-628.

Malerba, F. 2002. Sectoral systems of innovation and production. Research Policy, 31(2): 247-264. 
Malerba, F. 2007. Innovation and the dynamics and evolution of industries: Progress and challenges. International Journal of Industrial Organization, 25(4): 675699.

Malerba, F., \& Orsenigo, L., 1995. Schumpeterian patterns of innovation. Cambridge Journal of Economics, 19(1): 47-65.

Maletz, M. C., \& Nohria, N. 2001. Managing in the whitespace. Harvard Business Review, 79(2): 102-11.

March, J. G. 1991. Exploration and exploitation in organizational learning. Organization Science, 2(1): 71-87.

McCain, K. W. 1990. Mapping authors in intellectual space: a technical overview. Journal of the American Society for Information Science, 41(6): 433-443.

McCain, K. W. 1983. The author cocitation structure of macroeconomics. Scientometrics, 5: 277-289.

McClellan, J. E., \& Dorn, H. 2006. Science and technology in world history: An introduction. Johns Hopkins University Press.

McGrath, R. G., \& Nerkar, A. 2004. Real options reasoning and a new look at the R\&D investment strategies of pharmaceutical firms. Strategic Management Journal, 25(1): 1-21.

McNamee, R. C. 2013. Can't see the forest for the leaves: Similarity and distance measures for hierarchical taxonomies with a patent classification example. Research Policy, 42(4): 855-873.

Mercer, D. 2006. The telephone: The life story of a technology. Greenwood Press, Wesport, USA.

Merton, R. K. 1968. The Matthew effect in science: the reward and communication systems of science are considered. Science, 159(3810): 56-63.

Merton, R. K. 1972. Insiders and outsiders: a chapter in the sociology of knowledge. American Journal of Sociology, 77: 9-47.

Merton, R. K. 1973. The sociology of science: Theoretical and empirical investigations. Storer NW (ed). University of Chicago Press: Chicago.

Meyer, H. W. 1971. A history of electricity and magnetism. MIT Press.

Miller, D. J. 2006. Technological diversity, related diversification, and firm performance. Strategic Management Journal, 27(7): 601-619.

Mintzberg, H., \& Waters, J. A. 1985. Of strategies, deliberate, and emergent. Strategic Management Journal, 6(3): 257-272.

Mitchell, T. R., \& James, L. R. 20o1. Building better theory: Time and the specification of when things happen. Academy of Management Review, 26(4): 530-547.

Mokyr, J. 2005. The intellectual origins of modern economic growth. The Journal of Economic History, 65(2): 285-351.

Mokyr, J. 2002. The gifts of Athena: Historical origins of the knowledge economy. NJ: Princeton University Press.

Mokyr, J. 2005. The intellectual origins of modern economic growth. The Journal of Economic History, 65(2): 285-351.

Montgomery, C. A. 1994. Corporate diversification. The Journal of Economic Perspectives, 8: 163-178.

Montgomery, C.A., \& Hariharan, S. 1991. Diversified expansion by large established firms. Journal of Economic Behavior and Organization, 15: 71-89.

Moore, W. E. 1966. Global sociology: the world as a singular system. American Journal of Sociology, 475-482.

Morton, D. 1999. "Viewing television's history," Proceedings of the IEEE , 87(7): 13011304. 
Mosakowski, E., \& Earley, P. C. 200o. A selective review of time assumptions in strategy research. Academy of Management Review, 25(4): 796-812.

Mowery, D. C. \& Rosenberg, N. 1989. Technology and the pursuit of economic growth. Cambridge University Press.

Mowery, D. C. \& Rosenberg, N. 1993. The U.S. national innovation system (29-75). In R. R. Nelson (Ed) National Innovation Systems : A Comparative Analysis. Oxford University Press.

Mowery, D. C. \& Rosenberg, N. 1999. Paths of innovation: technological change in 2othcentury America. Cambridge, UK: Cambridge University Press.

Mudambi, R., \& Swift, T. 2014. Knowing when to leap: Transitioning between exploitative and explorative R\&D. Strategic Management Journal, 35(1): 126-145.

Mumford, M. D., \& Gustafson, S. B. 1988. Creativity syndrome: Integration, application, and innovation. Psychological Bulletin, 103(1): 27-43.

Murmann, J. P. 2013a. The coevolution of industries and important features of their environments. Organization Science, 24(1): 58-78.

Murmann, J. P. 2013b. The co-development of industrial sectors and academic disciplines. Science and Public Policy, 40 (2): 229-246.

$\mathbf{N}$

Nard, C. A. 2008. The law of patents. NY: Aspen Publishers.

Nelson, R., \& Winter, S. 1982. An evolutionary theory of economic change. Cambridge: Harvard University Press.

Nelson, R. R., \& Rosenberg, N. 1998. Science, technological advance and economic growth. In A. D. Chandler, P. Hagstrom \& O. Solvell (Eds) The dynamics firm: The role of technology, strategy, organization, and regions. Oxford University Press.

Nelson, R. R. (Ed) 1993. National innovation systems: A comparative analysis. Oxford University Press.

Nelson, R. R. 1994. The co-evolution of technology, industrial structure, and supporting institutions. Industrial and corporate change 3(1): 47-63.

Nelson, R. R., \& Nelson, K. 2002. Technology, institutions, and innovation systems. Research Policy, 31: 265-272.

Nelson, R. R., \& Sampat, B. N. 2001. Making sense of institutions as a factor shaping economic performance. Journal of Economic Behavior E Organization, 44(1): 31-54.

Nelson, R. R. 2005. Technology, institutions and economic growth. Harvard University Press, Cambridge, MA.

Nelson, R. R. 1962. Introduction, in: The rate and direction of inventive activity: Economic and social factors (1-16). NBER, Princeton University Press.

Nerur, S. P., Rasheed, A. A., \& Natarajan, V. 2008. The intellectual structure of the strategic management field: an author co-citation analysis. Strategic Management Journal, 29(3): 319-336.

Nesta, L. 2008. Knowledge and productivity in the world's largest manufacturing corporations. Journal of Economic Behavior E Organization, 67(3): 886-902.

Nesta, L., \& Saviotti, P. P. 2005. Coherence of the knowledge base and the firm's innovative performance: Evidence from the us pharmaceutical industry. The Journal of Industrial Economics, 53(1): 123-142.

Newman, M. E. J. 2006. Finding community structure in networks using the eigenvectors of matrices. Physical Review, E74, 036104 (available at: arXiv:physics/o605087v3). 
Nissani, M. 1997. Ten cheers for interdisciplinarity: The case for interdisciplinary knowledge and research. The Social Science Journal, 34(2): 201-216.

Nonaka, I. 1994. A dynamic theory of organizational knowledge creation. Organization Science, 5(1): 14-37.

Nonaka, I., \& Takeuchi, H. 1995. The knowledge-creating company: How Japanese companies create the dynamics of innovation. Oxford university press.

Nooy, W. D., Mrvar, A., \& Batagelj, V. 2005. Exploratory social network analysis. Cambridge University Press: Cambridge.

North, D. C. 2005. Understanding the process of economic change. Princeton University Press.

Nunnally, J. C. 1978. Psychometric theory. 2nd ed., McGraw-Hill Book Company: New York.

$\mathbf{O}$

Ogburn, W. F. 1922. Social change: With respect to culture and original nature. NY: B. W. Huebsch, Inc.

Okoroanyanwu, U. 2010. Chemistry and lithography. SPIE and John Wiley \& Sons, Inc., USA.

Osterman, M. 2007. The technical evolution of photography in the 19th century. In Peres, M. R. (Ed) Focal encyclopedia of photography (4th ed.), Elsevier Inc.

$\mathbf{P}$

Palacios-Huerta, I., \& Volij, O. 2004. The measurement of intellectual influence. Econometrica, 72(3): 963-977.

Palomeras, N., \& Melero, E. 2010. Markets for inventors: learning-by-hiring as a driver of mobility. Management Science, 56(5), 881-895.

Paruchuri, S., Nerkar, A., \& Hambrick, D. C. 2006. Acquisition integration and productivity losses in the technical core: Disruption of inventors in acquired companies. Organization Science, 17(5): 545-562.

Patel, P., \& Pavitt, K. 1997. The technological competencies of the world's largest firms: Complex and path-dependent, but not much variety. Research Policy, 26(2): 141-156.

Pavitt, K. 1984. Sectoral patterns of technical change: towards a taxonomy and a theory. Research Policy, 13: 343-73.

Pavitt, K. 1984. Sectoral patterns of technical change: Towards a taxonomy and a theory. Research Policy, 13(6): 343-373.

Pavitt, K. 1998. Technologies, products and organization in the innovating firm: What Adam Smith tells us and Joseph Schumpeter doesn't. Industrial and Corporate Change, $7(3): 433-452$.

Pelosi, G. 2010. The great men in telecommunications: Giovanni Caselli and the Invention of the pantelegraph or fax. IEEE Antennas and Propagation Magazine, 52(3): 194-198.

Peres, M. R. (Ed), 2007. Focal encyclopedia of photography (4th ed.). Elsevier Inc.

Perez, C. 1983. Structural change and assimilation of new technologies in the economic and social systems. Futures, 15(5), 357-375.

Perez, C. 1985. Microelectronics, long waves and world structural change: New perspectives for developing countries. World Development, 13(3): 441-463.

Perez, C. 2010. Technological revolutions and techno-economic paradigms. Cambridge Journal of Economics, 34(1): 185-202.

Perkmann, M., et al., 2013. Academic engagement and commercialisation: A review of the literature on university-industry relations. Research Policy, 42(2), 423442 . 
Phene, A., Tallman, S., \& Almeida, P. 2012. When do acquisitions facilitate technological exploration and exploitation? Journal of Management, 38(3): 753-783.

Pilkington, A., Liston-Heyes, C. 1999. Is production and operations management a discipline? A citation/co-citation study. International Journal of Operations \& Production Management, 19(1): 7-20.

Pilkington, A., \& Meredith, J. 2009. The evolution of the intellectual structure of operations management-1980-2006: a citation/co-citation analysis. Journal of Operations Management, 27(3): 185-202.

Porter, M. E. 1985. Competitive advantage. Free Press, New York.

Porter, T. M., \& Ross, D. (Eds) 2008. The Cambridge history of sciences: The modern social sciences (Vol 7). UK: Cambridge University Press.

Powell, W. W., \& Snellman, K. 2004. The knowledge economy. Annual Review of Sociology, 30: 199-220.

Prahalad, C. K., \& Hamel, G. 1990. The core competence of the corporation. Harvard Business Review, 68(3): 79-91.

Price, D. J. d. S. 1965. Networks of scientific papers. Science, 169: 510-515.

Puranam, P., \& Srikanth, K. 2007. What they know vs. what they do: How acquirers leverage technology acquisitions. Strategic Management Journal, 28(8): 805825 .

Puranam, P., Singh, H., \& Chaudhuri, S. 2009. Integrating acquired capabilities: When structural integration is (un) necessary. Organization Science, 20(2):313-328.

Q

Quatraro, F. 2012. The economics of structural change in knowledge. Taylor \& Francis.

Quintana-García, C., \& Benavides-Velasco, C. A. 2008. Innovative competence, exploration and exploitation: The influence of technological diversification. Research Policy, 37(3): 492-507.

$\mathbf{R}$

Ramos-Rodriguez, A. R., \& Ruiz-Navarro, J. 2004. Changes in the intellectual structure of strategic management research: A bibliometric study of the Strategic Management Journal, 1980-200o. Strategic Management Journal, 25(10): 981-1004.

Ranft, A. L., \& Lord, M. D. 2002. Acquiring new technologies and capabilities: A grounded model of acquisition implementation. Organization Science, 13(4): 420-441.

Roberts, R. M. 1989. Serendipity: Accidental discoveries in science. NJ: John Wiley \& Sons, Inc.

Rogers, E. M. 2010. Diffusion of innovations. The Free Press, NY.

Romer, P. M. 1990. Endogenous technological change. Journal of Political Economy, 98(5): S71-S102.

Roper, S., \& Hewitt-Dundas, N. 2015. Knowledge stocks, knowledge flows and innovation: Evidence from matched patents and innovation panel data. Research Policy, 44(7): 1327-1340.

Rosenberg, N. 1963. Technological change in the machine tool industry, 1840-1910. The Journal of Economic History, 23(4): 414-443.

Rosenberg, N. 1969. The direction of technological change: inducement mechanisms and focusing devices. Economic Development and Cultural Change, 1-24.

Rosenberg, N. 1979. Technological interdependence in the American economy. Technology and Culture, 20(1): 25-50.

Rosenberg, N. 1990. Why do firms do basic research (with their own money)? Research Policy, 19(2): 165-174. 
Rosenberg, N. 1994. Exploring the black box: Technology, economics, and history. Cambridge University Press.

Rosenberg, N. 2000. Schumpeter and the endogeneity of technology. Routledge.

Rosenberg, N., \& Frischtak, C. R. 1984. Technological innovation and long waves. Cambridge Journal of Economics, 8(1): 7-24.

Rosenberg, N., 1963. Technological change in the machine tool industry, 1840-1910. The Journal of Economic History, 23: 414-443.

Rosenkopf, L., \& Nerkar, A. 2001. Beyond local search: Boundary-spanning, exploration, and impact in the optical disk industry. Strategic Management Journal, 22(4): 287-306.

Rubinov, M., \& Sporns, O. 2010. Complex network measures of brain connectivity: Uses and interpretations. NeuroImage, 52: 1059-69.

S

Sachs, E. et al., 1993. "Three-dimensional printing techniques." U.S. Patent 5,204,055, issued April 20, 1993.

Sachs, E. et al., 1994. "Three-dimensional printing techniques." U.S. Patent 5,340,656, issued August 23, 1994.

Sachs, E. et al., 1998. "Three dimensional printing system." U.S. Patent 5,807,437, issued September 15, 1998.

Sampson, R. C. 2007. R\&D alliances and firm performance: The impact of technological diversity and alliance organization on innovation. Academy of Management Journal, 50: 364-386.

Sanderson, S. W., \& Simons, K. L. 2014. Light emitting diodes and the lighting revolution: the emergence of a solid-state lighting industry. Research Policy, 43: 1730-1746.

Schoenmakers, W., \& Duysters, G. 2010. The technological origins of radical inventions. Research Policy, 39(8): 1051-1059.

Schumpeter, J. A. 1934 [1911]. The theory of economic development: An inquiry into profits, capital, credit, interest, and the business cycle. Harvard University Press: Cambridge, Mass.

Schumpeter, J. A. 1942. Capitalism, socialism, and democracy. Harper \& Brothers: New York.

Schumpeter, J. A. 1947. The creative response in economic history. The Journal of Economic History, 7(02), 149-159.

Schumpeter, J. A. 2003 [1942]. Capitalism, socialism, and democracy. Routledge Taylor \& Francis Group e-Library, UK.

Sears, J., \& Hoetker, G. 2014. Technological overlap, technological capabilities, and resource recombination in technological acquisitions. Strategic Management Journal, 35(1): 48-67.

Serrano, M. Á., Boguñá, M., \& Vespignani, A., 2009. Extracting the multiscale backbone of complex weighted networks. Proceedings of the National Academy of Sciences, 106: 6483-6488.

Seymore, S. B. 2009. Serendipity. North Carolina Law Review, 88: 185-211.

Shapiro, G. 1986. A skeleton in the darkroom: Stories of serendipity in science. San Franciscso: Harper \& Row.

Sharp, B. M., Bergh, D. D., \& Li, M. 2013. Measuring and testing industry effects in strategic management research: An update, assessment, and demonstration. Organizational Research Methods, 16(1): 43-66. 
Shi, W. S., \& Prescott, J. E. 2012. Rhythm and entrainment of acquisition and alliance initiatives and firm performance: A temporal perspective. Organization Studies, 33(10): 1281-1310.

Simon, H. A. 1962. The architecture of complexity. Proceedings of the American Philosophical Society, 106(6): 467-482.

Simonton, D. K. 1979. Multiple discovery and invention: Zeitgeist, genius, or chance? Journal of Personality and Social Psychology, 37(9): 1603-1616.

Simonton, D. K. 2004. Creativity in science: Chance, logic, genius, and zeitgeist. Cambridge, England: Cambridge University Press.

Singh, J., \& Fleming, L. 2010. Lone inventors as sources of breakthroughs: Myth or reality? Management Science, 56(1), 41-56.

Sirmon, D. G., Hitt, M. A., \& Ireland, R. D. 2007. Managing firm resources in dynamic environments to create value: Looking inside the black box. Academy of Management Review, 32(1): 273-292.

Slywotzky, A. J. 1996. Value migration: How to think several moves ahead of the competition. Harvard Business Press.

Small, H. G, \& Griffith, B. C. 1974. The structure of scientific literature: Identifying and graphing specialities. Science Studies, 4: 17-40.

Small, H. G. 1973. Co-citation in the scientific literature. A measure of the relationship between two documents. Journal of the American Society for Information Science, 24: 265-269.

Small, H. G. 1978. Cited documents as concept symbols. Social Studies of Science, 8: 327-340.

Small, H. G. 1980. Co-citation context analysis and the structure of paradigms. Journal of Documentation, 36: 183-196.

Solymar, L. 1999. Getting the message: A history of communications. Oxford University Press Inc., New York.

Somaya, D. 2012. Patent strategy and management an integrative review and research agenda. Journal of Management, 38(4): 1084-1114.

Stettner, U., \& Lavie, D. 2014. Ambidexterity under scrutiny: Exploration and exploitation via internal organization, alliances, and acquisitions. Strategic Management Journal, 35: 1903-1929.

Stuart, T. E., \& Podolny, J. M. 1996. Local search and the evolution of technological capabilities. Strategic Management Journal, 17(S1): 21-38.

Suárez, F. F., \& Utterback, J. M. 1995. Dominant designs and the survival of firms. Strategic Management Journal, 16(6): 415-430.

Susskind, C. 1970. The early history of electronics V: Commercial beginnings. Spectrum, IEEE , 7(4): 78-83.

Sutton, J. 2001. Technology and market structure: Theory and history. MIT Press.

Swedberg, R. 2012. Theorizing in sociology and social science: Turning to the context of discovery. Theory and society, 41(1): 1-40.

Szücs, F. 2014. M\&A and R\&D: Asymmetric Effects on acquirers and targets? Research Policy, 43(7): 1264-1273.

T

Tabah, A. 2001. Literature dynamics: studies on growth, diffusion, and epidemics. Annual Review of Information Science and Technology, 34: 249-286.

Teece, D. J. 1986. Profiting from technological innovation: Implications for integration, collaboration, licensing and public policy. Research Policy, 15(6): 285-305. 
Teece, D. J., Rumelt, R., Dosi, G., \& Winter, S. 1994. Understanding corporate coherence: Theory and evidence. Journal of Economic Behavior E Organization, 23(1): 1-30.

Tushman, M. L., \& Anderson, P. 1986. Technological discontinuities and organizational environments. Administrative Science Quarterly, 31: 436-465.

Tushman, M. L., \& Nelson, R. R. 1990. Technology, organizations, and innovation: Introduction. Administrative Science Quarterly, 35(1): 1-8.

U

Uotila, J., Maula, M., Keil, T., \& Zahra, S. 2009. Exploration, exploitation, and financial performance: Analysis of S\&P 500 corporations. Strategic Management Journal, 30(2): 221-231.

Uricchio, W. 2008. Television's first seventy-five years: The interpretive flexibility of a medium in transition (286-305). The Oxford Handbook of Film and Media Studies, Oxford: Oxford University Press..

Utterback, J. M., \& Suarez, F. F. 1993. Innovation, competition, and industry structure. Research policy, 22(1): 1-21.

V

Van Andel, P. 1994. Anatomy of the unsought finding. Serendipity: Orgin, history, domains, traditions, appearances, patterns and programmability. The British Journal for the Philosophy of Science, 45(2): 631-648.

Veblen, T. 1898. Why is economics not an evolutionary science? The Quarterly Journal of Economics, 12(4): 373-397.

W

Weber, Y., Shenkar, O., \& Raveh, A. 1996. National and corporate cultural fit in mergers/acquisitions: An exploratory study. Management Science, 42(8): 1215-1227.

Weick, K. E., \& Quinn, R. E. 1999. Organizational change and development. Annual Review of Psychology, 50:361-386.

Weitzman, M. L., 1998. Recombinant growth. Quarterly Journal of Economics, 113: 331360.

Wernerfelt, B. 1984. A resource-based view of the firm. Strategic Management Journal, 5(2): 171-180.

Wertheimer, M., \& Riezler, K. 1944. Gestalt theory. Social Research, 11(1): 78-99.

White, H. D., \& Griffith, B. C. 1981. Author cocitation: a literature measure of intellectual structure. Journal of the American Society for Information Science, 32: 163-171.

White, H. D., \& McCain, K. W. 1989. Bibliometrics. Annual Review of Information Science and Technology, 24: 119-186.

Wolfe, R. A. 1994. Organizational innovation: Review, critique and suggested research directions. Journal of Management Studies 31(3): 405-431.

$\mathbf{Y}$

Yu, Y., Umashankar, N., \& Rao, V. R. 2015. Choosing the right target: Relative preferences for resource similarity and complementarity in acquisition choice. Strategic Management Journal. DOI: 10.1002/smj.2416.

$\mathbf{Z}$

Zahra, S. A., \& George, G. 2002. Absorptive capacity: A review, reconceptualization, and extension. Academy of Management Review, 27(2): 185-203. 



\section{SUMMARY}

Technological change is a central topic in the field of economics and management of innovation. This thesis proposes to combine the socio-technical and technoeconomic perspectives of technological change in a gestalt system, hereby termed as the socio-techno-economic system (STES). The aggregate technological change that manifests in transformative changes in the structure of STES is particularly important due to the scope and magnitude of its impact. Identifying the locus of transformative technological change (TTC) and determining its direction is an important problem from the perspective of public policy as well as business strategy. Following Peter Drucker's insights, this $\mathrm{PhD}$ thesis proposes that this problem can be solved by shifting the focus from the product space to the knowledge space as the 'place' scientific inquiry. It posits that knowledge as the DNA and ideas as genes determine the evolution of STES and that structural change in this system follows the structural change in the universe of knowledge that is broadly organized in two domains, science and technology. Accordingly, useful knowledge is mainly produced by two groups of actors, universities and the technology-based firms (TBFs). The knowledge produced by universities largely flows into the domain of science whereas the knowledge produced by TBFs mainly flows into the domain of technology, though both sets of actors draw on extant knowledge from both domains. In general, TBFs tend to be more effective and efficient than universities in sensing the need for useful knowledge and responding to it in a timely fashion because they are driven by the need to earn profit on their investments in the production of knowledge.

In order to capture the most important aspects of change in the structure of the universe of knowledge, we set out to examine changes in the nature of knowledge production from input/output perspective on the one hand and changes in motivations and conduct of the producers of knowledge, on the other. To this end, we asked four substantive questions to guide our research. These are:

1. How scientific domains emerge and co-evolve?

2. How technology domains emerge and co-evolve?

3. How emergence and co-evolution of scientific and technology domains lead to structural changes in the techno-economic system?

4. Why do firms enter multiple domains and how do they benefit from a multi-technology multi-product capability base?

Accordingly, this $\mathrm{PhD}$ thesis is comprised of four empirical essays corresponding to these questions.

Essay 1: Thinking inside the box? Intellectual structure of the knowledge base of innovation research. Science is purportedly becoming increasingly interdisciplinary and the inter-disciplinarity is generally considered as the source of 
growth in scientific knowledge, particularly among social sciences. In order to test this conjecture, we selected the "innovation studies" as an empirical case. We collected the publication data of innovation-related papers that were published in top twenty journals in four major social science disciplines-economics, sociology, psychology, and management-during the 21-year period between 1988 and 2008. We used scientometric approach and bibliometric method to perform longitudinal and structural analysis of the publications. The co-citation analysis helped us identify major research traditions in the field, determine the content and disciplinary composition of each tradition, and map the changes in the intellectual structure of the field over time. To our surprise, we found that innovation research is becoming increasingly compartmentalized between economics and management disciplines and each segment is becoming increasingly self-contained. This finding, coincidentally, provides yet another reason to integrate relevant knowledge from multiple disciplines to develop a more holistic understanding of the coevolutionary dynamics of social, technological, and economic changes. This essay has been published as a research article in Strategic Management Journal.

Essay 2: Co-evolution of technologies: A historical perspective on the emergence and convergence of information and communication technologies. Technology is the outcome of experimentation with different ideas and pieces of knowledge that tend to be scattered in time and place. The temporal and spatial proximity and prior relationship of ideas and relevant knowledge greatly affect the rate of creation and speed of diffusion of new technologies. This signifies the relevance and importance of those technologies that facilitate the preservation and transmission of information. Therefore, in order to understand the locational and combinatorial dynamics of inventive activity, we used historical approach and explored the origins and timing of the discoveries and inventions related to information and communication technologies during the 18th and 19th centuries. This essay presents the historical account of major information and communication technologies and describes how these technologies co-evolved. We found that inventive activity tends to be contextualized by the societal and technological problems prevailing at a given time that are pursued by scientists and engineers working in the domains of science and technology. The insights from the study are put in the context of Hebert Simon's idea of nearly decomposable hierarchical systems and neo-Schumpeterian perspective of clusters of technologies. We find that the former is more practical from an artifact-based perspective of technology while the latter is more useful from the knowledge-based perspective of technology. We conclude that the latter perspective can help solve the problem of measuring the rate and direction of technological change in STES. 
Essay 3: Structure of transformative technological change. Structural change in the STES is a matter of interest from the perspective of public policy as well as business strategy because it essentially involves the well-known "creative destruction". Conventionally, structural changes have been studied ex post using the context of industries, that is, the product space as a frame of reference. These changes are always underway in the realm of industrial system due to the processes of innovation. However, STES periodically undergoes structural changes of great magnitude that alter not only the structure of industrial system but also the institutional and social structure of society. Accordingly, we refer to this kind of change as "transformative technological change" (TTC).

In this essay, we attempted to capture the dynamics of such transformative changes through a conceptual framework. This novel framework is based on the Neo-Schumpeterian approach (that can be traced to the contributions of William F. Ogburn) that emphasizes the role of invention due to the fact that it precedes innovation and hence transformative changes in the STES occur due to the emergence of new clusters of technologies. We extend this perspective by proposing that technology space is a better 'place' to locate TTC than the product space, more so because it can help identify transformative changes ex ante. Thus, TTC is a manifestation of structural changes in the technology space. We illustrate this framework with the help of all available US patent data till 2009. We found that there occurred three successive episodes of TTC during the 2oth century; the first took place around 1950, the second occurred around 1980, and the third took off around 2000 and it is currently underway. The first episode involves migration of locus of inventive activities from mechanical engineering-related technologies to the chemical engineering-related technologies and the second episode involves the migration of locus from the chemical engineering-related technologies to the information and communication technologies. The direction of the third episode may be determinable through further inquiry.

Essay 4: Exploitation, Exploration, or Excursion? When and how technologically diversified firms benefit from technological mergers and acquisitions? Large TBFs perform a key role in creating new technologies and products through R\&D and inventive activity has become increasingly concentrating within these firms during the 2oth century. TBFs tend to be multi-technology multi-product firms and hence simultaneously operate in multiple domains of knowledge and technological ecosystems. Due to their institutionalized R\&D, they also play an important role in the assimilation, creation and diffusion of new technological knowledge in the STES. Accordingly, the structure of their technological capabilities co-evolves with multiple domains of knowledge and technological ecosystems. Therefore, understanding the determinants of structural change in their technological capabilities and portfolios is important to understand the determinants of structural 
change in knowledge domains which drive structural change in the STES. This essay contributes towards understanding mergers and acquisitions as a popular strategic tool and an important mechanism through with TBFs enter multiple domains and technological ecosystems.

In this essay we build on prior research that has established that technological M\&As positively contribute to the technological output of the acquirers and seek to extend the research that aims to identify the drivers of postacquisition performance. The extant research based on resource-based and organizational learning theories assumes that organizational search is deliberate and driven by the strategic intent to use existing capabilities of the firm or develop new capabilities through M\&As. Accordingly, it is also assumed that organizational search through M\&As and the performance outcomes thereof either constitute exploitation or exploration. We argue that these assumptions need to be revisited for two important reasons. First, TBFs ultimately seek technological opportunities rather than technological capabilities per se. Second, TBFs also come across unintended and serendipitous opportunities that constitute the emergent aspect of organizational search and performance thereof. In case of M\&As, unintended or unexpected technological opportunities are likely to emerge due to technological complementarities and substitutabilities between the technological bases of the acquirer and target and many of these emergent opportunities are likely to fall outside the core domains of the acquirer and the target. We argue that such emergent opportunities constitute "excursion" which are distinct from exploration which involves the pursuit of intended opportunities. Therefore, we argue that exploitation and exploration can be understood better by (i) changing the frame of reference from capabilities to opportunities and (ii) isolating excursion from exploration.

This essay explicates and illustrates these ideas using 160 TM\&A deals of large TBFs from global information and communication technology sector during a 21-year period and measuring the post-acquisition inventive output of acquirers. Empirical evidence suggests that excursion is a sizeable contributor to the postacquisition inventive output of TBFs alongside exploration and exploitation. Results of negative binomial regression analysis of the panel data suggest that technological diversity of the acquirer negatively affects the post-acquisition exploitative and explorative output, exploitative output is negatively affected by technological history of the acquirer, and technological similarity between acquirer and target negatively affects explorative output.

In short, this thesis proposes the use of technological ecosystem approach and establishment of an integrated global intelligence system to monitor TTC. The technological ecosystem approach suggests that knowledge is not only the quintessential input but also the principal output that determines the quantity and quali- 
ty of solutions to the societal needs and problems. This perspective links the knowledge-base of the society with its problem-suite and may help create greater value and better allocate resources. From this perspective, the nature or kind of knowledge being produced and used may be more useful frame of reference for identifying and classifying actors and activities, regardless of the products they are producing. This approach, together with the suggested intelligence system, can also help all stakeholders to be more informed about the developments, including but not limited to the scientific and technological advancements, that may eventually result in the TTC. This approach may also help improve the role of concerned actors in the long run, save them from the perils of ignorant adaptation to their local environments, and help them co-evolve with the STES in a timely fashion. 



\section{VALORIZATION OF KNOWLEDGE}

[K]nowledge that tendeth but to satisfaction is but as a courtesan, which is for pleasure and not for fruit or generation... [I]n the courts and services of princes and states it is a much easier matter to give satisfaction than to do the business; so in the inquiring of causes and reasons it is much easier to find out such causes as will satisfy the mind of man and quiet objections, than such causes as will direct him and give him light to new experiences and inventions.

Sir Francis Bacon (1561-1626): Valerius Terminus

Technological change that transforms the structure of socio-techno-economic system (STES) is important from the perspective of public policy and business strategy because its scope is vast and its impact is profound. TTC involves the emergence of clusters of new technologies and industries and migration of the locus of inventive and innovative activities from the established technologies and industries to the emerging ones. It is an inevitable outcome of the evolution of the STES and poses great challenges for management. It offers new opportunities for development and growth which demand new routines and structures that often necessitate the destruction of established ones. Its depiction and prediction is important because in the absence of this knowledge actors tend to adapt to their local environments without considering the consequences of local adaptation in the larger context of the evolutionary changes in the STES. Such ignorant adaptation to evolutionary changes may culminate into the necessity of revolutionary changes or threat of demise as explicated by the famous fable of the frog that gets boiled alive due to her adaptation to the increasing temperature of water surrounding her.

This thesis posits that the nature and direction of TTC can be depicted as well as predicted by looking at the substantive changes in the nature and purpose of useful knowledge produced in the society during any given period. TTC occurs in the knowledge space well before it manifests in the product space that constitutes the world that we can 'see'. TTC begins to sprout when new knowledge begins to emerge in order to help solve some interrelated scientific and technological problems in the creation of new technologies that, in turn, seek to help solve some practical problems of the society at the time. Since every technology is a particular configuration of knowledge that produces a particular effect, the kind of effects needed by the society in a given era determine the kind of technologies it will value and demand, which in turn determine the kind of scientific and technological knowledge needed. Thus, from the standpoint of economics and management of technological change, TTC occurs as a result of the interaction between the demand for and supply of useful knowledge which, in turn, are determined by the actors, structures, and processes concerning knowledge production, dissemi- 
nation, and utilization. The interaction between the demand and supply of knowledge and the aggregation of their effects that form the TTC take place due to the interaction among social, technical, and economic forces that shape the "collective wisdom" (cf. Landemore \& Elster, 2012).

Collective wisdom emerges in various parts, and at various levels, of the STES due to the aggregation of the pursuits of boundedly rational actors within their respective spheres of action and influence. Two well-known social forces that bring about coherence and aggregation of individual and collective pursuits are zeitgeists and paradigms. A zeitgeist represents the overall mood or ambience prevalent in the society in a given era regarding major problems of the society while a paradigm is a broad approach to a given problem that is shared by most of the actors engaged with the problem. Knowledge is the prerequisite to solve the societal problems because the actors need to know why do/undo something, what to do/undo, how to do/undo that could solve a given problem. Since the needs and problems of the society continue to change systematically and new needs and problems continue to arise, the need for new knowledge and the drive for its production continue to remain there. Particularly, technical problems of the society require scientific and technological knowledge that could help produce particular technical effects that can solve the chosen problems.

Since the amount of problems facing a society at any given time is indeterminable, the society needs to prioritize the problems in order for utilizing the resources available to it efficiently and effectively. Collective wisdom is the selection mechanism through which individual actors, and hence the society, prioritize their needs and problems. Thus zeitgeists and paradigms shape the collective wisdom that determines and prioritizes the kind of knowledge to be created. However, the evolution of collective wisdom through 'natural' process of aggregation and its culmination in TTC tends to be slow because boundedly rational actors remain largely unaware of it due to their focus on their respective spheres of action and influence. Selective adaptation to local environments is by far the predominant force that shapes the collective wisdom of actors. Thus the collective wisdom that manifests in TTC is by and large the product of deterministic evolution rather than voluntary determination of the structure of STES. Consequently, deterministic adaptation to the technological changes in their locales tends to keep the actors ignorant of the potential fruits and ultimate destruction of TTC. Due to this reason, this thesis posits that voluntary determination of technological change is preferable than deterministic adaptation by the actors and hence the collective wisdom shaped by the ex ante resolution is preferable than the ex post aggregation, depiction, and explanation of the phenomenon.

Voluntary determination and ex ante resolution are needed to reap the fruits of TTC and minimize the destruction caused by it. This requires that the actors serving the domains of science and technology create the knowledge that is 
useful in catering to the needs and solving the problems of the society. However, linking the knowledge-base of the society with the problem-suite of the society and minimizing the costs of blind experimentation and ignorant adaptation require that the collective wisdom is enhanced and deliberately shaped through public policy and business strategy. Public policy is an influential tool in shaping the zeitgeists in the contemporary world whereas business strategy is the principal mechanism through which resource-base of the society is shaped and harnessed.

This thesis posits that voluntary determination and ex ante resolution are possible by adopting a technological ecosystem approach facilitated by an integrated global intelligence system. The dominant paradigm in contemporary policy and strategy is to use the nature of products as the frame for reference for identifying and classifying the actors and activities. For instance, activities are often grouped into sectors and industries on the basis of the nature of the output as the basis of policy and strategy. Technological ecosystem approach provides an alternative, and possibly complementary, perspective of thinking about activities. It suggests that knowledge is not only the quintessential input but also the principal output that determines the quantity and quality of solutions to the societal needs and problems. This perspective suggests that the nature or kind of knowledge being produced and used may be more useful frame of reference for identifying and classifying actors and activities, regardless of the products they are producing. This perspective links the knowledge-base of the society with its problem-suite and may help better allocation of resources besides creating greater value. For instance, if a firm identifies itself as the user and producer of a particular kind of knowledge, who are other producers and users, and what alternative applications this knowledge has, the firm is more likely to identify new opportunities for exploitation of their existing resources and find new avenues for invention and innovation through exploration and excursion. Similarly, if policy indicates which kind of new knowledge has begun to emerge and what are the potential uses of that knowledge in relation to the problem-suite of society, the production of that kind of knowledge is likely to be further stimulated and expedited. Such directive use of policy may be more helpful in societal development and growth than purely regulative use. Above all, this approach can help all stakeholders be more informed about the developments, including but not limited to the scientific and technological advancements, that may affect their role in the long run and save them from the perils of ignorant adaptation to their local environments.

Technological ecosystem approach can be adopted better if there is an integrated global intelligence system that continuously monitors and appropriately classifies the scientific and technological knowledge. A great deal of experience has already been accumulated in relation to scientific indexing, patent classification, and concordances among various classification schemes. However, these efforts have been disconnected and followed different purposes and rationales. It may be fruitful to revisit and integrate all such schemes with the help of infor- 
mation technology and the information gathered is made accessible to the public. The proposed approach and the intelligence system are expected to stimulate the actors to span their silos, minimize the costs of duplication, increase the linkages across science and technology domains, expedite the otherwise slow process of convergence, and lower the costs of ignorant adaptation and destruction from unanticipated TTC.

\section{References}

Landemore, H., \& Elster, J. (Eds) (2012). Collective wisdom: Principles and mechanisms. Cambridge University Press. 


\section{CURRICULUM VITAE}

Muhammad Shafique was born in 1975 at Rawalakot, State of Azad Jammu \& Kashmir, Pakistan. He obtained initial schooling in his native village and attended the college in his home town. He finished college in 1994 by securing second position in the state-wide examination of the Board of Intermediate and Secondary Education of the state and earned the Silver Medal. He obtained his bachelor degree in business administration in 1997 from the state University of Azad Jammu \& Kashmir by securing first-class-first position in the university and earned the university Gold Medal. For his outstanding performance as a student at bachelors level, the President of Pakistan conferred upon him the Award of Academic Excellence. He completed MBA in 2000 from the same university by securing the firstclass-first position and the highest possible grade point average, first ever secured by any student in the university, and earned the university Gold Medal. Again, for his outstanding performance as a student at master level, the President of Pakistan conferred upon him the Award of Academic Excellence. After his MBA in 200o, he joined SME Bank, a public sector development financial institution of Pakistan, as Credit Officer. In 2002, he returned to academia as Lecturer in Business Administration at the University of Azad Jammu \& Kashmir. In 2004, he joined the M.Sc. program in Economics and Business Administration, International Marketing and Management concentration, at Copenhagen Business School, Denmark. After completing the M.Sc. in 2006 in a record period of 18 months, he returned to Pakistan and joined the Faculty of Management Sciences, International Islamic University Islamabad as Consultant and Head of Strategy and Management Group. In 2007, the Selection Board of the university selected him to become a permanent faculty member of the university as Assistant Professor. In 2008, he earned scholarship from United Nations University to work as PhD Fellow in the doctoral program of UNU-MERIT in the area of economics and management of innovation and technological change. He completed his PhD thesis under the supervision of Professor Dr. John Hagedoorn. He is currently serving as Assistant Professor at the Faculty of Management Sciences, International Islamic University Islamabad. 

UNITED NATIONS UNIVERSITY

\section{UNU-MERIT}

\section{6}

102. Muhammad Shafique

Essays on the role of knowledge, R\&D, and technology-based firms in the evolution of sociotechno-economic system

\section{Serdar Türkeli}

Governance of Innovation Policy: Empirical Studeis on Applied Political Economy by Multi-Methos Analysis

\section{5}

\section{Hibret Belete Maemir}

Dissecting Aggregate Productivity:

International Integration and Growth with

Heterogeneous Firms

\section{Giorgio Triulzi}

Looking for the Right Path: Technology Dynamics, Inventive Strategies and Catching-up in the Semiconductor Industry

\section{Abdul Baseer Qazi}

Knowledge flows and networks in the ICT sector: The case of Pakistan

\section{Ajay Thutupalli}

Technology Paradigm Shifts in Agriculture: Drivers of Sustainability and Catch up

\section{Eduardo Urias}

Improving access to HIV/AIDS treatment in Brazil: When are compulsory licenses effective in price negotiations?

\section{Francesca Guadagno}

Why have so few countries industrialised?

\section{Daniel Opolot}

The evolution of beliefs and strategic behavior

\section{Alejandro Lavopa}

Structural Transformation and Economic

Development: Can Development Traps be Avoided?

\section{Jinjin Zhao}

Urban water management reform: The case of China

\section{4}

\section{Dirk Crass}

The Impact of Brands on Innovation and Firm Performance: Empirical Evidence from Germany

\section{Samyukta Bhupatiraju}

The Geographic Dimensions of Growth and Development

\section{François Lafond}

The evolution of knowledge systems

\section{Annalisa Primi}

Promoting Innovation in Latin America: What Countries Have Learned (and What They Have Not) in Designing and Implementing Innovation and Intellectual Property Policies

\section{Fatoumata Lamarana Diallo}

Evaluation of Meal and Deworming Programs for Primary Schools in Rural Senegal

\section{3}

\section{Anant Kamath}

Information Sharing through Informal Interaction in Low-Tech Clusters

\section{Flavia Pereira de Carvalho}

What we talk about when we talk about Brazilian Mulitantionals: an investigation on Brazilian FDI, economic structure, innovation and the relationship between them

\section{Jun Hou}

Complementarity in Innovation and Development: A Cross-country Comparison

\section{Rufin Baghana}

Impacts of Government Incentives to R\&D, Innovation and Productivity:

A Microeconometric Analysis of the Québec Case 


\section{Lilia I. Stubrin}

High-Tech Activities in Emerging Countries: A Network perspective on the Argentinean biotech activity

\section{2}

\section{Abdul Waheed}

Innovation Determinants

and Innovation as a Determinant:

Evidence from Developing Countries

\section{Bilal Mirza}

Energy Poverty and Rural Energy Markets in Pakistan

\section{Benjamin Engelstätter}

Enterprise Software and Video Games: An Empirical Analysis

\section{Fulvia Farinelli}

Natural Resources, Innovation and Export Growth: The Wine Industry in Chili and Argentina

\section{Rodolfo Lauterbach}

Innovation in Manufacturing: From Product Variety and Labor Productivity Growth to Economic Development in Chile

\section{Kirsten Wiebe}

Quantitative Assessment of Sustainable Development and Growth in Sub-Saharan Africa.

\section{Julio Miguel Rosa}

Organizational Strategies, Firms' Performance and Spatial Spillovers. The Canadian Case in Research and Development.

Johannes Wilhelmus Marie Boels

Joseph Schumpeter, honderd jaar economische ontwikkeling. Een historisch-theoretische beschouwing.

\section{1}

\section{Daniel Vertesy}

Interrupted Innovation: Emerging economies in the structure of the global aerospace industry.

\section{Tina Saebi}

Successfully managing alliance portfolios: an alliance capability view.

\section{Nora Engel}

Tuberculosis in India - A case of innovation and control.

\section{Evans Mupela}

Connectivity and growth in Sub-Saharan Africa: The role of communication satellites

\section{Nantawan Kwanjai}

Cross cultural intelligence amid intricate cultural webs: A tale of the UnDutchables in the land of 1002 smiles

\section{Lina Sonne}

Innovation in Finance to Finance Innovation: Supporting pro-poor entrepreneur-based innovation

\section{0}

\section{Fernando Santiago}

Human Resources Management Practices and Learning for Innovation in Developing Countries: Pharmaceutical Firms in Mexico

\section{Zakaria Babutsidze}

Essays on Economies with Heterogenous Interacting Consumers

\section{Bertha Vallejo}

Learning and Innovation Under Changing Market Conditions: The Auto Parts Industry in Mexico

\section{Donatus Ayitey}

Technical Change, Competitiveness and Poverty Reduction: A Study of the Ghanaian Apparel Industry

\section{Sergey Fillipov}

Multinational Subsidiary Evolution: Corporate Change in New EU Member States

\section{Asel Doranova}

Technology Transfer and Learning under the Kyoto regime; Exploring the Technological Impact of CDM projects in developing countries 


\section{Alexis Habiyaremye}

From Primary Commodity Dependence to Diversification and Growth". "Absorptive Capacity and Technological Catch Up in Botswana and Mauritius".

\section{Yoseph Getachew}

The Role of Public Capital in Economic Development

\section{Sandra Leitner}

Embodied Technological Change and Patterns of Investment in Austrian Manufacturing

\section{Semih Akçomak}

The Impact of Social Capital on Economic and Social Outcomes

\section{Abraham Garcia}

The Role of Demand in Technical Change

\section{Saurabh Arora}

Coherence in socio-technical systems: a network perspective on the innovation process

\section{8}

\section{Rutger Daems}

Medicines for the developing world

\section{Johannes Hanel}

Assessing Induced Technology: Sombart's Understanding of Technical Change in the History of Economics

\section{Rifka Weehuizen}

Mental Capital: the economic significance of mental health

\section{Danielle Cloodt}

The relationship between R\&D partnership formation, social embeddedness and innovative performance

50. Sabine Fuss

Sustainable Energy Development under Uncertainty

\section{Tobias Kronenberg}

Reconciling Environmental Conservation with Economic Prosperity: The Feasibility of Double Dividends in the Short and Long Run

\section{Viktoria Kravtsova}

Assessing the Impact of Foreign Direct Investment in Transition Economies

\section{Suhail Sultan}

The Competitive Advantage of Small and Medium Sized Enterprises: The Case of Jordan's Natural Stone Industry

\section{6}

46. Bulat Sanditov

Essays on Social Learning and Imitation

\section{Mamata Parhi}

Dynamics of New Technology Diffusion: A Study of the Indian Automotive Industry

\section{Andreas Reinstaller}

Social structures and the innovation process: Their role in the demand of firms and consumers

\section{Rose Kiggundu}

Innovation systems and development: the journey of a Beleaguered Nile Perch Fishery in Uganda

\section{Thomas Pogue}

The Evolution of Research Collaboration in South African Gold Mining: 1886-1933

\section{Geoffrey Gachino}

Foreign Direct Investment, Spillovers and Innovation: The Case of Kenyan Manufacturing Industry

\section{0. Önder Nomaler}

Technological Change, International Trade and Growth: An Evolutionary, Multi-Agents-Based Modeling Approach

\section{5}

\section{Samia Satti Osman Mohamed-Nour} Change and Skill Development in the Arab Gulf Countries 


\section{Elad Harison}

Intellectual Property Rights: Economics and Policy Analysis

\section{Daniel Dalohoun}

The relationship between R\&D partnership formation, social embeddedness and innovative performance: a multi-level approach of social embeddedness

\section{Müge Ozman}

Networks, Organizations and Knowledge

\section{Bas Straathof}

Product variety and economic growth: The counteracting effects of scale and idiosyncrasy

\section{Wilfred Schoenmakers}

Knowledge Flows between Multinational

Companies: A Patent Data Analysis

\section{Myriam Cloodt}

Mergers and Acquisitions (M\&As) in High-Tech Industries: Measuring the Post-M\&A Innovative Performance of Companies

\section{4}

\section{Paola Criscuolo}

R\&D Internationalisation and Knowledge Transfer. Impact on MNEs and their Home Countries

\section{Maarten Verkerk}

Trust and Power on the Shop Floor

\section{Gottfried Leibbrandt}

Adoption, harmonization and succession of network technologies across countries

\section{Mark Sanders}

Skill Biased Technical change - Its Origins, the Interaction with the Labour Market and Policy Implications

\section{3}

\section{Nadine Roijakkers}

Inter-firm cooperation in high-tech industries: a study of R\&D partnerships in pharmaceutical biotechnology

\section{Viki Sonntag}

Speed, Scale and Sustainability

\section{Masaru Yarime}

From End-of-Pipe Technology to Clean Technology

\section{Stéphane Malo}

The combinatorial Chemistry Revolution -

Sustaining a Superior Performance Position through Technological Learning

\section{2}

\section{Annelies Hogenbirk}

Determinants of Inward Foreign Direct Investment: the Case of the Netherlands

\section{Bastiaan Johan ter Weel}

The Computerization of the Labour Market

\section{1}

\section{John Adeoti}

Technology Investment in Pollution Control in SubSaharan Africa: The Case of the Nigerian

Manufacturing Industry

\section{Edward Huizenga}

Innovation Management: How Frontrunners Stay Ahead. An Empirical Study on Key Success Factors in the ICT sector

\section{0}

\section{Machiel van Dijk}

Technological Change and the Dynamics of Industries. Theoretical Issues and Empirical evidence from Dutch Manufacturing

\section{9}

\section{Jan Cobbenhagen}

Managing Innovation at the Company Level: A Study on Non-Sector-Specific Success Factors

\section{Marjolein Caniëls}

Regional Growth Differentials: The Impact of Locally Bounded Knowledge Spillovers

\section{8}

\section{Aldo Geuna}

Resource allocation and knowledge production: Studies in the economics of university research 


\section{Reinoud Joosten}

Dynamics, Equilibria, and Values

\section{Hugo Kruiniger}

Investment, R\&D, and the Financing Decisions of the Firm

\section{5}

\section{Hans van Meijl}

Endogenous Technological Change: The Case of Information Technology. Theoretical Considerations and Empirical Results

\section{René Kemp}

Environmental Policy and Technical Change. A Comparison of the Technological Impact of Policy Instruments

\section{Rohini Acharya}

The Impact of New Technologies on Economic Growth and Trade. A Case Study of Biotechnology

\section{Geert Duysters}

The Evolution of Complex Industrial Systems. The Dynamics of Major IT Sectors

\section{Marjan Groen}

Technology, Work and Organisation, A Study of the Nursing Process in Intensive Care Units

\section{4}

10. Huub Meijers

On the Diffusion of Technologies in a Vintage Framework; Theoretical Considerations and Empirical Results

\section{Theon van Dijk}

The Limits of Patent Protection. Essays on the Economics of Intellectual Property Rights

\section{Hans Voordijk}

Naar Integrale Logistiek in Bedrijfsketens, Ontwikkelingen in de Bouw

\section{Paul Diederen}

Technological Progress in Enterprises and Diffusion of Innovations. Theoretical Reflections and Empirical Evidence.

\section{Ben Dankbaar}

Economic Crisis and Institutional Change. The crisis of Fordism from the perspective of the automobile industry

\section{Hanno Roberts}

Accountability and Responsibility: The Influence of Organisation Design on Management Accounting

\section{2}

\section{Bart Verspagen}

Uneven Growth Between Interdependent Economies. An Evolutionary View on Technology Gaps, Trade and Growth

\section{Sjoerd Romme}

A Self-organization Perspective on Strategy Formation

\section{9}

\section{John Spangenberg}

Economies of Scale, and Atmosphere in Research Organisations

\section{8}

\section{John Hagedoorn}

Evolutionary and heterodox innovation analysis: a study of industrial and technological development in process control and information technology 
